$$
\text { 20 }
$$

the 


$$
\text { ช }
$$



. . (2) 



DISEASES OF THE HORSE. 


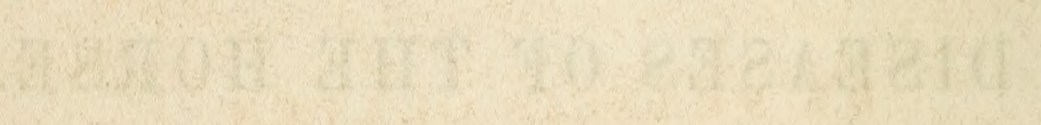




\section{E V E R Y M A N}

\section{HIS 0 WN FARRIER:}

CONTAINING

THE CAUSES, SYMPTOMS, AND MOST APPROVED METHODS OF CURE,

OF THE

\section{DISEASES OF HORSES.}

\section{BY FRANCIS}

AUTHOR OF "EVERY MAN HIS OWN CATTLE DOCTOR," AND HIS SON, JOHN CLATER.

FIRST AMERICAN FROM THE TWENTY-EIGHTH LONDON EDITION.

WITH NOTES AND ADDITIONS, BY J. S. SKINNER.

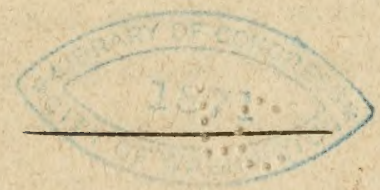

P H I A DEL P H A :

L E A A N D B L A N C H A R D.

1845 . 
Entered, according to the Act of Congress, in the year 1845 , By Lea and Blanchard,

In the Clerk's Office of the District Court, for the Eastern District of Pennsylvania.

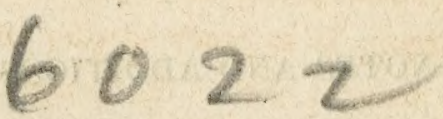

$59^{55}$
$G_{1845}^{62}$

C. Sherman, Printer, 19 St. James Street. 


\section{P R E F A C E.}

That this work should have passed through twenty-eight editions in England, where so many by different authors have been published on the same subject, ought to be deemed sufficient proof of its value, as well as of its popularity; while the date of the last edition (1843) offers assurance that the one founded on it, and here presented to the American public, embraces whatever is most new and reliable in the veterinary art.

To those who may naturally inquire whence the necessity for this work, in addition to the one on the Horse by YovatT and Shinner, put forth recently by the same publishers, it may be answered, that while that work is much more historical and elaborate, this is confined to diseases and their cures; and though equally practical in that respect, is so much smaller and cheaper than the larger work, as to place it within the convenient reach of every one. The two are adapted to meet the demands of the scholar and the groom; the former claiming a place in the library of every gentleman, as this one should be found for daily reference in every stable, along with the curry-comb and the brush.

\section{J. S. Skinner.}

Baltimore, April, 1845 



\section{ADVERTISEMENT}

\section{TO THE TWENTY-EIGHTH LONDON EDITION.}

THE Proprietors of this work, induced by the extensive sale of former editions, and animated by the desire of rendering the present worthy of public patronage, have placed it in the hands of a Veterinary Surgeon, well known both as an author and a practitioner, under whose superintendence it has undergone a careful revision throughout.

The corrections and additions it has received will, it is hoped, by rendering the work more corresponding to the improved state of Veterinary Surgery, enhance its usefulness, and extend its claims on public favour.

December, 1843. 



\section{ADVERTISEMENT}

\section{TO THE TWENTY-SEVENTH LONDON EDITION.}

Trie Editor makes no apology for the freedom which he has taken with the last Edition of this Work. In fact, a new era in Veterinary Science has commenced since Clater first wrote. His book was valuable at the time, but the Veterinary Art could scarcely then be said to have existence; and there is more difference in the knowledge and mode of practice of Veterinary Surgeons now and forty years ago, than has taken place in human medicine in the last four hundred years.

The work is, in a manner, re-written, or, at least, it is accommodated to the altered and improved character of the art; and it may be honestly said to embody the sentiments and practice of the best Veterinary Surgeons of the present day.

'The list of drugs which was appended to Clater's former work is omitted, because in the revised edition of his "Cattle-Doctor," by the Editor of the present publication, ${ }^{*}$ a sufficient list was given of the medicines used in Veterinary Practice, and to that the reader is referred.

The present edition has been carefully revised, and many very important corrections and additions have been made.

* Every man his own Cattle Doctor, containing the Causes, Symptoms, and Treatment of all the Diseases incident to Oxen, Sheep, Swine, Poultry and Rabbits, by Francis Clater. A new and enlarged edition, with extensive improvements by the Editor of this edition of the Farriery, 12me., just published, by Lea and Blanchard, Philadel. phia. 



\section{ONTENTS.}

Introduction-The Anatomy and Physiology of the Horse
The Head
The Nostrils
The Eye
The Ears
The Mouth
The Teeth.
The Neck
The Chest .
The Withers, Spine, and Back
The Stomach
The Intestines
The Liver

Chap.

1. Inflammation and its Treatment . . . . 33

2. Inflammation of the Brain (Phrenitis) . . . . . 54

3. Vertigo (Megrims) . • . . . 56

4. Stomach Staggers (Indigestion) . . . . . 58

5. Rabies (Madness) • • • $\quad 59$

$\begin{array}{lll}\text { 6. Inflammation of the Eye-Cataract-Gutta Serena } & \cdot & 53 \\ 7 . & 61\end{array}$

7. Inflammation of the Tongue-Blain ... . $\quad 67$

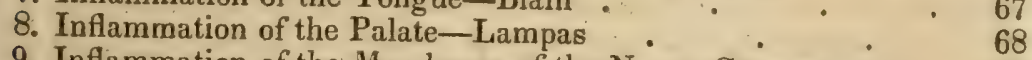

9. Inflammation of the Membrane of the Nose-Coryza . $\quad 78$

10. Specific Inflammation of the Membrane of the Nose-Glan. ders . . . . . 70

11. Inflammation of the Absorbents-Farcy . . . . 75

12. Inflammation of the Cellular Substance under the JawStrangles $\quad . \quad \ldots \quad \ldots \quad . \quad 0 \quad 79$

13. Inflammation of the Glands-Sore Throat-Vives-Barbs or Paps-Gigs or Bladders . . 82

14. Inflammation of the Bronchial Tubes-Bronchitis ' . 85

15. Epidemic Catarrh-Catarrhal Fever-Distemper-The $\mathrm{Ma}$.

16. Influenza . lignant Epidemic . 
17. Inflammation of the Lungs-Pneumonis-Thick. WindBroken Wind-Chronic Cough-Roaring-Consumption.

18. Inflammation of the Pleura-Pleurisy-Water in the Chest

19. Inflammation of the Heart-Carditis-Pericarditis-Hypertrophy. .

20. Spasm of the Diaphragm

21. Tetanus-Locked Jaw-Epilepsy-Palsy .

22. Inflammation of the Stomach-Poisons-Bots-Worms

23. Inflammation of the Bowels-Spasmodic Colic-Flatulent Colic-Strangulation-Calculi in the Bowels .

24. Inflammation of the Kidneys and Bladder-Profuse Staling -Difficulty of Staling-Gravel-Stone . .

25. Castration, Swelling of the Sheath-Amputation of the Penis -Warts-Inversion of the Womb-Inversion of the Bladder-Polypus in the Vagina

26. Docking-Nicking . .

27. Diseases of the Skin-Want of Condition-Hidebound-Surfeit-Mange-Moulting

28. Excoriations-Wounds-Ulcers-Poll Evil-Fistulous Withers-Penetrating Wounds

29. Injuries and Lameness of the Fore Extremities-Shoulder Lameness-Sprains-Injuries of the Elbow Joint-Broken Knees-Speedy Cut-Splent-Sprain of the Back Sinews -Windgalls-Sprain of the Fetlock Joint-Rupture and Sprain of the Suspensory Ligaments-Culting-Sprains of the Pastern and Coffin Joints-Ringbone-GrogginessFractures

30. Injuries of the Hind Extremities-Lower Fracture of the Haunch-Sprain of the Round Bone-Stifle LamenessThorough-pin-Capped Hock-Bog Spavin-Bone Spavin -Enlarged Hock-Curb-Swelled Legs-Grease.

31. The Structure and Diseases of the Foot-Brittle Hoof-Sand. Crack-Tread or Overreach-False Quarter-Contraction - Inflammation of the Laminæ-Pumiced Feet-Wounds -Quittor-Bruise of the Sole-Corns-Canker-Thrush - Navicular Joint Disease.

32. The Principles of Shoeing-Description of the Different Shoes 


\title{
THE ANATOMY AND PHYSIOLOGY
}

\author{
OF \\ TH E H O R S E.
}

\section{INTRODUCTION.}

A Natural historian would say that the proper characteristics of this noble animal are, six cutting, or fore-teeth in the upper and under jaw; two tushes in the upper and under jaw in the male, and seldom any, or only small ones, in the female; a space between the tushes and the cheek-teeth or grinders; and six grinders above and below in each jaw, flattened on the top, and with several ridges of enamel running down the body of the teeth. The eyes are large; the ears also large and erect; the upper lip capable of more motion than is usual in herbivorous animals generally: the foot having but a single toe, and that covered with a thick hoof; the tail covered all over with long hair; two teats in the female, and those placed in the groin; one stomach, but the lining of it composed of two membranes; the stomach unusually small, and the intestines, and particularly the cœcum, proportionably large.

The Head.-The head of the horse should not be too large in any breed, for that ustially indicates stupidity, and makes the saddlehorse heavy on the hand. A head small in proportion to the size of the horse shows that he has much Eastern blood in him, and is generally accompanied by considerable spirit; but, occasionally, by one of an unmanageable and untameable nature. A head bearing a fair proportion to the general size, and the bulk of the head consisting in the breadth of the forehead more than the length of the face, the eye at the same time being a little prominent and livelythese peculiarities will in most cases indicate the manageable and serviceable horse. The breadth and the flatness of the forehead, and the shortness of the face, should be particularly regarded and sought after for general and light, yet lasting work; but the narrow 
and rounded forehead, and long nose and face, may do well, or perhaps should be selected, in the quiet, strong horse of heavy work. For common purposes, a horse with a sinking or hollow across the nose, a little below the eyes, should seldom be chosen; it tells of ill temper, especially if joined with a more than usual display of the white of the eye. The line of the face should be nearly flat, yet a little prominence, and a very little one-a slight resemblance to the Roman nose of the human being-will generally characterize the good-tempered, good-feeding, strong, lasting, manageable, but not very light or speedy horse.

The setting-on of the Head.-There are few things more connected with the comfortable use of the horse than this. A great deal of the pleasure of riding, and much of that of driving, depend on the manner in which a horse carries his head. It must form a certain angle with the neck, so as to play easily backwards and forwards, or the mouth cannot be light and pleasant. A horse boring with his nose before him except when he is going at considerable speed, will tire any arrns, and will always be unsafe.

The Lips.-If we take the parts of the face individually, the lips are of more importance than is generally imagined. A firm and compressed lip gives proper bearing and support to the bit; and when the muscles of the lips are continually acting, as they must to keep the lips compressed, it is a pretty sure pledge that the muscles every where have considerable power. A horse with his lips flabby and hanging down is sure to be diseased, or sluggish, or old. The lips should not only be firm, but they should be small and thin; indeed they must be small and thin in order to be firm; for the interposed fat will always make them loose, and, what is worse than this, will interfere with that delicacy of feeling about them on which the easy management and guidance of the horse so much depend.

The Nostrils. - So far as the speed and the spirit of the horse are concerned, the form of the nostrils is of considerable moment. The horse breathes entirely through his nose: he does this even when he is most distressed; and therefore, if all the air that is to supply the lungs must enter through the nostril, and if, in exertion, the horse requires a great deal more air than at other times, a large nostril is an excellent provision. Nature generally suits the parts of the animal to his wants, and the purposes for which he was designed; and if a horse has much speed and endurance about him it is usually indicated by the wideness of the nostril. This is one main point of difference between the blood horse and the common country horse. The usual breathing of the horse wiil generally show the degree of expansion of which the nostril is capable-a rattling trot of a fe:v minutes' duration will leave no doubt about the matter. The thinness of the skin of the nostril is another indispensable accompaniment of speed and sound wind. The nostril of the cart-horse, with its thick skin, and all the fat that is contained 
in and about it, cannot possibly expand to the extent which a horse requires when at full speed.

The False Nostrils. - I'here is a curious formation of the nostril in the horse which we do not observe in any other animal. The whole of the external opening does not conduct into the cavity of the nose, but the outer part of the nostril is a mere blind pouch: it is formed of a doubling of the skin, and is lined with hair throughout. The fact is, that the nose is not only concerned with breathing, but it is the seat of smell; and should the air, or particles of matter introduced with the air, fall rudely upon the membrane, on the sensibility of which the acuteness of smell depends, it would be injured, and its functions destroyed. That part of the inside of the nose which is supposed to be most concerned with smell lies on the upper and outside portion of it; while the passage for the air is principally on the floor of the same cavity, and along the inner side towards the central cartilaginous division of the cavity of the nose. Then the use of this false nostril probably is to turn off the current of air from the parts most connected with the sense of smell, and to direct it to its proper passage leading to the windpipe and the lungs.

The Cartilaginous Division of the Nostril.-A firm piece of cartilage runs up the centre of the nose of the horse as well as that of the ox, dividing the cavity into two parts. The intention of this is plain enough : viz., that if injury or disease should occur on one side of the nose, the other might be kept sound, and fit for the purpose of breathing. There are two things deserving of remark in this cartilaginous septum or dividing wall of the nose of the horse. From the more flexible nature of the nostril, more of it, or of the membrane that covers it, is seen in the horse than in the ox; and that practitioner is wise who avails himself of this circumstance in order to judge of the existence and character of every inflammatory disease of the chest. The membrane covering this cartilaginous dividing wall, and the nostril generally, is a continuation of that which lines the wirdpipe, and the passages of the lungs. It participates in inflammatory affection of that membrane, and therefore by its redness or its paleness (redness being the character of inflammation, and paleness, or want of extra blood in the vessels, prosing the absence of inflammation) it generally shows the degree of in. flammatory action existing in some other part of the membrane, and probably in the chest, and the danger which is to be apprehended. There is another circumstance of an anatnmical nature belonging to this wall of division, and which should not escape observation. In the $\mathrm{ox}$ and in the other domesticated quadrupeds it does not run through the whole extent of the cavity of the nose; but, towards the upper part of it, there is a communication between the two nostrils under the septum. There is sufficient support to the bones of the lower part of the face, and sufficient provision against the dangers to which this animal is usually exposed. The horse, however, is subject to a disease, and a dreadful and a fatal one, from which 
the ox is exempt, and at its commencement a disease often of the membrane of the nose alone-I mean glanders. The cartilaginous septum running from the bottom to the very top of the cavity guards against the spread of this, and preserves one nostril sound if the other should be ulcerated.

Of the remainder of the external part of the head I have little to say. The more angular the face is, the more breeding it discovers; and the shortness of the face, in proportion to the whole head, indicates the same thing.

The Eye.-No horseman needs to be told how much and how rightly he judges of the horse by the appearance and expression of the eye. The countenance of the human being is not a surer guide to the temper and the health, than is the eye of the horse. We always like to see a large eye in the horse, and one a little prominent. If the eyelids swell or project over it, and give it a sunken appearance, there has been inflammation of the eyes. If one eye is somewhat larger than the other, inflammation has existed in that eye alone, or worse in that eye than in the other. I shall have to speak of this more fully in its proper place, when, likewise, I shall have to show of how much consequence is a perfect transparency of the eye.

The Zygomatic Arch.-Above the eye is an angular projection of bone, nothing of which is seen in the ox. It is particularly brought under observation by the difficulty with which a collar a little too small is passed over it. It is designed to give both strength and room; strength, because the horse is exposed to serious injury from the brutality of those who have the care of him, and the blow will oftenest fall about this spot; and also to protect the extremity of the lower jaw, round which the temporal muscle, by whose contraction it is moved, is entwined: there is also room for the greater bulk of muscle, and the more extensive motion of the jaw of the horse. The ox has nothing to do but crop the soft herbage, and afterwards ruminate at his leisure: while the horse has to masticate often with considerable rapidity harder food; and in a state of nature his teeth are formidable weapons of offence and ủefence.

The Frontal Sinuses.-In the ox there is a continuation of cells under the forehead, and between the outer and inner plates of the skull, running from the end of the cavity of the nose to the very horn, and up the horn; and being intended to give strength to the base of the horn, and to remove it from immediate contact with the bone over the brain, and thus to avoid occasional and dangerous concussion in the contests between cattle whose horns are their weapons of offence. In the horse these cells extend but a little way up the forehead, under the name of the frontal sinuses; and, above them, a dense plate of bone covers and securely defends the brain.

The Ears.-As it regards the beauty, and temper, and spirit of 
the horse, considerable attention is deservedly paid to the ear. It should be small and erect, pointed forward, and quick in motion. A large and lop ear is a sad blemish, and tells tales both as to the breeding of the horse and his degree of activity. He has but little true blood in him, and he is usually a perfect drone. Some have endeavoured to remedy this by cropping the ears, and it was once the fashion to crop all horses, whether the ears were large or small. It was a barbarous practice; it gave an unnatural appearance and false character to the horse; it interfered materially with the hearing, for the vibration of sound could not be so numerously and perfectly collected: it souretimes produced inflammation that led on to perfect deafness; and many a horse became permanently shy and vicious, from the soreness of his ears caused by cropping.

The inside of the ear is lined with soft velvety hair. It was placed there to keep out the cold and insects, and occasionally to break the concussion of the air. 'The groom, however, finds great fault with it, and often cuts it out with his scissors, and singes it with his candle, and if he does not sometimes make very troublesome sores, and render the horse difficult to halter, he will at least expose him to annoyances from which Nature had defended him.

The Tongue.-There are some peculiarities in the mouth of the horse with which the horseman and the practitioner should be well acquainted. The tongue is considerably shorter than in the ox, and is tied down by a longer and thicker bridle. This was designed to render it a firmer and securer cushion for the bit to rest upon.

The Bars.-The palate is divided into numerous transverse ridges, called bars. They are thickenings or duplicatures of the membrane of the palate, and their edges are curiously fringed, the points of the fringe pointing inwards in a direction to the back of the mouth. The uneven surface presented by the bars, and the pointing of the fringe inwardly, contribute to retain the food in the mouth, while they afford no obstacle to its passing towards the gullet.

The Soft Palate. - The horse is the only animal who cannot, except under the most violent excitation, vomit through the mouth. This is caused by the peculiar construction of the curtain at the back part of the tongue, which separates the mouth from the gullet. It hangs down from the edge of the rounded bone of the palate, and in every other animal forms only an imperfect division. There is room between the botton of the curtain and the tongue for the air to pass, and the fond to be returned; and therefore vomiting is more or less ensily accomplished in them all. But in the horse, the curtain, or soft palates reaches down to, and rests upon, not only the back part of the tongue, but the upper portion of the windpipe, and forms a complete separation. It is so contrived that when the food has been gathered torether by the tongue, and by the action of the tongue, and that of the back part of the mouth, is 
pushed against the soft palate, that gives way; but if the pressure comes on the other side, the back of the tongue prevents the curtain from yielding, and the contents of the stomach are returned through the nostril alone. It is not, therefore, any thing about the palate which renders the act of vomiting so difficult in the horse; but it depends on the peculiar construction of the stomach, which I shall describe in the proper place. The length and singular attachment of the soft palate, however, prevent the horse from breathing through the mouth, and cause him to vomit through the nose alone.

The Teeth.-The manner in which the age of the horse may be determined by an inspection of the teeth will be presently considered; but there is something in the situation and construction of them that deserves notice. The nippers, placed in the front of the mouth in order to cut the grass, are covered with a hard substance, the enamel, to prevent then from being worn away. One simple coat of enamel, however, would, not effect the purpose. There is a great deal of wear and tear when the ground is dry and the stalks of the grass withered aad hard, and the hardest enamel would soon be destroyed. To prevent this a beautiful contrivance is adopted. The enamel, as it passes over the top of the tooth, is indented and sunk into it, forming a pit or hollow, lined by enamel, and the edges of the enamel projecting above, and preserving the body of the tooth, for a while, from being injured. In process of time, however, it is worn down below the hollow, and so the black mark in the fore teeth, which was nothing but the inside of this ho!low, gradually disappears.

The Tushes.-There is a small space between the nippers and the tushes, and a larger one between the nippers and the grinders: it seems, as it were, left on purpose for the reception and safe lodging of the bit; and on its proper degree of sensibility depends what is termed the goodness of the mouth, which materially affects the value of the animal. If, for instance, the membrane which covers this part is thick, hard, and insensible, the horse has a hard mouth; and on the other hand, if it is very thin and sensitive, the animal has a tender mouth, and cannot bear the hard pressure of the common bit. A good mouth is one between these extremes, having a sufficient degree of sensibility as to obey readily the pressure of the bit, and yet at the same time sufficient firmness to prevent this pressure being injurious. Nuch of the education of the animal will depend on giving him a proper mouth as it is termed, that is, teaching him to obey accurately and readily the slightest pressure of the bit. This requires considerable care. Many hasty, ill-tempered breakers absolutely spoil a horse in this respect; and it is by no means uncommon to find this part. particularly in young animals, considerably injured by the bit, so much so tirat a portion of the bone sometimes dies and exfoliates, leaving behind it a troublesome ulcer. 
The Grinders.-Behind are the grinders, and they are very curiously constructed. It would not be enough for the food of the horse to be cut and bruised: it must be actually ground down to a certain extent, or, worked as he is at uncertain intervals, and, perhaps, all day long, there would not be time for it to digest. The back teeth are so furmed as to constitute the most perfect grindstones that can be imagined, by means of the flat yet roughened surfaces which they present to each other. That these surfaces may not be worn down, or even worn smooth, there is not only one indentation of enamel, as in the front teeth, but several columns of it, penetrating down through the body of the teeth. The body of such a tooth is long wearing down; and when it does wear away, the bony matter between the columns of enamel goes first, and the enamel is left projecting; so that on an average, as fast as they are worn a way, they will present an unequal surface. To this must be added that they are continually growing, so that they will stand at nearly the same height as long as the horse lives.

Wnlves' Teeth. - There is often found before the first grinder an additional tooth-a very small one, and called, but I know not why, a wolf's tooth, and strange stories have been told of the pain which it gives the animal, and the injury it sometimes occasions. I confess I know not the use of these teeth, but on the other hand I have no proof of the mischief they do. I have seen them in the mouths of horses sixteen years old, that have never appeared to suffer the least inconvenience from them. Should it ever seem to be necessary to remove them, it may be easily effected with the common keyed instrument used for extracting human teeth, or even with a pair of small pincers.

[Many persons of close observation, are of opinion that blindness in the horse is often occasioned in some way not understood, by wolf's teeth; they confidently believe that the disease may be arrested ant removed, by the removal of these teeth, which is easily effected.

[As there is nothing into which the purchaser so sharply inquires as the age of the horse, and as our author has not been so full as we could have wished on this point, we here give with illustrations, the best instructions we have seen, and can testify to their general accuracy. We call attention particularly to what is said of the bridle tnoth or tusk, situated between the fore and the jaw teeth or grinders in the male. Mares rarely have them. When the inside of the bridle tooth loses the gronve and becomes rounded and the point of it worn off and blunted, the horse may be considered as past eight years old at any rate.]

Age of the Horse.-There are no certain marks by which we can judge truly of the age of a horse but his teeth; and these only for a certain time: after that time, there is no method to be depended upon, but we may form a good guess by the front teeth of his upper jaw, until he is about iwelve or thirteen; especially if we take into 
consideration the countenance of the horse, with some other marks which we shall point out. A horse has forty teeth, twenty-four called grinders, from which we learn nothing of his age; then six above and as many below, in the fore part of his mouth, called gatherers, or cutting teeth, and it is from these we know his age; then four tushes, two above and two below, sometimes named bit teeth, making in all forty. Mares generally have no tusks, their teeth are therefore only thirty-six. When a colt is foaled, he has no teeth in the front of his mouth; in a few days, two above and two below make their appearance; soon after these, four others appear; after these, it is usually three or four months before the corner teeth make their appearance. These twelve colt's teeth in the front of the mouth, continue without alteration, till the colt is two years or two years and a halt old; he then begins to lose his colt's teeth for permanent ories, sooner or later, according to the manner in which he has been fed.

As it is from the front teeth of the lower jaw a horse's age is known, until he is in his eighth year, it is to these only we shall confine our attention. At about tivo years and a half old, he sheds the two middle teeth of the six; (as these first appear in the colt's mouth, so are they the first to disappear); these are succeeded by two permanent or horse teeth, stronger, of a deeper colour, and grooved or fluted from top to bottom, with a black cavity in the centre; he is now rising three.

His mouth continues thus till some time in the latter part of the fourth year, when the same process takes place with the teeth on each side of the two in the centre; so that at four years old, he becomes possessed of four liorse teeth in the middle, with their natural black marks in the centre; and one colt's tooth only on each side.

The next he sheds are the two remaining. or corner teeth; when he has got the successol's to these, his mouth is full; he is then called a horse, five years old: he has the black mark now in all the six front teeth.

During the course of this year, the tusks, situated beyond the corner teeth upon the bars, appear; he is now five years old, off; and through the whole of the year is "rising six:"-we say, "he will be six years old next grass." Some time in the last six months of the sixth year, the black cavities of the two middle teeth are gradually filled up; and when he is turned six yenrs old, they are nearly, or quite smooth upor the surface. In the latter part of the seventh year, when the horse is termed "six off," six past, or rising. seven, the teeth on each side of the two centre ones, become gradually possessed of the same appearance; and when he is seven years old, the two outside or corner teeth only, are marked with the black cavity.

After this period, the horse is said to be aged; and from this time to the completion of his eighth year, the mark in the corner teeth 
continues gradually to disappear, till it is quite gone, when the age by the teeth is no longer known. He is now "past the mark of the mouth."

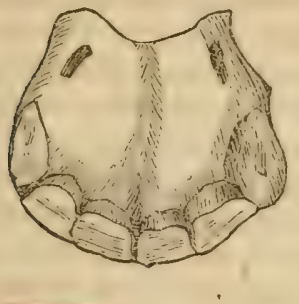

TWO YEARS AND A HALF.

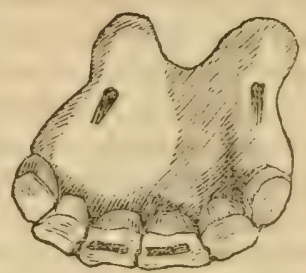

RISING THREE YEARS.

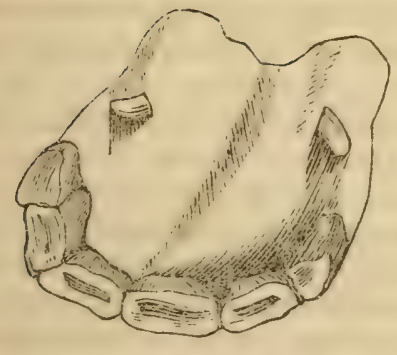

FOUR YEARS.

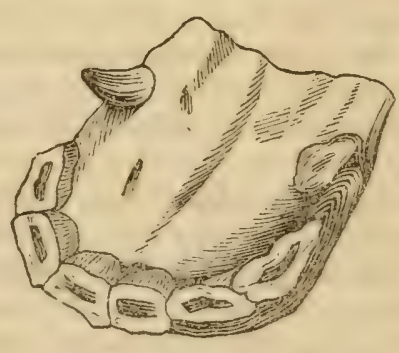

FIVE YEARS.

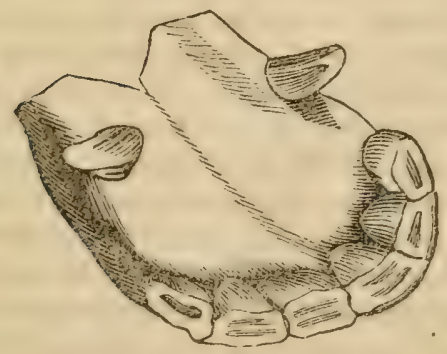

SEVEN YEARS. 
After this period, yon may judge of the age by the marks or cavities in the upper teeth. At about ten, the two front teeth have lost their marks; the two next them have but little left, but in the corner teeth these marks may be readily seen; these gradually wear out, and during the twelfth year are quite erased. The tushes, like the teeth, are gradually changing their appearance; they are small, sharp, and shell-like at first, and are grooved on their inner surface; they gradually become larger and longer; the concavities or grooves on their insides also lessen ; and at about eight, they are nearly lost. At about eleven and a half, or twelve, the inside of the tush begins to approach towards a round form, and after becomes quite round; they are then blunt at the top and of a yellowish brown colour. 'The teeth of horses as they advance in years, appear longer, from the gums shrinking from them, they get more oblique in their position; they also acquire a much darker colour. Horse dealers are said to practise numerous artifices in order to deceive their customers, with respect to their horses' ages: one of these is termed bishopping; that is, making artificial marks in the teeth, when the natural ones are worn out; but there is always a want of resemblance between the natural and artificial mark; you may likewise compare them with the state of the tushes. They also knnck out the corner teeth of four year olds, to make them appear five; for when these are removed before their time they are soon succeeded by horses' teeth: this my be detected by the want of tushes. In racing, all horses take their ages from Mayday.

The Lower Jaw.- Some attention should be paid to the size of what is called the channel, that is the space between the branches of the lower jaw. If it is narrow, the head will sit awkwardly: for the rounded projection of the windpipe cannot be received between the branches of the jaw ; and the head will always be poking out, diminishing materially from the beanty of the horse, and being a sad inconvenience to the rider, for the animal will bear heavily upon the hand, and cannot be reined in except by extreme force. There are few things of so inuch importance with regard to the appearance of the horse, and the pleasure of the rider or driver, as that at which I have already hinted-the setting-on of the head-and this depends more upon the width of the channel than any thing else.

The Neck.-On the shape of the neck I need not say much: it should be proportionate to the body, but a little too long rather than too short, and small rather than thick, at least towards the upper part of the neck, in order that the head may be well set on, and have freedom of motion. Plenty of muscle, nevertheless, may be allowed or should always be found at the base of the neck; otherwise there will be a looseness in the motion of the neck unpleasant to the rider, and sometimes indicating weakness in the horse. If, however, this thickness extends far up the neck, it gives a heaviness 
to the appearance of the animal, usually accompanied by heaviness of disposition, and of action. If the thickness is about the middle and under part of the neck, the evil is worse. A ewe-necked horse is an unpleasant goer, for there cannot be that angle formed between the head and the neck on which the pleasant management of the mouth essentially depends.

I will pass over the shoulders until I come to describe the diseases of the feet and legs; for the structure and the diseases of these parts cannot well be separated.

The Chest.-Although many horsemen, and even veterinarians, too carelessly regard the chest in their examination of the horse, it is by far the most important part about him, for it contains most of the vital organs. There are two main things to be considered about the chest of the horse. In the first place it must be capacious. There must be room enough for the heart to beat, and the lungs to heave. There nust be room enough for the exertion of sufficient power to circulate the blood through the whole frame, and for the lungs to prepare that blond, in order to supply the nourishment, and keep up the action of the frame. Therefore a long-legged, narrow-chested horse will never carry much flesh, nor be capable of continued severe work; and he will be peculiarly liable to inflammation, and other diseases of the chest.

There is a pnint of more consequence, and also frequently overlooked; I mean the form of the chest. We do not want the horse to carry flesh and fat, which a large and round chest would cause him to do, and which it does in the ox, and is all that we require in the ox; but we want the chest to accommodate itself to the different degrees of exertion. It has not only to prepare and circulate sufficient blood when the animal is quiet, but to enlarge, and to be capable of preparing and circulating a great deal more, when it is rapidly expended in rapid motion. Therefore we must have a deep as well as a wide chest. A circular chest is capable of little or no enlargement. The figure of a circle can never be changed so as to make it contain more than it naturally does. A deep chest may enlarge: it may become more circular, and the lungs can expand, and ardmit more air, and arterialise more blood, or render it capable of supporting life and action. Therefore we admit of the circular chest in the ox; we admit of it in the heavy draught horse ; but in the hackney and the horse of light work and speedy draught we look for something else.

For another reason we want the deep chest in horses for light and speedy work. The circular chest will be weighty in front: its very form will require thick and fleshy shoulders in order to adapt themselves to it; and this will give a heaviness before, a heaviness and slowness of action, a battering and bruising of the fore-legs and feet, and a want of safety: for the centre of gravity will be too near the front support of the horse, and will be too readily thrown beyond that support. The deep chest usually has its principal fulness behind 
the elbow, and thus the weight is thrown more under the horse: therefore, the form for useful purposes will be that of moderate breadth, depth at the girth, and a barrelling behind the elbow.

It will be the duty of the veterinary surgeon to attend to this in his treatment of disease, and especially in the opinion which he gives of the probable termination of disease of the chest. The varying capacity of the chest, adapting itself to the exigencies of the case, is quite as important with reference to the increased quickness of breathing in inflammation or fever, as to that produced by exertion alone. If the little narrow chest will scarcely allow room for the lungs to play at all, and if the circular chest was previously full, there will be considerable danger from the hurried breathing of fever; and therefore it is that many more of the narrow and round-chested horses fall victims to inflamed lungs, than of those who possess a deep and expansible chest.

Again, there ought to be plenty of room in another way; the chest should be long; the ribs slould be somew hat apart from each other, so that they may reach back under the loins, and towards the hips. We have then more room for the organs of respiration before, and for those of digestion behind. There is more support given to them, and they are better able to discharge their healthy functions. Therefore a horse ribbed home, or the space between the last rib and the hip bone being small, is almost sure to be strong and enduring. He may not be very speedy, for room at this part has more to do with the organs of digestion than the ficulty of speed; but he may be depended upon as having a gnod constitution, and as being capable of all ordinary work. It we require from the horse only the occasional exertion of more than common speed, we may excuse a little hollowness of the flank, provided there is strength enough behind; for there will be more room for the full stretch of the hind extremities, and therefore for a longer stride, and greater speed.

The Withers. - There are a great many important points connected with the back and spine. The withers are the spinous processes, or upright projections of the ten first bones of the back. High withers have, in the opinion of every judge of the horse, been associated with superior action; and the reason of this is plain. In proportion as the withers are high the shoulder-blades are long and well developed, their action is thereby extended, and the muscles connected with them and the shoulder-bones have the advantage of additional leverage; and in the same manner have the muscles connecting the shoulder-blades with the withers. Thus, then, if the conformation of the other parts of the fore extremity correspond, we have generally good and high action cornected with high withers. The withers thus afiord an illustration of the mechanical advantage gained by the application of the lever. It is a law of mechanics that in proportion as the arm of the lever to which the power is applied is lengthened, the weight will be more easily raised; and therefore 
in proportion to the height of the withers will the muscular power expended in elevating the fore quarters be diminished. For the horse of quick work, the hunter, and even the hackney, high withers are desirable, but not for horses of heavy draught; for, in proportion to this power of elevation, there is usually a lightness before, which would be a considerable defect in him whose excellence depends on the weight and muscular power which he is able to throw into the collar. High withers would be a defect rather than an excellence in the dray-horse. In race-horses, too, the withers may be too high, by causing the action to be too lofty, and thereby diminishing the length of the stride.

The Spine of the horse is a beautiful contrivance. The chest and belly contain organs of the greatest importance, and essentially connected with life. If they were suspended from an unyielding bar, as of iron or wood, the concussion inevitably would be fatal to him. Again, in the speedy action of the animal, the horse was designed for our convenience and pleasure; and next in importance to the safety and swiftness with which he carries us, are the easiness and pleasantness of his action. If the back were unyielding, who could bear to be jolted by him for a single mile?-On the other hand, if it yielded too much, it would betray a degree of weakness incompatible with many of the tasks which we impose upon him. The spine is therefore divided into numerous bones, and these are connected together by a cartilaginous elastic substance, forming so many joints, each of which possesses a little motion; the aggregate motion of the whole giving sufficient ease to the rider, without lessening the strength of the back. The strength of the spine is secured by a mechanism that deserves peculiar attention. The round head of one bone accurately corresponds with a cup or hollow in.that before it, and between them is placed this cartilaginons substance: there are also strong ligaments above and below, and on either side, so that, although we sometimes hear of a fractured spine-although the bones may yield to violence, the joints are rarely dislocated.

Man, brutal or avaricious, will sometimes overload the horse, or urge him to too great, or too sudden exertion: then there is so much stress on these joints, that the ligaments are injured, and inflammation ensues; the usual consequence of inflammation about a ligament or a bone takes place, bony matter is thrown out around them, and the joints lose their springiness, or rather they are destroyed. The back then becomes stiff, and the horse is not pleasant to ride: he turns with difficulty, and he will rarely lie down: he is "chinked in the chine," and materially lessened in value.

The Length of the Back.-Few, except those who have closely examined the structure of the horse, are aware what difference there is in the length of the back in animals of the same height. Compare the Suffolk punch horse and the lengthy Cleveland in this respect. There can be no doubt that the long-backed horse is 
easier in his paces, for a long spring has a more extensive and gentler motion than a short one. He will usually be speedy, for he will be able to bring his hind legs with more advantage under him, and thus, in the act of galloping, will have more purchase in order to send his fore limbs forward, and to lengthen his stride; but just in comparison to the length of the spring will be its weakness; and in proportion as the distance between the supporters of the frame increases in the horse will be the weakness of the back, and the ease with which he may be overweighted and strained. On the other hand a back a little too short may promise strength; but it will be accompanied by short and rough action, by a deficiency of speed, a tendency to unsafeness, and particularly to overreaching. No decided opinion can be given about this matter, with respect to any particular horse, without reference to his form in other respects, and the purposes for which he is required. A slim flat-sided horse, with a long back, can be good for nothing at all. A stouter horse, with breadth of loin and muscular quarters, requires length, not only to carry off an appearance of clumsiness, but because he can afford to part with a little strength for the sake of greater pleasantness of action and speed: however, for general purposes, a shortbacked horse is properly preferred, as possessing all the strength that can be required, a hardihood of constitution which in a manner bids defiance to disease, and as much speed as is usually required.

The Line of the Back.-The proper form of the back is a depression immediately behind the withers, and then a straight or gently rising line to the loins. There are two deviations from this, the saddle and the roach back. In the first there is a hollowness, as if the back was made expressly for the saddle. This betrays some degree of weakness, but is accompanied by easiness of action, and a fine arched crest. It is scarcely an objection if the horse has to carry a light weight, and it gives a nobleness to his appearance in single harness. The roach-backed horse is dear at any price, for there is no keeping the saddle upon him, or his back from being galled; his hind legs are awkwardly doubled under him, and his head is low, and he is heavy on hand.

The Loins.-The loins should be most carefully exarnined by the horseman. They are rightly considered a test of the general strength or weakness of the animal. If they are broad and muscular, he will be equal to considerable work: but if there is no substance about them, he is of little worth for the saddle or the collar.

The haunch and the quarters will be most advantageously considered when I describe the hind extremity, as introductory to a consideration of the diseases of that part of the animal.

Referring my reader to the Treatise on Cattle, for an account of the contents of the chest and belly, and of all the important functions there carried on, I will briefly notice a few peculiarities in the structure of the stomach, intestines, and liver of the horse; and then proceed to the nature and treatment of disease. 
The Stomach.-There is a strange difference between the four stomachs of the ox-one of them so large-and the little stomach of the horse. It is smaller in proportion to his size than that of any other animal. It will not contain half of that which an ox would eat at an ordinary meal. The horse is valuable to us on account of his speed as well as his strength: he is liable to be called on to exert himself, and that to the utmost, at all hours, and whether full or fasting; and when we are journeying with him, scarcely sufficient time is allowed for the grinding of his food, and none for its digestion. His stomach is also placed close against the diaphragm --that muscular division between the chest and belly which was described as the chief agent in breathing, - which, by its protrusion into the chest, and pressing upon the lungs, and forcing out the air, produces the act of expiration; and by its contraction enlarges the chest, and admitting the air, causes the inspiration. In every act of inspiration the diaphragm presses against the stomach, and more or less displaces it. If the stomach were large, this singular muscle would have hard work to move it when full and heavy, and the horse would be soon exhausted by the violence of the exertion; or, perhaps, more truly speaking, it would not be able to move the stomach at all, and the breathing would be laborious, and the animal in continual danger of suffocation. Therefore this small stomach was given to hirn, that he may be always ready for our work, and that without serious annoyance to himself' or us. Some persons have affirmed that he is the only animal that can work with safety and comfort on a full stomach. He can do so better than others: but many a horse is blown, and even destroyed, by being hurried after a plentiful meal; and thousands of them used to be rendered brolien-winded, and comparatively worthless, by being galloped after watering, because the groom happened to imagine that this was necessary in order that the water might not chill or gripe the animal.

The stomach is not only small, but its structure is singular. Onehalf of it is cuticular, like the whole of the paunch of cattle, and constitutes a mere reservoir for the food. The horse is often compelled to eat too fast for the food to be properly chewed and prepared for digestion; therefore it is retained awhile in this cuticular portion of the stomach, in order that it may be macerated and softened. After all, it passes into the other part of the stomach, where the process of digestion is performed. From the smallness of the whole stomach, and a portion of it being employed as a mere reservoir, the food is necessarily hurried on before the work of digestion can be half accomplished. It must, however, be accomplished somewhere, or the animal could not obtain sufficient nourishment.

The Inlestines.-Digestion continues to be carried on in the first portion of the intestines, the duodenum, which is comparatively larger than in almost any other animal, and which for the purpose 
of continuing the process of digestion, is provided with a thick villous coat with numerous projecting folds, like a second stomach. The process still proceeds in the small intestines, which, in a horse of the usual bulk, are no less than sixty-six feet in length, and would contain eleven gallons of fluid ; and it is not perfected until it has passed the larger intestines. The first of these, the colon, and which, although long, is not bulky in cattle, is of an enormous size in the horse, and will usually contain no less than twelve gallons of fluid. Here a curious provision is made for the retention of the yet imperfectly-digested food. The colon is curiously puckered into a great many deep cells, through every one of which the food must pass, and in each of which it is for a while detained. The cœcum, or blind gut, which, although not properly a continuation of the small intestines, lies at the extremity of them, the more fluid part of the food seerns to be sent into the cœeum, which will contain at least four gallons of fluid. Its construction of cells is even more complicated than that of the colon, and plainly designed for the same purpose, the retention of the aliment. When the contents of the stomach, after having passed through all this complicated apparatus, has at length reached the rectum, or last intestine, a very small portion of undigested food will remain.

The Liver.- Two fluids enter the duodenum by small orifices, in order to contribute (but in what way has not been satisfactorily determined) to the process of digestion. The one, from the pancreas, is nothing different from that which has been described in cattle; but the bile comes immediately from the liver, instead of first passing through the usual reservoir, the gall-bladder. The horse has no gall-bladder: his stomach we have said is small; it must, therefore, be oftener replenished, and the food must be oftener passing out of it, and there can be no necessity for the gall being detained in any reservoir for use at a distant time.

There is nothing peculiar about any of the other contents of the belly, and therefore I will proceed to the consideration of another subject,-Breaking,-which is of great importance, as it developes the character of the Horse, and, by good management, establishes his future usefulness.

[On Breaking.-Before we proceed with our author to the consideration of the diseases of the Horse, we may be permitted to say, on a subject which it is true does not come within the purview of this work, that horses are often abused, and not unfrequently permanently injured in their qualities, in the act of breaking them! An undertaking which should be conducted with singular judgment and gentleness, is often committed to the rudest hands, force is substituted for persuasion, and feelings of resentment and antipathy are deeply implanted, where the sole aim should be to inspire confidence. When we reflect how great is the change to be wrought in the condition of the animal; that the yet unbridled colt is to be driven up from where he "paweth in the valley and rejoiceth," to 
be thoroughly subdued, and doomed through life to abje at diud gery, humanity and reason alike suggest that the process should be as far as practicable one of pure gentleness and persuasion.

The art of breaking young and even the wildest and most indomitable horses, on this principle of easy and cautious approaches to our object, constitutes the chief article in a small volume, which deserves to be better known were it only for the testimony it bears to the obvious benevolence of the author-Willis J. Powell, Esq., Its title is "Tachylippodamia, or the art of quieting Wild Horses in a few hours, as discovered by the author in the year 1814-to which are added many useful instructions concerning Horses, in French, Spanish and English." We take the liberty of extracting as much as will serve to convey an outline, or we may say the main principle of his process, intending thereby to recommend the work itself to public attention, and thus promote the sale of it, and respect for its author.]

He says, "a horse is gentled by my secret in from two to sixteen hours. The time I have most cornmonly employed has been from four to six," and under the head of "the secret," goes on to observe "cause your horse to be put into a small yard, stable or room. If in a stable or room, it ought to be a large one, in order to give him more exercise with the halter, before you lead him out. If the horse belongs to that class which appear only to fear man, you must introduce yourself gently into the stable, room or yard where the horse is. He will naturally run from you, and frequently turn his head from you; but you must walk about extremely slow and softly, so that he can see you, and whenever he turns his head towards you, which he never fails to do in a short time, say in a quarter of an hour, or half an hour-I never knew one to be much longer without turning towards me-at the very moment he turns his head, hold out your left hand towards him, and stand perfectly still, keeping your eyes upon the horse, and watching his motions, if he makes any. If the horse does not stir for ten or fifteen minutes, advance as slowly as possible, and withnut making the least noise, always holding out your left hand, without any other ingredient in it than what nature put in it. The reason of my having made use of certain ingredients before people-such as the sweat from under a man's arm, \&c.- - was, to disguise the real secret; and Drinnen, as well as several others, believed that the docility to which the horse arrived, in so short a time, was owing to those ingredients. It will be seen, in this explanation of the secret, that they were of no use whatever; but, by placing so much confidence in them, those who had succeeded in breaking one horse, failed in another, and that is what I foresaw.

No one can accuse me of bad faith, to whom I discovered this or any part of the secret; for I always intended to publish the whole. In the second place, many revealed what I had told them, after the most solemn promise to the contrary. Caution is the parent of 
safety: I, therefore, by multiplying the ingredients, caused a confusion amongst those who thought they knew the real secret. Though I revealed enough of the secret for a man to break a horse in a few hours, it was not enough to make the horse remain gentle; that is, generally speaking: for some horses would be perfectly gentle ever after; but the greater number would not. The implicit faith placed in these ingredients, though innocent of themselves, became faith without works; and thus men remained always in doubt concerning this important secret. The secret is a complete lesson of morality; for all is GENTLENESS-PATIENCE-PERSEVERANCE.

But I return to the explanation of the secret. If the horse makes the least motion when you advance towards him, stop and stand perfectly still till he is quiet. Remain a few minutes in this position, and then advance again in the same slow, almost imperceptible manner. Take notice: if the horse stirs, stop without changing your position. It is very uncommon for a horse to stir more than once, after you begin to advance, yet there are exceptions. He generally keeps his eye steadfast on you, till you get nigh enough to touch him upon the forehead. When you are thus near to him, raise slowly, and by degrees, your hand, and let it come in contact with that part just above the nostrils, as lightly as possible. If the horse flinches, (as many will, repeat with great rapidity those light taps or strokes upon the forehead, going a little further up towards his ears by degrees, and descending with the same rapidity, till he will let you handle his forehead all over. Now let the strokes be repeated with more force over all his forehead, descending by lighter touches to each side of his head, till you can handle that part with equal facility. Then touch, in the same light manner, making your hands and fingers play around the botton or lower part of the horse's ears, coming down, now and then, to his forehead, which may be looked upon as the helm that governs all the rest. Having succeeded in handling his ears, advance towards the neck with the same precautions, and in the same manner; observing always to augment the force of the strokes, whenever the horse will permit it. Perform the same on both sides of the neck, till he lets you take it in your arms without flinching. Proceed in the same progressive manner to the sides, and then to the back of the horse. Every time the horse shows any uneasiness, return inmediately to the forehead, as the true standard, patting him with your hands, and from thence rapidly to where you had already arrived; always gaining ground, a considerable distance further on, every time this happeris. The head, ears, neck and body being thus gentled, proceed from the back to the root of the tail. This must be managed with dexterity, as a horse is never to be depended upon that is skittish about the tail. Let your hand fall lightly and rapidly on that part next to the body a minute or two, and then you will begin to give it a slight pull upwards every quarter of a minute. At the same time, you continue this handling of him, augmenting the force 
of the strokes, as well as the raising of the tail, till you can raise it and handle it with the greatest ease, which commonly happens in a quarter of an hour in most horses; in others almost immediately, and in some much longer. It now remains to handle all his legs. From the tail come back again to the head; handle it well, as likewise the ears, neck, breast, \&c., speaking now and then to the horse. Begin, by degrees, to descend to the legs, always ascending and descending, gaining ground every time you descend, till you get to his feet. Talk to the horse in Latin, Greek, French, Lnglish or Spanish, or in any other language you please, but let him hear the sound of your voice, which at the beginning of the operation is not quite so necessary, but which I have always done in making him lift up his feet:- 'Hold up your foot'-'Lève la pied'-'Alza el pié' -'Aron ton poda,' \&c., at the same time lift his foot with your hand. He soon becomes familiar with the sounds, and will hold up his foot at command. Then proceed to the hind feet, and go on in the same manner; and, in a short time, the horse will let you lift them, and even take them up in your arms. All this operation is no magnetism, no galvanism. It is merely taking a way the fear a horse generally has of a man, and familiarizing the animal with his master; as the horse doubtless experiences a certain pleasure from this handling, he will soon become gentle under it, and show a very marlsed attachment to his keeper." 



\section{E V ER Y M A N}

\section{HIS 0 W N FARRIER.}

\section{CHAPTER I.}

\section{ON INFLAMMATION.}

A VERY great proportion of the diseases of the horse are connected with, or consist in, Inflammation; for the heart is large, the arterial system is strong, and the animal is exposed to many causes of irritation. Inflammation is an increased flow of blood; the heart or the vessels act with too much energy, and the blood is driven too rapidly, or in too great quantity, along. This may be either local or general. We may have inflammation of the eye, or of the lungs, or of the foot, and the general constitution may not be much affected: the inflammation is then said to be local; but, after a while, the vessels of the whole frame will take on the same action as those of the diseased part, and sympathetic or symptomatic fever is produced. In some cases, the action will be general from the beginning, or rather, we are unable to ascertain the part which was first, or which is chiefly affected: this form of inflammation is termed simple fever. All these will in turn pass in review before us.

Inflammation may be either acute or chronic. It may have suddenly arisen, and may be exceedingly violent, and may endanger life; but by prompt treatment it may speedily disappear, leaving scarcely any trace behind except debility of the part: at other times it may rapidly destroy the part by its intensity. Sometimes it may have slowly and gradually come on: it may never reach any great degree of intensity, but it is fixed, and it is evidently doing permanent mischief: it is altering the structure, as well as disarranging the functions of the parts.

The treatment will vary according to the nature of the organ attacked and the violence of the inflammation, and scarcely any 
general rules can be laid down; but the two most successful opponents of inflammation are bleeding and purging. It may be convenient to say a few words with regard to each of them before we proceed.

\section{BLEEDING.}

If inflammation consists in a too rapid flow of blood through some vessels, or through the frame generally, there can be nuthing so likely to subdue it as the lessening of the quantity of blood. In general inflammation, blood should be extracted from the jugular vein : it is the most convenient vessel to get at, and the blood may be taken quickly away. In genera! inflammation, and in violent inflammation of any part which threatens to affect the whole system, the practitioner should never hesitate to bleed, and to bleed largely. The precise quantity of blood that should be taken away in inflammatory cases can never with propriety be previously determined; but, the finger of the operator being kept on the artery, the blood should be permitted to flow until the pulse becomes materially Eofter, or flutters, or the horse begins to blow hard, or threatens to fall. This is the golden rule in the treatment of acute inflammation, of every kind, viz., to bleed promptly and copiously, and until the circulation is evidently affected. Many a man has repented of small bleedings: he has played with the disease and not beaten it; he has undermined the strength of the patient, but he has not diminished the intensity of the local inflammation: but rarely has any one repented of one prompt abstraction of blood, however profise.

Next to the quantity of blood taken away, and of almost equal importance with it, is the quickness with which it is abstracted. The loss of four quarts, poured out in a full stream, will affect the horse more, and make a greater impression upon the disease, than double the quantity suffered to escape in a small stream, or merely to dribble down the neck. 'The fleam of the lancet should, therefore, be sufficiently broad-shouldered.

The lancet is the most portable instrument: it appears the most surgical one, and after a little practice may be as much depended upon as the fieam, while the horse is not frightened by the flourish of the stick, nor the vein bruised, nor the opposite side of it cut through by the violence of the blow.

When a suficient quantity is taken, and before the blood is sponged away from the neck, the edges of the orifice should be brought together wilhout lifting the skin more than possible from the neck, and kept in contact by a small sharp pin passed through them. It is the pulling up of the slsin and suffering the blood to pass into the cellular membrane under it, which, next to the bluntness or foulness of the fleam, or the violence of the blow, often causes a swelled neck after bleeding.

Should considerable swelling appear, and the lips of the wound 
open, and a thin ichorous fluid be discharged from the wound, and the neck feel hot, the part should be fomented several times in the day with warm water, and a little Friar's Balsam applied to the lips of the wound.

Inflamed vein is one of those cases that must not be trifled with. If the wound does not, within a day or two after the application of the basalm, appear disposed to heal, the edges of it must be lightly touched with the hot budding-iron, or some other caustic. The incision should be kept apart with the finger and thumb of the left hand, while the point of the budding-iron is introduced as lightly as possible, brought into contact with both edges, and immediately withdrawn. Nothing should then be done to the wound for a day or two, except to cleanse it if necessary.

Sornetimes the first indication of an inflamed vein is a swelling of the part, which often increases rapidly above the seat of bleeding from the inflammation of the vein obstructing or stoppinir the flow of blood in its course towards the heart. When this is the case it becomes a somewhat serious and tedious affair. If the swelling is considerable it should be subdued as much as possible by fomentations and lotions. The head of the horse should be tied to the rack, and his diet consist principally of mashes, so as to avoid the movement of the jaws as much as possible. A dose of physic may be given, and in a few days the swelling should be blistered. The blister should be washed off the second day, and repeated as soon as the parts are clean enough. If any matter issues from the wound it should be pressed out daily, and a little caustic applied to its lips.

With this treatment the horse will generally be fit for work in about a month: although the vein will frequently be lost, yet the swelling will subside, the blood find new channels, and little or no after inconvenience will be experienced.

When there is much mange about the neck, there is always considerable hazard in bleeding from the jugular. The skin is already in an irritable, if not inflamed state: this is much increased by the wound inflicted by the lancet, and troublesome swellings, sinuses, and sloughing often ensue.

If the practitioner should fail to open the vein at the first attempt, it will be best to endeavour to bring it exactly under the orifice he has made through the skin, and to strike again more gently upon it, than to make a fresh wound; but if it is necessary to have recourse to bleeding three or four hours after the first operation, the old wound should not be opened, but a new incision always made.

If, after the lapse of four or six hours, the first bleeding has not lowered the inflammation, more blood should be taken, without any unnecessary delay.

In cases of local inflammation, the bleeding should take place as nearly as possible to the diseased part, but with this proviso, that it shall be between the disease and the heart. It will be easily com- 
prehended that, while much of the good effect of general bleeding will be obtained, and all of it if the bloud can be taken away quickly enough, this further advantage will be gained, that the inflamed part will be drained of its blood, and its gorged vessels relicved. If, however, the bleeding is practised further from the heart than the seat of inflammation, the effect can at best only be that of a general bleeding, and will not, in fact, be half so beneficial, because it will be scarcely possible to take away the blood so rapidly from any other part as from the jugular vein. Therefore the surgeon may bleed from the arm for injuries in the knee or fetlock, or from the coronet, or the toe, in font-cases. The proper bleeding places will be pointed out as we consider the inflammations or other diseases of different parts.

\section{PURGING.}

There are few medicines so abused by the groom, and sometimes by the more intelligent proprieter of the horse, as purgatives. They are given without any rhyme or reason, and in excessive, and injurious, and sometimes fatal doses; and perhaps I may affirm that more horses are destroyed by physic than by any one disease to which they are subject. On the other hand, there are no medicines so useful as purgatives when judiciously employed. They are especially useful in inflummatory complaints. They produce, while acting, or preparing to act, a kind of nausea-a general relaxation, highly to be desired in a complaint, the essence of which is undue action of the circulating vessels. They remove from the stomach and bowels any cause of irritation which might have existed there, and which may prolong, if it did not produce, the complaint. They cut off the temporary supply of nutriment to the frame- for the chyle is hurried along the intestines and expelled, instead of being taken up by the lacteal absorbents; and, more especially, and next to bleeding, and sometimes to a greater extent than bleeding, they lessen the quantity of fluid circulating through the system. 'The bulk of aqueous fluid discharged by the action of a brisk purgative is sometimes enormous, and a great portion of it would otherwise have entered into the circulation.

In the early stages of fever, physic is indispensible; and also in every local inflammation, except in some cases of the intestinal canal, or where there is a strong sympathy between the disensed part and the bowels, so that there is danger that the inflammation may be transferred from its first seat to the intestines, when they are excited and irritated by the purgative. On this account it is hazardous practice to administer a strong purgative in inflammation of the lungs.

This leads to the observation that there is another way in which a purgative may be useful in cases of inflammation, viz., by determining in some degree the current of the blood from the inflamed 
part, and thus giving double relief, by the different direction of the current, as well as by the diminution of the actual quantity circulating through the vessels.

Horses that are fat and plethoric are much benefited by physic, and a great deal more so than by bleeding. I do not hold with the regular purging at certain times of the year. It is a good maxim "to let well alone;" yet periodical physickings are much more harmless than bleedings, for they simply evacuate the bowels, and by that frequently do permanent good. Sportsmen know that physicking is the first step in order to get a horse into working condition; but the effect of bleeding on a fat horse is doubtful even at the time, and most certainly injurious afterwards; for it produces a disposition to create more blood, and a greater quantity than that which was lost; and in a short time the horse becomes fuller of blood, and more pursy than he was before.

In greasy swellings of the legs, lameness attributable to the joints, old cough, worms, and mange, physic is very useful.

The purgatives of the horse are very few in number. The superior efficacy of the Epsom salts was spoken of in the work on Caltle; they are uncertain in the Horse, although given in enormous doses; and occasionally they gripe sadly. They are useful only in clysters. Glauber salts have no better or more certain effects. Castor oil, although the furrier gives bottle after bottle of it, to the great expense of the owner of the horse, is not only an uncertain, but sometimes a decidedly injurious medicine. Mild and harmless as it is in the human being, and given to relieve griping and remove irritation, it is too apt to gripe the horse, and some. times violently, and there is no doubt that it has occasionally pro. duced fatal inflammation of the bowels. Linseed, olive, and neat's foot oils are better things: they will rarely do harm, but they are often uncertain. The best and almost the only purgative that can always be depended upon is aloes.

There has been a great dispute about the kind of aloes. The Cape is the cheapest, and the Barbadoes usually three or four times as dear. The Cape will work tolerably, but in a somewhat larger dose, and after considerable exercise: the Barbadoes are most certain in their effect in common cases, and where exercise is admissible, and can alone be depended upon when the disease under which the horse labours forbids exercise: the Cape will sometimes gripe, the Barbadoes will very rarely do so. In his practice in his own infirmary, the surgeon or the proprietor of the horse may safely use the Cape aloes; but he must never send out any other ball than one composed of Barbadoes aloes for patients that cannot be exercised at all; and of an equal mixture of the two where exercise can be given, and he can depend on the groom for giving it.

The following will be a good physic mass for common use :- 


\section{RECIPE (No. 1).}

Physic Mass.

TAKE-Barbadoes aloes, very finely powdered, seven pounds and a half; Cape aloes, also powdered, seven pounds and a half;

Ginger, powdered, one pound; and

Palm oil, seven pounds and a half:

Beat them well together, and keep them in a jar closely bladdered.

[Here we think it well at once to deseribe the different kinds of aloes, as we find it laid down in that excellent work, Johnson's Sportsman's Cyclopedia; it will be seen that he recommends aloes as "the most effectual purgative for horses," and gives the quantity and proportions for a dose.]

"Aloes are distinguished by the name of the place from whence they are bronght. The Socotrine aloes are brought from the island of Socotra, and are supposed to be more safe in their operation than the other kinds. This aloe is of a dark brown colour, opaque, and has a less disagreeable smell than the others. The Barbadoes aloe is brought from Barbadoes, and has been generally considered apt to produce griping, and other unpleasant effects; it is of a darker colour than the former kind, less brittle, and of a stronger and more disagreeable smell. It is more active than the Socotrine, and for that reason is more used in veterinary practice than it, though this kind of aloes has its advocates. The Cape aloe is rather transparent, very brittle, easily powdered, and is of a bright yellow colour; its smell is not so strong as the Barbadoes, but stronger and less agreeable than the Socotrine. It is much lower in price than either of the others, but is so uncertain in its effects, that it is hardly ever employed in medicine. The aloe is the most effectual purgative for horses with which we are acquainted; it is generally made into balls with the addition of soap, which makes them operate more speedily. The dose of Socotrine aloes is about six drachms; Barbadoes, from four to six drachms; and of the Cape aloes, from six to seven drachms; but the dose depends upon the form of the horse, and not his size, as might be supposed."

The addition of the oil, and the powdering of the aloes, where the practitioner can depend upon the druggist for not cheating him in the pounding, will very much insure the effect, and prevent griping.

A very mild ball of this mass will weigh an ounce and a quarter, and it may be increased to an ounce and three-quarters.

If mercurial physic is wanted-it should never be used without evident occasion-it may be thus made:-

RECIPE (No. 2).

\section{Mercurial Physic Ball.}

TAKE,-Physic mass, from 10 to 14 drachms; and

Calomel, from one drachm to one and a half;

Beat them together, and form them into a ball. 
The common mode of giving the calomel over night, made into a little ball with ginger or linseed meal, and the physic ball in the morning, is objectionable. It is borrowed from human medicine: but in the horse, calomel is not a purgative: it only assists the action of purgatives; and by separating it from the purgative, we are not only deprived of that for which it is principally valuable, but we run the hazard of salivating the horse.

The addition of soap, or the carbonates of potash or soda, with the physic ball, is also objectionable. This also is borrowed from human medicine, and designed to hasten the solution of the aloes, and prevent them from producing their supposed irritating effect on the rectum or last intestine. In the horse they have not this tendency to spend themselves on the rectum, and they dissolve soon enough: the soap and the alkali, therefore, can produce no other effect than to divert a portion of the nervous energy to the urinary organs, for they are diuretics; and thus the action of the physic will be somewhat weakened.

In some cases, as in inflammation of the brain, it is desirable that the physic should act as quickly as possible. There is another purgative which may then be resorted to, but which, from its irritating properties, should otherwise be avoided, and that is, the Croton nut.

The following would be the prescription:-

\section{RECIPE (No. 3).}

\section{Very strong Physic Ball.}

TAEE-Physic mass, 10 drachms; and

The farina of the croton nut from 10 to 15 grains:

Beat them together, and make them into a ball.

This may be given at first if it is wished that the physic should work quickly; but if purgative medicine has been already administered, and has not produced its desired effect, ten grains of the farina of the croton may be made into a ball with a little linseed meal, and given.

The preparation for physic is as important as the physic itself. The horse should be well mashed (a simple bran mash) for twentyfour hours before he has the physic; and mashes should be given until and during the working of the physic.

The management during physic is also deserving of consideration. If the weather and the disease will permit, the horse should be walked out for a quarter of an hour three or four times on the day on which the physic is administered. On the following morning he should be exercised again; and if the physic does not work, at the expiration of twenty-four hours fiom the time of its administration that walk may be changed to a gentle trot; but no quicker pace must be allowed. If at the end of the second day the physic should not operate nothing should be immediately done except to adminis- 
ter injections of warm water, in each of which half a pound of Epsom salts has been dissolved, and which will generally do good, and can never be prejudicial. If all these means fail, another ball may be given two or three days afterwards.

As soon as the horse begins to purge, the exercise should cease. There is not a more general and fatal error of the groom than with regard to this-when the physic begins to work he increases the exercise. The horse then certainly purges more, but more than a rational man would wish : he is likewise often griped, and, now and then, inflammation of the bowels supervenes, and one that is not easily subdued.

From the time of administering the physic the water should be given to the horse lukewarm, if he will drink it so; at all events its coldness must be taken off. No corn should be allowed until the medicine has ceased to work; and then always mixed with bran, either dry, or made into a mash, if the horse can be induced to eat it.

When the horse is physicked to get him into condition, a second ball may be given on the fifth day after the setting of the first, and of the same weight, if the first operated fairly. Two balls will generally be sufficient; but in the groom's estimation there is something magical in the number three.

Back Raking. - The introduction of the hand into the rectum, and the removal of the dung which it may contain, is a useful operation, when the physic is slow to work, and should always be practised when physic is given in illness, and it is desirable that it should operate quickly; not only a portion of dung, which by its presence and weight might retard the operation of the medicine, is removed, but the excitement of the rectum, by the introduction and motion of the hand, extends, by sympathy, to other portions of the intestinal canal, and they are disposed more readily to respond to the stimulus of the purgative.

This is the history of the action and the benefit of injections, which are too much neglected in retarded purgation, and in various cases in which steady and copious purging is required. Simple, warm water, or soap and water, or a Eolution of Epsom salts, not more than balf a pound at a time, are the best injections; and in every veterinary surgeon's practice, and in every large establishment, the Patent Injection Pump has superseded the use of the old bladder and pipe, and even of the syringe, on account of the ease and quickness, additional quantity and force, and diminished annoyance to the animal, with which the fluid may be introduced.

[Here we deem it best to give observations from the work already quoted, which appears to be very judicious and useful on the general subject of physicking horses.]

"Physicking.-The practice of administering purging medicines, to horses, is on a supposition that they tend to preserve health and contribute to activity. 
"An indiscriminate use of purgatives (Mr. Denny very properiy observes) is so prejudicial in veterinary practice, that more valuable horses have been lost by improper courses of them than from any accidental cause.

"It is surprising that this erroneous notion, that horses frequently require to be purged should prevail, and that this important undertaking should so generally be left to the direction of the groom. Reasoning from analogy, would a man, whose strength was daily declining from some defect in the digestive organs, submit to the experiment of taking two or three doses of drastic purgatives, to recover the tone of his stomach, and repair his strength? Certainly not! For every man must know so well the debilitating effect of purging, as to be certain that such a course would tend only to diminish still more his remaining strength.

"This evinces the absurdity of that common practice of giving horses physic in every disease. Discrimination and judgment can alone determine when purgatives are requisite, and when on the contrary, they are injurious.

"It is commonly known (says Denny) that besides aloes and calomel, employed as purgatives, there are many others, as jalap, rhubarb, salts, and syrups of various kinds, in daily use, from the supposition that the efficacy of the medicine must be increased by the number of ingredients.

"Such is the prepossession in favour of these useless medicines, that I have known men of abilities discountenance a simple but efficacions dose of physic, only because it was not prepared with syrup of buckthorn; which, though obtained genuine, as is hardly to be expected from any druggist, yet it can, in reality, only answer the purpose of so much treacle. The safest and only certain purgative is aloes. In particular cases, calomel is also necessary. But very large doses of other medicines employed for the human subject have no effect upon the horse, as experience sufficiently confirms. This may easily be conceived by those who are acriuainted with the structure of the horse's stomach, which differs essentially from that of the human, exclusive of the difference in length of the intestinal canal. Unless therefore the stimulating quality of the medicine remain long after it has passed from the stonach, it will have no effect on the bowels; a circumstance which accounts for the failure above mentioned. The horse, in a state of health, requires a constant supply of food to repair the waste of the body. As this aliment occupies a large space, the natural motion of the intestines is slow, so as not to expel their contents before the nutritious part is completely absorbed. A gain, the quantity of matter remaining in the small intestines requires the constant stimulus of the bile, to propel it into the large ones. A constant supply of bile being therefore required, the horee does not stand in need of a reservoit for that fluid, and therefore is not provided with a gall- 
bladder; the bile, as it is secreted by the liver, flowing from its duct into the intestines.

"Considering, therefore, the length of the intestines, and the slowness of their motion in the horse, it is natural to suppose that a powerful dose of physic will so increase this action, and forcibly propel their contents, as to produce in some part of the intestines violent pain and spasms, succeeded by inflummation, which frequently terminates in the death of the animal; too many instances of which preclude the possibility of its being doubted.

"In all cases, therefore, where the strength of the animal is not exactly ascertained, a small dose should be first given, which may be afterwards increased, if found necessary: thus every advantage will be secured, without hazard; for horses of the same breed, and size, differing as much in constitution as the human subject, the same dose, at different times, will produce very different effects.

"Mr. Denny, in a very adequate manner, points out the cases in which purging-physic may be used with advantage.

" "Horses coming from camp (says he) into warm stables, should have one or two doses of mild physic administered.

" "Many of those inconveniences that arise from a sudden change of temperature, as swelled legs, inflamed eyes, colds, \&c., would also be prevented, by having the doors and windows kept open, to admit a free passage of air during the few first days. It is likewise advantageous to give each horse a cold mash or two daily, and afterwards close the doors and windows gradually, to prevent any bad consequences from the transition, which might otherwise be hurtful.

" 'Young horses should always have two or three doses of physic; and afterwards sufficient time allowed them to get into condition before they are sent to the riding-school. The service loses annually many valuable horses, by their being too hastily formed for the ranks; which generally produces inflanmation of the lungs.

" 'Horses require ophysic after having been long fed on green food; and also in the autumn, before preparing them for the field. Those also that have swelled and cracked heels, from their high feeding, or irregular exercise, will be much benefited by purgingphysic.'

"We cannot omit the following, which Mr. Denny has found extremely useful as physic for horses.

\section{RECIPE (No 4).}

\section{Purging Balls.}

TAKE.-Of Barbadoes aloes, in fine powder, four ảrachms; Ginger, in fine powder, one drachm;

Treacle, enough to form the ball.

"This is particularly suited to blood horses. 


\section{RECIPE (No. 5).}

TAKE,-Of Aloes in fine powder, six drachms;

Ginger, in fine powder, one drachm and a half;

Treacle enough to form the ball.

"This is better adapted for horses used in hunting, or on the road.

RECIPE (No. 6).

TAKE.-Of Aloes, in fine powder, one oz.

Ginger, in fine powder, two drachms;

Treacle, enough to form the ball.

"This is suitable for labouring horses.

"The author observes, that if these doses should not be found sufficiently strong, a drachm or two of aloes may be added to any of them. In those cases where mercurial physic is deemed necessary, it is a commendable practice to give a calomel ball in the evening, and the aloëtic purge, No. 4, the next morning.

"The following are Mr. Denny's.

\section{RECIPE (No. 7).}

\section{Mercurial Balls.}

TAKE.-Of Calomel, one drachm;

Aniseeds, in powder, half an ounce ;

Treacle, enough to form the ball.

\section{RECIPE (No. 8).}

TAKE, - Of Calnmel, one drachm and a half; Aniseeds, in powden half an ounce;

Treacle, enough to form the ball.

\section{RECIPE (No. 9).}

TAKE-Of Calomel, two drachms;

Aniseeds, in powder, half an ounce;

Treacle, enough to form the ball.

"He advises the second aloëtic ball to follow the mercurial ball, No. 9, as these will be found sufficient.

"The treatment of horses during a course of physic should be as follows:

"Mashes of scalded bran, with a handful of corn in each, should be given for one or two days previous to taking the ball, which is to be given early in the morning.

"Two or three quarts of warm water only to be allowed for the first four hours. Afterwards give a warm mash, which is to be 
repeated two or three times during the day. The water given should be warm, but not in larger quantities than usual. A small allowance of hay is proper at night. If mashes and water be refused, as is often the case, gruel must be given instead of them.

"Next morning the horse should be walked out, for half an hour, or longer, if necessary; at which time the physic generally operates. He may be exercised again in the middle of the day.

"Mashes and warm water are to be continued until the evening. His feed may then consist of equal parts of dry bran and oats; and the following day his food be as usual.

"Horses under physic require additional covering; they being then more susceptible of cold than at any other time.

"The practice of trotting horses violently, to assist the operation, is both absurd and dangerous. Almost every instance of physic failing to produce its effect is in consequence of mismanagement or neglect in the stable.

"An interval of eight or nine days must be allowed before the second dose is given, during which period he should have one or two hours' walking exercise daily, taking care that he be well groomed on his return to the stable, and regularly fed.

"Purging Horses.-Purging medicines are given to horses with different intentions, that is, either to prepare their bodies for active exercises, or to cure them of diseases. In the first case they are always to be considered as in a state of health; in the second, in that of disease. Previous to entering on these different heads, and that they may be better understood, it will be necessary to premise a few things relating to the stomach and intestines, the chyle, the different systems of vessels, with their contents, which will serve to illustrate what may be advanced on the subject of purging horses.

"The stomach of a horse, notwithstanding his size of borly, is but small, and its coats are thin; the numerous circumlocutions and foldings of the intestines, are wisely ordered, to detain the aliment till such time as it is thoroughly drained of its nourishing particles by those vessels called the lacteals, the office of which is, to absorb or drink up, and to convey the chyle or nourishment into the blood; their mouths open into the inner cavity of the intestines. The length of the alimentary canal, from the upper end of the gullet to the anus or fundament, is said, by Doctor Braken, to be about thirty-five yards. 'The intestines have a motion peculiar to themselves, which forms its resemblance to that of a worm, is called peristaltic or vermicular; according as the motion is diminished, the evacuation by stool or dunging is in a great measure regulated.

"The stomach is supplied with a humour or juice peculiar to itself, which, by mixing with the food, as the saliva, bile, and other juices, supplied by the pancreas, \&c., undergoes a fermentative process of a peculiar nature, which is called digestion, and from which the chyle is the result. 
"The insides of the intestines are covered with a slimy mucus, which is separated from the glands, in order to preserve them from being irritated by the food, in its passage backwards. The coats of the stomach and intestines are supplied with an infinite number of blood-vessels and nerves, which are every where dispersed; and hence they are exceedingly liable to inflammation, irritation, spasms, \&c.

"Besides the vascular system, which includes the arteries and veins, there may be said to be another system of vessels, called absorbents; they are of two kinds, the lacteals, and the lymphatics. The use of the former has been already mentioned. The lymphatics, are tubes or canals, furnished with valves, which convey fluids that are taken up by absorption on the external surface, and from the extremities of the body; they likewise absorb particular fluids from the different cavities of the body, and from the cellular parts, \& c., which are by them conveyed into the thoracic duct, where it is mixed with the chyle, and from thence it is carried into the blood. -Let us now consider the manner in which purging medicines operate on the first passages only.

"The action of purging medicines consists in irritating the sensible fibres of the stomach and intestines, by which means, not only the peristaltic motion of the latter is very considerably quickened, but also the secretions of mucus and lymphatic juices, and vapour, which ooze every where into the cavities of the intestines, are increased, together with unusual quantities of pancreatic juice and bile from their several sources; hence it will be obvious, how great a quantity of the soundest humours, or even the chyle that is derived from the food, before it is mixed with the blood, may be carried off by purging medicines, and how much the whole mass of fluids in general may be decreased and drawn off.

"Since, therefore, purging is occasioned by giving such medicines as are found, by their irritating quality, to stimulate the coats of the stomach and guts, and, at the same time, quicken the peristaitic motion of the latter, so as to cause them to shake or throw off their contents by stool, it would appear, that the different kinds of purging medicine differ only in degrees of strength, and that they operate no otherwise upon the different humours of the body than as they stimulate the first passages more or less, and hence cause a greater or lesser evacuation by stool. So that, by this operation, we only lessen the quantity of the fluids, and clear or scour the first passages from any offending matters that may be lodged there. From hence it may likewise be inferred, that there is no such thing as elective purgation, that is, by giving certain medicines, we drain off this or that particular humour from the body. This may be farther illustrated in the following case or example:-When a horse, which has swelled legs, or greasy heels, gets purging medicines, they do not act immediately on the fluids contained in the legs, by carrying them off only, they act by revulsion, that is, by 
drawing away the fluids, \&c., from the intestines; those that are in the legs are, at the same time, absorbed or drawn away from the extremities by the absorbent vessels, to supply the want in the former; and hence the swellings in the legs, \&c., subside.

"It is a common phrase, when a horse is any way out of order, to say, that such a horse is foul in the body, or that he is full of hilmours, an expression which can only mean that the horse is in a bad habit of body; as to a horse's being full of humours, the propriety of the expression in this sense cannot be admitted, as every horse, even in the highest state of health, properly speaking, is full of humours, as every gland in the body, of which there is a considerable number, separates a particular humour, which becomes necessary for a variety of purposes in the animal economy; thus, the liver separates the bile, the testicles the semen, and every joint in the body has its glands, which separate a particular humour, and so of others. Therefore, the expression or phrase of a horse's being full of humours, in the common acceptation of it, is improper, and betrays a want of knowledge of the animal economy.

"Many people are but too fond of giving purging medicines, and frequently prescribe them whether the case may require them or not. Doctor Bracken has a very pertinent remark on this head.- This sort of evacuation (says he) seems very much to quadrate with the outward senses, and makes the ignorant part of mankind (whose heads are fuller of humours than their horses) imagine, that purging medicines carry off the offending matter in most disorders, never considering the general rule, which ought still to be kept in mind, viz., that in proportion to any one evacuation's being heightened or increased, most, or all, of the other natural evacuations, are proportionally diminished.'

"It is a practice with many people, to ride their horses very hard before they give them purging medicines, in order as the phrase is, to stir up the humours, that, when they are afloat, (according to their ideas) they may be carried off by the purging. It has been already observed how exercise operates on the blood, by increasing its velocity to a great degree, and hence inclining it to an inflammatory disposition, which, in this case, is the very worst thing that could happen, upon the supposition that the horse is in a bad habit of body; for purging medicines, when they are given in this state, may occasion inflammation in some of the principal viscera or intestines; or they may bring on a fever, or other disorders, which if they do not prove mortal, yet they may, as is sometimes found to be the case, occasion those disorders that terminate in blindness, incurable lameness, or in some chronic disorder, which may render the horse useless.

"Riding horses about the day after they have got purging medicines, in order to forward their operating, if continued too long, till the horse is warm, or to produce sweating, ought always to be guarded against, as such treatment not only exposes them to catch 
cold, but hinders the operation of the medicine in the ordinary way; for it has been observed, that purging medicines sometimes go off by sweat, or by urine, \&c., which the ignorant and unskilful are not acquainted with; they therefore conclude, that, as they see no great discharge of dung, the dose has been too weak, and give another too soon, without allowing a proper interval between them, which, at the same time, is made considerably stronger than the former, which weakens the horse very much, and a considerable time elapses before he recovers his usual strength.

"I have already taken notice of the great length of the intestines; this, together with the horizontal or prone position of the body of a horse, is unfavourable to the operation of purging medicines, which, on that account, remain in the bowels a considerable time before they operate, being from eighteen to twenty-eight or thirty hours, according $t$ ) the state of the bowels at the time, and, in some constitutions, even longer. In these cases, it is not advisable to give any medicines in order to quicken or hasten their operation; walking exercise, but not long-continued at a time, together with plenty of warm water, if the horse will drink, is the best and the safest means to forward the operation of them. At the same time, it will be necessary to notice whether the horse stales more than usual, as purging-medicines, as I have just observed, are found sometimes to operate in that way, without any considerable evacuation by dung. I would likewise recommend a general caution in giving purging balls, which is, that the operator should push the ball over the root of the tongue, and that he be certain of the ball's being swallowed entire, and not broke or thrown out of the mouth; mistakes of this kind have frequently occurred: when the ball breaks, one half, perhaps, is only swallowed, the other drops out of the mouth, or it may happen that the whole ball drops out unperceived. In these cases, it is concluded, from the purge's not operating in due time, that it has been too weak, and, therefore, the next dose is made considerably stronger, and hence a superpurgation ensues, attended with great sickness, loss of strength, and other bad consequences; therefore, when purging balls are given to horses, the head should be kept up, and care taken that the ball passes down the gullet, which may easily be discovered sliding down from the outside; but, if any doubt remains of its being swallowed, a little water may be given the horse to drink, and one gulp or two will put it out of all doubt.

"It is a common practice to give purging balls early in the morning, upon an empty stomach; this, in some constitutions, occasions great sickness, faintness, trembling, griping pains, \&c., a long while before they begin to operate; to prevent which, I have always ordered, and with success, a mash of bran to be given about an hour before the ball, which prevented these effects, and the purge operated in the most gentle and easy manner; and, perhaps, 
this practice would be advisable in all cases, and in all constitutions, when purging-medicines are necessary.

"Another error many people fall into is, that, although a purge operates very well, yet, if the horse is not very sick during its operation, they conclude that it will have no effect, nor will be of any benefit to the horse; they therefore give the next purge made a good deal stronger, in order, as they say, to stir up the humours; for they conclude, that the sicker a horse is under this operation, the humours are the more stirred up, and the easier carried off by the purge, without considering the danger that attends this operation, and how much they expose the life of the horse by such injudicious treatment.

"When purging-medicines are intended to be given to horses, it is necessary that they should be kept quiet, and rest for some time before, that is, from any violent exercise; and the same rule should be observed for some days after they have done operating, walking exercise only excepted. It is owing to the want of these, and such Jike precautions, already mentioned, that so many accidents happen daily in the purging of horses.

"It may be now expected, that I should make some observations espon the practice of purging horses, by way of preparing them for she race-course, hunting, \&c. It must be acknowledged there is a difficulty in combating a practice which too generally prevails, although there are a number of facts which will serve to demonstrate, that the purging of horses indiscriminately is not necessary in order to prepare them for these active exercises. On the contrary, it must, and indeed is, in many cases, exceedingly hurtful to horses, on account of the too frequent repetition of them, together with the too short intervals generally allowed between each purge.

"As to the vulgar opinion of humours falling down into this or that particular part of the body, if horses are not properly purged, $\& c$, before they are put to these active exercişes, it is exceedingly erroneous, and must depend on a variety of circumstances, that ought to be taken into the account.

"It may be of use to the practitioner, to explain what is meant by the phrase of humours falling down; but, at the same time, I must inform him, that this phrase is so generally in use, that, when a horse's eyes are affected, the humours are said to fall down into them, although they are situated nearly in the most elevated part of the body. But, to explain their falling down to the extremities, I shall talie a case that frequently occurs:-When a horse that is in the highest state of health, but too fat and full of juices, \&c., and accustomed to stand much at rest, is suddenly put to violent or longcontinued exercises, his legs, \&c., will be apt to swell soon thereafter; they will perhaps continue in that state for some time; they may at least break out in running sores about the heels, and form cracks, scabs, \&c.; in this situation, it is then said that the humours 
have fallen down to the legs. Here a question naturally occurs, where were these humours before the horse got this hard ride, or other severe exercise, and how came they to fall down on this occasion only? This requires a different explanation.

"It has been observed, in the article on exercise, the effects it produces when too sudden and violent, before a horse is gradually habituated to it for some time previous to his undergoing such violent or long-continued exercises. The vessels being too full of fluids, they, from the rapidity of the circulation during the exercise, especially the finer capillary vessels, admit the grosser fluids, that do not circulate in them in ordinary; they likewise are liable, in these cases, to rupture; hence the fluids they contained are extravasated into the cellular parts, where they stagnate, and, being then out of the course of circulation, they occasion a swelling. If this happen in the legs, as they are the most depending parts of the body (the humours are then said to be fallen down), the swelling causes a distension of the skin, \&c.; the cuticular pores are then enlarged, and admit through them the thinner parts of the fluids to the nutward surface on the skin, which, on being exposed to the external air, are then changed in their quality, and acquire, according to circumstances, either a soapy, clammy, or greasy appearance, or a sharp, fœtid, ichorous quality, that erodes the skin, and, by lodging there, forms small ulcers.

"It is well known, that horses, by good feeding, regular exercise, \&c., may be brought to perform the most active exercises, and that many instances daily occur of horses both running and hunting, without undergoing any previous preparation by purging medicines; and it is likewise well known, that even when purging medicines are given, still regular exercise is found to be absolutely necessary, in order to habituate the horse to this kind of active labour.

"Post-horses likewise furnish a farther proof of what has been advanced; it is well known how they an be brqught to travel very long stages, and with great speed, without any preparation farther than good feering, and inuring them by degrees to this violent labour. Dr. Bracken, who understood this subject very well, and who was likewise a great sportsman, has been at great pains in exploding this manner of reasoning, by a variety of sound argumente, in his second volume of Farriery Improved, where he has likewise given it as his opinion, 'that in most cases, good feeding, regular exercise, \&.c., will, in time, make a horse fit to start for a plate, without so much noise of the virtue of this or that drug or composition, to carry off grease, and mend his wind; for, in my humble opinion, the jockeys are too fond of giving purges to horses, wherehy they weaken their constitution, by causing the fibres of the stomach and guts to become lax and flabby.' And, in the same volume, he mentions the following case of a mare of his own, "that she had run six years with on!y two purges; neither had she an ounce of any kind of medicine during that time, except every morn- 
ing, and mostly every evening, about the bigness of a pigeon's egg of my cordial ball; and, I fancy, she performed as well as most of her neighbours, for she won eight plates out of nine, and four out of six every year.'

"It ought always to be remembered, that great evacuations weaken an animal's body, and if they are repeated too frequently, and too close upon one another, without allowing a proper interval between each, or, if they are carried to excess, which is sometimes the case, the weakness in the animal system is thereby increased, the powers of life are quite overcome, and death follows of course.

"I would not be understond, from what has been said, to mean, that purging medicines are never to be used on these occasionsno, I am fully sensible of their good effects, when judiciously administered, and horses properly managed during their operation; but I do not approve of repeating purge after purge, merely because this or that horse is to run or hunt, without first considering whether the animal be fat or lean, or whether he has been kept at hard meat, with proper exercise, or whether he has run a considerable time, or late in the season, at grass; all these, and a number of other circumstances necessary to be attended to, ought to be duly weighed, and maturely considered, before purging medicines are administered; for example, if a horse has run long at grass, and is of a plethoric or full habit of body, evacuations by purging, and diuretic medicines, to a certain degree, are necessary, together with length of time, good feeding, and regular exercise, to bring his body into that proper habit to enable him to perform, with freedom, such active exercises. But, if a horse is of a lean, low, or dry habit of body, whether it may proceed from the want of proper food, from fatigue, \&c., why reduce him still lower by repeated evacuations of any kind? There is such an inconsistency in this practice, that it would not even deserve to be mentioned, or taken notice of, if it were not too much practised every day ; for, with some people, it is no matter of consideration with thein what state or habit of body a horse may be in, that is, whether he be of a fat, or full, or lean dry habit of body, stiil he is said to be full of humours, and which must be purged off before he can run, \&c. Horses, in the latter situation, require only good feeding, and regular exercise, to strengthen and improve their constitutions, which cannot fail of taking place, if the viscera are sound, and the lorse otherwise in a healthy state. And, even although a horse may be inclined to be fat, or of a plethoric habit, yet, from the use of diuretic medicines, which are commonly given on these nccasions, together with regular airings and proper exercise, good feeding, dressing, \&c., he may be brouglit into that proper habit of body, which will enable him to perform the most violent labour with the greatest ease to himself, and without any bad consequences arising from it.

"But, farther, from the too frequent use of purging medicines to horses, their constitutions, though otherwise good, are ruined by 
it, their strength is impaired; it likewise contributes to shorten their days. Besides, it frequently happens, that, when they are brought to action too soon after such evacuations, their strength being quite exhausted by the treatment they have undergone, they fail in performing what was expected from them.

"From these, and a variety of other arguments which inight be urged, and which will readily occur to the judicious reader, it is obvious, that repeated evacuations, of any kind, are not necessary to horses, in order to prepare them either for running or hunting; and, if those that are intended for the latter were only allowed the spring grass, and taken up about the middle or towards the end of June, before the grass becomes too rank, although it may be rather inconvenient to have them in the house at that season, yet the owner would find his account in it; the allowance of oats may be but small for some time, and which migh be increased, together with the horse's exercise, as the hunting season approached. Running horses might be treated in the same manner, according to the season in which they are to run, allowing both a greater length of time in the habitual practice of these exercises, together with proper feeding, dressing, \&cc. This treatment, together with the use of those alterative and diuretic medicines, which are usually given on these occasions, would render horses much stronger and fitter for these active exercises, without wearing out their constitutions by the repeated use of purging medicines, too frequently very injudiciously administered.

"I shall close this head with a case that happened here some years ago:- Two military gentlemen betted their horses to run against one another on Leith sands, for a considerable sum, and which was to take place three weeks after the bet; the horses to be rode by their grooms. Captain R-'s was a pony about thirteen and a half hands ; Captain M-'s was a gelding about fifteen hands high; both their grooms were bred at Newmarket, and were keen advocates for bleeding and purging (notwithstanding both the horses had been kept on dry food and in the best order, and the short interval of time for such treatment), in order to prepare them for running, \&c. Captain M-'s horse was blouded once, and purged twice; Captain R-'s was blooded once, and purged once; they were both sweated in the stable with a great load of clothes; at the sarne time, their stables, though separate, were kept uncommonly hot and close shut up, night and day, in the midst of summer. From this treatment, they soon lost their appetite for food, and, in about eight or ten days, they were hardly able to undergo their exercise on the sands, their strength was so much exhausted by the treatment they had undergone, the constant and violent sweating in the stable, which of all evacuations, when continued, weakens a horse the most. In this situation, Captain $R$ - gave up his bet as lost, together with his pony, for which he had a great value; luckily for him, however, his groom, who was rather inclined to be corpu- 
lent, had put himself under a course of physic, \&c., in order to reduce his weight; the pony was then put under my care, with another groom to attend him; his clothing was immediately reduced to a single rug, the stable windows were thrown open in order to admit fresh air, the pony recovered his appetite for food, together with his strength, spirits, and activity; whilst his antagonist continued under the manner of treatment above mentioned. And, although bets were considerably against the pony at starting, yet he won with great ease, and which Captain R- frankly acknowledged was entirely owing to the difference of treatment they had been under.

"I have hitherto confined my observations on the administering purging medicines to horses in health, in order to prepare them for active exercises, as running, hunting, \&c.; it remains to consider their use in diseases.

"It would take up too much of the reader's time to enumerate the various forms of prescriptions that are in use for purging horses, or to confute the ridiculous encomiums bestowed on the variety of recipes that are handed about with a probalum est, or attestation of their peculiar virtues in carrying off this or that particular humour, \&c., as many of these compositions, when examined, appear to be a confused jumble of ingredients, calculated more for the apothecary's profit, than benefit to the patient; and the bad effects arising from them in practice, are too apparent in a variety of cases which occur daily.

"The substances that are used for purging or emptying the alimentary canal, may be distinguished into two kinds, the lenient, which open the belly gently; and the drastic, which purge more briskly. The lenient onght always to be preferred when there appears any unusual commotion in the vascular system, which may easily be known from the quickness of the pulse, \&c.; for, although purging medicines increase the motion of the pulse during their operation, yet they afterwards abate or lessen the motion of the blood, by drawing off a considerable auantity of the animal fluids by stool; they likewise clear the intestines of sharp stimulating matters or worms, which occasion an unusual degree of irritation in the system; they likewise may be given with different intentions, as circumstances may require, in small doses, to keep the body open, and prevent an accumulation of frees or dung in the intestines, which happens in diseases. In cases of frequent returns of the gripes or colic, but not during the fit, lest the guts should then be inflamed, they should therefore be given in the intervals, in order to prevent the return of the complaint.

"But in cases where it is thought necessary to clear the intestines thoroughly in strong robust horses, the drastic purges may be given, provided there is no great commotion in the circulation of the blood at the time. Purging medicines are of great service in cases where the intestines appear to be loaded with viscid or thick 
slime, or when it appears, by long continued costireness, that the peristaltic motion of the intestines is in some degree suspended; in gross habits, especially where there is any tendency to swelling in the legs, attended with running sores, \&c.; in dropsical swellings in any part of the body; in diseases of the head, rheums, or defluxions about the eyes; in rhenmatic lameness, when the pains seem to move from one limb to another; in the jaundice; in obstinate coughs, especially when the horse is of a full habit of body; in most cutaneous diseases, or when a number of small pinples or lumps arise on the skin, and suddenly disappear again, or when the lumps discharge a sharp fluid of an ichorous quality; in plethoric or full habits, when the horse is intended for violent or active exercises, as running, hunting, \&c., in cases where it is judged necessary to lessen the general mass of fluids, or to divert them from flowing to any particular place in too great a quantity, as in inflammations of the lungs; in this last case, liquid purges are most proper, as they operate more expeditionsly. In very delicate constitutions, rhubarb should constitute the greatest part of their purging medicines; they are hlkewise most proper in cases of want of appetite; no doubt there nay be other cases where purging medicines may be necessary; but these must depend on the discretion and judgment of the prescriber.

" On the other hand, it $"$ ill be prudent 10 avoid giving purging medicines during extreme cold weather; likewise in all feverish complaints, when the pulse beats strong and quick, till such time as these symptoms are considerably abated; in all cases of extreme weakness, whether arising from fatigue or long continued diseases; in all lean dry habits, unless thre is reason to apprehend it proceeds from worms; in cases of very obstinate costiveness, till such time as that complaint is in some degree removed by clysters, soft feeding, \&c.; in cases when a horse labours under any violent acute complaint; in diarrhœa or looseness. Aloetic purges, or those in which aloes enters into the composition, are to be avoided likewise in severe colics or griping pains, although liquid purges, that are quicker in their operation, and less irritating, may be given with safety in the intervals, when it is observed that horses are subject to frequent attacks of this complaint.

"Previous to the giving of purging medicines to horses, especially to those which have been kept on hard meat, it will be prudent to keep them from all violent exercises for some days before the purge is given. If they are fat, and of a full habit, it will be necessary to draw some blood, to lower their feeding, and to give them that which is soft and relaxing, as boiled barley, mashes of bran, malt, \&c. When horses are to be purged at grass, no preparation is necessary, farther than, in plethoric or full habits, to treat them as above, observing, at the same time, that they be not costive, as this frequently happens although feeding on grass; in that case, 
they are to be taken into the stable, and treated as if they had been on hard feeding.

"In giving purging medicines to horses, it will always be most prudent to begin at first by giving mild lenient purges, in order to find out the strength of the constitution, \&c., as very strong robust horses, to appearance, are sometimes easier purged than those of a more delicate make; and it frequently happens, that the same horse is easier purged at one time than at another, according to the state of the stomach and intestines at the time the purge is given.

"Mild purges are therefore much safer at all times, and of more benefit to the constitution, than too strong ones; for the latter cause too great an irritation of the stomach and bowels; hence follow griping pains, great sickness, \&c., and sometimes inflammation of the intestines; they likewise may occasion a superpurgation, by which the bowels are so much weakened, that they never afterwards recover their former tone ; and hence follow loss of appetite, general weakness, and, perhaps, an habitual diarrhœa or looseness.

"When it is intended to give mercury with purging medicines, which is necessary in cases of worms, or as an alterative, it is proper to give the mercury in the evening, and the purging-ball the next morning, as formerly directed. In this case, great care should be taken that the horse be not exposed to cold, nor suffered to drink very cold water, although he may be indulged in plenty of water milk-warm, mixed with a little oatmeal."

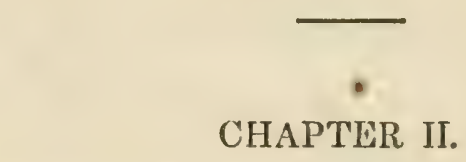

PHRENITIS (INFLAMMATION OF THE BRAIN).

THE term staggers, by which several of the diseases of the head used to be designated, should now be completely laid aside. It was derived from the staggering gait which frequently accompanied these affections, either in some period, or as a greneral characteristic of them; but other diseases besides these primarily of the head are occasionally accompanied by symptoms that may easily be confounded with them; ard it is somewhat disgraceful in the present state of the veterinary art, to confound together diseases of the same organ which materially differ in their cause, their progress, and their result.

Inflammation of the brain is either that of its substance or membranes, or both. It is a determination of blood to the brain, produced by over-exertion in close and sultry weather, especially if the horse is gross and fat, and has lately had only a little work. It is sometimes the consequence of other diseases: it is the metastasis, or 
change of inflammation from one organ to another. Inflammation has suddenly left the bowels, the foot, or even the lungs, and attacked the head; but it is oftener connected with some affection of the stomach.

The first symptoms are those of compression of the brain (sleepy staggers). The horse is dull, hanging his head as if he were going to sleep, or half asleep. In the midst of eating, a lethargy will come over him, and he will droop his head, with his tongue hanging out of his mouth, or the saliva dribbling from it, and he will stagger and almost fall. If he is suddenly roused, he will look vacantly around him, and slumber again. If he falls, he will appear to be frightened and scramble up, but it will be to wander, and to stagger and to fall again. It is determination of blood to the head, pressing upon the origins of the nerves, and producing this half unconsciousness.

This continues for twelve or twenty-four hours, and then, suddenly, the scene changes. The horse is all alive, his ears are pricked, his eyes are glaring, he is shifting his posture every moment, pawing and stamping. For a little while he seems to know where he is and what he is about, but that soon passes over: his flanks heave, and his nostrils expand, and he whinnies, and roars, and dashes, and plunges, and bites, and kicks, without object, and without consciousness. There are periods of remission. $\mathrm{He}$ exhausts himself by his violent efforts, and lies stupid, or seemingly asleep; and so he goes on, until he has probably ruptured some vessel of the brain, and caused greater effusion and pressure, and then perfect stupor ensues; or he wears himself out by the violence of his struggles.

If he is seen in this violent state, there can be no doubt about the disease: it is pure phrenitis, or inflammation of the brain. Then, with due regard to his own safety, the practitioner must contrive, if he can, to open both jugulars, and to let the blood flow as long as it will. The only hope is in producing faintness and temporary collapse. If it can be effected, in some moment of comparative quietude, a purgative should be administered in the form of a strong solution of aloes, with croton farina. The following is the best formula for this occasional and quickly-operating purgative. It is that which the surgeon in much practice should always keep by him, for it will remain undecomposed for several weeks, or with merely the precipitation of the aloes, which may be easily shaken up again.

\section{RECIPE (No. 10).}

\section{Sirong Physic Drink.}

TAKE-Barbadoes aloes, two ounces;

Gum arabic, one ounce; both being powdered.

Pour on them a pint of boiling water. A portion of the aloes will 
be dissolved, and the greater part of the remainder suspended by the solution of the gum. Four ounces of this may be taken, and ten grains of the farina of the croton nut rubbed down with a little of it, and the rest cautiously added, and the misture given every six hours until it operates.

If this cannot be administered in consequence of its bulk, forty grains of the croton nut or forty drops of croton oil should be given in the most convenient form possible. If the horse seems to recover a little from the attuck, he must be let alone; his diet being spare, and consisting chiefly of mashes or a little green meat, and his bowels kept open by small doses of aloes. A seton may be inserted at the back of the head after the violence of the symptoms are abated.

I know but of two diseases with which it is at all possible that this complaint can be confounded, and they are colic and madness: but in the first he strikes and stamps his belly, he rolls rather than plunges, and looks piteously at his flanks, and is perfectly conscious; and in madness, although he plunges strangely about, and does much mischief, there is method and perfect consciousness in that mischief.

The most unpleasant and puzzling state of the case is when the stupid fit is on the horse. It is absolutely necessary to get at the cause of that stupor, or the mode of treatment canmot be determined on. If the horse is at grass, the owner or practitioner should carefully inquire whether he has heen lately turned on richer pasture; or, if he is in the stable, whether he may have got at the corn-bin, or gorged himself with what ought to have been the porcion of his companions; or whether he had been lately worked long and hard on an empty stomach, and then fully or more than usually fed; or whether he has laboured under any other inflammatory affection that has lately and almost suddenly ceased. If neither of these things appears to have happened, it is either the commencement of phrenitis, or it is pure apoplexy, or simple determination of blood to the head, and in either case the course of the practitioner is plain.

\section{CHAP'TER III.}

\section{VERTIGO (MEGRIMS.)}

THis is the mildest form under which determination of blood to the head, or congestion of blood in the vessels of the brain, shows itself. A horse will cominence his journey apparently well, and pleasantly perform a portion of it: but the day is hot - he is a little too full of flesh-he has not been lately in full work-or he has been driven a little faster than usual-or he wears a collar a little too 
tight: all at once he begins to faiter-he shakes his head repeatedly -looks around him half unconsciously, and perhaps stops short and trembles. If the driver is aware of what is the matter, and will give him a minute's rest, he will sometimes recover and go on again, although not quite so freely as before. But at other times, either without warning, or any warning that the driver has observed, he drops-he lies for two, three, or five minutes apparently insensible, and then scrambles up, and goes on again: or he falls, and violent struggles commence, which, however, in a few minutes subside. 'The horse gets up, looks wildly about him, and continues his journey, yet somewhat oppressed and exhausted: but he will occasionally drop and die at once.

The causes of this are what have been stated in the beginning of the description of the symptoms, and the method of giving present relief is simple and effectual enough. With a lancet, or a penknife, cut deeply across the bars, and set them bleeding, and the giddiness will speedily go off. It may be prudent to look to the collar, and slacken it a little, and let down the bearing-rein a hole or two.

When the horse gets home he should be well mashed, and, if he can be spared, a dose of physic should be given, and afterwards a little green meat afforded him. When the physic has set, some alterative medicine will be serviceable, a ball of which may be given every night, for ten days or a fortnight.

\section{RECIPE (No. 11).}

\section{Alterative Ball.}

TAKE-Powdered nitre, three drachms;

Sulphur, two drachms;

Black sulphuret of antimony (black antimony,) two drachms;

Linseed meal, two drachms:

Beat them into a mass with palm oil.

Turning out for a month or six weeks will always be useful; but a horse that has once had megrims will be too subject to them agrain, and after several attacks will be speedily disposed of by the prudent man. 


\section{CHAPTER IV.}

\section{STOMACH STAGGERS (INDIGESTION.)}

THE symptoms of this disease have been sufficiently described at page 54, where the various indications of the early stage of inflam. mation of the brain passed in review: in this case, however, the staggering about and sleepiness, and unconsciousness, with hard breathing, and fixed staring eye continue, and the animal becomes more and more insensible and helpless: these drowsy symptoms then sometimes subside, and are succeeded by violence, of the same kind as that of phrenitis, but not to so great an extent: this is followed again by stupor, and the horse dies.

It is essentially necessary to ascertain the cause of this disease, if it can possibly be done. A very frequent one is over-distention of the stomach. 'The horse may have got loose in the night, and filled himself with corn, or beans, or chaff; or he may have been worked longer and harder than usual on the preceding day, and have had a double feed given him at night; and the powers of the stomach having been exhausted with those of the frame, it is unable to contract upon its contents, so as to expel them. If no positive information can be obtained with regard to these things, the appearance of the horse may guide in some degree as to the probability of their having eccurred; for he will be evidently bloated and swollen, and the lethargy will be more complete than when it arises from other causes.

This disease has often made its appearance in large establishments, where horses have been kept long fasting, and then allowed an unlimited quantity of dry food. In these cases the stomach has first been weakened by this long fasting, and then distended beyond its power of contracting, and the brain has been affected either from sympathy, or from the pressure of the stomach on the chest obstructing the circulation of the blood.

This disease, however, will sometimes occur without this strange distention of the stomach; yet not without evident affection of this viscus. When the hours of feeding are irregular, the stomach becomes weakened by being long empty, and is oppressed even by a usual meal of ordinary food. This happens to farm-horses after too long a day's ploughing, and especially if the food with which they are afterwards supplied is not very good. It is foolish economy to keep the half-mouldied and poisonous provender of the farm for home-consumption. Old horses are particularly subject to stomach staggers from this cause; and they are so, if, when the stomach has been debilitated by too long fasting, they should happen to get a 
few days' rest, and to be fed somewhat better than usual. The weakened stomach will not be able to bear the unusual stimulus, and indigestion will ensue. In other cases it has prevailed as an epidemic, and appeared amongst horses at grass as well as those in the stable; and though the symptoms have been very similar, yet they could not be referred to a distended stomach, although they might in great measure be owing to a loss of energy in this organ from the presence of some deleterious principle.

The ordinary cause of this disease may be considered to be indigestion, from distention of the stomach with food, and sometimes with gas. The treatment, therefore, must be principally directed to the removal of the offending body. If the pulse is strong, and fever or inflammation is denoted, copious bleeding will be required; but if there seems depression of the system, blood-letting should be abstained from. Liquids should be thrown into the stomach by means of Read's Syringe, with a view of diluting its contents, and this should be followed by physic, such as the draught, No. 10, page 55 , to which may be added an additional dram of ginger, and two of chloride of lime, so as to condense any gas that may produce or assist in producing the distention of the stomach. The bowels should be relaxed by frequent injections.

It will not be advisable to repeat the aloes, lest it should accumulate and produce inflammation; but in its stead, a pint of linseed oil with two drachms of gentian should be given every six hours until the bowels are properly opened. When this is accomplished, the diet should consist of green food, carrots, or mashes in sparing quantities, and the following ball may be administered daily.

RECIPE (No. 12).

Alterative Tonic Ball after Indigestion.

TAKE-Powdered nitre, two drachms;

Sulphur, one drachm and a half;

Physic mass, one drachm;

Powdered gentian, one drachm and a half;

Powdered ginger, one drachm;

Beat them together with palm oil, and make them into a ball.

\section{CHAPTER V.}

\section{RABIES (MADNESS).}

There is a disease, and one of the nervous system, which may be occasionally confounded with phrenitis, and which may now be conveniently considered, viz,, Rabies. 
If a horse has been bitten by a mad dog, or his muzzle (the angles of the lips having been galled by the bit) has been licked by one of those dogs which are too often and foolishly harboured about the stable, and which may have becorne rnad, he will most probably, in his turn, also become rabid. The disease will suddenly appear, and at the commencement bear considerable resemblance to phrenitis. The horse will stop, look about him, stagger, and fall. He will immediately get up again, and proceed on his jomrney, but presently he will begin to stagger once more, and the sooncr he is got home the better. 'The difference between rabies and phrenitis, in this stage of the disease, is that the rabid horse is perfectly conscious, or only a little wild: however, before twenty-four hours have passed, he usually becofnes violent to an extraordinary degree, stamping, kicking, biting, tearing, and demolishing every thing within his reach. Here again the difference between the two complaints is sufficiently manifest: the rabid horse knows what he is about, and is trying to do mischief: the other is struggling and plunging involuntarily.

There is no remedy but the bullet, and the sooner that is applied the better.

Although hydrophobia, or the dread of water, is the characteristic of this disease in the human being, it is singular that, in the domesticated animals, and particularly in the dog, by whom the disease is oftenest communicated to men, it should have no existence. The horse, however, is an exception to this, for in most cases he does exhibit something approaching to hydrophobia-either he is unwilling to drink, or the head is violently snatched from the pail in the midst of his drinking, and the muscles of the face are strangely distorted, or he trembles from head to foot, or sometimes fulls to the ground convulsed at the sound of falling water.

When a horse is known to have been bitten by a mad dog, the wound shonld either be cut out, or the lunar caustic applied to it, so as to destroy every part of it; and, if this is carefully done, all danger will be removed. 'The lunar caustic, if it can be made fairly to reach the bottom of the wound, is the most effectual preventive: a skilful veterinary surgeon should, however, be here employed. Medicine will be completely uscless, and all the pretended nostrums, which are celebrated in various parts of the country, are mere delusions. After the disease has once appeared in the horse, no one should be permitted to hazard his life in the attempt to administer medicine of any kind; and it should otherwise be recollected that the attendant on the rabid horse is always in danger, and that the saliva that falls from his mouth, or is thrown furiously about, if received upon a wound, or the slightest abrasion, may produce as dreadful effects as those from the saliva or bite of a rabid dog.

Having thus considered all the varieties of inflammation of the brain, we will next dispose of the other parts of the head. 


\section{CHAPTER VI.}

INFLAMMATION OF THE EYE.

Turs is one of the most annoying maladies that the practitioner has to do with. A horse, and particularly a young horse, may be perfectly well on a certain day, but when he is examined on the following morning, his eyelids are swelled; they almost cover the eye; they are hot and tender; the eye itself is cloudy, and the conjunctiva covering the white that surrounds the coloured part of the eye, and the lining of the lid, are red: there is a considerable fluw of tears, and the horse hangs his head, and is in evident pain. It will be always prudent to examine, in the first place, whether this may have been the effect of accident; whether the horse may have been bitten by his companion, or struck by his attendant, or whether a bit of hay or husk of oat may have got into the eyes: in the majority of cases, however, nothing of this kind will be found. Sometimes the horse will have catarrh, and discharge from the nose; but at other times the eye alone will be the part affected, and that without any appreciable cause.

Young horses, about fuur or five years old, are most subject to it; they are approaching to or have reached their full growth, and they have a great deal of superfluous humour about them, and consequent tendency to inflammation. Black horses are said to be more subject to inflammation of the eyes than those of any other colour. Now and then it will be very prevalent in the neighbourhood, or two or three horses in the same stable will be attacked at the same time: it is epidemic : it is dependent on some peculiar atmospheric influence; but it does not seem to be in any case infectious.

Improper management may lay the foundation of this disease. If the horse is kept in a hot and close stable, and his eyes daily exposed for many an hour to the stimulating ammoniacal fumes that arise from the urine, and which a person going into a stable in the morning cannot bear many minutes without inconvenience, it is easy to suppose that they will be both irritated and weakened, and disposed to take on inflammation from very slight causes. This, however, prepares for the disease, but does not produce it: for it is seen in stables that are not so hot and close, and it sometimes occurs in a colt at grass. There is no complaint that is more plainly and probably hereditary; and it has spread over whole districts from the incautious use of a blind stallion, or one that had serious disease of the eyes.

The practitioner or the owner of the animal will carefully examine the circumstances under which the disease appears. If it 
is connected with cold, he will treat the horse as for catarrh; and generally, the inflammation of the eye will disappear with the general tendency of inflammation. If there is considerable heat, and swelling, and weeping, and impatience of light, it may be as well to do something to the eye, besides the internal treatment usually adopted for catarrh. Fomentations of warm water may be applied. Warm applications agree with the eye of the horse much better than cold ones. Frequent fomentations, and the eye being left uncovered, and the stable darkened as much as possible, will be more useful than any wetted pad kept in contact with the eye, which often increases the irritation by its pressure, and the heat which it soon acquires or imparts.

If the inflammation is otherwise than slight, the practitioner should open the eyes, and turn the lids upwards and downwards, and lightly scarify them with a keen lancet. The abstraction of even a few drops of blood from the immediate seat of inflammation will often be productive of the very best effects. The fomentations should then be more diligently continued, in order to encourage the bleeding.

Some sedative application may afterwards be made to the eye. Either of the following lotions may be tried: but there is often a peculiarity or caprice about this complaint; and that which will succeed in abating inflammation at one time will have no effect at another. It would be proper to apply them in the order in which they stand:-

RECIPE (No. 13).

\section{Goulard Wash for the Eyes.}

TAKE-Extract of lead, one drachm;

Distilled or the softest running water, eight ounces.

\section{RECIPE (No. 14).}

\section{Anodyne Wash for the Eyes.}

TAKE-Laudanum or tincture of digitalis (the latter to be preferred), half an ounce;

Distilled or soft water, eight ounces.

These must not be wasted about the outside of the eye, but, with a camel-bair pencil, or a bit of clean sponge or rag, they must be introduced into the eye.

If these lutions should not remove or abate the complaint, that which the human practitioner finds so useful, but which is not always so beneficial in the horse, may be tried-viz., the Vinous Tincture of Opium; two or three drops of which should be got into the corner of the eye by means of a camel-hair brush.

If, however, there cannot at the beginning be traced any con- 
nexion between this inflammation of the eye and cold or catarrh, and if it seerns to bid defiance to these applications, it may be suspected that it is that peculiar specific inflammation which is the bane of the eye of the horse, and in so many instances terminates in blindness; and the practitioner sets to work to attack the disease more in good earnest.

He administers a dose of physic, not because he often sees any immediate good effect from it, but because it seems to be one of the means by which he has the fairest chance of success; and he bleeds if he imagines that there is any fever; and, if the inflammation is very intense, he bleeds largely from the jugular, and to this he adds local bleeding. He gets as much blood as he can from the angular vein, that vein which he finds at the inner corner of the eye, and which comes from the orbit of the eye, for by bleeding there he will be most likely to unload the congested vessels of the eye. He continues diligently, and for weeks together, the local applications just recommended; giving a fair trial to each, and changing them as each seems to lose its effect; and he inserts a seton under the jaws, to which he perhaps adds a seton in the cheek; but the former is the more effectual. He regularly administers the medicines which he would use in cases of fever, and with a view to lower the circulation every where, and, among the rest, in this inflamed part. The best fever ball that can be given to the horse, and which is applicable to almost all cases, is the following :-

\section{RECIPE (No. 15):}

\section{Fever Ball.}

TAKE-Powdered digitalis, one drachm;

Emetic tartar, one drachm;

Nitre, three ärachms;

Sulphur, one drachm;

Linseed meal, two drachms:

Beat together with palm oil.

There is one thing which he should never do, although it is the continual practice of the farrier. The haw partakes of the general inflammation, and is enlarged. It is drawn over the eye in order to protect it from the light, and, on account of its enlargement, it cannot again be retracted. To the ignorant observer it would seem to be an injury, and a nuisance to the eye. Unnaturally protruded as it is, it is doirg good, for it is partially sheltering the eye from the light; and when the general inflammation is abated, it will become of its natural size, and return to its place of concealment. If the practitioner cuts it away, he may give a little relief from the bleeding which will follow, but he would give a great deal more if he had scarified the eyelid, or opened the angular vein; and he would not have deprived the horse of the means of defending his eye 
from the dust of the roads, or wiping away the dust when it does get into the eye, or entailed upon him a degree of suffering of which the pain that he feels when his eyes are annoyed by a cloud of dust, will give him no very indistinct idea. The haw is no unnatural excrescence produced by inflammation: it is the mere enlargement of a very useful part, which has swollen from participating with the surrounding inflammation, and which will resume its natural appearance, and size, and usefulness, when that inflammation abates.

After a great deal of trouble, and the exercise of no little patience, perhaps the eye gets better: but there remains a cloudiness about it, and of a very singular character. It is thicker to-day, and in a great measure clearing up to-morrow; on the third day becoming more opaque than ever, and at length being in a manner fixed. The sugar, or salt, or pounded glass of the farrier will renew the inflammation, and increase the opacity oftener than diminish it. A weak solution of corrosive sublimate will be the best application here.

RECIPE (No. 16).

Wash for Cloudiness of the Eye.

TAKE-Corrosive sublimate, four grains;

Rectified spirits of wine, twenty drops :

Rub them together in a glass or marble mortar, until the sublimate is dissolved; and add,

Water, four ounces:

Get a little of this into the eye three or four times every day.

A slight degree of inflammation, with redness of the conjunctiva, and wealsness of the eye, and weeping, may yet remain. The disease has assumed a chronic forn, and must be combated by stimulants. The following will oftener succeed, perhaps, than any other :-

\section{RECIPE (No. 17).}

\section{Wash for Chronic Irflammation of the Eye.}

TAKE-Sulphate of zinc, eight grains;

Water, four ounces:

Rub them together until the zinc is dissolved; bathe the eyes frequently with the lotion, introducing it as much as possible into them.

At length, however, the practitioner seems to have succeeded, and the eye is once more clear and bright. He must not exult too soon. Three or four months pass over, and, too often, the disease again appears, and attacks either the same eye, or perhaps the other. This attack is got rid of with greater difficulty; and after that another follows, and the horse ultimately loses one eye or both. 
Hence comes the necessity of being a ware of the traces, oftentimes difficult to be detected, which this complaint leaves behind it. The slightest cloudiness of the cornea will engender suspicion that the eye has not been at all times right; and this will be confirmed, if the eyes, or rather the opening of the eyelids, are different in size: if one of the lids is thicker than the other, and particularly towards the inner angle; and there is a little puckering there, or a dim line around the cornea, and perhaps a very minute and scarcely detectable spot in the centre of it, - a haziness rather than a spot,- and faint gossamer lines radiating from it.

It is important to distinguish between these appearances and those caused by a blow or other external injury. In the latter case, after the inflammation has subsider, there is frequently left an opacity of some part of the cornea, sometimes extending over half the eye. It will be found, however, that the internal parts of the eye are perfectly clear and free from disease, and that distinct vision is enjoyed except in that part where the opacity exists, and which on examination is found on the conjunctiva and external part of the cornea alone. Sometimes when the injury proceeds from the lash of a whip, one or two superficial streaks will be found across the eye, and the other parts perfectly clear.

The natural process of the disease is the spread of the inflammation to the membrane that covers the crystalline lens; and that becoming opaque, and the inflammation and opacity still extending into and through the lens, this is termed cataract; the general effect of it is blindness-irremediable blindness; for if, in despite of the power of the retractor muscle, the eye could be brought forward and fixed, and the pearly lens extracted, the horse could have no distinct vision, as he would be deprived of that which refracted the rays, and brought them to a focus, and formed the picture of surrounding objects on the retina.

A very considerable change has lately taken place in the opinion of veterinary surgeons on the subject of cataract. It is supposed to be capable of forming, and, in fact, often forms, in much less time than was once thought to be possible. It may appear, and become almost perfectly formed in the space of five or six days.

It is also ascertained that cataract may appear without any previous active inflammation, without any apparent disease of the eyes. It is now still further believed, or, more properly speaking, fully proved, that partial cataract, that is, slight specks or spots on the lens, or rather its capsule, do occasionally disappear.

When a cataract supervenes after inflammation of the eye, it is generally the case that the inflammation does not again recur; and if the cataract takes place in one eye only, the other is generally preserved. So likewise, if the cataract is partial, that is, still admitting some degree of vision, the eye is likely to remain in this state afterwards. This is indeed one of the most favourable terminations of ophthalmia : for too frequently we find a general disorgan- 
ization of the structure of the eye existing either with or without cataract.

It will easily be seen what alteration this must produce in the decisions of veterinary men on cataract, when regarded as one of the species of unsoundness to which the horse is subject.

\section{GUTTA SERENA, OR GLASSY EYE.}

There is another species of blindness, which, although not the result of inflammation, should here be noticed. The cornea is perfectly transparent, but the iris seems to be in a constant state of contraction: the pupil is permanently dilated, and more of the transparent humours being seen, the eye has a peculiar bright and glassy appearance. The same influence, or want of influence-the same disease which palsies the muscles of the iris, renders the retina, or that expansion of the optic nerve at the back of the eye which is the seat of vision, insensible, and so the horse is blind. This is frequently overlooked, and especially when confined to one eye. I have known some of the best judges of the horse astonished when they first discovered a blindness, which must have existed many weeks or months. Gutta serena is usually the consequence of pressure on the brain. If a horse has had several attacks of staggers, and ultimately recovers, yet this species of blindness will often be left behind, which no operation can remove, and which is beyond the reach of medicine.

When, however, Gutta serena, or amaurosis, is the consequence either of disordered bowels or other disease of the viscera, or of blows or injuries of the head, it will frequently disappear with the removal of the cause which produced it. Gutta serena is a disease almost peculiar to the draught-horse. On account of the tightness of the collar preventing the return of the blood from the head, he is most subject to those accumulations of it on the base of the brain, which, pressing upon the optic nerves, produce palsy of them. These horses are also very irregularly fed, and nothing more disposes to staggers than the too suddenly overgorging the stomach after long continued fasting. The introduction of the nose-bag has contributed more than any other thing to render this disease much more unfrequent than it used to be. 


\section{CHAPTER VII.}

\section{INFLAMMATION OF THE TONGUE-BLAIN.}

This disease is neither so frequent nor so fatal in the horse as it is in cattle; but it does sometimes occur, and the nature of it is frequently misunderstood. 'The horse will refuse his food, hang his head, and a considerable quantity of ropy fluid will be discharged from the mouth. If the lips are closed, he resists the opening of his mouth to such a degree, that the suspicion arises that he has lockedjaw. If the mouth is a little open, it will require great force to make him close it; and this also will cause the idea of locked-jaw to occur to the mind of the practitioner or owner. The observation, however, that there is not the peculiar attitude and gait, which will hereafter be described, as characteristic of locked-jaw, will prevent every careful person from being misled.

On examining the mouth, the tongue will be found considerably enlarged, and, running along the side of it, there will be a reddish or dark-purple bladder, which sometimes protrudes between the teeth. The neighbouring salivary glands are enlarged, and the discharge of saliva is very great; while the soreness of the swelled and blistered part causes the horse obstinately to resist every motion of the jaws.

The cause of this inflammation of the tongue is unknown. Sometimes it seems to proceed from indigestion; in these cases the breath and the fæces are fœtid. At other times it accompanies various inflammatory complaints. It is seen in violent catarrh, or epidemic or general fever. It is a frequent accompaniment of locked-jaw.

The cure of it is very simple-the bladder must be deeply lanced from end to end. There will not be any great flow of blond, for the tumour seems to be chiefly filled with a red-coloured gelatinous fluid, which will slowly onze out, after which, in the course of fourand-twenty hours, the horse will often be relieved, if not completely well. If he can be spared from his work, a dose of physic will remove the stomach affection, and any slight degree of fever that might have existed : in all cases, a few fever balls (Recipe No. 15, p. 63) will be useful after the physic.

If the disease is neglected, the swelling will at length burst, and corroding ulcers will remain along the side of the tongue, eating deeply under it, being exceedingly offensive, and also very difficult to heal. The stench may be removed by a solution of the chloride of lime, and this will at the same time usually give a healthy appearance to the ulcers. 


\section{RECIPE (No. 18). \\ Solution of Chloride of Lime.}

Take-One drachm of the chloride of lime in porvder, and dissolve it in a pint of water. IKeep the bottle closely stopped when not in use.

In the whole class of horse-medicines there is not a more useful application for foul ulcers of every kind than the solution of the chloride of lime. To dispose the ulcers more readily to heal, a wash composed of equal parts of tincture of myrrh and water will be very useful. An infusion of catechu will afford a cheaper, and often as efficacious an application.

\section{RECIPE (No. 19). \\ Infusion of Catechu.}

On two ounces of powdered catechu pour a quart of boiling water. Keep it in some covered vessel for an hour, occasionally shaking it: then pour off the clear liquor, add an ounce of spirit of wine, and bottle for use.

Should both of these fail, the solution of common alum may be resorted to. It is a powerful astringent in these cases; but it sometimes corrugates the skin of the mouth to such a degree, and renders it so harsh, that the horse refuses his food.

\section{RECIPE (No. 20).}

\section{Solution of Alum.}

Dissolve two ounces of powdered alum in a quart of water, and keep it for use.

\section{CHAPTER VIII.}

\section{INFLAMMATION OF THE PALATE-LAMPAS.}

The palate of the horse, although a fibro-cartilaginous substance, is, and especially in young horses, very subject to inflammation. Until the second teeth are grown, and sometimes after that, the bars at the fore part of the palate swell, and become hot and tender; and when they become on a level with the front upper teeth, or even extend below them, they seriously interfere with the feeding of the horse, on account of the pain which be feels when the food 
presses upon them. He loses his appetite, or is afraid to eat, and the fond falis half-chewed from his mouth.

The principal cause of this affection of the bars is the irritable state of the parts until the process of dentition is completed, and also occasionally some temporary indigestion.

A great deal more is made of this disense than is necessary. If it is merely a trifling enlargement of the bare, it will generaliy subside after a few mashes, with one dose of laxative and two or three of fever medicine; but if the bars are level with the teeth or below them, and the horse quids his hay, some blood should be taken from the part. The bars should be cut across, and, if they are cut deep enongh, plerty of blood will flow. The bleeding may be encouraged as long as the surgeon pleases, depending on the degree of enlargement and fever; and will usually be stopped at pleasure by the pressure of a sponge cliarged with cold water on the part.

This is not recommended as a proper way of bleeding in ordinary cases, for the quantity of blood taken away cannot be measured, and in a very few instances, when the palatine artery has been divided, the bleeding has been arrested with considerable difficulty. If, however, the incisions are made about an inch from the front teeth, and in the direction of a line extending backwards from between the central and second teeth on either side, not only will more blood be obtained, because the principal vessels lie there, but, by means of a string tied round the front teeth and across the palate, a compress may be easily placed over the incision.

The farrier usually recommends the searing of the bars with a hot iron. - a most injudicious and barbarous operation. The animal must be sadly torlured in order to burn down the enlarged bar, and after all it will not be perfectly done.

Connected with the lampas, and often existing at the same time, is what is commonly termed bags or washes, which is enlargement of the membrane lining the cheeks, and particularly that adjoining the anterior molar teeth, so that when the horse attempts to masticate, this membrane gets between the teeth, and occasions much pain. When this materially interferes with the feeding, a portion of the membrane should be excised with a pair of scissors or a bistoury, the bleeding from which will lessen the inflammation, and as the wound cicatrizes it will contract the membrane, and prevent it from interfering with the teeth. 


\section{CHAPTER IX.}

\section{INFLAMMATION OF THE MEMBRANE OF THE NOSE-CORYZA.}

THE essence and nearly the whole of every cold, at its commencement, is inflammation of the membrane of the nose, and characterized by redness of that membrane, increased discharge from the nose, weeping from the eyes, a little general heaviness, and a slight degree of fever. It is that which a warm mash or two, a comfortable stable, and warm clothing will frequently remove without any medical treatment; but which, if neglected, degenerates into catarrh, cold, sore throat, or inflammation of the lungs. There is, however, another kind of inflammation of the nose, of a very singular nature-it is truly a specific one, and demands most serious attention.

\section{CHAPTER X.}

\section{SPECIFIC INFLAMMATION OF THE MEMBRANE OF THE NOSE- \\ GLANDERS.}

This is a sad and intractable disease, and destroys thousands of horses every year. At its commencement it seems to be strictly an inflammation of the membrane of the nose; not characterized, indeed, by the usual florid red of inflammation, but by a leaden or purple colour, sometimes of a very pale hue, and generally so at the commencement, but afterwards becoming darker. This is accompanied by a very slight discharge from the nose; generally from one nostril only, and that most frequently the left one. At first it can scarcely be distinguished from the natural moisture of the nose, -it is thin and transparent like it. It seems to be the natural moisture a little increased in quantity. It may continue in a deceitful state for many weeks or months, and even two or three years. There is no cough, no loss of appetite, no apparent illness of any kind, scarcely any enlargement of the glands beneath the lower jaw, and yet the horse is glandered, and capable of communicating the infection.

By degrees the disease proceeds. The discharge becomes decidedly, although to a very slight extent, increased; but it is still watery and transparent, and is to be distinguished from the natural 
secretion only by a slight degree of stickiness when it is rubbed between the fingers. It is also distinguished from the discharge of catarrh by this stickiness, and by its being constant, while the other varies at different times, and is usually thrown off in quantities more or less accumulated. The glands beneath the jaw sympathize with the membrane of the nose, and they enlarge, and the horse is jugged. This enlargement of glanders is distinguished from that which often accompanies catarrh, by the glands not being so hot and tender, and, more particularly, by their being more fixed, and seeming to adhere sometimes to the jaw-bone, and at others, hard and firm, and unattended by any enlargement of the surrounding parts.

By degrees the discharge increases; it becomes more adhesive; it sticks about the nostril; it is still often confined to one nostril, and the hardened gland is found on that side alone. It is now, perhaps, recognised for the first time, by the owner of the horse, or his servants; but the mischief is done-it is highly probable that no medical care can now save the animal, and he may have propagated the disease among his companions.

Hence the necessity of attending to the very earliest symptoms of this complaint, and seriously regarding, and with much suspicion, the slightest increased discharge from the nose, or livid or purple colour of its membrane, whether it be accompanied by enlarged submaxillary glands, or even if no tumour whatever can be detected.

The disease may even now be long stationary. Too many of these horses, with decided glanderous discharge from the nostril, and adherent glands under the jaw, draw our wagons, or are employed in agriculture; and they are otherwise in good health and co their work well, and that for months and years. This should not be permitted, for the contagion is often widely spread by means of these horses.

In the next step the discharge is rapidly augmented; from being mucous or glairy, yet transparent or white, and usually without smell, it becomes brown or bloody, and mixed with pus, and often fotid. If the nose is then examined, chancres are seen upon the membrane of the cartilaginous septurn between the nostrils. They are plainly not the excoriations which are sometimes observed in violent catarrh, but they are small, distinct, circular ulcers, with a rounded edge and an uneven corroded base.

Even after this the horse may for a while retain his condition, appetite, and capability for work; but the period is uncertain, and often short. The constitution begins to be affected. The virus which is secreted by the ulcers is absorbed, and empoisons the whole frame. The horse begins to lose flesh, and appetite, and spirits; the oily secretion of the skin disappears, and the coat is unthrifty and pen-featliered; the inflammation extends down the windpipe, and the lungs are affected, and a harsh and hollow cough 
bespeaks the mischief which is going on there. The ulcers extend in the nose; they become larger and more numerous; the membrane thickens; the nostril and the whole of the nose swell; the air passages are impeded; the horse is threatened with suffocation; and a grating, choking noise attends every act of respiration. The discharge from the nose is greater, consisting more of pus and of blood, and more fetid. Symptoms of farcy now appear. Ulcers break out in various parts, and the animal is at length worn out and dies.

This is the usual progress of the disease when it is bred in the animal, or produced by our stable mismanagement; but there is another species of the malady, termed, from the rapidity of its progress, the acute glanders. When the disease is communicated by infection, its march is sometimes fearfully quick, and the horse is soon destroyed. The disease is the same, but the difference consists in the violence of the symptoms, and the rapidity with which they succeed to each other.

Sometimes, after the disease has proceeded slowly for many a month, the complaint all at once takes on the acute form, and destroys the animal.

Glanders may thus be produced by various causes, such as contagion, exposure to a foul atmosphere, hard work, poor feeding, and, more frequently than is generally imagined, common colds and strangles. In these latter cases the seeds of glanders are usually present in the system, and are called into action by the irritation of these diseases.

The treatment of glanders is very unsatisfactory. There are cases on record in which horses appear to have been cured by every variety of treatment, and some when all medical treatment was neglected. It is very probable that in these cases nature did a great deal more than the medicine.

The method, however, which has oftenest succeeded, and from which most success might reasonably be expected, is to endeavour to subdue the local inflammation by sedatives, and at the same time to strengthen the constitution against the continued influence of the disease by the administration of tonics. It fortunately happens that there is a tonic which seems to have its principal determination to the membrane of the nose, and that is the sulphate of copper. The following ball has often been serviceable; and it has sometimes apparently cured the horse, at least for a time.

RECIPE (No, 21).

\section{Ball for Glanders.}

TAKE-Sulphate of copper (blue vitriol) powdered, from half a drachm to a drachm;

Ginger and gentian, of each a drachm;

Linseed and palm oil, sufficient to make a ball. 
One of these balls should be given morning and night for a fortnight, and then daily as long as may be necessary. Or the constitutional treatment recommended in the next chapter for farcy may be adopted. Some of the relapses after the seemingly successful treatment of glanders are evidently to be traced to the premature discontinuance of the medicine; but others, indeed, are more truly explained by the inveteracy of the disease.

Green meat will always be a valuable auxiliary in the treatment of glanders, whether in the stable, or the horse being turned out to grass. In both cases the infectiousness of the discase should never be forgotten.

Care should be taken that the hands of the person who administers the balls are perfertly sound, for the disease is infections with regard to the human being, as well as the horse, and nuany farriers have lost their lives by inattention to this. The most prudent method would be never to ball a glandered horse without the balling-iron and gloves.

What, then, is the practitioner to do when consulted respecting a case of glanders? Unless the disease is in a very early stage, or the animal an exceedingly valuable one, the best advice he can give is, at once to destroy the horse. The first loss will probably be the least.

The horse having been destroyed, let all his body-clothes, and the halter, be burned,- the leatliers well scoured, first with soap and water, and then with a solution of the chloride of lime (Recipe, No. 18, p. 68)-the bit and all the iron-work subjected to the cleansing influence of the fire, not heated so intensely as materially to injure them-the brushes and currycomb burned - the rack and manger, and the partitions of the stable, first scoured with soap and sand, and then with the solution of the chloride of lime-the floor thoroughly scrubbed with water, and then wetted with the same solution-and the walls either cleansed with the chloride of lime, or washed, or both.

If, however, the horse is valuable, or the owner wishes that medical treatment should be adopted, let him be renoved from his former stable, if he had companions in it, and let the stabie undergo the purification just described. It would be worse than useless to remove the other horses, for they may have been already infected, and may carry the contagion to other stables. Let the horse be placed in some shed or old stable, or, what is better, turned out with a shed to run into; or, in short, let decisive measures be taken to prevent any communication with other horses.

In the pursuit of any course of medical treatment, the practitioner should never be induced to the practice of any cruelty. Operations of every kind have been attempted, and their perfect inutility, and the absurdity of most of them, clearly demonstrated. No injection, whether up the nostril, or through a hole bored in the forehead, can possibly be of service-for it can only be brought into contact with 
a very little portion of the diseased surface. If a mild application could be spread over the whole of the interior of the nose, it would clearly be ineffectual in a complaint like this; and irritating ones would only add to the inflammation, and increase the sufferings of the animal and the intensity of the disease.

The principal chance of doing good lies in prevention; and the practitioner will be best able to prevent the disease when he thoroughly understands the nature and cause of it. The nature of it is a specific inflammation of the membrane of the nose, the poison secreted by which when under inflammation, or when ulcerated, being received into the system, and spreading over the frame. The cause of this inflammation is, first of all, infection. In a very great number of cases the disease has its origin here. The matter of glanders has come in contact with some sore or abraded surface, or has lodged on some membrane, through which it might be absorbed. When we consider the habits of horses standing near each other, and the little sores which will often be found about the lips, or muzzle, or mouth, produced by the bit, or the harness, or the food, we need not wonder at the propagation of glanders. Hundreds of horses have been lost in this way, by merely drinking out of the same pail with a glandered horse, or licking the manger, or eating out of the manger from which a glandered horse had been fed.

Besides this, our whole stable management is pregnant with danger, as it regards the production of glanders. The heated air of a close stable must irritate the nostril through which it passes in its way to the lungs, and must render the meinbrane of the nostril liable to inflammation - the foul air of the same stable will have a tenfold more pernicious effect. The membrane of the nose is the guard of the lungs, and scarcely a particle of the pungent and poisonous vapour which mingles with the air in a close and heated stable reaches the lungs. It is arrested by the membrane that lines the intricate passages of the nose. Then, in a mismanaged stable, in the stimulating air of which we can scarcely bear to remain even during a few minutes, and the whole of which falls upon, and is arrested by, and spends all its injurious effects upon the membrane of the nose, can we wonder that that membrane is irritated, inflamed, and disposed to take on this specific inflammation among others?

By encouraging, and, so far as he has the power, insisting upon ventilation and cleanliness in the stable, the practitioner will do more to arrest the progress of glanders, than by any experiments on the curative treatment of the disease.

There is no place in which glanders is so prevalent as in the illmanaged stable of the postmaster. It is lamentable to hear what serious losses he sometimes incurs from the ravages of this pest. The membrane of the nose is first injured by the gases to which it is exposed in their neglected establishments; and then, when the constitution of the animal is worn down by the hardships to which 
he is so peculiarly exposed, this most injured and weakened part goes first; and experience proves that the winding up of the life of the post-horse is, in numerous instances, glanders or inflammation of the lungs.

There is another disease that frequently accompanies glanders, and which, indeed, is only another form of it, and will therefore properly be the subject of the next chapter.

\section{CHAPTER XI.}

\section{INFLAMMATION OF THE ABSORBENTS.-FARCY.}

In the Cattle Doctor ( $p .32)$, I have described the absorbents as vessels which are opening upon every surface, and every part of the body, and carrying away the worn-out portions of the frame, or the fluid that fills any cavity, or rests upon any surface, - and this for the purpose of converting them again into nutriment, or of expelling them. These vessels follow the course of the veins, and are furnished with valves like the veins, so that amidst the action of the muscles, and the change of position of the limbs, the fluid may never retrograde, but pursue its forward course to its proper destination. Some of these absorbents open upon the surface of the glanderous ulcers, and take up the poison which is secreted there; and that poison is of so corrosive a nature, that it inflames the absorbents as it passes along; and when it is arrested for awhile at the valves of the absorbents, the inflammation increases there, and little tumours are formed, which suppurate and ulcerate.

The glanderous ulcers are superficial, and therefore the superficial absorbents are first affected, and there are small hard cords running along under the skin by the side of the veins, particularly where the skin is thinnest; while, at certain intervals, there are small tumours or knots (farcy-buds), which break, and small ulcers (farcy-ulcers) remain.

These buds have some resemblance to the patches on the skin which are known by the name of surfeit, but they may readily be distinguished from them by their hardness, and by their running in lines.

By degrees the deeper-seated absorbents are affected by the poison, and their result sudden and painful swellings of the limbs, or large tumours on various parts, which also break and leave deep and corroding and loathsome ulcers. The disease often commences in, and is sometimes altogether confined to, one of the hind limbs; at other times the head and the muzzle are first affected, and there is swelling of the muzzle, and a discharge of offensive bloody matter from the nostrils: sometimes the disease appears in the form of bad 
grease. The characters which it assumes are various, and often puzzling; but during the whole course of the disease the horse is hide-bound, and losing flesh and strength, and ultimately dies a mass of corruption.

Farcy is, like glanders, contagious; but the disease is much oftener to be attributed to bad stable management. It usually rans its course more speedily than glanders, although sometimes, like that malady, it lurks long in the frame before it produces its destructive effects. It may often be considered as an after-stage of glanders, and it is essentially the same disease, but under a different form.

Although it is thus identified with glanders, it is somewhat more manageable than that complaint. There are very many cases of the apparent recovery of the farcied horse, and not a few in which the disease has been permanently eradicated; but it is only when it is confined to the corded absorbents, or superficial ulcer, or swelled limb, that it admits of cure;-when the deep corroding ulcer appears, or the swelled head, and the fetid discharge, the case is as hopeless as that of confirmed glanders.

The treatment is either local or constitutional. The first consists in the dispersion or destruction of the farcy-bud, or the healing of the farcy-ulcer; and the method of procedure in order to accomplish this is simple enough. The part on which the virus lies must be destroyed, and the virus with it. A sharp budding-iron is the most convenient instrument for this, by which the bud may be pierced, or the ulcer cauterized to the very bottom. The collection of virus at the bud, or the secretion of it from the surface of the ulcer, being got rid of, the inflammation of the absorbents will sometimes cease. When the disease is ascertained, the buds should be opened as soon as they appear, and in every place. It will be useless to attempt to disperse them by any embrocation or discutient fluid. When they have been thus opened, the ulcers should be washed with a strong solution of sulphate of iron.

\section{RECIPE (No. 22).}

\section{Lotion for Farcy.}

TAKE-An ounce of sulphate of iron (green vitriol), reduce it to a rough powder, and dissolve it in a quart of spring water. To every pint of the solution add a quarter of an ounce (by weight) of sulphuric acid (oil of vitriol).

The ulcers should be freely bathed with this lotion morning and night. Some of it may be rubbed along the course of the corded absorbent with probable advantage, and the enlarged limb may also be bathed with it.

The constitutional treatment will consist in the administration of tonics, in order to support the system against the widely-spreading 
and destructive influence of the poison. The most effectual medicine in this case is the bi-chloride of mercury (corrosive sublimate).

RECIPE (No. 23).

Ball for Farcy.

TAKE-Corrosive sublimate, ten grains;

Powdered gentian root, two drachms;

Powdered ginger; one drachm;

Linseed meal, half an ounce:

Make the whole into a ball with palm-nil.

This ball should be given morning and night for a fortnight. If advantage then appears to have been derived from it, the quantity may be gradually increased to a scruple of the sublimate in each ball; but the horse must be carefully watched, lest salivation or violent purging should be produced.

In both cases the mercurial balls must be discontinued. In salivation the mouth should be frequently washed with the solution of the chloride of lime (Recipe, No. 18, p. 68), and that succeeded by the infusion of catechu (Recipe, No. 19, p. 68); and an alterative ball (Recipe, No. 11, p. 57) should be given morning and night.

If much purging and griping have been produced, let plenty of thick starch or arrow-root be horned down, and the following drink given morning and night:-

\section{RECIPE (No. 24).}

\section{Drink for Purging from Corrosive Sublimate.}

Take-Powdered opium, two drachins; rub it well down with the yolk and white of an egg. Add the contents of two more raw eggs, rubbing the mixture well together as each is added: then gradually pour in half a pint of thin gruel, continuing to stir the mixture.

If $t w o$ days should pass, and the purging not be reliever, continue the starch and arrow-root, and give the following drink:-

\section{RECIPE (No. 25).}

\section{Astringent Drink.}

TAKE-Prepared chalk, an ounce;

Powdered catechu, two drachms;

Powdered opium, one drachm;

Powdered ginger, one drachm;

The contents of one egg:

Rub them well together, and gradualiy add eight ounces of thin gruel. This mixture should be given murning and night until the purging begins to cease. 
If at the expiration of a fortnight's trial of the corrosive sublimate no benefit seems to have been obtained, recourse should be had to the sulphate of copper (blue vitriol).

RECIPE (No. 26).

\section{Another Ball for Farcy.}

TAKE-Blue vitriol, one drachm;

Powdered gentian, two drachms:

Powdered ginger, one drachm;

Linseed meal, three drachms;

Palm oil, sufficient to make a ball.

This ball may be given morning and niglst, and continued with perfect safety as long as may be deemed necessary; but if, after the trial of a month, no ground has been gained, the case may be abandoned as hopeless.

In farcy, even more than in glanders, green meat is necessary; and if the horse can be turned on spring grass, or into a salt marsh, it will always be productive of temporary benefit at least. A run at grass should always succeed an apparent recovery from farcy.

Cantharides, in union with aromatics and tonics, as caraways or ginger, and gentian, have lately been successfully used in the treatment of farcy. The proper dose is four grains of the cantharides, given daily, and gradually increased to eight grains, and a drachm each of the other three ingredients.

A blister composed of tincture of cantharides is also applied with success to farcy swellings of various kinds. There can be no doubt respecting the hereditary character of farcy.

Still more recently a new medicine called diniodide of copper, being a compound of mercury with sulphate of copper, has been used with success in farcy, and in discharge from the nostrils resembling glanders. The dose is from half a drachm to a drachm and a half, combined with gentian and other vegetable tonics, and given once a day. The ointment of iodine has also been rubbed on the corded swellings with advantage. 


\section{CHAPTER XII.}

\section{INFLAMMATION OF THE CELLULAR SUBSTANCE UNDER THE JAW-} STRANGLES.

Strangles is a disease from which few young horses escape. It is slightly contagious; but it is more a natural process which the young animal rnust go through.

At some time, usually between the third and fifth year, the colt will be out of condition and spirits, and have a slight husky cough; the appetite will fail; there will be occasional discharge from the nose, and weeping from the eyes; and he will probably continue thus for several days, or even during some weeks; not decidedly ill, but evidently far from well. The horseman says that the colt is "breeding the strangles," and so he generally is.

The owner suspects the real nature of the disease on account of the age of the animal; the greater discharge from the nose than is usual in common catarrh; the appearance of some purulent matter with the discharge; and sometimes the drivelling of thickened ropy saliva from the corner of the mouth.

The cough becomes at length more troublesome, and the nasal discharge and weeping increase, until a fulness appears under the lower jaw, and occupies the channel. It is hot and tender, and the swelling increases until it assumes the form of a defined hard tumour in the centre of the channel. The cough now becomes more urgent; it is sometimes almost suffocating. The tumour grows, and points, and, if suffered to take its natural course, breaks, and a considerable ulcer remains; but after the matter is fairly run out, the ulcer speedily heals, and the colt is well. The disease is essentially the formation, and suppuration, and discharge of this tumoutr.

If the proprietor of the horse or the veterinary surgeon does not too much intermeddle with this process, it is rarely that much danger attends on strangles. Some weakness may remain; but that gradually disappears, and the colt enjoys far better health than he did before.

There should be no bleeding while strangles is coming on, or the tumour forming, except there is considerable fever; nor should any physic be administered, except a very mild dose if the animal is costive; but mashes should be given morning and night, with green meat, and the quantity of corn a little but not much diminished. Bleeding will only weaken the colt, and retard the progress of the tumour, or possibly prevent its coming to full maturity.

As soon as the fulness under the jaw is evident, and the tumour 
is forming, its progress should be hastened by the application of strong stimulants to the part. There is evidently a struggle going forward between nature and the disease, while the tumour is assuming a palpable form, and proceeding to suppuration; and it is the continuance of this struggle that produces the weakness during and after strangles, which sometimes alarms, and is not always speedily removed. It is evident that the sooner the struggle is terminated the better; and the object of the practitioner should be to effect this by hastening the process of suppuration.

Mary persons apply poultices and fomentations to the part. 'The effect of these is doubtful. The poultice is not always kept on the tumour; and as the hair cannot always be perfectly dried after the fomentation has been used, the cold produced by evaporation from the damp surfuce will do more harm than the warmth of the fomentation had done good. Warm fomentations and linseed poultices, frequently and carefully applied, are certainly the quickest method of hastening the suppurative process, and should therefore be applied if the young horse is valuable and has been long domesticated. In ordinary cases, however, and particularly if the aninal is very young, the throat should be blistered as soon as the tumour begins to be formed. The suppuration will be accelerated by many days, and much expenditure of strength will be saved. A slight blistering application may even be applied when poultices are also adopted.

There are few things more disgraceful in the farrier's Pharmacopœia than the composition of blister ointment. It would almost seem as if it were the object of the practitioner to torture the poor animal, and permanently to blemish the part, rather than to apply a safe and useful blister: hence, euphorbium, and oil of vitriol, and corrosive sublimate are so often fonnd in the vesicatories of the farrier. The very best blister that can be composed has the Spanish fly alone for its basis. The following is the recipe:

\section{RECIPE (No. 27).}

\section{Blister Ointment.}

TAKE-Spanish flies, one pound, and reduce them to fine powder; melt togcther, palm.oil, four pounds, and resin, one pound, and when they begin to cool, add the flies, continuing to stir the mass until it is set.

This ointment, if it is well rubbed in, will always vesicate, and never blemish.

Then comes a question: the tumour rapidly coming forward, is it to be suffered to take its natural course and break, or should the escape of the pus be hastened by the lancet? No good practitioner would willingly have an ulcer with ragged elges, and difficult to heal, and that would generaliy be the result of the spontaneous 
bursting of the abscess. As soon as a tolerable quantity of fluid can be detected in the tumour, and the skin begins to be prominent and soft in some parts of the swelling, the lancet should be used. The incision should be from half an inch to an inch in length, or the orifice will be apt to close before the pus is all discharged. There should be little or no squeezing of the tumour, in order to force out the fluid; but a poultice should be applied, or fomentations frequently used; and when the discharge is beginning to cease, the wound should be dressed with "Tincture of Aloes or Myrrh; or a little of the Tincture may, with advantage, be injected into the abscess.

The horse will usually begin to mend as soon as the abscess is opened; yet the practitioner inust not be in ton great haste to open it. The matter should be suffered evidently, and in some quantity, to form. If the tumour is lanced before this, the inflammation of the part will be increased, while the suppuration will be delayed, and, in some cases, altogether prevented: the horse will then linger on, neither sick nor well, for a long time, and will never thrive so thoroughly as when, by a copious discharge from the abscess, he has got rid of that which was preying on the constitution.

The medical treatment of strangles will depend on the degree of fever that accompanies the formation of the tumour. It is a rule almost without exception, that a horse should never be bled in strangles, unless there is considerable fever. The little acceleration of the pulse and heat of month, which usually accompany the disease, will be successfully combated by a few fever-balls (Recipe, No. 15, p. 63). Nashes should always be given, and green meat if it can be obtained.

If there is no fever, medicine is quite unnecessary, until the tumour is nearly healed, when a mild dose of physic may be administered. It will expel the humours that will now be afloat in the system, and prevent an attack of wrease, or swelling of the joints, or some acute inflammation after the animal is convalescent.

The weakness which sometimes remains in the latter stages of strangles, or when the disease is passed, may in most cases be left to the slow but renovating power of nature. If, however, the weakness should continue, or increase, or be accompanied by evident loss of flesh, bran or malt mashes, green meat, carrots, or a salt mash, will be serviceable, with one or two feeds of corn daily: nevertheless it should not be forgotten that ton much hard and stimulating food would be dangerous.

Should the wealiness still continue, a few tonic balls may be administered.

\section{RECIPE (No. 28).}

Tonic Balls.

TAKE-Sulphate of iron (green vitriol), two drachms;

Gentian, three drachms ;

Ginger, one drachm.

Make them into a ball with palm-oil, and give one daily. 


\section{CHAPTER XIII.}

\section{INFLAMMATION OF THE GLANDS.}

IN strangles, and in every case of severe calarrh and cold, and frequently even in milder cases, the glands of the mouth and throat will be affected, and will become hot, swelled, and tender. This will be evident externally at the slightest glance, and will be more decidedly shown by the horse quidding his food, that is, dropping it from his mouth partly chewed, being unable or unwilling to swallow it on account of the pain which it gives in passing over and pressing upon the inflamed and sore parts.

In common sore throat the gland usually first and most affected is that under the ear, the parotid glund. In its healthy state it reaches from the root of the ear to the angle of the lower jaw ; and when it is a little enlarged by inflammation, it can be seen, plainly enough, filling up and protruding from the hollow between the ear and the jaw.

The horse should be treated as described under the article catarru; he should be bled, and have sedative medicine according to the degree of fever which accompanies the sore throat. The head and neck should be covered with a hood; and the following: embrocation should be well rubbed in, reaching from ear to ear, extending over the greater part of the channel, and about three inches down the windpipe.

RECIPE (No. 29).

Embrocation for Sore Throat.

TAKE-Common liquid blister, two ounces;

Hartshorn, one ounce;

Olive oil, one ounce;

Oil of origanum, one drachm:

Shake them well together.

RECIPE (No. 30).

Strong Liquid Blister.

TAKE-Powdered Alkanet root, two ounces;

Spirit of turpentine, a gallon.

Pour the turpentine on the alkanet root, and let it macerate three days, frequently shaking it; on the fourth day let it stand undisturbed; then put one pound of Spanish flies, powdered, into another jar, and 
pour on them the clear turpentine from the first jar. Let these macerate a month, daily shaking them; then let the jar stand undisturbed four days, and pour off the clear fluid for use.

The last recipe will be the liquid blister in its strongest form, and should be applied only when a very nowerful external stimulant is wanted. It is excellent for blistering the sides and bristiet in inflammations of the lungs; and the belly in colic, or inflammation of the bowels. From this the

\section{RECIPE (No. 31).}

\section{The Common Liquid Blister.}

\section{Is made, by mixing-Strong liquid blister, and}

Spermaceti oil, equal parts.

This embrocation should be applied morning and night until either considerable scurfiness or swelling around the gland takes place. The horse will then be speedily and materially relieved.

In a few cases, however, the gland will continue to enlarge until suppuration or ulceration appears. This is a serious business, and requires the attention of a skilful veterinary surgeon. In the best of cases the healing of the ulcer will be difficult and tedious. Sometimes it may be necessary to destroy the gland, and at other times to make a new passage for the discharge of the saliva into the mouth. This is treated of at considerable length in the first volume of a very excellent monthly periodical-"The Veterinarian." The treatment will in general consist in keeping the wound clean by the application of occasional or frequent poultices; in having a dependent orifice, from which the matter may be freely discharged; in repressing all fungous granulations by the use of the canstic, and stimulating the surface of the wound to healthy action by the application of Friar's Balsam or a solution of zinc.

The other glands which suppiy the mouth with saliva will also generally share in the inflammation of the parotid. The submaxillary glands will be oftenest affected. It is very rarely indeed that the horse has cold without kernels, and sometimes large ones, being felt under the jaw. If they are neither very large nor very tender, it will be best to let them alone. The swelling will subside when the cold or fever is removed. Should they, however, attain a considerable size, and remain under the name of

\section{THE VIVES,}

the embrocation (Recipe, No. 29, p. \$2,) must be well rubbed in; but no one who values his horse will choose that he should be submitted to the barbarnus tratment of the farrier, who will sometimes endeavour to cui the glands out with his linife; or to sear them 
down with his heated iron; or to bring them to suppuration by the flame of a candle.

These indurated glands will generally be dispersed by the application of a linament like that recommended; but if it should fail to do so, a little of the following ointment, composed of

Iodide of potassium, one drachm;

Palm.oil, one ounce,

should be rubbed in daily, and in very obstinate cases it may be assisted by the internal administration of seven or eight grains of the iodide of potassium.

\section{BARBS OR PAPS.}

The submaxillary glands open into the mouth, under the tongue and on either side of the bridle of the tongue. When there is much inflammation of the glands, or of the neighbouring parts, the lips of these openings from the glands enlarge: perhaps the saliva is somewhat changed, and irritates the duct and excoriates the orifice, and a little swelling appears on each side of the tongue.

Tine proper way to treat that swelling is to combat the inflammation which produced it by bleeding, giving laxative and sedative medicines, and putting the animal on low living; and then, as soon as the inflammation begins to abate, the barbs or paps ivill gradually riminish, and all will be well. No ointment or lotion should be applied to them; for the cause ceasing, the effect will presently disappear. The farrier who proposes to cut or to burn them off shows the most disgraceful ignorance. He will not only put a roble animal to much unnecessary torture, but the new inflammation which he will produce in the part will close up the orifice of the duct. The secretion of the saliva, however, will still go on; and if it cannot be discharged into the mouth, it will accumulate somewhere, the duct will ulcerate and break, and a fistulous wound will be found in the mouth or under the jaw, which the practitioner will be sadly puzzled to get rid of.

\section{GIGS, BLADDERS, FLAPS.}

These are names for enlargements of the openings from the numerous little glands under the tongue and about the mouth - the sublingual glands chiefly-and which are the other agents in the production of the saliva. They, too, sympathize in the surrounding inflammation, and becoming enlarged, look like little pimples scattered about the mouth. In most cases nothing should be done to them, except that the Infusion of Catechu (Recipe, No. 19, p. 68), or the Alum Wash (Recipe, No.20, p. 63), may diminish the swelling or heal the little ulcers that may be formed; but if decided ulceration has appeared and is spreading, the Tincture of Myrrh will be the best principle.

In all cases of sore throat the nose-bag will be found exceedingly 
useful. In common cases scalded bran may be sufficient. It should be almost or quite at the boiling temperature, the bag, however, being sufficiently deep to secure the muzzle of the horse from being scalded. In bad cases, and attended with much difficulty of breathing, fresh yellow deal shavings may be used instead of bran. 'The membrane of the throat will sometimes be the principal seat of inflammation, or it will sympathize with the neighbouring glands, and partake of their disease; the vapour from the hot bran or sawdust will pass over the irritated surface, and have all the beneficial effect of a fomentation, while the turpentine which it contains will more readily cleanse the part., and, from its slight stimulus, relieve the inflammation beneath the membrane.

Inflammation of the throat, its glands, or its lining membrane, soon spreads to other parts. It will particularly extend down the windpipe, and be indicated by short and convulsive breathing, and often by a loud roaring noise which may be heard when the ear of the observer is placed over the course of the windpipe. The inflammation will not long confine itself to the windpipe: it will attack the ramifications of the bronchial tubes, or the small passages through which the air is conveyed to the cells in which it is to undergo its change. Inflammation of these air-passages will form the subject of the next chapter.

\section{CHAPTER XIV.}

\section{BRONCHITIS-INFLAMMATION OF THE BRONCHIAL TUBES.}

THIs disease consists of inflammation of the membrane lining the air-passages in the lungs, and is generally accompanied by a similar disease of the windpipe and the larynx. It is produced by the same causes as a common cold, and not unfrequently is the extension of inflammation from the throat downwards. It is often a very insidious and fatal disease, though sometimes slight and free from danger. It frequently creeps on so gradually and insidiously, that it often fails to attract attention until too late. It is not uncommon for a cough and a slight diminution of the appetite to be the only symptoms noticed for several days, although if the animal were examined at this stage, we should find a quickening and disturbance both of the pulse and the breathing. A discharge from the nostrils is also an early symptom. The disease, after creeping on in this manner for several days, sometimes exhibits on a sudden the most dangerous symptoms; the pulse being exceedingly quick and weak, the respiration greatly accelerated, the membrane of the nostrils and eyelids of a deep red colour, and the discharge from the nostrils 
diminished or suspended: the blood, if taken, will be found very dark. When bronchitis presents itself in this form, it is very commonly fatal-the membrane of the nostrils becomes of a purple hue, and the intensity of the inflammation suppresses all discharge, and death too frequently closes the scene in the course of a week or ten days.

The disease fortunately does not always exhibit itself in this severe or insidions form. We often find from the first a loss of appetite, dulness, discharge from the nostrils, and cough, and it may be distinguished from a common catarrh chiefly by the quickness of the pulse and the disturbance of the breathing; the former ranging from 45 to 60 in a minute, but generally somewhat weak. From common inflammation of the lungs it may be distinguished by the warmth of the surface and the extremities which usually prevails, and the more moderate acceleration of the pulse and respiration. It should, however, be observed, that it is by no means uricommon for this disease to be cornplicated with inflammation of the lungs, and when this is the case it is more dangerous than either simple affection. It is sometimes attended with costiveness, the dung being often offensive, and coated with mucus, and yet the membrane lining the bowels is so irritable as to be violently acted on if any physic is administered. On applying the ear to the chest, instead of the healthy murmur, we generally hear a wheezing sound, owing to the air struggling with the mucus; but this, of course, will depend very much on the presence and the quantity of this mucus. The membrane of the nostrils and the eyelids are red, and the mouth usually hot.

The treatment will commence with bleeding. There is a paramount necessity for this; and yet, violent as the symptoms may appear to be, the patient will not often bear the loss of much blood; while here, more than in any other disease, will appear the propriety of the caution which was recommended when treating of the operation of bleeding. No fixed quantity should be mentioned. The operation should never be left to the assistant or the servant, but should take place under the practitioner's own eye, and with his finger on the pulse, in order that the bleeding may be carried on until the pulse begins to falter, and then immediately stopped. There is no rule which admits of so few exceptions as this, that a disease of the nucous surfaces (and this is one) requires prompt and decisive treatment; but at the same time a very cautious one, from the rapid debility which is connected with all these affections.

It will rarely be prudent to abstract more than five quarts even at first; three will frequently be enough, but it will be generally requisite to repeat the bleeding the following or second day, and sometimes several times afterwards.

Although it will be desirable to relax the bowels, alnes will be dangerous, except in the quantity of one or two drachms, and not 
repeated; but it will be better to substitute a pint, or nearly so, of linseed oil, and assist its action by glysters if there is costiveness.

Sedative medicine, such as the fever-ball, (Recipe, No. 15, p. 63, ) should be given twice a day; and after the severity of the inflammation is in some mensure diminished, setons or rowels may be inserted in the brisket, or its surface blistered together with the sides.

Mashes, and hay or green meat, should constitute the only food of the horse.

The disease, however, will not always so decidedly attack the bronchial tubes alone: it will have a more diffused character, and rank under the next chapter.

\section{CHAPTER XV.}

\section{EFIDEMIC CATARRH-CATARRHAL FEVER-DISTEMPER.}

Tris disease, at all times distinguished by some common and characteristic symptoms, but strangely differing in different years, and seasons of the year, has a great variety of names, and is subject to a greater variety of treatment.

Its attack is usually sudden, and comes on in the night. It appears at first like violent catarrh:-the horse shivers: the pulse is quickened; the mouth is hot; the coat stares; the beliy is tucked up; the membrane of the nose is red; the eyes are red and weeping; the appetite fails; the flanks heave; and there is more or less congh, and generally a very sore one.

This may be mistaken for severe cold; perhaps at the beginning it is nothing more than catarrh. It cannot be inflammation of the lungs, for there are no deathy cold ears or feet; in general the extremities are hotter than usual. It cannot be pleurisy, for although there is cough, and a sore one too, it is not the short, interrupted one of inflammation of the pleura.

The second day, however, seldom passes over without the disease being plain enough to a careful observer. There is a degree of weakness which does not accompany any other affection of the chest. There may be disinclination to move, and stifiness of moving, in inflammation of the lungs; but this is downright weakness, and the horse begins to stagger as early as the second day. We are then sufficiently aware that it is this peculiar diseaseepidemic catarrh, or distemper. Epidemic it is: whether it be contagious is a question that has not been fairly settled; but when it once gets into a stable, every young horse, and almost every old 
one too, is sure to have it-and it gradually spreads from stable to stable throughout the neighbourbood.

When it is established, another train of symptoms succeeds, plainly marking out the peculiar nature of the disease. There is sore throat to a far greater degree than in catarrh; while sometimes, in inflammation of the lungs, there is no sore throat at all. The throat is sadly sure. The horse gives up eating at once, and, day after day, he obstinately refuses to feed. The discharge from the nose is far greater than in pueumonia, and even than in the worst cold. It appears earlier; it becomes purulent earlier; and, before many days have passed, it is frequently brown, bloody, and stinking. The legs do not get cold, at least not at first; or if they are cold at all, it is only for a little while; many times in a day they change from hot to cold, and from cold to hot. The breathing does not always become laborious, and seldom very decidedly so; but the sore cough continues, the loss of appetite, the discharge from the nose, the hanging of the head, and, most of all, the peculiar weakness. Often, ere the fourth day has passed, the horse staggers about as if he would fall every moment.

Swellings sometimes appear in different parts; under the brisket, or round the fetlock, or following the whole course of the flexor tendons. These are not unfavourable if they are not to ton great an extent, and if the breath is not very fœtid; but if, after a while, the membrane of the nose, which has all along becn redder than in pure pneumonia, becomes of a leaden, or livid, or purple hue; or the extremities, which had been variable in temperature, become icy cold; or the flanks, which had been comparatively quiet considering the degree of disturbance that evidently existed, begin to heave laboriously; or those symptoms of putridity, of which I shall speak more particularly in the next chapter, make their appearance, the case is hopeless and death not far distant.

The treatment of epidemic catarrh much resembles that of bronchitis. The measures adopted must be prompt and decisive, yet cautious. Blood must generally be taken, and in a full and free stream; but the finger must be on the pulse; and when that begins to flutter, or the horse begins to blow, the bleeding must immediately be stopped. The inflammation must be subdued, but the characteristic debility attendant on the disease must not be increased.

Next, the bowels must be gently opened, if they are not already somewhat loose. The following ball should be given:

RECIPE (No. 32).

Sedative and Aperient Ball for Distemper.

TAKE-Of the fever ball (No. 15, p. 63) ten drachms, and physic mass (No. 1, page 38) two drachms: beat them together, and give one morning and night. 
These balls should not be repeated more than twice, as purging is not desirable; but the fever ball alone may be given twice a day for a day or two, then once only. No change can well be made in this treatment for the first few days, unless the fever should be evidently subdued, and which the coolness of the mouth, the quieting of the pulse, the pale colour of the membrane of the nose, and a little increase of general strength, will best indicate. If there is soreness of the throat, as there generally is, the part may be stimulated with blistering liniment, or setons may be inserted over the larynx. As for diet, several days should pass before any attempt is made to drench the horse with gruel or more stimulating food; yet, as this is a disease, the essential character of which is weakness, it would be advantageous if a little nutriment could be given. There is one plan which will generally succeed, and which should be regarded as an indispensable portion of the treatment of distemper; and that is, not to give one drop of water, but to hang up in the box a pail containing very thin gruel, or white-water, from which the horse may quench his thirst as often as he pleases. Some degree of nutriment will be thus got into him, when it could have been effected by no other means.

If the season of the year will admit of it, some green meat, rye grass, or a few tares, may be placed before him, or damp hay offered to him by the hand; but only a little at a time.

When the inflammatory appearances are abated and much weakness remains, we may have recourse to mild tonics, such as the following:

RECIPE (No. 33).

\section{Mild Tonic Ball in Distemper.}

TAKE-Gentian, one drachm;

Powdered Ginger, half a drachm;

Cascarilla bark; one drachm;

To be made into a ball with linseed meal and treacle, or in a drink with half pint of warm water, and half an ounce to an ounce of sweet spirit of nitre.

One of these balls may be given morning and night: but they must be carefully watched, and if the pulse should materially quicken, or the flanks heave, they must be immediately discontinued, and recourse once more had to the fever balls. The proper treatment in the after stages of this disease, when the bad symptoms are slowly abating, is to leave nature, as much as may be, to herself.

If, however, the horse continues to lose flesh, and strength, and spirits, and the first tonic has produced no febrile reaction, a stronger one may be tried, and there is no better than Rccipe (No. 28, p. 81 ). Halt a ball should be given at first, morning and night, 
and the quantity gradually increased if the horse seems to bo improving, and no fever returns.

Should, at any later period of the treatment, the membrane of the nose become red, and the flanks begin to heave, and the extremities feel cold, and the countenance appear haggard, and the pulse be quickened, with some hardness, let not the practitioner be afraid to bleed, whatever may be the degree of weakness; but here, as in other cases already recommended, let him bleed with his finger on the artery, that he may stop the flow of blood as soon as the pulse begins to falter; and until it does falter, the blood should continue to flow. These sudden relapses, or sudden tendencies of the disease to degenerate into inflammation of the lungs, or pleurisy, are not unfrequent, and demand immediate treatment, or the horse will assuredly be lost.

The fever ball must be resumed, and blisters, if necessary, had recourse to; but, the symptoms having abated, the practitioner must once more remember the nature of the primary disease, and the weakness with which it is associated, and not push his depletive measures too far.

There is another termination of epidemic catarrh, which sometimes is much too frequent, and which, like the milder disease, appears to be dependent on atmospheric agency.

\section{THE MALIGNANT EPIDEMIC.}

Tine febrile stage of distemper often runs its course with fearful rapidity; so quickly, indeed, in some cases, that it is scarcely recognised, and an utter prostration of strength, and tendency to putridity, are the only, or the very carly symptoms. There is a vitiation of every secretion - the loss of all vital power-effusions and tumours are everywhere appearing-every discharge is strangely offensiveulcers form in the nose and mouth-the breath becomes fetid to the greatest degree, and the pulse quick, and small, and irregular.

The mode of treatment is often very difficult to be determined upon, and in many cases the closest attention of the most skilful practitioner avails nothing. Bleeding seems to be out of the question, unless the disease is fortunately detected while the stage of pure fever lasts, and the putrefuctive tendency has not commenced; but that having begun, bleeding would only hasten the termination of the business.

For the same reason purging should be avoided, except in the earliest stages: indeed a diarrhoa which bids defiance to the most powerful a-tringents is a usual symptom of malignant catarrh. In the early stage, however, a mild aperient might be permitted, as likely to carry off some offensive matter; but it must be closely followed by astringents. The astringent drink (Recipe, No. 25, p. 77) may be given, and, at the same time, some attempt should be 
made to rouse the sinking powers. The following drink will be generally useful :-

\author{
RECIPE (No. 34).
}

\title{
Stimulating Drink in the Malignant Epidemic.
}

TAEE-Gentian root, powdered, one drachm;

Colombo root, powdered, two drachms;

Ginger, powdered, one drachm;

Laudanum half an ounce;

Spirit of nitrous ether, half an ounce ;

Peppermint water, three ounces.

Let this be given twice in the day; and, if the horse can be coaxed to eat, Jet green meat be given, or malt mashes; and Jet glysters of thick gruel be frequently administered.

I have seen good effects produced by the internal administration of the chloride of lime.

RECIPE (No, 35)。

Antiseptic Drink in the Malignant Distemper.

TAKE-Spirit of nitrous ether, half an ounce ;

Laudanum, half an ounce;

Tincture of colombo, one ounce;

Solution of the chloride of lime (No. 18, p. 68), eight ounces, Give this twice in the day.

The ulcers should be frequently washed with the solution of the chloride of lime; the tumours, if there be any, freely lanced, and the wounds bathed with the solution; and the horse in a manner washed all over with the same solution. All offensive matter should be immediately removed; the stable sprinkled with the solution; and when the case is terminated, every thing that belonged to the animal, and every part of the stable, thoroughly soaked in solution of the chloride of lime, and then well washed. The unhealthy animals should, on the first appearance of the disease, be separated from the sound ones; and, if we can but too seldom save the patient, we should at least endeavour to prevent the spread of the infection. 


\section{CHAPTER XVI.}

\section{INFLUENZA.}

Tre epidemic disease, recognised under this term, which prevailed so extensively in 1836 , and again during the latter part of 1840, although in many cases resembling that described as epidemic catarrh, yet possesses features peculiar to itself, and therefore demands a separate consideration. It may appear in a very mild or a very acute form; either connected with severe inflammations, or comparatively fiee from any lucal inflammatory action. It has appeared without any recognisable atmospheric cause, and often follows the same disease in the human subject; and yet we must attribute it to atmospheric agency, though it is probably infectious, and spread by this means also. It often comes on suddenly, a loss of appetite being one of the earliest symptoms: the mouth feels hot; the pulse is soon much increased in frequency; the eyes begin to look dull; the lids swell and are suffused with tears, and sometimes altogether closed; the legs swell, and occasionally to an enormous extent, and watery swellings often appear under the belly and the sheath. Sometimes the bowe's are in their natural state, but there is generally some appearance of mucus, and occasionally there is constipation. Generally spealsing there is sorne affection of the throat, and the symptoms of inflammation of the air-passages or the abdominal viscera are occasionally present. The frequency of the pulse is remarkable, sometimes exceeding 100 in a minute, but usually feeble. The disease is evidently one of a febrile character, in which the mucons membranes are in a particularly irritable state. 'The treatment of this disease inust be characterized by moderation and discrimination. In many cases it will be proper to avoid blood-letting, and in all it must be comparatively moderate. In cases where general bleeding is not adopted, it will often be useful to open the angular veins, which will relieve the turgescence of the eyelids, and the headache. The mucous membranes being in a state of morbid irritation, great caution must be used in administering purgative medicines, although it is desirable, if possible, mildly to relax the bowels. Not more than two drachms of aloes, or twelve ounces of linseed oil, or ten drops of croton oil should be given, which may be added to the following:-

\section{RECIPE (No. 36).}

TAKE-Nitre, three drachms;

Tartarized antimony, one drachm;

Camphor, one drachm;

Sweet spirit of nitre, one ounce. 
The camphor should be powdered with the assistance of a little of the ether, and the other ingredients being added, the whole may be mixed with half a pint of warm water, and repeated without the purgative morning and night.

After the second day the draught should be given only once a day, and after five or six doses have been given the nitre should be omitted, and a drachm of gentian substituted instead. If the horse is anywise costive, glysters may be employed with advantage. In severe cases it will be proper to insert setons or rowels in the breast; and if the throat is affected, it sloould be stimulated externally with the blistering liniment, or setons may be inserted in the neighbourhood. Any local inflammation that may be present must be treated accordingly ; counter-irritation being adopted to a greater extent than blood-letting: for although inflammation of the airpassages or the chest justly demands bleeding, yet it must be had recourse to in a more moderate degree than when the peculiar symptoms of influenza are not present.

When the fever has evidently subsided, and there is much debility left, the tonic ball (Recipe No. 33, p. 89) may be given.

If there is enlargement of the legs, they should be well handrubbed and bandaged, and walking exercise and a loose box should be afforded. The diet should consist of green food, mashes, and hay, with what gruel the horse will take; and if the loss of appetite continue, he should be drenched with it.

\section{CHAPTER XVII.}

PNEUMONIA, OR INFLAMMATION OF THE LUNGS-THICK WIND,

BROKEN WIND, CHRONIC COUGH, ROARING, CONSUMPTION.

HAvING spoken of the inflammatory diseases of the air-passages, I now proceed to consider those of the substance of the lungs, or of the membrane lining the minute cells in which the vital change of the air is effected. Pneumonia, or pure inflammation of the lungs, is not a malady so frequent as some have imagined, for it has been ton much the fashion to consider every disease of the chest as inflammation of the lungs; but it does occur, too often for the interest of the proprietor, or the reputation of the practitioner.

I have hinted that it is an occasional consequence of the other diseases of the chest that have been described. Common eatarrh, and, much oftener, epidemic catarrh and bronchitis, will, if neglected, terminate in inflammation of the lungs. The disease will proceed along the air-passages, until the very substance of the 
lungs becomes affected. It may also be caused by exposure to cold; neglect after being heated by exercise; change from a hot to a cold stable; over-exertion, and neglect after that: sometimes it may be brought on by a change from a cold stable to an unnaturally heated one (it is easy to imagine how the air-passages may be irritated, and disposed to inflammation by this), in short, any thing that may lead to common cold is capable of producing inflammation of the lings.

It is of great importance to be able to distinguish the symptoms of pure pneumonia, in order that the proper treatment may be adopted without delay; for on account of the faulty management of the stabled horse, the constant irritation of the air-passages from the repeated breathing of an impure and poisonous atmosphere, and the injury which the lungs have received from our occasional cruel exactions of speed, when the lungs were not sound, or the horse otherwise indisposed for exertion, there is such a predisposition to an acute and fatal inflammatory action, the neglect of a very few hours may so establish the disease, that it will bid defiance to all medical skill. Many horses die of inflammation of the lungs within twenty-four hours from the commencement of the attack. In extreme cases they have perished in twelve, and even in six hours; therefore not a moment should be lost. When a fatal result takes place so rapidly as this, the lungs are found completely black, being engorged or suffocated as it were with black venous blood. This variety of disease has recently been termed pulmonary apoplexy, and is generally brought on by over-exertion, and is characterized by a more rapid and distressed breathing than is otherwise found, and a more oppressed pulse.

The first symptom of pneumonia usually is a shivering fit. This is a circumstance which should never be overlooked by the attendant. The moment a horse is seen to shiver, he should be most carefully examined; and if there are other suspicious circumstances about him, he should be bled without delay. Some endeavour to cut the shivering fit short by brisk exercise. The horse is taken out, and trotted or galloped, and then well groomed, and a hot mash put before him. This sometimes succeeds, and inflammation is prevented by rousing the system so as to throw off the evil by which it is beginning to be attacked; but on the other hand, there are thousands of cases in which the disturbance of the system, indicated by the shivering fit, and occasioned by the commencement of a disease that probably might have been slight and manageable, has been increased a thousand-fold by ill-judged exercise, and rendered fatal.

The nature of the shivering fit should be carefully observed. If, after a while, it passes over, and the natural warmth, or more than the natural warmith, spreads over the frame, but the legs and ears are cold-icy cold, there is a decided attack of inflammation of the Jungs. There is no symptom so invariable as this: it will never 
deceive. In common catarrh, in epidemic catarrh, or in bronchitis, the legs may occasionally be cool, yet oftener their temperature will be above the natural standard, or it will at least be variable, alternating from heat to cold; but a fixed icy coldness marls, without the possibility of mistake, an attack of pneumonia.

The pulse should be anxiously examined. In the other affections of the chest it will usually be quickened, and sometimes sharp: at other times it will be irregular, and even weak; but it will be distinctly felt:-in inflammation of the lungs the pulse will not always be quickened at first; it will seldom be hard; it will occasionally be scarcely detectable; but it will have an obscure oppressed feeling; it will give the idea of the blood being forced on slowly, and with difficulty; it will tell the careful observer what is actually taking place, and he will have a palpable demonstration that the blood is congesting in the substance of the lungs, and that the heart has not power to urge it forward.

The flanks will heave quickly and laboriously: there will evidently be the painful effort to force the blood through the clogged vessels of the lungs, and the idea of suffocation will be present to the attendant. Pain is sometimes indicated by the turning of the head, and anxious gaze on the side, a symptom which is not observable in the chest affections that have hitherto passed under consideration.

In addition to this, there is a stiff manner of standing-an evident attempt to make the limbs the fixed points, in order that the muscles which are common to the chest and the extremities may be employed in aiding to expand the chest, rather than to move the limbs. For the same reason, a horse affected with pneumonia can scarcely be induced to move at all; and he obstinately stands until he drops from fatigue, or to die. Other symptoms are the expanded nostril; the head drooping; the mouth hot; the membrane of the nose red; the appetite nearly if not entirely lost.

The treatment of inflammation of the lungs is simple enough, although not so efficacious as could be wished. The tirst thingfirst in order and in effect-is to bleed, and that most copiously. A broad-shouldered fleam, or lancet, should be used, and the blood drawn in the fullest stream that can be got, until the pulse first rises, and then falters, and the horse shows symptoms of faintness. There cannot be a more unscientific or dangerous practice than small bleedings in inflammation of the lungs. It will often be found, and chiefly in congestive pneumonia, that the pulse is extremely weak and small, and the blood cannot be obtained without much difficulty. In such cases it will be advantageous to give one or two ounces of spirit of nitrous ether previously, which will produce some reaction, raising the puise and enabling us to abstract a much larger quantity of blood.

Purging must not be attempted here, for there is too much sympathy between the lungs and the intestines: but clysters may be 
given, composed of soap and water, or water with Epsom salts dissolved in it; and afterwards, when the inflammation is somewhat subdued by the bleeding and the medicine, and yet considerable costiveness remains, two drachms of the physic mass may be added to a fever ball, and given two or three times; or, what is preferable, half a pint of linseed oil may be administered each time instead.

The fever ball (Recipe No. 15, p. 63) must be given as soon as the horse has been bled, and repeated three times daily for several days, or until the pulse begins to intermit. It should then be employed less frequently, or in a smaller quantity.

Means must next be adopted to produce some strong counterirritation, by which a portion of the inflammation may be transferred to a less dangerous part. A rowel may be inserted at the point of the chest, or between the fore-legs, consisting of tow well smeared with blister ointment. This may be useful on account of the irritation it produces in a part so near the seat of disease; but more so because considerable discharge will soon follow, and that will cause a certain determination of blood from the original seat of inflammation to the spot in which the rowel is inserted. This rowel, however, must be surrounded, and the whole of the brisket and the sides covered with a hister. This will produce more rapid, and far more extensive external irritation, and therefore will in that proportion be more likely to do good by diverting some of the inflammation from the vital organ which had been attacked. The blister is far preferable to the rowel; but the advantage of both may be obtained in the way I have mentioned: for the extensive service of irritation produced by the blister in the first instance, and the after-discharge of the rowel, may be combined in the treatment of the disease.

There are two ways of proceeding here:-either the sides and brisket may be shaved, and the blister ointment (Recipe No. 27, p. 80) well rubbed in, or the simple spirit, or oil of turpentine (the first is preferable), thoroughly rubbed over the parts, without any previous preparation by removing the hair. I prefer the latter method; the stimulant is more expeditiously applied, and the effect is more quickly produced: indeed, if plenty of friction has been used, the effect is immediate, and without so much temporary blemish as is caused by the blister, while the irritation is considerably greater than that which conld be excited by any blister.

One caution, however, is necessary respecting the application of the blister. The inflammation should have been somewhat diminished by the bleeding and the medicine. In the very intensity of the disease the blister will not rise at all, or may increase the general irritability and danger; but when the primary inflitmmation is to a certain degree abated, the blister is an excellent adjuvant. It is always an unfavourable symptom when the blister dues rot rise. Either the original inflammation is too intense, and absorbs soo much of the vital power, to permit any other part to be much 
excited, or the favourable moment has passed, and the system is utterly exhausted.

The horse should be turned into a cool, but not cold box. A cool and airy situation will be likely to lessen the inflammation and fever; but air too cold will drive the blood from the skin and the extremities, and determine it still more injuriously to the inflamed part within. For this reason, while the air is cool, the clothing of the animal should be warm, and the perspiration, sensible and insensible, should be promoted on the skin, as causing a salutary determination of blond there, and relieving the inflamed part.

The same consideration will show the propriety of hand-rubbing the extremities, and covering them well with flannel rollers. This may be greatly assisted by rubbing in a liniment composed of equal parts of spirits of turpentine, hartshorn, and olive oil. The intense coldness of the legs shows that little of the vital current reaches them: but when a comfortable warmth is restored, the usual proportion of blood has been solicited back to the feet, and proportionally less will flow to the inflamed and overloaded parts. A hood should also protect the head and neck.

As for food, the horse wili rarely touch any; and if he were disposed so to do, he should not be allowed more than an exceedingly small portion of hay or green meat. To water he may have free access; a pailful should always be slung in his box.

The patient should be seen again within a few hours after the first bleeding, and if the pulse is again oppressed (not weak), and the nostrils are dilated, and the membrane of the nose red, and the feet cold, more blood must be taken away, and that also until the animal falters: the fever ball must be repeated, with an additional half drachm of the digitalis in it.

Even after this, if the mouth is hot, and the extremities cold, the bleeding should be repeated. In the beginning of a case of decided pneumonia, the abstraction of blood must often be followed up until there are symptoms of amendment.

The fever ball also must be diligently given without scruple or fear; and not one particle of tonic or cordial medicine must mingle with it. The old doctrine of the farrier is here quite explodedexperience has at length made us wise; and it may now be laid down as one of the few rules which admit of no exception, that during the continuance of inflammatory action in pneumonia no cordial or tonic should ever be permitted.

Supposing that the case has gone on well, the inflammation has been subdued, and the patient is slowly returning to health, the care and caution of the practitioner should not even now be suspended: there is danger yet. The owner may be impatient, and the practitioner may not be sorry to get the case off his hands; but there is an old caution, seldom more applicable than here, "not to make more haste than good speed." After pneumonia, as well as epidemic catarrh, when health is once returning, nature will work 
more securely than the medical attendant. No tonic or cordial should be allowed, unless there is marked debility. So far from giving tonics, the fever medicine should not be quite discontinued; for although the fever may be subdned, the part is left weak-it may easily be injured again; and there is always a lurking tendency to take on inflammation once more. 'The horse must not too soon be set to work; to speedy work he must not on any consideration be subjected for a considerable time.

It is not invariably, however, that a perfect cure is accomplished. The horse may apparently enjoy as good health as ever, but he will not always be a sound horse. He may have

\section{THICK WIND.}

There is usually a great deal of congestion of the lungs in pneumonia. Many of the air-cells are filled with coagulated blood; and when they have long been distended by it, that blood becomes in a manner organized; the cells are quite obliterated; and this portion of the lungs is rendered a solid mass, and therefore unfit for respiration. The function of respiration, however, must be carried on; and if one portion of the lungs is thus taken away, that which remains pervious and sound must do the work of the whole: the act of breathing will be more laboriously performed, and must be more rapidly repeated, and the horse will have THIC wIND.

Thick wind is sometimes the consequence of bronchitis, or epidemic catarrh. Then it arises from the lining of the air-passages having been thickened by the inflammation, and consequently the air-tubes being lessened in calibre, and a smaller quantity of air admitted in ordinary breathing. On this account also, the breathings must be more rapid, and more laborious, and this will sometimes exist to such a degree as to threaten suffocation.

Tenderness of the part will long remain after inflammation. Even the ordinary act of breathing will give pain, and the respiration will be short; it will be only half accomplished, in order to avoid the suffering which arises from distension of the cells: the breathings must consequently be more rapid in order to make up for the shortness of each.

Some degree of thick-windedness, however, may arise from other causes. Most round-chested horses are, to a certain degree, thick-winded, because the cavity of the chest cannot sufficiently enlarge to enable the lungs to expand so freely and fully as is required in active and continued exertion. A horse unused to exercise is thick-winded, because the lungs cannot at once accommodate themselves to the fuller and deeper breathing which the exertion of speed. commands. A horse working on a full stomach is thick-winded, because there is not room for the lungs perfectly to expand.

The frequent occurrence of thick wind after inflammation affords 
another proof of the necessity of prompt and decisive treatment under that disease, that there may not be time for this congestion of blood in the cells, and organization there, and obliteration of the cells, and hepatization of the lungs, or the conversion of a portion of them into a solid substance like the liver, and the consequent loss of them for the purposes of respiration.

Of the medical treatment of thick wind little can be said. The cells once obliterated can never be restored. All that can be done may be comprised under the following particulars:-attention to diet; giving the food in as small compass as possible; more corn and less hay; not working on a full stomach; regular exercise; regularly exacting from the horse that degree of exertion of which he is capable without distress, and the regular requiring of which will gradually increase his wind and power. By these means a thick-winded horse may often be made serviceable for all common purposes.

\section{BROKEN WIND.}

This is sometimes the consequence of violent and protracted inflammation of the lungs; and it is also the result of the overworking of the thick-winded horse, but more frequently it is owing to sudden exertion with a loaded stomach. It is precisely what its name imports: it is a broken lung, a rupture of some of the cells of the lungs. The consequence of this is, that although the air is readily admitted during the expansion of the lungs, it is entangled among the ruptured cells, and cannot without great difficulty be forced out again. 'This satisfactorily accounts for the peculiar method of breathing which distinguishes the broken-winded horse. $\mathrm{He}$ inspires readily and naturally enough, but the expiration, or return of the air from the lungs, is not accomplished without a double effort, one succeeding to the other.

It is easy to see how broken wind may be the consequence of pneumonia. If some of the cells are filled and obliterated in the manner which has been just described, the sound part of the lungs must have more to do, and must be more violently acted upon; and, therefore, in more than usual rapid exertion, the delicate membrane by which thay are separated from one another may very readily be ruptured.

In the same way the occurrence of broken wind from violent exercise after feeding, or after watering, may be easily accounted for. That is a ruinous habit which some grooms have of galloping a horse immediately after he has been watered.

Nothing can be done for a broken-winded horse in the way of medicine. The disease, however, may be palliated, and that to a considerable extent, by attention to diet and exercise in the manner which has been just described under the article "Thick wind." . 


\section{CHRONIC COUGH.}

This is a frequent consequence of chest diseases, and still more so of sore throat, and admits of as easy an explanation as the other two. Whether the memibrane of the windpipe, or of the smaller air-passages, or the substance of the lungs themselves, have been inflamed, great soreness and irritability will long remain. When the membrane is irritable, a very trifling cause will produce cough. The very act of coughing is a proof of this irritability, and increases it, and speedily establishes a habit of it; and therefore it is that chronic cough is so difficult to remove, for we can neither get at the irritable membrane nor break the habit of irritability. Chronic cough, however, does not often exist to such a degree as to interfere with health, or even with soundness; and therefore there can be no necessity for adopting any long-continued or expensive measures in order to get rid of it. If it can be traced to inflammation of the upper air-passages, as the fauces, the larynx, or the trachea, a blister, reaching from ear to ear, and about eight inches down the windpipe, may be tried. If the horse is valuable, and the cough urgent, a blister should always be applied. It cannot do harm, and the slight blemish which it occasions will soon disappear.

Medicine will sometimes have effect in relieving the cough, and may be tried to a certain extent. If the cause is unknown, except that the cough is probably the consequence of some former chest affection, a sedative medicine that may gradually allay the remaining irritability of the membrane, and yet that shall not interfere - with the appetite or work of the horse, may be daily given; the very best is the following:-

RECIPE (No. 37).

\section{Ball for Chronic Cough.}

TAKE-Digitalis, half a drachm;

Nitre, two drachms;

Liquorice powder, four drachms;

Tar sufficient to make a ball :

Let this be given every night.

In a few instances chronic cough seems to be connected with worms; and the groom oftener attributes it to this cause than he is justified in doing. If, however, the coat is unthrifty, and the flanks tucked up, and there is mucus around the anus, and particularly if worms are discharged in the fæces, it will be proper to put the connexion between the worms and the cough to the tost. 


\section{RECIPE (No. 38).}

\section{Worm Ball.}

TAKE-Emetic tar, one drachm:

Sulphur, two drachms ;

Linseed-meal, four drachms; and make them into a ball with palm.oil.

A mercurial physic-ball should be first given (Recipe No. 2, p. 38 ), and after the physic has set, one of these balls should be administered every morning, a quarter of an hour before the horse is fed. A dozen of the balls may be thus given, and after that a second mercurial ball. If the cough is lessening, another dozen of the balls will probably remove it; but if no benefit has been obtained, it will be scarcely worth while to incur the expense or trouble of the second set.

Some benefit may be effected by attention to feeding. The oats and the hay should be good; a full allowance of the former, and a somewhat diminished one of the latter, should be given, and green meat, and especially carrots, if practicable.

\section{ROARING.}

This is another disease of the respira'rry passages. In a few cases it is the consequence of inflammation of the lungs, but oftener of that of the upper air-passages. It is recognised by the peculiar noise, an actual roaring, which the horse makes when galloped briskly; or by the short grunt which he utters when he is suddenly struck, or threatened to be so.

Roaring is caused by the sudden rushing of the air through some of the passages partially obstructed. If the obstruction is in the bronchial tubes, it is the consequence of previous inflammation of the membrane that lines them; but it is oftener caused by diminution of the passage through the windpipe, either by a thickening of the membrane which lines it, or the throwing out of a mucous substance during the inflammation of the larynx or trachea, which clings about the sides of the tube, or stretches across it, and by degrees becomes fixed and organized. It may be produced more mechanically, by pressure upon the windpipe, when the colt is cruelly lunged, or his head unnecessarily reined up while in process of breaking him. 'The last is the most frequent cause, although an unsuspected one, and therefore it is that fifteen roarers out of twenty are carriage-horses. The pressure of the lower jaw upon the laryns will produce flattening and distortion of that organ; and the passage being lessened both by the altered form of the tube and by the thickening of the membrane from inflammation, the air, in rushing through the diminished opening, produces the sound of roaring. 
The cause must be discovered if possible. It will be readily suspected in a carriage-horse, and the anatomist will detect it by a careful examination of the part. If there is distortion, the case is hopeless; but when it can be connected with disease, and is only forming, but not thoroughly established, bleeding, sedative medicine, and blistering the throat may be tried. The tar-ball recommended for chronic cough (Recipe No. 37, p. 100) may also be given. In the majority of cases, however, the labour of the practitioner will be lost, and the roarer may be dismissed as incurably unsound.

A skilful surgeon may, by applying his ear to different parts of the windpipe, possibly discover the precise spot whence the roaring proceeds; and if he also ascertains that there is no distortion, he may open the windpipe in that place with the hope of finding and getting rid of the obstruction; but it must be a skillful practitioner to whom such a case can be safely intrusted, and he will weigh the matter well before he attempts the operation.

\section{CONSUMPTION.}

One more consequence of inflammation of the lungs, and that the most of all to be dreaded, remains to be spoken of, and which answers so nearly to Phthisis Pulmonalis, or the consumption of the human being, that I hesitate not to give it that name. The congestion of the lungs, the pouring out of blood into the air-cells, the gradual organization of that blood, and the conversion of a portion of the lungs into a solid substance, have been already described; but in the process of inflammation, either a different fluid is poured into some of the cells, or it undergoes a different change, and it becomes harder than the surrounding substance, and harder than the most firmly hepatized lung. It forms a distinct and somewhat rounded body, varying in size from that of a pin's head to that of a walnut. These are called tubercles.

The tubercle is a serious evil in its hard state; for it takes up a portion of the lungs which should be devoted to respiration, and irritates by its presence and its pressure. These, however, are the least evils which attend the formation and existence of tubercles, for another process after a while commences. The tubercle softens towards its centre; it becomes fluid; it is converted into, or it contains, pus: it is a concealed abscess. The abscess thus formed is not long bounded by the original size of the tubercle; the pus increases; the cyst which contains it enlarges; it presses the lungs on every side; it comes in contact with other tubercles undergoing the same process; they give way; they run into each other; a larger abscess is formed; perhaps there are several of them in different parts of the lungs; and the lungs are corroded and eaten away by them. At length they burst, oftenest into some of the bronchial tubes, and there is a sudden, and, too frequently long-continued 
discharge of purulent, bloody, and fœetid matter from the nose. It is poured out in such great quantities as to plug up the passages, and the animal is quickly destroyed; or the cyst presses more and more upon the air-tubes, and gradual but certain suffocation is produced; or the abscess breaks through the covering of the lungs, and pours its contents into the cavity of the chest, and suffocation is, in this manner also, the consequence.

This is the state of the lungs in that dangerous and too often irremediable disease termed consumption.

The existence of this state of the lungs is usually marked with sufficient clearness. The practitioner can generally trace the pre-existent disease, and that is usually inflammation of the lungs, or some acute inflammatory affection of the chest. The horse has, to a certain degree, recovered from that disease, but still he is not well. He is out of condition; tucked up; his coat stares; he is hide-bound; easily tired; sweating if he is urged beyond a little more than a walk; his appetite is variable, and at no time good; the flanks heave a little; there is cough, sore cough, some discharge from the nose, and that occasionally purulent, bloody, offensive, and the breath is offensive too. He will not thrive, whatever is done for him; he loses ground every week; he is consumplive, and he will gradually dwindle away and die.

It is not often that much can be done for him in the way of medical treatment. Most good is generally affected when an opporturity is afforded for nature to act. A run at grass constitutes almost the only hope, and especially during the spring of the year, when the new grass is both nutritive and alterative. A salt marsh is the best of all places for a horse in this condition; but when the weather sets in hot, and the flies begin to annoy and torture, and, most of all, when they gather round and persecute the poor beast that has the seeds of death in him; and also when the cold of winter causes him to shiver, whose constitution is too much impaired to resist its.influence, he must be mmediately taken up again. He will be generally found to a certain degree relieved, and there will be some chance that medical treatment may be of more avail; but if he is taken up to be immediately consigned to hard work, his doom is sealed.

A great deal of management is necessary in the treatment of such a horse. The practitioner who undertakes such a case needs to be well acquainted with every symptom of irritative disease. Small bleedings may be necessary when unusual heaving at the flanks or redness of the nose is perceived. Counter-irritants will generally be indicated, but in the mildest form. A rowel in the brisket may be useful, but extensive blistering would produce too much irritation. If there is little or no discharge from the nose, the following ball may be administered. It has had decided good effect, but it must be watched, and omitted immediately if it increases the fever, or brings on a more urgent cough, or palls the appetite. 
RECIPE (No. 39).

Iodine Bull for Consumption.

TAKE-Iodide of potassium, five grains ;

Linsecd-meal, five drachms :

Make them into a ball with palm-oil.

One of these balls should be given every morning for a week. On the second week one may be given morning and night; but, beyond this, it will not be prudent to increase the dose.

If these balls should not agree with the horse, or should have no effect on the disease, the ball for chronic cough (Recipe No. 37, p. 100) may be tried, and, as in chronic cough, it should be continued during a considerable length of time.

Very little tonic medicine is allowable in these cases. It will usually increase the irritation, which it is an object of so much importance to allay; but if the horse labours under great and increasing debility, the mild tonic ball for distenıper (Recipe No. 33, p. 89) may be tried: it must, however, be watched, and suspended if it produces fever rather than recruits the strength.

The diet must be regulated with some care. Too much corn will generally be injurious; some portion, however, is allowable or necessary, and that should be given either bruised and mixed with a mash, or after boiling water has been poured over it, and then bran added to make a mash with the corn and the water. Green meat may be given almost without restriction, and changed as often as convenient, in order to suit the failing appetite of the patient. Carrots will constitute the best of all food, and if the horse will eat them freely, no corn should be allowed.

There is one caution with regard to the appearance of the lungs of these horses after death which cannot be too deeply impressed on the mind of the horse-owner and the country practitioner.

When a horse dies of chest affection, and, on being examined, his lungs appear gorged with blood, and black and broken down, they apply to those lungs the term rottenness; they conclude that he has been long ill; and they fancy that they have a claim on, or have been imposed upon by, the person fiom whom they bought him. Nothing can be more erroneous. This blackness is the congestion which has been so frequently referred to; and the breaking down and apparent rottenness of the lung is the yielding of its substance to the pressure of the blood, or other fluid. It is the consequence of acute, rapid, recent inflammation, against which the animal could struggle but a very few days, and by which he is sometimes destroyed in a few hours. There is no old affection here: on the contrary, it is the best proof of inflammation not many days old, but too violent to be arrested by any of the means employed.

The appearances which indicate real rottenness, and which alone 
would substantiate a claim upon the former owner, are very different. They are tubercles; tubercles of a large size; softening; softened; becoming abscesses; running together, and forming cavities, or vomica, in the lungs, of greater or less size. To these would occasionally be added the shrinking of some portion of the lungs; the hardening, or hepatization, of others; or adhesions between the lungs and the sides of the chest. These appearances, and these alone, would indicate an old affection, and warrant a claim upon the seller of the horse. There would, however, be need of caution even here; for no one has yet proved what time it takes for these tubercles to form, and to suppurate, and for abscesses to be hollowed out, through a great portion of the lungs. There are some facts which would encourage the suspicion that all this may be done in much less time than many have imagined. This is a difficult subject, and the horse-owner and the practitioner should think well before they commit themselves.

\section{CHAPTER XVIII.}

\section{PLEURISY.}

Tris is inflammation of the membrane covering the lungs and lining the chest. Its causes are the same as those of inflammation of the air-passages or the substance of the lungs, viz., exposure to cold; sudden alternations of temperature; hard riding; to which may be added, as more likely to produce pleurisy than pneumonia, the absurd and cruel practice of leading poor horses, when hot and panting, up to their chests in cold water, in order to save a little trouble in washing them; the riding against a sharp wind in a cold winter's day; and wounds which have penetrated into the chest, and injured the pleura, without reaching the lung's.

A careful observer will easily distinguish between inflammation of the investing mernbrane of the lungs and that of the lungs themselves. The preceding shivering fit is the same; the loss of spirits and appetite; the hanging of the head; the disinclination to move; the colsh, except that it is shorter and more pitinful; -all these are the same: but there are other symptoms peculiar to this complaint.

The breathing is different. The inspiration, or drawing in of the air, by the horse with pneurnonia, has been described (Chap. xvii. p. 93), as being effected as slowly as possible, and the expiration, or return of the air, being quick, and almost spasmodic. Here, on the contrary, the inspiration is short; it is a sudden effort, and broken off before the object is accomplished. The horse feels a 
stitchy pain from the distension of the inflamed membrane, and which puts a sudden stop to the drawing in of the air; and then, the chest being expanded, he suffers it to fall again, or he expires, as slowly as he can, in order to avoid a repetition of this stitch or spasm. The method of breathing is different from that of pneumonia, and there are also remissions and variations in pleurisy which are not found in inflammation of the lungs, so that in the former disease, when the horse is tranquil, there is sometimes little or no increase of breathing perceptible.

This being inflammation of the lining membrane of the chest, the sides of the horse will also be more or less tender, and sometimes exceedingly so. This will be rendered evident by tapping, or even pressing on the side, for the horse will shrink under the hand. The inflummation of pneumonia is more deeply seated; and, therefore, although in both diseases the horse shows that he feels pain in the chest by lnoking anxiously at his sides, the tenderness externally is generally confined to pleurisy.

In this disease, indeed, the pain is often so severe as to induce the horse to lie down and roll occasionally.

The most characteristic distinguishing circumstance, however, is the colour of the membrane of the nose. In pneumonia, this membrane is a continuation of that which is inflamed, and therefore intensely red; but there is no connexion between the membrane of the nose and the pleura, and therefore it is never so highly reddened; sometimes it is scarcely changed in hue until the substance of the lungs begins to be affected.

The extremities in pneumonia are icy cold: in this complaint there is either increased heat or variable temperature; and the pulse, which in pneumonia was oppressed, and often scarcely quickened, is here both hard and rapid. It is of importance to attend to these distinctions, because the treatment of the two disedses is somewhat different, and the progress of them is very much so.

In its main features, the treatment of pleurisy will resemble that of pneumonia. Bleeding, prompt and copious, that is, till the pulse can no longer be felt at the jaw, will be the first step; and the bleeding should be repeated until the infiammatory character of the disease is materially subdued; sometimes, indeed, a repetition will be called for within eight or twelve hours.

To bleeding will follow the use of the same sedative medicines, and as diligently and perseveringly administered. White hellebore, in doses of half a drachm, twice a day, has been strongly recommended, but it requires careful watching. Counter-irritation will be more plainly indicated, because the inflamed membrane is nearer the integument, and more' under command. 'The nature of the application will admit of no dispute; rowels and setons would be comparatively inefficient: there must be a blister, and almost as extensive as the membrane which is the subject of disease. 
Mustard poultices have been recommended as applications to the sides, producing considerable engorgement, which being lanced, effects the local abstraction of blood, - a very desirable result.

The bowels, if costive, as they usually are in this complaint, should be relaxed by a few half-pint doses of linseed-oil, and clysters should be early and repeatedly employed.

The diet should be spare, and should consist chiefly of mashes, carrots, or green food. The box should be airy, yet comfortable; and the clothing thick and warm, and even more so than in pneumonia. If the inflamed membrane is so near to the skin, there is a better chance of diverting some of the blood from it to the skin when the animal is clothed comfortably; and the practitioner is certain that he will injuriously send more blood from the skin to the inflamed part, if he suffers the animal to stand naked, or but thinly clothed. Such a horse should always be warmly clothed: it is one of the essentials to the comfort and the cure of the animal. While the stable or the box should not be too much exposed to the weather, it should, on the other hand, be comfortable, yet admit plenty of fresh air.

If the horse goes on well, the pulse will soon change its character: it will be both slower and softer. Next to this, the cough will be essentially changed: it will lose its short, stitchy sound, and its evident expression of intense pain. The horse will not gaze so intently at his flanks, and he will move about more freely. ithere is, however, almost as much danger attending pleurisy as pneumonia; and the following are the symptoms of the case going on badly. The horse is fidgety-uneasy-pawing: he will suddenly stop, and bend round his head, and bring his muzzle in contact with his side, and gaze mournfully on the seat of pain. All at once will come the pleuritic stitch, and he will start, and begin again to paw his litter. He will prepare to lie down, in order to try whether change of posture will give him a little ease; he will put himself in the posture for it again and again: but he is afraid: and he shifts and crouches, and bends and trembles, and sweats, and sometimes groans, and then all at once he drops as if he were shot.

It will only, however, be for a short time that he can lie down. He wants the muscles of his shoulders and his chest, in order to enable him to accomplish the now difficult act of breathing. His pulse gets quicker, smaller, and yet wiry: and patches of sweat break out all over him, and particularly about his sides. Gradually, however, he gets quieter: the pain has evidently abated, but other symptomas, and as fearful ones, ensue. He now begins obstinately to stand, and to stand fixed like the horse with pneumonia; and he is not only, like him, unwilling to move, but, at the slightest motion, his pulse beats rapidly, he looks wildly around him, every limb trembles, and he appears as if he would instantly fall: but he recovers himself, and slowly moves on with a staggering, balancing 
gait. The short stitchy inspiration is now gone: it is labour all; increasing labour; protracted suffocation; until the worn-out animal falls and suddenly dies.

The natural consequence of inflammation of a serous membrane has for some time been going on. The secretion from the membrane has been increased, and a fluid of varied character has been rapidly accumulating in the chest: it has been pressing upon the lungs; it has prevented their expansion. As the cavity has filled, a greater and still a greater portion of the lungs has been compressed, and taken from the office of breathing; and the remaining part has heaved more rapidly and convulsively; and the animal has experienced the horrors of lingering suffucation.

The lungs of the horse that has died of pleurisy present a very different appearance from that which has been described in a fatal case of pneumonia. The chest, on one side, or occasionally on both sides, is filled with a scrous fluid,-pale or yellow, or bloody: flakes of coagulated lymph are floating in it, or have been deposited over the pleura, or on parts of it, constituting a kind of additional (a false and adventitious) membrane, that is, in general, easily peeled off, but at other times closely adhering to the pleura; while bands of this matter are thrown across, and connect the pleura of the lungs with that of the chest, or the two pleuræ are grlued together by this interpnsed substance. The lungs are no longer gorged and black with congestion, seeming as it were more than to fill the cavity of the chest: but they are of a difigy leaden purple colour, and sometimes so collapsed as to appear not more than one-fourth of their natural size.

In other fatal cases of pleurisy no water will be discovered in the chest, but the membrane lining it will be found gangrenous in patches, and elsewhere greatly inflamed.

\section{IIYDROTHORAX.}

It is of great consequence to be enabled to detect the commencement of effusion, in order that measures may be taken which will give a chance of arresting its progress. The first symptom, and one that can scarcely be overlooked, is the absence of pleuritic pain. The next requires a little ract in the medical attendant, in order to be discovered. Horsemen begin now to be aware that, by applying the ear to the side of the animal, the act of breathing, or the murmur of the air as it passes in and out of the lungs, can be distinctly heard. This fluid, as it is thrown out, falls to the bottom of the chest, and is there interposed between the lung and the side of the chest; and being thus interposed, the murmur of the breathing carnot be heard through it. When, therefore, the ear is applied close to the chest, and moved from part to part, and, as the different portions of the chest are explored, the murmur is still heard, the examiner may be assured that there is no fluid yet 
thrown out. But when there is silence at the bottom of the chest, but the murmur continues to be heard above, and louder too,--for the lungs are there working harder,-and, at the next examination, the space where all is still is increasing, it is quite certain that effusion has commenced, and is proceeding, A diarrhœa very difficult to be checked, and a rapid wasting, usually accompany effusion in the chest.

In the majority of cases it is only at the commencement of the effusion that it can be attacked with any well-grounded hope of success. It is the signal that inflammation has left the membrane, and that debility has succeeded, and common sense will dictate that the mode of treatment must be essentially altered. That must be done which could not be attempted in pneúmonia. In the first place the absorbents must be roused to action. Diuretics will here be the sheet-anchor. As a common diuretic ball, and in order to cause the absorption of fluids thrown out any where, either in the cellular membrane or the thoracic or abdominal cavities, the following is as harmless (the word is used advisedly, for diuretics given without just cause are productive of a great deal of mischief), and at the same time as effectual, as any :-

\section{RECIPE (No. 40).}

\section{Diuretic Mass.}

TAKE-Of finely-powdered resin, two pounds and a half; Cream of tartar, half a pound ;

Sulphur, half a pound ;

Linseed-meal, one pound ;

Palm-oil, one pound;

The resin should first be rubbed down with the cream of tartar, for if the attempt is made to pulverise it alone it will cake together again in a few minutes: the sulphur and the linseed-meal should then be well mixed with the resin and cream of tartar, and the whole beaten up with the palm-oil. The dose will be from one to two ounces of the mass, according to the size of the horse.

If the practitioner still suspects lurking fever, although this part of the frame is weakened, it will be prudent for him to give the simple diuretic ball every night, and in the morning administer the following drink:-

\section{RECIPE (No. 41).}

TAKE-Spirit of nitrous ether, half an ounce;

Tincture of opium, half a drachm ;

Oil of juniper, ten drops;

Water to eight ounces. 
But if there is considerable general weakness, and the effusion is increasing, a tonic should be added to the diuretic.

\section{RECIPE (No. 42).}

\section{Tonic Diuretic Ball.}

TAKE-Gentian.root; powdered, one drachm;

Ginger, powdered, half a drachm;

Sulphate of iron, two drachms ;

Diuretic mass, half an ounce;

Oil of juniper, ten drops ;

Syrup of squills, half a drachm :

Beat them well together.

This may be given morning and night, and the Recipe No. 41 at noon.

The effusion being once established, the practitioner should think seriously of getting rid of the fluid by an operation. If, by the stillness at the bottom of the chest, and that stillness advancing, although but a little way, up the side, he is assured of the existence and the increase of the effusion, he should have recourse to tapping the chest, and evacuating the fluid; and, if he does this early, he will secure the following very important advantages: he will remove the fluid before the habit of effusion is inveterately formed, and when diuretic and tonic medicine may have some chance of rousing the absorbents to their duty; and he will husband much of the strength of the animal, which must be rapidly wasted, when a portion, and a decreasing portion of the lungs is compelled to do the duty of the whole. There will be a third and more important advantage-the lungs will sooner return to the discharge of their proper function, for the portion which has long been compressed by the fluid, and rendered flaccid and withered, very slowly, or never, resumes its healthy action.

The operation is simple in the hands of a skilful surgeon, and to him it inust be consigned: to him, however, it may be hinted, that the chest should afterwards be frequently examined, by applying his ear to the side; and that, if fluid continues to be effused, and to occupy the chest, it must be drawn off again and again. The most desperate cases will thus be, occasionally at least, successfully combated. 'The principal reason why this operation has been so seldom successful is that the practitioner has contented himself with having once evacuated the chest, and has not considered that the disposition to effusion will for a considerable time remain.

In many cases, however, if the effusion has once commenced, it will continue in spite of all that can be done, and the patient will be lost: or, should the horse apparently recover, there is no disease after which he is so liable to a relapse. The horse recovering from pneumonia must never be securely reckoned upon: the horse saved 
after an attack of pleurisy will long be an object of suspicion. The pleura has to recover from its maceration in the fluid-the lung has to recover from its maceration and collapse: while cough, and swellings of the legs, and disinclination to work, and occasional stitchy pains, will often remind the owner that the horse is not safe.

It must not be forgotten, and, indeed, cannot be ton often repeated, that the various diseases of the chest often co-exist in the same case, rendering the symptoms more obscure, and the sequel more unfavourable and dangerous.

\section{CHAPTER XIX.}

\section{CARDITIS AND PERICARDITIS; INFLAMMATHON OF THE HEART AND}

ITS INVESTING MEMBRANE.

THE heart is the grand agent in the function of circulation. It is the central pump, by the power of which the vital fluid is distributed to every part of the frame. It sympathizes with every irregularity in the action of the circulatory vessels, and every disease of them. If there is inflammation in any part, marked by the throbbing and increased action of the vessels of that part, it will not be long before the heart partakes of the irregularity and irritation, and the pulse will be evidently affected. But the heart is subject to disease, independent of any sympathy with the different portions of the frame, or the frame generally. It is itself the primary seat of inflammation. Carditis is a disease, not of frequent occurrence, or that has long been understood; but which is sometimes seen, and requires prompt and careful attention. It is, however, scarcely ever found unconnected with other disease.

It is recognised by quickness, and, more particularly, strength of pulse; and that referrible not to general affection or irritation of the arterial system, but immediately to the heart. Not only by applying the hand or the ear to the side is its violent action ascertained; but it is seen to beat. If the left side of the horse is regarded with attention, the chest evidently vibrates; nay, the pulsations are heard; they are heard as soon as the practitioner enters the stable, if he listens attentively; and sometimes they are so audible as to force themselves on the observation of those who stand by. At the same time there is an unnatural fire in the expression of the countenance. The horse is all alive. So far from appearing to be sick, he seems to be wound up to the highest pitch of energy, and capable of almost every thing.

There is a disease, however, to be described in the next chapter, with which it may be confounded. The beating of the heart is 
heard strongest at the heart-place, and when the ear is removed backwards, or higher up the chest, although still heard distinctly, it is not so loud: but in spasm of the diaphragm-the case referred to-there is the same jerking action shaking the whole frame, and heard at some distance; but it is not so distinct in the heart-place, as along the line where the diaphragm is attached to the sternum, the sides, and the loins. This jerking action of the heart is sometimes very irregular, subsiding, perhaps, for several minutes.

The real character of the disease being understood, there can be no doubt as to the treatment that should be pursued. The horse must be bled, and as copiously as for inflammation of the lungs. Such excessive action must be lowered, by taking away as much as possible of the stimulus to action; and, the finger being held on the puise, the animal must be bled until he almost faints. There must be no delay about this; for if an organ that is, and must be, always at work, is over-excited, and called upon to perform double labour, it will necessarily and speedily be exhausted.

The bleeding should be closely followed up by laxative medicine, linseed-oil being the safest, of which two pints may be given. Sedatives should quickly succeed, and, most of all, digitalis; and in doses of two drachms each: while all food should be removed, or, at most, mashes only be allowed.

Although a violent disease, it usually yields very readily to this prompt treatment.

Inflammation or over-action of the heart itself-the muscular substance of the heart-has hitherto been spoken of: the pleura of the heart-the pericardium-is also liable to inflammation equally dangerous; and the disease is termed-.

\section{PERICARDITIS.}

This disease, however, can seldom be recognised in the living horse; or, at least, veterinary men have not yet sufficiently agreed on its distinguishing symptoms; nor has the existence of it been clearly ascertained, except as the consequence of carditis, or of pleurisy. In the first case, the symptoms of carditis continue for a while; the throbbing of the heart is seen, producing a spasm of the whole frame, and which is heard at some distance; at length, when a fluid begins to be effused within the bag of the heart, in the same manner as it has been described to be within the bag of the lungs in pleurisy, there is irregular action of the heart; an evidently difficult action, attended with laborious breathing, and a feeling of suffocation. The pulse, at first regular but bounding, becomes irregular, weak, intermittent: it is roused to a rapid fluttering action by the least motion, and it gradually sinks again to almost absolute cessation.

This, however, is so identified with the kind of breathing arising from the pressure of fluid on the lungs, that the one cannot al ways be 
distinguished from the other; and, if it could, we should have no more power over dropsy of the heart than over that of the lungs; in addition to which it may be stated, that, from the situation of the pericardic bag, a puncture into it, and evacuation of the fluid, would be far more difficult and dangerous than puncture into the chest.

\section{ENLARGEMENT OF THE HEART:}

The heart is liable to several morbid changes, the most frequent of which is hypertrophy, or increase in its substance, which is sometimes so great as to double the natural size of the heart, and may be attended with an increase of its cavities, or not.

Sometimes this morbid growth of the heart is of a cancerous nature. I have known the heart double its natural weight, and quite altered in form, by fungous growth. The symptoms were principally an irregularity and a strong bounding action of the heart, and at length the horse died suddenly.

These various diseases, with several others, are uniformly fatal sooner or later.

\section{CHAPTER XX.}

\section{SPASM OF THE DIAPHRAGM.}

Thrs disease is introduced here because it may be confounded with carditis, and should be most carefully distinguished from it.

Let it be supposed that a horse a little out of condition, and perhaps with a full stomach, has been ridden far and fast. He is pushed on after he has shown symptoms of distress; or his own courage pushes him on until he comes to a perfect stand-still; and then, or soon afterwards, the following symptoms appear: he stands with his legs fixed, his neck stretched ont, his nostrils expanded to the utmost, every limb trembling, the flanks heaving, and the countenance exhibiting distress; and there is seen, at the same time, the convulsive jerking which has been described under carditis; and the thumping noise which accompanies carditis is heard at the same distance.

An inexperienced person would confound this with carditis, and he would set to work to bleed the horse, and to bleed him copiously; and as surely as he did so he would destroy him. Although this sound is heard from the chest, the heart has little to do with it. It is spasmodic action of the diaphragm.

The diaphragm is the grand agent in respiration; it has comparatively every thing to do, and it had here more than its usual 
labour, for the horse was out of condition, and had been out of work, and there was much fat about the chest, and the stomach was full. The truth of the matter is, that this muscle was sadly over worked, and then it assumed the kind of action which every other muscle does when completely exhausted, an involuntary spasmodic one.

A little care will clearly ascertain this. The beating is from the chest; but if the ear is applied to the chest the chief sound is not from the heart ; for the beating of the heart can be heard distinct from this. It can be most readily detected at the sternum, a little below and behind the heart; and then, if a line proceeding obliquely upwards and backwards is traced by the ear, the thumping will be heard the loudest in the direction of that line. The beatings of the heart and this thumping motion do not correspond. The heart beats half as quickly again. 'The diaphragm beats violently, the heart feebly. There can be no mistake about the matter, if the person who has the care of the horse will bestow proper aftention. As convulsions usually mark the last efforts of expiring nature-as spasmodic action of the frame generally, or of some parts of it, shows the general exhaustion, so this spasm of the diaphragm is a proof of the perfect exhaustion of the part.

No one would bleed an animal in a state of exhaustion; he wants a stimulant, and not a sedative. Bleeding would be fatal, and many a horse is murdered in this way. The skilful observer would first administer a cordial, and in a fluid form, as thus having the quickest and most powerful effect.

RECIPE (No, 43).

\section{Cordial Drink.}

TAKE-Powdered ginger, a drachm;

Powdered caraways, two drachms;

Tincture of opium, an ounce;

Sweet spirit of nitre, an ounce;

Good warm ale, half a pint.

If in the course of an hour no effect is produced, a cordial ball should be given.

RECIPE (No. 44).

Cordial Ball.

TAKE-Powdered ginger and

Powdered caraways, of each four pounds :

Powdered gentian, one pound;

Palm-oil, four pounds and a half;

Beat the whole together; give from one ounce to one ounce and a half for a dose. 
This mass will form the common cordial ball, but, in spasm of the diaphragm, half a drachm of opium and one drachm of the subcarbonate of ammonia (common smelling-salts) should be reduced to fine powder, and beaten up with the ball; while thin gruel, or white water, warm, should be put before the horse, and of which he should be suffered to drink as much as he pleases.

This will rarely fail of having its effect in rousing the general powers of the system, although it may not immediately reduce the violence of the spasm. But, the powers of the system having been once roused, and especially by a stimulus so energetic, more reaction may be excited than is wished. It may be violent and dangerous; it may run on to inflammation and fever. This, therefore, is to be guarded against, and therefore, now is the time to bleed. Eight or ten pounds of blood should be taken away; plenty of gruel supplied; and the horse left for a while to himself. Bleeding should also be practised in those cases neither attended with, nor proceeding from, exhaustion. In less than four-and-twenty hours all will generally be quiet, and a few tonic diuretics (Recipe, No. 42, p. 110) will alone be required.

The diaphragm has sometimes been ruptured, which may be produced by too sudden and severe exertion of the part. The symptoms are often very obscure, from the different degrees to which the injury may extend, but the most frequent are those of severe broken wind, and occasionally those of colic.

Before the diseases of the alimentary canal are considered, it will be necessary to refer to some of those of the spinal marrow.

\section{CHAPTER XXI.}

TETANUS-LOCKED JAW-EPILEPSY, AND PALSY.

Tetanus is constant spasm of the muscles of voluntary motion, and particularly those of the head, neck, and spine: it is called LOCKED JAw, becanse the nuscles of the jaw are earliest and most strongly affected. It is rarely preceded by any serious illness, although the horse will appear dull and deficient in appetite for a few days before the decided appearance of the disease. The attention of the owner or the groom is at length aroused, and he examines the horse a little more closely. He now finds that the animal gulps his water (he is obliged to produce some forcible action in the muscles of deglutition in order to swallow it); and he 
quids his hay, $i . e$. he partly chews it and then suffers it to drop from his mouth. Possibly the real state of the case is not even yet suspected. The owner may think that the horse has sore-throat, and he may act accordingly, unless he does, what in every affection of the organs of mastication he ought to do, examine the mouth of the animal carefully. The actual extent of danger will then be evident enough; there will be but little motion in the lower jaw, or it will be altogether fixed.

Other symptoms will now be observed, or might, perhaps, have been observed before. There is a stiffness in the neck; the horse is unable to turn his head round to his flank; the whole body must turn together, like a deal board; the muscles of the neck are knotted; the nostrils are dilated to the utmost; the ears are erect; the eye retracted; the haw drawn over it; the countenance of the horse the very picture of despair. The muscles of the extremities, although less affected, are considerably so; the poor animal is conscious of his loss of power over them, and of the torture which the least motion gives him, and he fixes himself as securely as he can, and nothing but absolute force can induce him to move. The fore-legs are wide apart, and inclined forwards; the hind-legs are strangely straddling, and inclined backwards; the tail is erect, and in constant quivering motion. He becomes more and more a fixture; and the jaws are, at length, so firmly clenched, that nothing except a little liquid, and scarcely that, can be got into the mouth.

That this is a disease of extreme suffering to the poor animal there can be no doubt. The human being tells us that his tortures are too great to be borne; and indeed the pain which results from the cramp of one muscle will give some idea of the horrible torture that must attend universal cramp, and that continued, and without intermission, for many days.

The cause of tetanus, or the manner in which that cause acts, is far from being well understood. There has, perhaps, been some slight injury; a nail has been driven tco close, or a piece of glass has cut the foot: sumetimes there has been more serious mischief, - the tail has been docked or nicked; the wound has very nearly healed, and then it has begun all at once to assume an unhealthy appearance; a thin ichorous fluid is discharged from it, and there is a spongy appearance around it. At other times the wound nearly heals-if it has quite healed the patient is secure-and almost at the mornent of closing, and without any seeming unhealthy change of appearance or discharge, this strange nervous affection is observed.

It is a nervous affection. The fibril of some nerve has been injured; irritation and inflammation ensue; they rapidly spread along the various branches of that nerve, and all its anastomoses with others; and as these are innumerable, the morbid irritability is by degrees established over the whole nervous system.

A disease so dreadful and universal requires decided treatment. 
What is most likely to allay such irritation? What is the most powerful sedative in such a case? Bleeding: therefore immediate recourse should be had to the lancet. The blood should flow here, as in other diseases of inflammatory or extensive action, in a free full stream; and it should flow on until the circulation is evidently affected. That will not soon happen, for the irritation is too great and too general readily to yield to any sedative; and more than ten or twelve quarts of blood will sometimes be taken away before the pulse indicates that any effect has been produced on the circulation.

The consequence of this copious depletion will generally be a temporary remission of the symptoms; and, although a temporary, it is a most valuable one. The muscles of the jaw will be sufficiently relaxed to enable a strong purgative ball, or drink to be given. 'This, of course, should always be the second object endeavoured to be accomplished; and if the bleeding did no other good than to relax the spasmodic muscles of the jaw and throat long enough for the administration of physic, it would have been of very material service. The physic should be the strong drink (Recipe No. 10, p. 55). The stomach-pump of Read will much facilitate the administration of medicine to ietanic horses.

Having proceeded thus fur, the disease should be attacked as much as possible locally. It is evidently a nervous affection-an affection of the nerves of the spinal chord; but, unfortunately, of those which proceed from the lower surface of the chord, and which are most out of reach. We must, however, do what we can, and bring the principle of counter-irritation to bear as far as it is practicable. A blister should be applied from the poll to the rump. The common blister ointment (Recipe 27, p. 80) will be as effectual as any. Some practitioners, and with very good effect, have carried the principle of counter-irritation a great deal further-they have blistered almost the whole of the sides and the belly. They have by this means excited such extensive inflammation of the skin, that, on the undoubted principle that no two perfectly distinct and violent inflammations can exist in the frame at the same time, the original affection of the spinal chord has subsided and disappeared. Setons also have been inserted along the course of the spine, with the view of causing the blister to act under the skin, and nearer the seat of disease; but they have rarely been productive of decided good effect. In order to produce more determination of blood to the skin, and thus relieve the spinal inflammation, sheep-skins should be placed on the horse's back, applied warm from the animal, reaching from the poll to the tail, and changed as often as they become offiensive.

Another way of treating the disease locally is, to find out, if possible, the wound or injured part from the irritation of the nerves of which the mischief has proceeded. Some nervous fibril may be compressed there;-a few deep incisions across the wound will liberate it. A morbid action going forward in the wound may pro- 
duce this sad affection of the nerve; - the cautery, or the caustic, will produce a healthy surface, and the irritation may cense. If the disease is from docking, another of the caudal vertebræ should be removed; if from nicking, the incision should be made deeper.

In some cases there may not appear to have been any local injury; but exposure to cold, the dripping of water on the back, indigestible food, or various diseases, may have produced it: then general means alone can be adopted.

The physic having beyun to work, or having been repeated until its effect is produced, the practitioner will next look around him for some sedative medicine in order to allay the dreadful excitation of the nervous system. Opium is the sheet-anchor here; and in conjunction with camphor it is almost uniformly beneficial. 'Two drachms of opium should be given as a first dose, with one drachm of camphor; and a drachm of opium with half the quantity of cam. phor should afterwards be given four times in the day. The medicine may be given as a drink by means of the pump; or, if the jaw is not quite fixed, a small ball, or successive portions of a ball, may be delivered in the back part of the mouth, by means of a pointed stick.

As for food-the horse is not able to take any solid nourishment, but he may have a mash more than usually wet in his manger, and a bucket of gruel may be slung in some part of the box, from either or both of which he may, perhaps, contrive to extract a little nourishment. Should it be possible to insert a small horn or the neck of a small bottle between his tushes and his grinders, almost any quantity of gruel may be given him, for the appetite of a tetanic horse rarely fails him, although he may be unable to eat; and when he is in a manner starved, it is interesting to see how eagerly the poor fellow will take what is attempted to be given to him in this way. The dreadful cramp of the muscles of his neck should not, however, be forgotten; and the gruel should be given to him as gently as possible, and without elevating his head more than is absolutely necessary. Frequent injections of arrow-root or gruel may also be thrown up.

While this is going forward the bowels must be kept in a relaxed state, and doses of aloes given occasionally in order to accomplish this purpose.

Nothing more than this can be done; and the use of these means must be persevered in day after day, and week after week. It occasionally happens that the horse does not begin to amend until ten or twelve days have elapsed; and in one case that occurred in the practice of the editor of this work, a month passed without more than an occasional remission of the symptoms, and that to a very slight degree. The treatment was nevertheless persevered in, and the animal perfectly recovered.

When the horse does begin to get better, not a particle of medicine should be afterwards administered. By giving tonic medicines 
much dangerous excitation may be produced. The best tonic is nourishing food, and even that should be supplied with caution. Green meat would be useful, but the animal must not be exposed to too much cold. If the weather, however, will admit of it, a run of two or three hours every day on good pasture will be of essential benefit. It will not only sooner bring him to the use of his limbs, but the grass will be an alterative and a tonic.

\section{EPILEPSY.}

Horses are not often subject to fits, any further than megrims and stornach-staggers may eomewhat loosely and improperly rank under this head: megrims and staggers, however, clearly arise from undue determination of blood to the head; epilepsy may proceed from some source of nervous irritation unconnected with any unusual flow of blood to the brain. Colts are now and then subject to' true epilepsy; full-grown horses are more rarely attacked by it.

There is no warning of the attack. The animal may be in the field or at home, at work or standing idle, when all at once he looks round him in a strangely frightened manner; he trembles, and falls; convulsions follow, sometimes slight, at other times, horrible enough; every part of the face is particularly convulsedthe person who has seen a horse in a fit will never forget this. The fit, however, soon passes over; the animal lies still for a moment, then gets up, looks unconsciously about him, and in a minute or two comes quite to himself, and begins to eat as if nothing had occurred.

Fits are very bad things, for the habit of having them is soon formed, and is very seldom or never broken. The cause can rarely be discovered, and still more rarely removed; and the best thing to be done is to get rid of the animal as quickly as possible.

\section{PALSY.}

The horse is seldom or never subject to that kind of palsy which oftenest attacks the human being, palsy of one side; nor has he often general palsy: When it does occur it is usually of the hinder limbs. It may be the consequence of disease. Much stiffness of gait always accompanies inflammation of the kidneys, and sometimes degenerates into palsy. It has been the consequence of inflammation of the bowels, - severe purging,-exposure to cold,poisons; but it is oftener the result of injuries of the spine, caused by accident or brutality. Falls in rapid action, and more particularly in leaping; awkward casting, or violent struggles after casting; blows on the back or loins; a heavy rider urging a small or weak horse too far or too fast; -all these are causes of palsy.

If palsy is the result of previous disease it will sometimes disappear when its cause is removed. If it does not, warm clothing, and the application of stimulating liniments, as the mustard poul- 
tice, or the common liquid blister (Recipe No. 31, p. 83), must be resorted to.

\section{RECIPE (No. 45).}

\section{The Mustard Poultice.}

$\mathrm{T}_{\mathrm{AKE}}$-Of mustard-flour and linseed-meal equal parts, and mix them together with a sufficient quantity of boiling vinegar.

This is one of the most powerfully stimulating applications that can be used, and it is perfectly safe.

When palsy is the result of accident or violence, the horse should be bled and physicked, and the back or loins well fomented with hot water several times in a day, for two or three days; after which the mustard poultice or liquid blister should be applied. Slight contusions on the spine, or sprain of any of its joints, may be thus relieved; but if there is dislocation or fracture, the sooner the poor anirnal is put out of its torture the better.

There are very few hardly-worked draught horses that have not, to a greater or less degree, evident stiffness of action; and it is scarcely credible to what an extent the spine will appear to have suffered, on examination after death. Ancliylosis, or loss of motion in the joints, has extended along almost the whole of the back and loins. A very common and unsuspected cause of this is the narrow stalls of some crowded or ill-built stables. 'The horse is often compelled to bend himself into a half-circle in order to turn. The ligaments of some of the joints of the spine must be stretched and sprained by this, and especially when the animal is too frequently forced to bustle round as quickly as he can at the command of a brutal servant. This injury may appear to be slight and temporary, but the repetition of it causes inflammation of the ligaments of the spine, and a conversion of them into bony matter; then, a degree of palsy that interferes much with the action and usefulness of the animal, and that can never be removed, is the result.

\section{CHAPTER XXII.}

\section{INFLAMMATION OF THE STOMACH-POISONS-BOTS-WORMS.}

The stomach of the horse is very small compared with the bulk of the animal. Nature designed this, in order that its weight might not rest too oppressively on the diaptragm, and interfere with the action of that important respiratory muscle, and especially in rapid exercise. 
The stomach is not only small, but it is singularly constructed. Nearly one-half of it is covered with insensible cuticle, and the food remains but a short time in the other villous and more sensitive and true digestive part; therefore it is comparatively little subject to inflammation: nor are the distinguishing symptoms of inflammation of the stomach well understood.

The stomach, however, occasionally becomes inflamed by the administration of poison or improper drugs. The mosi common vegetable poison is the yew. The horse will rarely eat it when green; but the half-dried clippings of the yew-tree are.now and then picked up. It will be well to remember this distinction when any case of supposed poisoning by yew occurs. The horse may often graze without danger, although there are yew trees about, or although the field may be surrounded by a yew-hedge. Natural instinct will teach him to avoid that which would be injurious; but when the clippings are dried, and the appearance, and smell, and taste of the yew considerably change, danger results.

The principal symptom of this kind of poisoning is a strange kind of drowsiness. The horse stands, propped up by a gate or wall, with his head hanging down almost to the ground, and he is regardless or unconscious of every thing around him. At other times he lies down, breathing loudly and hardly, and is with difficulty roused to momentary attention, while it is almost impossible to make him rise. In this way he sleeps or dozes on, until slight convulsions occur, and he presently dies; or else he sleeps himself away without consciousness or pain.

The nature of the poison having been understood, Read's stomachpump is to be had recourse to, and plenty of water thrown into the stomach until the animal is induced to vomit; or, if the act of vomiting, which is always excited with difficulty, cannot be induced, the fluid may be readily drawn out again, and fresh water injected until the stomach is well washed out. Then the following drink should be given:-

RECIPE (No, 46).

\section{Drink for Poisoning by Yew.}

TAKE-Strang physic drink (Recipe No. 10, p. 55), four ounces, with the farina of the croton-nut. Add,

\section{Vinegar, four ounces;}

Thick gruel, four ounces.

After the first dose the vinegar and warm water, with two ounces of the strong physic drink, but without the cruton, should be given every six hours, until purging is produced; and, after purging has commenced, two ounces of vinegar, with an equal quantity of warm water, should be administered every two hours.

The Mayweed (a species of wild camomile, Anthemis cotula) 
has sometimes, like the yew, caused violent illness and death. This is seldom eaten when found green in the field; but when mingling in its dried state, and in too great quantity, with the hay, it has done mischief. The stomach-pump should here also be immediately resorted to, with the gruel and vinegar; and, if costiveness follows, twelve ounces of linseed-oil should be given every six hours, until purging is produced. The oil may be mixed with the yolk of an egg, and a few drops of oil of aniseed added.

The Water Parsley has sometimes produced palsy, and the Water Dropwort has poisoned brood mares, who have taken it under the influence of that capricious appetite which all animals occasionally display during the period of pregnancy. The stomach-pump should here also be used, followed by bleeding, and the administration of vinegar and thin gruel.

If horses are destroyed by the mineral poisons, it is generally to be attributed either to design or unskilful treatment. All of the mineral poisons, in certain doses, are usetul in many diseases; in fact, they sometimes constitute almost the only means of cure: but the dose being too large, or the use of the drug too long persisted in, the animal may be destroyed instead of the disease.

It is fortunate for the horse that Arsficic is not so frequently resorted to, as an internal medicine, as it once was. It was always a dangerous tonic, and especially after acute disease. Many a horse that would have gradually recovered from strangles, epidemic catarrh, or inflammation of the lungs, has been lost by the practitioner being in too great a hurry to get him well, and administering arsenic. In cases of worms it has too often been given with fatal effect. It may be used with less danger as an external application. It has been applied largely in cankered feet, and many cases of ulcers; but it has occasionally done mischief here, and there are mariy safer and better caustics.

The symptoms of poisoning by arsenic are, the evident expressions of intense pain: the haggard countenance of the horse; the eager gaze at the flanks; the pawing and rolling; while the saliva runs from the mouth, and the purging is profuse, and sometimes bloody.

The case may not always be quite so plain, or the owner may wish to ascertain the truth or falsehood of some horrible suspicion. The presence of arsenic is then very easily detected. Some of the more fluid contents of the cæcum should be boiled in a glass or china vessel, and filtered through blotting-paper. A weak solution of blue vitriol, to which a few drops of hartshorn have been added, should then be poured into the clear liquor, and the presence of the arsenic will be detected by the fluid immediately, or after a little standing, assuming a green colour. A portion of the more solid contents of the intestines may be put on a plate of red-hot iron, and if there is any arsenic, a strong smell, resembling that of garlic, will be perceived. 
The treatment will rarely be successful. The poison will too frequently have done its work when the symptoms become sufficiently urgent to be recognised. Read's pump should be put into immediate requisition; and after the stomach has been well washed out, plenty of lime-water, or of chalk and water, should be injected, in order to convert the oxide into a less destructive carbonate.

Poisoning from Corrosive Sublimate is usually the result of unskilful treatment. Lotions of it are employed for the cure of mange, or the destruction of vermin, although, unfortunately, it is much more easily absorbed than the arsenic. Sometimes, also, the animal may lick off a fatal portion of the drug.

The symptoms are nearly the same as those from poisoning by arsenic. The test will be lime-water, which will change the slightest solution of corrosive sublımate to an orange colour. The remedy will consist of the whites of eggs mixed with starch or gruel.

\section{WORMS.}

Bots are the larvæ or maggots of a species of gadfly (the Qustrus equi), which deposits its eggs on those parts of the horse that the animal is most apt to lick. The egg is immediately hatched by the warmth and moisture of the tongue; the little worm adheres to the tongue, and is conveyed into the month; and thence it crawls down the œsophagus into the stomach. It adheres to the cuticular coat of the stomach, by means of little hooks, with which its mouth is furnished; and there it remains from the summer of one year to the spring of the next, nourished by the mucus of the stomach, or the food which it contains. Then, having attained its full size as a maggot, it loosens its hold, and is carried along the intestines with the other contents of the stomach, and evacuated with the fæeces. Before it drops, it generally clings for a while to the verge of the anus; while doing this it tickles and teases the horse, and that sometimes to a very great degree. When the groom sees the bot under the tail, he is alarmed, and thinks that it must be doing a great deal of mischief, and he hastens to give strong and injurious purgatives, in order to get rid of the evil.

Bots, except they exist in most unusual numbers, do neither good nor harm during their residence in the stomach of the horse. It is the habitation which nature assigned to them; and the safety of so noble an animal as the horse would not have been compromised for the sake of a maggot and a fly. The advice, therefore, to the owner and the groom would be-let thetn alone; or, at most, to be content with picking them off when they appear under the tail. There are two good reasons for this: the first is, that there is not any medicine that will expel them: the strongest and even the most dangerous purgative is insufficient. The horse may be injured or destroyed by the violent measures adopted; but the bot sets 
the practitioner at defiance. The second reason is, that, if the bots are let alone, they will, in due time, come all away without our help or meddling. At the latter end of the spring the larva detaches itself from the stomach, is carried along the intestines, drops on the ground, burrows into it, and becomes a chrysalis or grub. In a few weeks it undergoes another and more wonderful transformation: it awakes from its state of sleep, bursts through its horny shell, and assumes the form of a fly.

There are, however, Worms in the intestines which are injurious to the horse, yet seldom to the extent which the groom fears. The small intestines contain a round white worm, from six to twelve or fourteen inches in length. This worm (the Lumbricus teres) very much resembles the common earth-worm, and it lives either upon the mucus of the bowels, or the chyle, or the nutritive part of the food. A strong dose of physic will often expel an almost incredible number from a horse that was apparently in perfect health: therefore, the appearance of one or two should never cause alarm.

It is however probable that, when the intestines are in a manner full of them, they may take away too much of the nutriment of the food, and may also irritate the coats of the intestines. The proof of the existence of this injurious quantity of worms will be the unthrifty appearance of the horse; the tucked-up belly; the staring coat; a ravenous appetite; or a harsh hollow cough.

Even now it will not be necessary to have recourse to any violent measures. No strong mercurial physic, which endangers or half kills the horse, is needed. The following ball will usually be effectual, and cannot possibly do harm:-

RECIPE (No. 47)。

\section{Worm Ball, for Long Round Worm.}

TAKE-Emetic tartar, two drachms;

Powdered ginger, half a drachm;

Tin-filings, six drachms;

Linseed-meal, one drachm; Make into a ball with palm-oil.

One of these balls should be given every morning, half an hour before the first feed; and, after six or eight of them have been taken, the horse should have a dose of common physic, if he can be spared from his work: but the physic, however, is not necessary in the majority of cases:

A quart of linseed-oil is the best purgative in cases of worms.

The owner should not be dissatisfied if only a few worms are voided. They are usually destroyed within the intestines by the emetic tartar, and digested there. The best proof of the medicine having been effectual will be that the worms cease to appear, and the horse improves in condition. 
Another lkind of worm (the AsCarines) inhabits the larger intestines, and particularly the last of them,- the rectum. It is a little worm, $t$ wo or three inches in length, and not much larger than small twine; but it often exists in very large quantities. It is rarely dangerous; but it is occasionally sadly annoying, for it causes great irritation and itching in the lower intestines, and about the anus, and sometimes this irritation has produced extensive inflammation.

The strongest physic, as it is usually administered, will seldom expel the ascarides. They must be attacked in their stronghold,their very residence.

RECIPE (No. 48).

Injection for Ascarides.

TAKE-Powdered aloes, half an ounce;

Powdered gum arabic, half an ounce;

Pour on them half a pint of boiling water; shake the mixture well until the aloes are dissolved or suspended; then take

Linseed-oil, one quart; and

The white of an egg :

Rub them well together until they are thoroughly incorporated; and gradually add the solution of aloes, stirring the oil as the aloes are added.

Let this be injected into the rectum, twice in the week, as long as any ascarides are voided with the injection.

There is another slender worm which somewhat resembles the ascarides, though rather longer and larger: it is called the StronGyuUs, and when voided its body is dark.

In the treatment of them, as well as other kinds, due regard should be paid to the general health. Powerful medicines should not be given when there is great poverty and debility, but vegetable tonics should be first employed to amend the condition of the animal. 


\section{CHAPTER XXIII.}

\section{INFLAMMATION OF THE BOWELS-SPASMODIC COLIC-FLATULENT} COLIC-STRANGULATION-CALCULI IN THE INTESTINES.

Or inflammation of the bowels there are two kinds, - that of the external and the internal coat.

\section{ENTERITIS; INFLAMMATION OF THE FIXTERNAL AND MUSCULAR} COATS OF THE BOWELS.

This is a very frequent and fatal disease, and is recognised by the farrier under the name of the red colic. It is caused by the application of cold to the belly of the horse, either by taking him into the water, or washing him about the belly with cold water, or suffering him to drink plentifully of it when he is heated. Exposure to rain, over-exertion on a full stomach, and especially after the horse has been fed on dry, stimulating food; also the previous existence of inflammation of the lungs, are very usual causes; but the disease will sometimes occur without any assignable cause. From whatever cause it arises, it runs its course with fearful rapidity. Like pneumonia, it sometimes destroys the horse in less than twenty-four hours, and occasionally in less than twelve.

The symptoms of enteritis should be carefully studied, for many a horse will be lost when they are not early recognised. One of the earliest symptoms is the expression of very acute pain. The animal paws; strikes at, although he does not touch his belly; looks at his flanks with a more sudden turn, and a wilder gaze, than in inflammation of the lungs; rolls; struggles violently; lies upon his back; groans; the legs are cold; the mouth not hot, and sometimes clammy cold; the membrane of the nose very little reddened, sometimes paler than the natural hue; the flanks heave violently; the horse shivers and sweats; the pulse is quick and hard, yet often scarcely to be detected; and the belly is hot, and exceedingly tender. 'The violence of the symptoms, however, soon begins to abate, and the horse soon becomes weak and scarcely able to stand.

This disease may be distinguished from colic by the pain, though less violent, continuing without remission; also by the quickness of the pulse, coldness of the extremities, and high colour of the eyelids and nostrils.

The treatment is plain enough. The patient must be bled promptly and copiously; the stream must flow until fainting nearly or quite succeeds. This is another of those diseases in which there is a golden moment that must not be suffered to escape. In the 
early stage the horse will bear that kind of bleeding which is necessary to subdue an inflammation so intense; but, twelve hours having passed, the strength of the animal will be exhausted, and copious bleeding will not be practicable; or, if it were, it would not be safe.

The next thought should be about some local application. Strong physic is out of the question; the bowels are already too irritable; it would be adding fuel to fire: but mild aperients may be administered. Linseed oil, however, is the only aperient that can be ventured on. A pint may be given where costiveness is present, and with it the following :-

\section{RECIPE (No. 49).}

TAKE-Powdered opium, two scruples;

Sweet spirit of nitre, six drachms;

Warm water, four ounces.

This medicine may be repeated every six hours with half a pint of the oil, which, however, should generally be discontinued after a quart has been administered, whilst the opium, \&c., may be continued longer. Frequent injections should be thrown up.

Next comes the important principle of counter-irritation. The whole of the belly should be stimulated either with the strong Jiquid blister (Recipe No. 30, p. 82), or spirit of turpentine; and these appliances should be as hardly and thoroughly rubbed in as the tender state of the belly will allow. Hot fomentations, or the application of steam to the abdomen, should also be employed, and in desperate cases it has even been fired with good effect. The horse, at the same time, should be warmly clothed, and his legs bandaged; for these may cause some determination of blood to the skin and the extremities, and, in that proportion, relieve the inflamed part.

The horse should by no means be removed from his stall or box, and exercise of every kind should be carefully avoided.

The food should consist of mashes and thin gruel, except green meat can be procured, which may be given in moderate quantities. It should be perfectly evident that the disease is subdued before any hay or corn is allowed; and, even then, the horse should very slowly return to the use of hard meat. If, when he is getting convalescent, the weather will admit his being turned out during the day, it may be of considerable advantage to him.

\section{INFLAMMATION OF THE MUCOUS COAT OF THE BOWELS.}

This is usually the consequence of physic, either of bad quality, or given in an over-dose, or under circumstances which shonld have warned the prastitioner of an irritable state of the bowels, and the consequent danger of physic. If physic has not been given, yet the 
horse may have been ridden or driven far and fast, with nothing but green meat in his belly; or, and oftener than is generally imagined, inflammation of the lungs, or the feet, or the head, may have quitted its primary situation, and have attacked the mucous membrane of the intestines. Being inflammation of the internal coat, the numerous open vessels which secrete the mucus or the other fluids that are formed in the intestinal canal share in the irritation, and pour out an increased quantity of fluid; and purging ensues. This disease can hardly be confounded with the foregoing. The pulse, although small, is not so much so as in enteritis, nor is it so hard or wiry. The muzzle and extremities are not so cold; sometimes they are warm. The horse shows that he suffers intense pain; he looks anxiously round at his flanks; he is continually shifting his position; he lies down, and immediately rises again; but he does not roll so violently, nor does he kick so desperately, nor is there any heat or much tenderness of the belly. At the same time he is purging instead of exhibiting the obstinate costiveness which generally accompanies enteritis.

Thousands of horses are destroyed every year by over-physicking; for the purging, once running on to the production of any considerable degree of inflammation of the mucous membrane, can seldom be effectually stopped, nor indeed would it be prudent to attempt to stop it at once. The first inquiry should be as to the length of time that the purging has existed; the degree of pain that the animal has evinced; and the nature and quantity of the discharge. If not more than iwenty-four or thirty-six hours have elapsed since the physic began to work; if the dejections are very foetid, or simply water, without much mucus, even although the discharge should be abundant and frequent, it will not be quite prudent to attempt immediately to arrest it; and especially if there is no great heat of the mouth. Plenty of tolerably thick gruel or starch should be horned down; and the practitioner should for a little while await the issue. The starch will possibly sheathe the coats of the stomach from the effect either of some portion of the physic, or the acrimony of the secretion; and the purging gradually stop. If, however, eight-and-forty hours have passed, and the discharge continues as abundant as ever; or, although it may have decreased in quantity, and even have become thicker, $j$ is voided with pain, and mingled with much slime; and the mouth is hot, and the countenance anxious, and the flanks heave, and the pulse is much accelerated, prompt measures inust be adopted. 'The heated mouth, and the heaving flank, and the quick pulse, will indicate bleeding, notwithstanding any continuance or profuseness of fæcal discharge. There is irritation of the mucous membrane, which must be subdued, the very discharge of which is aggravating. Moderate bleeding, carefully watched, and stopped when the pulse falters, will often be of very great service. The gruel, or starcb, must be given thicker, and in greater quantity; and 
astringent medicine must now be administered. Nothing better can be given than the drink recommended in Recipe No. 25 (p. 77). It should be administered every two hours, until the purging begins to abate, or the painful symptoms are a little relieved, and then twice only, or even once in the day, and discontinued as soon as the case will admit of it.

In this species of inflammation, as well as in the last, warm clothing, and bandages about the legs, will be of essential service, and the horse should be kept as quiet as possible.

When the fæces are accompanied with much slime, the disease is termed Dysentery, and is also sometimes designated molten grease. This slime, or mucus, is secreted by the internal coat of the bowels, which is in a state of inflammation, and not unfrequently the bowels are constipated.

This disease, like diarrhcea, may be brought on by cold applied to the surface, by over-exertion and unwholesome food.

The treatment should consist of moderate bleeding, oily laxatives, fever medicine, and stimulants to the abdomen, and frequent injections, which may be followed by small doses of opium, and, if the liver is affected, combined with calomel; a drachm of the latter being given with a half a drachm of the former once a day.

\section{SPASMODIC COLIC.}

This is a very frequent disease, and no horses are more exposed to it than those belonging to farmers. If it is timely attended to, little danger appears to accompany it; and almost every groom has a supposed specific for it, and one that is often successful. The chief object is to know the disease when it occurs, and not to confound it with inflammation of the bowels, especially that of the external coats, and which requires very different treatment. The circumstances by which the one may be distinguished from the other can be ascertained after one or two cases have been carefully observed. In both there is pain, stamping. looking at the Hanks, and rolling; but in inflammation of the bowels the pain is constant; in colic there are moments of remission. In the first, although the horse stamps violently, he takes great care that he does not touch his tender belly; in the second disease he often strikes his belly desperately with his hind feet. In the first, the belly is hot and tender, and pressure on it gives pain; in the other, there is neither heat nor tenderness, and moderate pressure, and particularly friction, evidently gives ease. In inflammation of the bowels, the pulse is, from the beginning, small, wiry, and quick, and the mouth is first hot, and then clammy, or deathy-cold; in colic the pulse is not always affected at first, although, after a while, it quickens, but it becomes quicker and harder as the spasm is gradually degenerating into inflammation; and the mocth, at first of its natural temperature, acquires heat by degrees. There are usually some 
premonitory symptoms-as dulness, depression, loss of appetitebelonging to an attack of inflammation : colic often comes on suddenly, and without any warning at all. Motion sadly aggravates the pain of inflammation: a horse with colic becomes a little easier if he is walked about.

The history of the case should also be inquired into. If the horee, previously in perfect health, has, when heated, had access to cold water, or been exposed to a cold wind; or if he has been exercised violently on green meat, either colic or inflammation of the bowels may be the result; but if the symptoms follow a little feverishness, and sluggishness at work, and want of appetite for a few previous days, it is most probable that inflammation exists.

The following drink should be given, in a half-pint of warm ale or water :-

\section{RECIPE (No. 50).}

\section{Colic Drink.}

TAKE-Spirit of turpentine, two ounces; Spirit of nitrous ether, one ounce; Laudanum, one ounce.-Mix.

If almost immediate relief is not obtained, it will be better to bleed, rather freely, as this is not only calculaled to prevent inflammation, but also materially assists in lessening the spasm.

If, in half an hour, or an hour, relief is not obtained, the draught should be repeated without the turpentine, or with only half the quantity. If, at first, there is any doubt as to the presence of inflammation, the turpentine should be dispensed with, the nitrous ether being increased, or half an ounce of sulphuric ether added. The abdomen should be well rubbed or fomented.

After the second drink has been given without relief, it will be proper to add an aperient to the stimulant: accordingly half an ounce of Barbadoes aloes should be dissolved and given with a pint of linseed oil, and the stimulant before advised; but if inflammation is threatened, the aloes may be omitted, and the oil doubled. Injections should be thrown up frequently, and the abdomen should be fomented with hot, or if there is much inflammation, with boiling water, and the other directions, given under the head Enteritis, should be followed.

A horse recovering from a fit of spasmodic colic should have his water a little warmed for several successive days.

In stercoral colic which proceeds from a collection of food in the bowels, and is attended with a cessation of the discharge of the frecs after a few emissions, the symptoms are not so violent, though longer continued and more dangerous.

Bleeding should be employed freely, and repeated to keep inflam- 
mation down; clysters should be frequently thrown up: large doses of oil given every six hours, the pain being subdued by laudanum or opium.

\section{FLATULENT COLIC.}

This species of colic, although essentially different from the spasmodic, both in its nature and treatment, is scarcely recognisable from it in the early stage of the disease. The one is a spasmodic constriction of the bowels; the other is distension of the bowels from the extrication of gas. There is the same uneasiness, pawing, rolling, with little change in the pnlse or the temperature of the extrernities; but in flatulent colic the distension of the stomach or bowels, or both, soon causes an evident enlargement of the abdomen, while at the same time there is greater discharge of flatus per anum.

'The drink for colic (Recipe No. 50, p. 130) should be first administered, substituting, however, half an ounce of sulphuric ether for an ounce of the turpentine; but if this does not give relief in the course of an hour or two, the friction of the belly, and the walking or trotting of the horse, would endanger a rupture of the intestines; and this has sometimes occurred when the distension has been very great.

Two methods of treatment have been surgested, founded upon the means used to remove the honve in cattle. The first is to puncture the cœecum, as the rumen of the cow is sometimes punctured. This might answer in the hands of a skilful veterinary surgeon, but no other should attempt the operation. It is often performed by the French veterinarians, and has been lately introduced by some Scottish practitioners. This dangerous operation, however, should only be employed as a last resource.

Chemistry, however, has discovered a safer and far more efficacious mode of cure. It has been ascertained that the gas by which the bowels are distended is one of the compounds of hydrogen, either the sulphuretted or the carburetted. Chlorine has a very strong affinity for hydrogen, and rapidly unites with it, and forms a well-known fluid that does not occupy a thousandth part of the space: therefore a combination of chlorine with some alkali is exhibited, and that which is most easily met with is the chloride of lime. Half an ounce of the powiler is given dissolved in a quart of water. The chlorine quits the lime, and unites with the hydrogen of the bowels, and forms muriatic acid, and the intestines are suddenly relieved from their distension; and then the muriatic acid thus formed unites with the lime which was liberated, and the harmless muriate of lime is produced. The dose may be repeated with perfect safety in half an hour should not the first appear to have its full effect. In other respects the treatment of this disease must pretty much resemble that before described. 
STRANGULA'TION AND INTROSUSCEPTION OF THE INTESTINE.

When spasmodic colic does not readily yield to the means employed, either inflammation of the bowels is at hand, or strangulation-twisting or tying of them-so as to cause an insuperable obstruction to the passage of the fæces, has taken place. Occasionally, however, the spasmodic action, being long-continued, may produce, or may change into, a motion contrary to the natural one of the bowels; and then one portion of the gut is apt to enter into and be confined in a neighbouring portion, and thus also an insuperable obstruction is formed. No good can be done here; and we can only guess at the existence of these things by the obstinate costiveness of the horse, by the continuance and increase of the pain, and these circumstances not being attended by the expected degree of fever.

[A table, distinguishing between colic or gripes and inflammation of the bowels of horses, by the symptoms that mark the character of each.

\section{Spasmodic or Flatulent Colic.}

1. Pulse natural, though sometimes a little lower. (1.)

2. The horse lies down and rolls upon his back.

3. The legs and ears generally warm.

4. Attacks suddenly, is never preceded, and seldom accompanied, by any symptoms of fever.

5. There are frequently short intermissions.
Inflammation of the Bowels.

1. Pulse very quick and small. (2.)

2. He lies down and suddenly rises up again, seldom rolling upon his back. cold.

3. Legs and ears generally

4. In general, attacks gradually, is commonly preceded, and always accompanied, by symptoms of fever.

5. No intermissions can be observed.

(1.) Pulse natural.-When in health, the pulsations or strokes are from thirty-six to forty in a minute; those of largुe heavy horses being slower than those of the smaller; and those of the old ones, slower than those of young animals. When either are just off a quick pace, the strokes increase in number, as they do if he be alarmed or animated by the familiar cry of the hounds.

(2.) Pulse very quick and small.-Fever, if the simple or common kind, usually increases the pulsations to double the healthy number. As the fever increases in violence, and particularly in cases of inflammation of the bowels, the pulse beats still higher, and reaches to a hundred in a minute, or more. 'To ascertain either state, the attendant should apply the points of his fingers gently to 
the artery which lies nearest the surface. Some prefer consulting the temporal artery, which is situated about an inch and a half backward from the corner of the eye. Others again, and they are the greater number, think it best to feel it underneath the edge of the jaw-bone, where the facial artery passes on under the skin only to the side of the face. In either case, too great pressure would stop the pulsation altogether; though by so irying the artery against the jaw-bone, will prove whether it be in such a rigid state of excitement as attends high fever; or elastic and springy, slipping readily from under the finger, as it does when health prevails, and the strokes follow each other regularly. The presence of high fever is further indicated by a kind of twang, or vibration given by the pulse against the finger-points resembling much such as would be felt were we to take hold of a distended whip-cord or wire between the fingers and cause it to vibrate like a fiddle-string, sharply. Whereas, in health, a swell is felt in the vibration, as if the string were made of soft materials and less straitened. Languid or slow pulse, and scarcely perceptible in some of the beats or strokes, indicates lowness of spirits, debility, or being used-up; if this languor be felt at intervals only, a few strokes being very quick, and then again a few very slow, this indicates low fever, in which bleeding would do harm, \&c.]

\section{CALCULI IN THE BOWELS.}

In some horses, and particularly in those that work in dusty mills, these are not unfrequent. Some little portion of stone, or oftener of iron, is swallowed, and becomes entarigled in the cells of either the cœcum or colon; particles of half-digested food, or earthy matter, begin gradually to surround it, layer over layer, until the stone sometimes attains an almost incredible size and weight. In some instances these have been found after death when the horse had seemed to enjoy perfect health; at other times he has been occasionally off his feed, or appears to have had slight, or even severe, colicky pains, and has been unwilling to attempt, and indeed has been almost incapable of, rapid action. If the presence of these calculi could be ascertained, there are yet no safe means by which they could be got rid of. 
CHAPTER XXIV.

\section{INFLAMMATION AND OTHER DISEASES OF THE KIDNEXS AND BLADDER.}

THe kidneys are actively employed in separating and carrying away the watery parts of the blood, and also a peculiar principle, the urea, which, if it were suffered to remain and accumulate in the circulation, would prove poisonous. The practitioner is sometimes anxious to separate as much as he can the watery portion of the blood, because, by thus lessening the quantity of the circulating fluid, he lessens the labour of the heart, and also the proportion of blood which would be forced through parts in a state of inflammation, and consequently overloaded and oppressed: also, by diminish. ing the natural quantity of blood in circulation, he rouses the absorbents to take up certain dropsical collections or portions of fluid effused in different parts of the frame. Therefore it is that in all cases of inflammation he adds diuretics to his sedative medicines: and places his principal reliance upon them in all effusions of fluid into the cellular membrane, as anasarca, or swelled legs; and in all collections in cavities, as dropsy of the chest or abdomen.

Experience, however, proves that every organ overworked is subject to disease; and as few organs are more overworked and abused in common stable management than the kidneys, there are few that are more frequently injured. If the kidney is too much irritated by the improper use of diuretics, or of any lisind of food that stimulates the urinary organs, one frequent consequence is

\section{DIABETES, OR PROFUSE STALING.}

This is an annoying and a very weakening complaint; and the horse affected with it cannot endure much hard work: it indicates weakness of the part, and leads to weakness of the frame generally. Diabetes is founded on, and connected with, inflammation; and, therefore, the first indication of cure is to abate that intlammation. This is attempted to be accomplished by bleeding; and which is particularly called for when the profuse staling is accompanied by any tenderness or heat across the loins. The bleedine, however, must not be profuse, lest, by producing some degree of general weakness, the weakness of the kidneys should also be increased.

Next, the current of blood, which now unduly flows to the kidneys, must be diverted into another channel, and therefore a dose of physic is properly given. When the blood is thus determined to the bowels, the overworked vessels of the kidneys will have comparative rest, and may recover their natural tone.

Should neither bleeding nor physic have effect, recourse must be 
had to astringents, and particularly to those which seem to have power over the excretory vessels generally; and at the head of these stands the catechu.

\section{RECIPE (No. 51).}

\section{Ball for profuse Staling.}

TAKE-Catechu, two drachms;

Opium, half a drachm;

Linseed-meal, two drachms;

Make them into a ball with treacle.

One of these should be given morning and night. If such astringent drugs should confine the bowels, this injurious effect may be prevented by adding a drachm of aloes to each ball. At the same time, the dry food must be very carefully examined, and green meat daily given if the time of the year will allow of it.

\section{DIFFICULTY OF STALING.}

This is another and an opposite consequence of bad food, or the tampering with diuretic medicines, and is far more dangerous than the other. The horse strains very much in attempting to void his urine; the effort is evidently attended with a great deal of pain; and, after all, he is able to evacuate only a small quantity at a time. The groom, little thinking that this is owing to the closing of the excretory vessels, either from spasm, or swelling of the surrounding substance, both of which are the consequence of inflammation, gives a diuretic ball to overcome the stoppage. He does overcome it, for he determines a quantity of fluid to the part which no obstacle can resist; but he does this at the hazard or the certainty of producing greater inflammation and permanent injury.

A few mashes, a little green meat, plenty of gruel or linseed-tea, or, if these fail, a mild dose of physic, or possibly the abstraction of a little blood, will generally set all right.

\section{INFLAMMATION OF THE KIDNEYS.}

This is a very serious disorder, and not unfrequently a fatal one, because it attacks a part already in too many cases injured by previous absurd treatment. Inflammation of the kidneys can scarcely be mistaken by an observant practitioner. There is considerable fever, even more so than when other organs of greater bulk are affected. This is clearly indicated by the heat of the mouth, the heaving of the flanks, and the acceleration of the pulse. The feeling of very acute pain is plainly shown by the frequent stead-. fast gaze at the affected part; and that part is marked out by the direction of the muzzle to the loins more than to the belly. There is disinclination to move, because the inflammation rapidly spreads 
from the kidneys to the muscles of the loins, and the least motion of them will give intense pain. In order that there shall be as little stress as possible upon these muscles, the hind legs are straddled very curiously and widely apart. It is the position of the horse with tetanus, so far as the hind extremities are concerned, and for the same reason,-in order to make the legs perfectly fixed points. This disinclination to move, or rather the inability to move without acute pain, assumes, in bad cases, the form of palsy of the hinder extremities, and occasionally runs on to actual palsy. It seems to shift from side to side, and from leg to leg, in proportion as the inflammation shifts from one kidney to the other. If the hand is now placed on the loins, an unnatural warmth is felt, and the horse shrinks and crouches under the slightest pressure.

The urine, which from the beginning was voided with some difficulty, escapes in smaller and smaller quantities, and the discharge of it is accompanied by increasing pain. It becomes highcoloured, perhaps bloody. It diminishes by degrees, until only a few drops are voided at a time, and at length it ceases altogether to appear; yet still the horse strains on, and the straining is accompanied by increasing agony.

The mere difficulty of staling, however, and its gradual ceasing, may be referrible to another cause, namely inflammation of the neck of the bladder. It then becomes necessary to settle this point, and that is easily accomplished. The hand well oiled should be introduced into the rectum. If there is inflammation of the kidney the bladder will scarcely be felt under the gut; but if it is inflammation of the neck of the bladder, the protrusion of the distended vessel cannot possibly be mistaken.

Inflammation of the kidneys is the subject now under consideration. The case must not be played with. The secretion of the urine is one that can be suspended but a very little while without manifest danger, or certain death. The patient must be bled, and that as copiously as in any of the inflammations that have passed under consideration: he must be bled until the horse threatens to fall. If remission of the symptoms has not been obtained, more blood must be abstracted five or six hours afterwards.

To this must succeed physic; but it must be physic that is not likely to have a diuretic effect, and which, while it will be effectual, will not irritate the neighbouring parts. Ejpsom salts must not be given. No calomel must mingle with the aloes. Aloes alone must be exhibited; and the solution (Recipe No. 10, p. 55) will be the best form, but without the croton. The effect of this may be quickened or secured by eight-ounce doses of linseed-oil, beaten into an emulsion with the yolk of an egg, being given every eight hours until purging is produced. Plentiful injections of warm water should be thrown up, for they will answer a double purpose; they will assist the physic, and act as useful fomentations in the immediate neighbourhood of the inflamed part. 
To these, as in other cases, will succeed counter-irritation. The loins should be frequently fomented with hot water, or, what is far better, a blister should be applied over them. The majority of the blisters, however, in common use have a diuretic as well as a vesicatory effect, and not one of them must be resorted to. Turpentine and cantharides must be avoided as pregnant with mischief. The mustard.poultice (Recipe No. 45, p. 120) will be a very effectual one, which has no stimulating effect on the urinary organs. loins.

The horse should be warmly clothed, and particularly over the

While the inflammation is high, little food, and that of the mildest nature, should be given. The patient may have a bran mash before him, and a bucket of linseed-tea within his reach. All medicine should likewise be avoided until the physic has ceased to operate, and then almost the only drug that can be given with safety is the white hellebore.

\section{RECIPE (No. 52).}

Hellebore Ball in Inflammation of the Kidneys, or as a Sedative generally.

TAKE-Fresh white hellebore-root, powdered, half a drachm;

Linseed-meal, four drachms :

Make into a ball with treacle.

One of these may be given morning and night while the inflammation is acute; but they must be suspended when the disease begins to subside, or if saliva should flow from the mouth, or the horse should hang his head with any appearance of stupidity or unconscionsness. The bowels should at the same time be kept in a rather relaxed state by means of small doses of aloes or linseed-oil.

This is a disease which often leaves mischief behind it. There will long be a tendency to a return of it, and, perhaps, an incapability of very hard work. The strictest attention should be paid to the food. Green meat will be useful. A ramble in the paddock during the day, when the weather is fine, is always desirable. The hay a nd corn should be carefully examined, and no diuretic medicine should be suffered to be brought into the stable. If the horse is worked, and at all hours and in all weathers, he should, if he is a draught-horse, have his loins protected by a leathern flap; if he is a saddle-horse, the rain should not be suffered to drip on his loins as he stands waiting for his rider. If, after a very severe attack of this disease, the horse does not gain the full and free use of his hind limbs, or if he is suliject to inflammatory affections of the kidney from the most trifling causes, a charge over his loins will be of very great service. 
RECIPE (No. 53)。

A Charge for the Loins or Legs.

TAEE-Pitch, three pounds;

Tar, one pound;

Bces-wax, half a pound:

Mix them together, and, when they are cool enough to be conveniently applied, spread the charge thickly over the loins, and scatter some flocks of short tow over it before it gets quite cold and firm.

\section{INFLAMMATION OF 'THE BLADDER.}

Inflammation of the mucous lining of the bladder is sometimes co-existent with inflammation of the kidneys. The nature of the urine is changed by the diseased state of the gland that secretes it. It becomes acrid, and irritates the coat of the bladder. Stimulating food, some poisonous herbage, and certainly the presence of any strange body, such as a stone in the bladder, are occasional causes of the disease. It is recognisable by the frequency of staling; by the mingling of mucus, or pus, or blood with the urine; by the slight additional heat which is felt when the hand, introduced into the rectum, rests upon the bladder, and also by the acute pain which that pressure occasions, as evinced by the shrinking of the animal.

Little can be done in such a case. Bleeding and mild physicking would perhaps be indicated, with plenty of linseed-tea; and some relief might be obtained by the injection of linseed-tea into the bladder, which may be effected by means of a catheter invented by Mr. Read. The aloes must be good, and not in too great quantity; for the lower intestines generally sympathize considerably with the irritable state of the bladder, and if there is not much purging there will be tenesmus, and, perhaps, dangerous inflammation of the bowels.

A slighter degree of inflammation of this viscus, and properly described by the term "irritability of the bladder," is frequently observed. The urine dribbles away in small quantities, and is occasionally mingled with blood, the consequence of some previous disease of the bladder, or, perhaps, oftener of some derungement of the digestive organs. This is suffered to continue and increase until the horse loses condition, the appetite is impaired, and the animal becomes unfit for work.

Small quantities of aperient medicine, with vegetable tonics, will be serviceable in this case.

\section{RECIPE (No. 54).}

\section{Drink for irritable Bladder.}

TAKE-Linseed-oil, six ounces, and beat it up with the yolk of an egg; then add

Powdered gentian-root, two drachms; and

Gentian, and uva ursi, of each one drachm.

Give this every third morning. 


\section{INFLAMMATION OF THE NECK OF THE BLADDER.}

This disease is attended with spasm of the sphincter muscle at the neck of the bladder, closing the orifice so firmly that very little or none of the urine can escape. It may be the consequence of irritability of the membrane of the bladder generally; or a stone pressing on or near the neck of the bladder; or gravel passing through and injuring the urethra; or the diabolical custom of some miscreants-injecting a tincture or infusion of cantharides up the vagina of the mare, in order to produce or hasten the periodical horsing.

At first there will be frequent discharge of the urine, then a gradual decrease both in the quantity discharged, and of the stream in which it escapes, and, at length, a total cessation of it. The distended bladder can be plainly felt under the hand in the rectum, somewhat painful but not hot.

The object in all our treatment should be to get rid of the spasm; bleeding should therefore be tried to its fullest extent, and until the horse actually falls, and then advantage should be taken of the temporary relaxation of the spasmodic action thus induced to pass a catheter into the bladder, and evacuate its contents. From the curved direction of the penis, it used to be considered impossible to do this without cutting into the urethra at the commencement of the curve, and introducing a catheter through the incision (which was always difficult to heal), and so pushing it on into the bladder; but $\mathrm{Mr}$ : Read has now invented an elastic instrument, which may be readily introduced into the bladder, without any wound being made into the urethra.

The simple evacuation of the bladder will always give great relief, and, when it has been preceded by the full bleeding recommended, the spasm is sometimes removed at once, or does not recur so violently.

The next step in order to subdue it will be the raking of the rectum, and the exhibition of a mild dose of physic. Mashes, or green uneat, must alone be allowed as food, and linseed-tea as drink; and the bladder must be emptied of its contents, whenever, by examination through the means of the rectum, it seems to be distended. After this, an infusion of belladonna may be injected in to the urethra, and thrown into the bladder.

\section{RECIFE (No. 55).}

\section{Infusion of Belladonna.}

TAKE-The extract of belladonna, two drachms; or

The dricd leaves of belladonna, two ounces;

Pour on them a pint and a half of boiling water; cover the vessel, and let the infusion stand until it is cold. 
At the same time, a scruple of the powdered belladonna may be given internally, morning, noon, and night, made into a ball with linseed-meal and treacle, or the following ball :-

\section{RECIPE (No. 56).}

\section{Antispasmodic Ball.}

TAKE-Powdered opium, one drachm; Powdered belladonna, ten grains ; Linseed-meal, three drachms:

Make into a ball with palm-oil or treacle.

Spasm of the neck of the bladder is often unattended with inflammation, and is generally produced by going too long without staling. It is attended with pain, though much less acute than in colic: the horse endeavours to stale, and sometimes succeeds in voiding a few drops. The bladder, of course, will be found full, and sometimes by gently pressing it the urine may be evacuated. If this does not sticceed, a clyster should be thrown up, an ounce of laudanum given, and some blood taken, and then the flexible catheter, being oiled, should be carefully passed up the penis.

\section{GRAVEL AND STONE IN THE BLADDER.}

These are far from being unusual complaints. It is very com. mon to see a horse discharge a great deal of gravel with his urine. Several pounds have been evacuated in the course of a few months. There is nothing that will act upon, or dissolve, these calculi with safety to the patient; and all that the practitioner can do is to give a diuretic ball, and, an hour after that, half a pound of common salt dissolved in a quart of water, in order to make the animal thirsty, so that plenty of water shall be drunk and discharged, and the gravel sooner, and more effectually, washed out.

'The symptoms of stone in the bladder, or in the kidney, are very obscure. Stones are found much oftener in the kidney than in the bladder of the horse, which is altogether contrary to what occurs in the human being; and, could we detect a stone there, we could neither dissolve nor dislodge it. Stone in the bladder may be suspected when the horse is occasionally subject to colicky pains; and during the access of these pains he voids his urine with difficulty, or strains violently in the act of voiding it. This should be kept in mind whenever a case of supposed gripes is brought for examination.

The nature of the complaint being once suspected, it is very easily put to the test; for, as was observed when the diseases of the bladder were described, that viscus is easily felt from the rectum, and the presence, and situation, and size of the stone readily ascertained. 
Nothing but the removal of the stone by an operation can give relief; and the circumstances to be taken into consideration, with regard to the performance of that operation, are the age, and health, and value of the horse, and the size of the stone. If none of these manifestly forbid the operation, there is considerably more chance of success than in the human being.

The operation being resolved on, the horse should be thrown, and one of Read's elastic catheters, with a groove, passed into the bladder. This is far preferable to the common whalcbone staff, for one incision only will then be necessary. The catheter being held firm, the operator makes an incision into the urethra, where it winds round the arch of the pelvis: into this he introduces a bistoury, likewise moving in the groove of the catheter or staff, and he carries his incision obliquely upwards, and through the pelvic portion of the urethra, and throngh the prostate gland, and the neck of the bladder, into the bladder itself, the length of the incision being regulated by the size of the stone, which has already been ascertained through the rectum. The bistoury should have been held with its cutting edge towards the angle of the thigh, and by this means easier access is gained to the bladder, the rectum is not so likely to be wounded, and the artery of the bulb and the suspensory ligaments of the penis are spared. The forceps are then introduced into the bladder, and the stone is seized so as to bring its smallest and narrowest extremity into the wound; the right hand being in the rectum will materially assist in accomplishing this. The stone having been firmly grasped, is attempted to be withdrawn with a gentle movement of the hand, from side to side, in order to surmount any difficulty in the passage, and to prevent unnecessary contusion, or laceration. After the stone is once grasped, the operator must be exceedingly careful not to lose hold of it until it is extracted.

In a great many cases, perhaps in the majority of them, the forceps will be unnecessary; for the fingers of the left hand being carried through the external wound into the bladder, the right hand introduced within the rectum will not only direct the stone to them, but assist in forcing it through the orifice. No stitches are passed through the edges of the wound. The urine will at first flow almost wholly through it, but it will gradually close, and at the expiration of about a month will usually be healed, and the whole of the urine discharged through the urethra. 


\section{CHAPTER XXV.}

\section{CASTRATION, AND THE DISEASES OF THE GENERATIVE ORGANS.}

Custom, and indeed the pleasant and safe use of the horse, require that the colt should usually be gelded. The operation of

\section{CASTRATION}

is performed with greatest safety before the colt is weaned; but as the form of the neck and shoulders is materially affected by the length of time the colt remains perfect, the carriage-horse, and the horse of heavy draught, should rarely be castrated before he is a twelvemonth old. If his fore-quarters are then large and muscular, the sooner he undergoes the operation the better; if they are weak and thin, six months more should be given to him; but many dealers do not castrate until the colt is two years old. The operation should be performed in temperate weather, and the patient should be prepared by the administration of a dose of physic.

A great many new methods of castration have been lately promulgated, and each has had its defenders. Wooden clams, with and without caustic, and with the testicle covered and uncovered, have been recommended: but the old method is the best; and with common care, as to the weather and the preparation of the colt, and the proper (not too great) heat of the searing-iron, there is comparatively little danger about the operation.

A collar of the common girthing web is to be placed, not too tightly, about the neck of the colt, and he is then to be thrown on the left side. The croup is to be raised a little, and the right leg drawn up as far as it can be towards the collar. Some persons, however, prefer to draw up both legs, and turn the colt on his back.

The operator should then place himself behind, or somewhat to the left of the patient, according to the manner in which he has been thrown, and begin to examine the scrotum, and ascertain the situation of the testicles, and whether they are so thoroughly come down as to enable him to grasp them firmly. It is not always that he can do so; for the testicles may not have come completely down, and then the power of the muscle of the scrotum is great. If the operator anticipates difficulty in retaining them in his grasp, let him pull them down as low as he can, but without violence, and place a pair of clams above them.

It will be, on the whole, more convenient for the operator to begin with the left testicle first, and the man at the head being on 
the alert, and the twitch having been put on, the operator grasps the testicle, pushes it down to the bottom of the bag, and thus makes the scrotum tight and smooth over it: then, if he is experienced in his business, he, with one incision from before, backwards, and along the whole extent of the lower edge of the testicle, cuts through the scrotum, the dartos muscle, and the tunica vaginalis, and the testicle slips ont.

Some prefer to make the incision through the scrotum with a red-hot firing-iron. There is an appearance of brutality about this. The sufferings of the animal are increased, and the wound does not heal so readily: in a few cases, however, and only a few, this has been said to be an advantage, for the incision has closed while matter continued to be thrown out within the scrotum.

The operator must now shift his hand downwards, and scize the testicle, holding it steadily; not drawing it forcibly out, but humouring the struggles of the animal, while the man at the head is steady, and the other tightens the twitch.

The struggles of the animal, which will probably be great at this time, having somewhat ceased, the operator draws the testicle down a little farther, and places the clams upon the cord, having wound a little tow about them, in order to cause them to press more equally and securely upon the cord, and perhaps deaden the pain, as well as prevent the bleeding. The vas deferens, which is continued from the lower part of the testicle, should be divided, which will also save the colt much unnecessary pain. The point at which he will afterwards divide the cord having been settled in the operator's mind, leaving it neither so long as to protrude from the scrotum, nor so short as to be seized with considerable difficulty, if, unfortunately, hæmorrhage should ensue, the clams are closed and fastened, and that sufficiently tight to stop the circulation of the blood, but not unnecessarily to bruise the cord.

The cord is now to be divided. It would appear to be the most surgical way to do this with the knife, and afterwards to sear the end of the cord, in order to prevent subsequent hæmorrhage; but hæmorrhage will sometimes occur after this, to the great trouble and mortification of the operator. A better way is, to draw a firingiron, with a sharp edge, rapidly and repeatedly, yet lightly, across the cord, and not too much in the same line, until it is divided; the vessels will thus be far more securely closed, and much bleeding will very rarely ensue. The clams should now be a little loosened, that the operator may see whether the bleeding is effectually stopped. If there is oozing of blood, in however small a quantity, from the end of the cord, it is much more prudent to apply the firing-iron again than to run the risk of the vessels being gradually forced open by the pressure of the blood. There is no point, however, about which the surgeon should be more anxious, than to apply the iron with just sufficient severity to accomplish the intended purpose, and no more; for nine out of ten of the colts that 
are lost in castration die from inflammation produced by the needlessly severe application of the cautery.

The same mode of proceeding being adopted with regard to the other testicle, the operation is at an end, except the mere cleansing of the part with cold water. No unguent or balsam is to be applied, either now, or, generally speaking, during the healing of the wounds. The colt should be turned irito a loose box; for the little exercise which he will thus take will assist the escape of any pus, or other fluid from the bag, and will prevent both swelling and inflammation. He may even be walked out for a quarter of an hour, daily; but immediately to turn the colt out into a paddock, and abandon him to the flies and the weather, is a cruel and dangerous practice.

Little attention is afterwards necessary. A considerable degree of swelling there will often be, and perhaps extending beyond the scrotum, and along the belly; but if, on the third day, there is a discharge of healthy pus, there will be no cause for fear, for the swelling will gradually and perfectly subside; if, however, there is no discliarge of pus, whether there is or is not swelling of the parts, it will be prudent to open the wounds a little with the fingers, in order that the pus which is pent up in the scrotum may escape. Should much fever ensue after castration, and the colt begin to be evidently ill, the peritoneum is probably inflamed, from sympathy with, or proximity to, the scrotum. General bleeding, and warm fomentations to the parts, should be resorted to. Very great swellings of the scrotum, evidently containing fluid, and the integument having a shining appearance, are best treated with slight scarifications and fomentations.

A mode of castration by means of the clams has been lately introduced and somewhat extensively practised. A dry branch of elder, or of some other wood, is selected, about an inch in diameter, and five or six inches long. This is sawed or otherwise cut lengthwise through the middle; and the internal surface of each thus exposed is smoothed, and a small portion of it planed off at each end. About half an inch from each end of each, a niche is cut sufficiently deep to hold a strong waxed string, and these are tied together at one end, their flat surfaces being exposed to each other.

There are two ways of operating with these clams, called the covered and the uncovered. For the covered, and the preferable way, the testicle is taken in the hand, an incision is made through the scrotum and the dartos muscle, taking care not to divide the tunica vaginalis. The scrotum must be then pushed back from over the testicles, and the clam placed above the epididymis, and the vas deferens is divided. Theri, care being taken that every thing except the cord is detached, the other ends of the clams are brought over each other, and so closely and firmly tied as completely to stop the circulation of the blood through the cords; others, before the application of the clams, cut through the tunica vaginalis, as 
well as the scrotum and the dartos. The clams being sufficiently pressed together and secured, the testicle is usually cut off; but in order effectually to guard against after-bleeding, the testicle is suffered to remain until the clam is removed, which is usually about the third day. The principal art in the performance of this operation is to make the clams press equally and sufficiently firm.

This mode of castration is almost uniformly adopted in France, but the generality of English practitioners adhere, and very properly, to the old iron clams and the cauters. The patient certainly does not suffer half so much pain from the old operation, nor are the after inflammation and swelling and the danger so great. Another mode of castration has been attempted with considerable success, and which, from the comparative little pain which it inflicts on the animal, is well worthy of adoption. The horse is secured; an incision is made throngh the scrotum, dartos muscle, and tunica vaginalis. The vas deferens and the cellular membrane above the epididymis are then detached, and the testicle is left supported by the spermatic artery and vein alone. A pair of forceps constructed for the purpose, and called the "torsion forceps," is then applied as tightly as possible on the spermatic artery, three inches from the epididymis, and the testicle is cut off. The forceps are then turned six or seven times, the cord is suffered to retract as far as it will, the forceps are still held that a clot of blood may be formed, and then being opened, the operation is at an end.

\section{SWELLING OF THE SHEATH OF THE PENIS, AND AMPUTATION}

OF THE PENIS.

Sometimes at the close of severe illness the sheath of the penis will become suddenly enlarged, and œdematous, and pitty. The treatment will depend on the circumstances of the case ; but, generally speaking, a few cordial diuretics, or a mild dose of physic, with gentle exercise, will effect a cure. At other times a swelling, not so large, but hard and painful, will proceed from the accumulation of oily dirty matter within the sheath. The sheath of every henvy gross horse should be occasionally examined, and well cleaned out with soap and water, a very dilute solution of chloride of lime heing afterwards applied. This filth being long suffered to remain unnoticed will sometimes cause excoriations and ulcers, eating deeply into the part, and producing such a mass of disease on the g'ans of the penis as to render it necessary to amputate that member. Masses of fungous substance, weighing three or four pounds, will sometimes cover the glans. It is useless to attempt to remove a mass like this with the knife or the cautery, for it will very soon sprout again. Amputation of the penis is the only remedy, and this is an operation neither difficult nor dangerous.

The sheath should be turned back; the penis drawn out as far 
as possible, and then cut through at one or two incisions as far below the diseased part as may be deemed necessary. The remaining portion of the penis will be retracted within the sheath as soon as the operator quits his hold of it. Little hæmorrhage will follow, except that a slight bleeding will sometimes be perceived for a few days in the act of passing urine. The orifice of the urethra is leept sufficiently open by the gush of the urine, and it is seldom that any unpleasant circumstance occurs.

\section{WARTS.}

A collection of them on the glans of the peris will sometimes make it impossible to retract that member when protruded, and render the operation just described absolutely necessary. They are oftener, however, on the sheath of the penis, and extend along the groin. In a few cases they are on the eyelids, the nostrils, and the muzzle. The most effectual way of destroying them is by cutting them off with a sharp red-hot firing-iron. The ligature is often a tedious and uncertain way of getting rid of them; to cut then off with a knife, except the cautery is afterwards applied, is bad treatment, for they will speedily grow again, and others will appear wherever the flood flows.

\section{INVERSION OF THE WOMB.}

This is a very uncommon case, and is the consequence of violent throes in parturition. The protruded mass will sometimes reach even to the ground. If the mare has not been perfectly exhausted by the length and violence of her labour, and a skilful practitioner is at hand to return the uterus before it is excoriated or wounded, there is considerable probability of her being saved. Assistants must support the protruded mass by means of a strong, double cloth, while, with his arm bare to the shoulder, and well covered with oil, the surgeon, placing his closed hand against the fundus of the womb, endeavours to force it gradually back again into the vagina. After working hard, and for a long tirne, he may succeed: but he has then to contrive to keep the parts in their situation; for the throes are apt to return under the name of after-pains, and the uterus will be forced out again. There are two methods of accomplishing this.

The first is, to pass two strong stitches through the lips of the vulva ; but the after-pains may return so violently, and that violence may be increased by the irritation of the stitches, that they may give way, and the womb be perfectly forced out again. Whenever this mode of treatment is adopted, a good dose of opium should be given to the mare; the pains may then possibly subside, and on the following day the stitches may be removed.

A more successful way is, after the womb has been returned, an 
assistant in the mean time keeping his arm in the vagina, to buckle a girth tightly round the mare's chest-to attach a roller to this girth under the chest-to pass it between the fore legs-and then, having slit it at the point of the chest, to bring the two parts up the neck, and over the shoulder, and back again to the girth on the back, and there to fasten them securely. A second roller must now be fastened to the other edge of the same girth under the chest, and brought backward, and between the hind legs, and over the vulva and anus; and being slit at the tail it also is carried on to the girth, and fastened there. 'This roller prevents the possibility of any protrusion, and, at the same time, is no source of irritation. The opium may be given as in the other case, and the pains having passed off, the roller may then he removed, and the mare will do well.

The probability of ultimate success, however, depends on the practitioner being called in early and setting to work immediately.

\section{INVERSION OF THE BLADDER.}

In some rare cases the pains have been so strong as to cause protrusion of the bladder, a circumstance that would be deemed almost impossible. It may be distinguished from inversion of the womb by its smaller bulk, and by the hand passing into the vagina; and from polypus in the vagina by its villous coat, and by the discharge from the ureters. There is no possibility of returning the bladder, and the advice of the practitioner should be to destroy the poor animal. If, however, the owner wishes something to be attempted, the bladder must be amputated, and the edges severely cauterised, in order to stop the hæmorrhage: but the urine will continue to be secreted, and must be discharged; and the mare will live a nuisance to herself, and a disgusting object to every one who sees her.

\section{POLYPUS IN THE VAGINA.}

This also is not of frequent occurrence, but it has been found, and of immense size. Its removal must be attempted by a ligature, attached as nearly to the root of the pedicle as possible. This ligature should be tightened daily, and in the conrse of three or four days the pedicle will generally be cut through, and the tumour will drop off:

Some have attempted to remove the polypus by means of the knife. The objection to this is the bleeding which will often follow, especially if the tumour is large; but if the ligature is used, although the pedicle is thick and not readily cut through by it, the polypus may be safely taken off by the knife about half an inch below the ligature, and three days after it has been applied. The continuance of the pressure during this time will have closed the vessels, and little hæmorrhage will take place, and such only as may be readily stopped by the cautery. 


\section{CHAPTER XXVI.}

\section{OPERATIONS ON THE TALL-DOCKING.}

Fasmion and convenience have determined that the tail of the horse shall usually be shortened. The length of the portion removed depends upon the caprice of the owner or operator; as does, likewise, the time selected for the operation. Many breeders dock the colt a few days after it is foaled; and they act with much judgment in selecting so early a time, for the little animal is more manageable; the hrmorrhage is less; the pain is evidently less; and inflammation very rarely occurs. It is subject, however, to the objection that the young animal is partially deprived of that weapon which nature furnishes for the purpose of keeping off flies.

The length of the tail being determined on, the operator searches for the nearest joint above or below; for it is a matter of great importance, and particularly as affecting the healing of the wound, and the prevention of sloughing, and the probability of locked jaw, that the division should take place through a joint. The hair which grows round the joint is cut off; and that which, although growing above the joint, hangs over it, is turned up and confined by a string. The side line is now put on, and the twitch tightened; then, availing himself of the partition between the stalls, or in any other convenient way, the tail is cut off at one blow, either by the machine or a mallet and knife.

The gush of blood will be considerable. It would rarely happen in a young animal, that any danger would ensue if the tail were left to bleed on; but as the proprietor may be a little alarmed at the quantity of blood lost, or, in a very few cases, the animal may be considerably weakened, it is usual to stop the hæmorrhage by means of a circular piece of iron affixed to a handle, and with a hole in the centre of it. This having been made red-hot, is carefully applied so that the ring shall rest on the muscular parts and bleeding vessels, and the bone shall be secure from injury in the centre of it. Should the iron come in contact with the bone, and sear it with any severity, there will be danger of exfoliation taking place, or even of the bone sloughing out as far as the next joint. The iron should not be pressed too hardly upon the part, nor retained too long; and a little bleeding afterwards should not be regarded. The main vessels being stopped, a slight hæmorrhage can never do harm; but the renewed application of the cautery might lay the foundation for a locked jaw.

In a very few cases, however, the bleeding is troublesome: then a piece of tape must be tied very tightly round the tail, two inches above the wound; a large pledget of tow, dipped in the following 
styptic wash, should be placed upon the stump, and, over that, other pledgets dipped in the common tar stopping; a piece of thick poultice-cloth should be laid over that, and the whole fastened and buckled on as firmly as possible, and not removed for twenty-four hours.

\section{RECIPE (No. 57).}

\section{Styptic Wash.}

TAEE-Alum, two ounces;

White vitriol, two drachms;

Dissolve in a quart of water, and keep for use.

The bleeding having been arrested, no other treatment is required in the majority of cases; and the horse will do much better at work than standing idle in the stable.

\section{NICKING.}

Docking is justifiable on the score of convenience. The long tail, which would switch away the flies in a state of nature, would often be a sad nuisance to the rider; but nicking is a cruel operation, and has nothing to plead in its excuse but the supposed, and in many cases falsely supposed, better carrying of the tail in consequerice of it.

The side line is put on, or, by the prudent operator, the horse is cast: then, at about three inches from the rump, the centre of one of the bones of the tail is sought for, and an incision is made down to the bone, across the under part of the tail, and from one side to the other. Another or a third incision follows at the centre of the next bone below, or the next to that, according to the kind of horse, or the whim of the operator. The portions of muscle which protrude into the incisions must then be removed with a pair of sharp curved scissors, and so the first part of the operation terminates.

These muscles below the tail are the agents in depressing it; their power is thus destroyed: but the muscles on the upper side, concerned in the elevation of the tail, remaining uninjured, it is carried somewhat higher, and that in proportion to the number or depth of the incisions.

If, however, these divided muscles were left to themselves they would soon unite and heal, and regain their former power; therefore comes the most serious and barbarous part of the operation of nicking. A pledget of tow is introduced into each of the incisions, so as completely to fill it. It used to extend the wounds to the utmost, and was firmly bound down into them; but so much inflammation frequently ensued, accompanied by swelling, fever, and even death, that these pledgets are not now either so large or so tight, and are confined to their only proper office, the stoppage of the 
bleeding. If the horse is very uneasy they should be slackened a few hours after the operation, and quite removed when twenty-four hours have elapsed. Next to wounds in the foot, there was not, a few years ago, a more frequent cause of locked jaw than applying the cautery too severely in docking, and tying too tight, or neglecting to remove, the first bandage after nicking.

The manner of turning the tail back and appending a weight to it by means of a cord fastened to its end, and passing over a pulley, is too well known to need any description !ere. Care should be taken that the whole weight is not hung on at once, when the tail is sore and painful from the operation, but gradually increased; and that the animal is released from the pulleys two or three hours every day for the purpose of exercise. A knowledge of the continued contraction of the skin and neighbouring parts, even after the closing of a wound, would prompt the use of the pulleys for two or three weeks after the incisions are healed.

As to the healing of the part, nothing more is necessary than the daily cleaning of the wounds, and the application of the tincture of aloes; unless the discharge should be offensive, which a weak solution of the chloride of lime will soon remedy. The discharged pus should be carefully washed away from the roots of the surrounding hair, otherwise it will form a filthy hardened mass, and the hair will certainly come off. Its being kept tightly bound up so long will also loosen and injure it at the roots, and render it likely to drop: it should therefore be occasionally untied and combed out.

A new mode of nicking has lately been introduced. At the edge of the tail between the joints, and at the point where the old incision used to commence, a probe-pninted bistoury was introduced, and carried beneath the skin, and round the under part of the tail to the other side; it was then turned and the muscles were cut through to the bone from side to side. The open gashes of the old method were thus avoided, while it was thought that by the use of the pulley the divided depressor muscles might so far be prevented from perfectly uniting again as to give the required elevation to the tail: not only, however, has this effect been rarely accomplished, but the blood and purulent matter have often been unable to escape through the small puncture made by the bistoury, and inflammation and sloughing have takerr place to a dreadful extent, and the animal has been destroyed. This mode of operating, therefore, is justly laid aside. 


\title{
CHAPTER XXVII.
}

\section{DISEASES OF THE SKIN :-WANT OF CONDITION-HIDE-BOUND-}

\author{
SURFEIT-MANGE-MOULTING.
}

\section{WANT OF CONDITION.}

Ture connexion between the skin and the healthy state of the horse generally, and particularly the proper discharge of the digestive functions, is much closer than either horsemen or veterinary surgeons seem at all times to imagine. A soft, loose, mellow coat, easily raised from the muscular substance beneath, and the hair either curling naturally, or lying smooth, and presenting a glossy appearance, are considered in cattle as indications of health and a disposition to thrive; and in horses these are proofs of condition, and a capability of work: but the connexion between these things and the stomach is too much overlooked. Condition in the hackney, the hunter, the race-horse, or the common cart-horse, are very different things, but they all agree in the particulars here mentioned: they all take for granted a mellow state of the skin, and a smooth and natural lying of the hair.

The skin is pierced by innumerable pores, through some of which exudes an unctuous ratter that gives the peculiar softness and subtleness of the healthy skin. If there is any peculiar mismanagement in the feeding; if, unprepared, the horse is remuved from the straw-yard to the full allowance of the stable; if the grooming, the clothing, or the exercise are neglected, or improperly managed, the evil effect of this is speedily shown by the want of pliancy and elasticity in the skin, and the accumulation of scurfy matter upon it, and the irregular lying of the hair.

The treatment of want of condition will somewhat vary with the supposed cause of it; but, generally speaking, the first thing indicated is a mild dose of physic. From eight to ten drachms of the physic mass (Recipe, No. 1, p. 38) should be given. A second or third dose may follow if the horse is much out of condition; but otherwise, one of the alterative balls (Recipe No. 11, p. 57), given on eight or ten successive nights, will, with proper attention to diet and clothing, and temperature and exercise, be all that is required.

\section{HIDE-BOUND.}

This is not only a suspended secretion of the oily matter intended to keep the skin supple, but also an absorption of the cellular sub- 
stance which is interposed between the skin and the muscular parts beneath; and in consequence of both of these circumstances, not only does the skin feel hard and harsh, but it is very difficult to raise it from the subcutaneous muscle below. From the same clinging of the skin the horse with hide-bound has a peculiar tuckedup appearance. It is a diseased state of the skin, and the parts below it; but depending upon, and produced by, a diseased state of the digestive organs generally.

Mild physic, and the alterative balls, and particularly the latter, combined with frequent mashes, green food, and especially carrots, good grooming, and regular exercise, will be the most effectual remedies for hide-bound.

Connected with, and often produced by hide-bound, but at other times quite independent of it, is-

\section{SURFEIT.}

This consists of lumps which appear on the skin of the horse, and more, perhaps, in the spring than at any other time of the year. They are sometimes scattered all over the animal; at other times they are thickest upon, or confined to, his neck and fore parts; or they are seen on the loins or quarters alone. Occasionally they are attended by a great deal of itching; but in other cases they do not seem to inconvenience the animal in the slightest degree. They usually appear with little or no warning, except a very slight listlessness and diminution of appetite, and they not unfrequently disappear as suddenly as they came. This is particularly the case when they seem to run in lines, and have an appearance very similar to the wheals from a whip. Much oftener, however, the eruption assurnes the form of a pustule of greater or less size, which breaks, and the viscid fluid that it contains clings about the rnots of the hair, which comes off as far as the pustule had extended, leaving a bare spot, or one covered only by a scaly scurfiness. The hair in process of time usually grows again upon these spots, and there remains litile or no trace of what has happened; but in some instances where the case has been altogether neglected, and the pustules have been thick and large, and the horse has liumour or fever about him, surfeit degenerates into mange of a virulent character, and difficult to be subdued.

The name surfeit is an unintelligible, or, at least, it is often an inappropriate one. It seems to refer the eruption of the skin to indigestion, or to some diseased state of the stomach. There is no doubt that violent indigestion will produce in most animals inflammation and pustular eruption on the skin. Surfeit has been evidently traced to kiln-burnt oats, or mow-burnt hay, or poisonous plants: but oftener it has followed the action of some direct stimulus on the skin, as exposure to cold when the horse was hot, and especially at the moulting season. Whatever be the cause, the nature 
of the complaint is evidently obstruction of the pores of the skin in certain parts, or universally.

It would seem to be a curious circumstance that physic rarely does immediate good in this affection, and sometimes is decidedly injurious; but the explanation of this circumstance must be referred to the connexion between the skin and the stomach, and the probability that that which for a whlle deranges the stomach and bowels, may cause a temporary aggravation of the eruption. This, however would pass over, and that which lowered the irritability of the system generally, would lessen the inflammatory affection of the skin. The cooling alterative medicine (Recipe No. 11, p. 57), so often recommended, will be highly useful here; and the disease will generally yield to it, without the temporary aggravation and inconvenience produced by physic. The evening will be the best time for the admiristration of these alteratives, because the warmth of the stable during the ensuing night will be most likely to insure the diaphoretic and cleansing effect of the antimony and sulphur on the skin. Some attention should be paid to the clothing of the horse, and, more particularly, the stable should be confortable and warm.

All this should be preceded by bleeding, in a fair and moderate quantity, according to the size of the horse, but not to the extent that fever would require. The loss of three or four quarts of blood will often remove the surfeit without any other means being used. Mashes will be proper, and such green meat as the season will allow.

\section{MANGE.}

This filthy and intractable disease is produced by various causes. Neglected or ill-treated, or inveterate surfeit will take on the character of mange. A sudden change of diet, from that which is deficient in quantity or nutriment, or both, to full and stimulating feeding, will sometimes produce an eruption on the skin, and speedily degenerate into mange. Poverty is a yet more frequent cause. Diseases of the digestive organs will lay the foundation for those of the skin, as in the cases of surfeit and hide-bound; and it is easy to imagine that such deprivation of food as will occasion not only weakness of the digestive organs, but of the frame generally, will produce a worse disease. There are very few who, from false economy or from want of feeling, are accustomed to turn their horses out in the winter, where the situation is bleak, and the food scanty, who have not cause to repent of their folly in the spring. Their horses come up starved and weak, and unfit for work, and the general debility to which they'have been reduced will often have laid the foundation for a violent mangy affection that will soon afterwards break out.

Contagion is, however, the chief source of mange. There is no 
disease, not excepting glanders itself, which is more infections. If it once appears in a stable, or in a straw-yard, or on a common, scarcely a horse will escape from it.

It is sometimes difficult to distinguish between mange and surfeit; and yet it is very important that the surgeon or horse proprietor should recognise them at a single glance. When there is considerable redness on any part, changing to scurfiness as the infiammation dies away, and leaving the hair thinned, and the skin thickened and corrugated, or puckered, this is most assuredly mange. When there are numerous little bare places or spots, with or withont much scurfiness, and the hair is thin between and about them, mange is indicated. The bare spots or patches accompanying surfeit are produced by the hardening of the matter discharged around the roots of the hair, and thus causing it to fall off; while the coat around is as thick as it was before, although, perhaps, not so smonth, from the want of cundition; mange, on the contrary, produces, and especially about the extremities, and the hind legs more than the fore ones, a loss, or great thinning of the hair, and where there is no eruption. A looseness of the hair generally, and particularly at the edge of the mane, is a prevalent symptom of mange. If to these circumstances are added a great, and sometimes almost insupportable itching, with hide-bound, a tucked-up belly, a staring coat, and a marked appearance of poverty, the case can rarely be mistaken.

The treatment of mange is sufficiently plain, although it is too often unsuccessful. Bleeding is indicated in moderate quantities if the animal is in tolerably good condition, but if poor it should be avoided.

Physic, likewise, will be indicated, unless the animal is very poor, and then tonics should be given.

After this it will be desirable to give the following alterative, in order to charge the system with sulphur.

\section{RECIPE (No. 58).}

TAKE-Flowers of sulphur, half an ounce;

Black antimony, one drachm.

Mix, and give once a day in the food for ten days or a fortnight.

Medicine, however, will only assist in the cure. Mange is a local disease, and must be treated locally. Sulphur and mercury are the drugs which will have most efficacy here. The following ointment should first be tried, and will succeed oftener than any other application. 


\section{RECIPE (No. 59).}

\section{Ointment for Mange.}

\section{TARE-Flowers of sulphur, eight ounces; \\ Common turpentine, two ounces; \\ Strong mercurial ointment, two ounces; \\ Linseed oil, one pint;}

First rub down the sulphur with a fourth part of the oil; then rub in the turpentine and the inercurial ointment, and bring the whole to a soft semi-fluid state, by gradually adding the remainder of the oil.

Let the horse first be curried as thoroughly as the tender state of the skin will permit, and all the scurf be well brushed out; then with the hand (there is no danger to the man) let half of the ointment be well rubbed in, wherever any mange appears, and, if necessary, all over the horse. This should be repeated three days, and, on the fourth day, the ointment which is already about the horse should, as nuch as possible, be rubbed in. Every part should be carefully gone over. On the sixth day the whole should be washed off with soft soap and warm water; it will then be seen what progress has been made towards a cure, and the skin will have been prepared for a repetition of these dressings, which will in the majority of cases be necessary, and almost al ways expedient.

If, after the second course of dressings, no ground appears to have been gained, the application must be changed. The next remedy that should be tried is the chloride of lime, well rubbed in with a wetted flannel, and four times the strength recommended in Recipe. No. 18 (p. 68).

If this also should fail, recourse may be had to the oil of petroleum, or spirit of tar, mixed with a double or treble portion of linseed-oil, and applied with a brush, and well rubbed in.

In cases of mange arising from neglected or inveterate surfeit, and which are always the most difficult to be cured, it may be prudent to proceed at once to a very strong application, which may torment the horse for a little while, but will often get rid of the disease.

\section{RECIPE (No. 60).}

\section{Oil for Mange.}

\section{TAKE-Oil of turpentine, one pint;}

Sulphuric acid (oil of vitriol), two ounces :

Very gradually add the acid to the turpentine, stirring the mixture well, and carefully avoiding the fumes. If the acid is poured in too quickly, the whole will possibly burst into a flame. To this add,

Linseed-oil, one quart. 
Four ounces, or half a pint of this, according to the size of the horse, or the extent of the disease, should be well rubbed in with a brush every second day, until it has been applied three or four times. It will appear to give the horse considerable pain. It is possible that some redness and thickening of the skin may be produced, but this will shortly pass away, and when the inflammation subsides, the mange will frequently have disappeared.

The practitioner, who has once been plagued with the mange, will treat every cutaneous afiection, and indeed almost every kind of itchiness about the horse, more seriously than is often done. He will be much to blame if he suffers any considerable itchiness to remain many days without bleeding and diuretics. If it is not removed by this, he will administer a dose of physic; and if it still continues obstinate, he will endeavour to persuade the owner of the horse to give up the animal for a few days, during which he will apply the mange ointment (Recipe No. 59, p. 155). Many a troublesome attack of mange will thus be prevented, and no harm can possibly be done by the dressing beyond the temporary loss of the labour of the horse.

Little spots of mange often appear about the tail or mane, and sometimes under the collar, which should be dressed with the ointment, and got rid of, before the constitution is affected.

The practitioner needs not to be told how necessary it is that every thing about the horse, or with which he could by possibility have come in contact, should be thoroughly cleansed after the disease has subsided. Infection lurks in every thing about him; infection of which he may again become the victim, and from which other horses will not escape. Every article that is capable of being washed should be thoroughly scrubbed, first with soap and water, and then with a solution of chloride of lime, as recommended under glanders. The manger, the racks, the partitions, should also undergo an ablution with soap and water, and then with the chloride of lime. The walls and floor should be washed with the solution; the clothes well scoured, and afterwards washed with the solution; and every thing, and more particularly the brushes, to which the solution cannot be thoroughly applied, should be burned.

A horse recovering from mange should have occasional alteratives, and a fair allowance of green meat, or be sent to a salt marsh.

\section{MOULTING.}

This cannot be considered as a disease. The changing of the coat is a natural process, that takes place every spring and autumn. It is, however, a critical time with the horse, and he frequently shows indisposition to a greater or less extent. The truth is, that the vital energy which, generally diffused, should render him equal to his work, is partially distributed. More than the natural share 
of it is determined to the skin, and employed in the reproduction of the hair, and therefore there is a degree of languor, and indifference to, or incapacity for work, about the horse: he sweats with the slightest exertion; he is partially off his feed; the pulse is somewhat quickened; and he clearly labours under a slight degree of fever.

That which is wanted here is not the stimulus, nor the injurious cordial, which is so often employed under the delusion of the apparent debility; but something to allay the irritability and fever produced by the unequal distrobution of vital power. A mash should be allowed once in the day; green meat in moderate quantities; a little warmer clothing should be used; violent exercise should as much as possible be avoided; and either the alterative balls (Recipe No. 12, p. 59), or half doses of the fever ball (Recipe No. 15, p. 63), should be given. The first will usually be the most effectual; the second will be indicated if the fever should in any degree increase.

Good grooming is now more than ever beneficial. It will loosen the old hair, and hasten the growth of the new, and that being once accomplished, the horse will regain his former spirits, appetite, and health.

\section{CHAPTER XXVIII.}

THE TREATMENT OF EXCORIATIONS, WOUNDS AND ULCERS-POLL EVIL-FISTULOUS WITHERS, ETC.

THe most frequent excoriations are those produced by an unequal pressure of the saddle, or any part of the harness, and termed

\section{SADDLE-GALLS.}

If properly treated before they become too large, or too much inflamed, or begin to deepen, they are easily cured. The saddle or the collar should be carefully exumined, and all inequality of pressure taken away by padding or chambering. The only inequality which should be permitted, and that only a temporary one, is in order to prevent all bearing upon the sore part.

The sore should be bathed two or three times every day with the following embrocation:-

RECIPE (No. 61).

Lotion for Saddle-Galls.

TAEE-Infusion of eatechu (Recipe No. 19, p. 68), one quart;

Tincture of ditto, four ounces;

Dissolve in them eight ounces of common salt.

\section{1}




\section{WARBLES.}

Sometimes instead of an excoriation, or loss of cuticle, little tumours will be formed by the pressure of the saddle. If they are very tender, and hot, they should be frequently fomented with warm water, and as soon as a little of the tenderness has subsided, the lotion for saddle-galls should be resorted to.

\section{SIT-FASTS.}

If, however, pressure is continued on the warbles, another change will take place of a very curious character. Ulceration commences around the warble, and the injured cuticle separates all round from the healthy and sound skin: it nevertheless still adheres firmly to the parts beneath, so firmly indeed as to warrant the name which is given to this process: the cuticle deprived of its vitality separates from the parts around, but sits fast upon those beneath.

The parts beneath must be roused to activity, in order to be better enabled to throw the sit-fast off by the natural process of sloughing. A blister should be applied over the part, and in two or three days the sit-fast will either fall off, or may be separated without difficulty, and a superficial sore or ulcer will remain; or instead of this, or at first, the sit-fast may be dissected out with a knife.

\section{SUPERFICIAL WOUNDS.}

Few ointments agree with the horse, and all wounds whether superficial or deep will be more speedily healed by the application of a liquid balsam. The tincture of aloes is the cheapest and the best of any.

\section{RECIPE (No. 62).}

\section{Tincture of Aloes.}

TAKE-Barbadoes aloes, powdered, eight ounces;

Myrrh, powdered, one ounce;

Proof spirit, two quarts;

Water, one quart:

Let them infuse for three weeks, shaking them well daily.

The wound should be bathed with this twice every day. If there is no danger that the horse will get at it, to lick or nibble it, or that dirt and gravel will get into it, the wound will sooner heal by being kept open, than by any careful exclusion of the air. Should the surface of the sore become unhealthy, and especially should fungous granulations threaten to spring up, they should be washed swith the following lotion, before the tincture is applied:- 
RECIPE (No. 63).

\section{Mild Caustic Wash for Wounds.}

TAEE-Sulphate of copper (blue vitriol), an ounce; reduce it to a powder, and dissolve it in a pint of water.

If this is not sufficiently strong to repress the fungus, a powder may be lightly sprinkled over the sore.

\section{RECIPE (No. 64).}

\section{Caustic Powder for Wounds.}

TAKE-Acetate of copper (verdigris), and super-acetate of lead (sugar of lead), equal parts: reduce them to powder, and rub them together in a small porcelain mortar.

Sprinkle a little of this powder over the wound, and cover it with the pledget dipped in the tincture of aloes.

\section{INCISED AND IACERATED WOUNDS.}

The grand principle in the treatment of these wounds is to close them as much as possible by the first intention. If it is a simple cut, and the edges not lacerated, and they are neatly brought together and confined by a bandage or adhesive plaster, they will adhere, and the wound, or the greater part of it, will speedily heal.

In a deeper and lacerated wound, some parts of it may, by the removal of a few ragged portions, or even without this, be brought together, and healed somewhat in the same way. All that is neces-。 sary in these cases, is to leave an orifice, or opening, as much as possible in the lowest and most dependent part of the wound, in order that the natural discharge from it may readily escape.

The wound should be carefilly cleansed from dirt, gravel, and extraneous matter. If there is much inflammation, it should be poulticed; but the poultice should not remain after the inflammation has abated, and the wound begins to look healthy and discharges good pus.

The wound should be kept cleaned, and the tincture of aloes should then be applied externally, or injected into the wound, if it is of any considerable depth. The mild caustic wash (Recipe No. 63 , above) should be applied, if the suppuration does not go on well, or fungus should threaten to grow, or the caustic powder (Recipe No. 64, above) may be sprinkled over it: if the discharge should become offensive, the solution of the chloride of lime (Recipe No. $18, \mathrm{p} .68$ ) should be freely used.

After violent contusion, injuring and destroving the cellular membrane, or miscular substance beneatis, a deeply-seated and corroding 
abscess is sometimes formed. The horse is particularly subject to two of these.

\section{POLL EVIL.}

From accident or brutality the horse occasionally receives a violent blow nn the back part of the head, and the cellular and muscular substance of the poll and over the atlas, or first bone of the neck, becomes bruised. Inflammation follows; the part becomes hot and tender; it enlarges, and, at length suppurates, and breaks; and an ulcer very dificult to heal is formed. This happens much oftener in country than in town practice, either because the roof of the stable, or the doorway, is too low, and a horse in the least degree restive bruises himself against them; or because country horses are far more exposed to brutal treatment than the owners dream of. The practitioner always looks at a case of poll evil with a great deal of suspicion, and institutes every inquiry ; and the owner should never spare the fellow whose ungoverned passion or careless management has caused the mischief.

The veterinary surgeon should carefully examine the case, and think whether there is so much inflammation, or tendency to suppuration, as to prohibit the attempt to disperse the tumour.

The following lotion will be as effectual as any for this purpose :-

RECIPE (No. 65).

Discutient Lotion for Poll Evil.

TAKE-Common salt, four ounces;

Vinegar, half a pint

Cold water, a quart;

Spirits of wine, an ounce;

Laudanum, an ounce:

Dissolve the salt in the fluids, and bathe the parts well with it three or four times a day.

If this does not succeed, the effect of cold may be tried. Nitre, while dissolving in water, cools the liquid many degrees.

RECIPE (No. 66).

Cooling Lotion.

Dissolve an ounce of nitre in a pint of water, and use it the moment the solution is complete.

A colder lotion (and every thing should be attempted in order to disperse the swelling, when there is a possibility of so doing) will be formed by adding half an ounce of sal-ammoniac to the nitre. A 
greater quantity of sal-ammoniac would produce a still colder lotion; but there would be danger of its irritating the skin, and hastening rather than retarding the process of suppuration.

To these local applications should be added the most efficient general sedative treatment. The horse should be bled, and until the pulse is evidently affected: a strong dose of physic should be given, and mash-diet alone allowed.

Should suppuration have commenced when the practitioner is first called in, or should it appear in the most circumscribed spot afterwards, the plan must be entirely changed, and every effort made to hasten the perfect formation of the matter. Linseed-meal poultices should envelope the part, and to each of them an ounce of common turpentine should be added; and if the swelling does not then come quickiy to a head, the mustard-poultice (Recipe No. 45, p. 120) should be substituted. The horse should be better fed, and a fair allowance of corn given to him, not abandoning, however, the mashes.

When the tumour feels decidedly soft at some part, and the presence of matter can be certainly ascertained, it should be immediately opened. If the suppuration is left to go on until the swelling breaks, the wound will be unnecessarily large, and, from its raggedness, will not easily be healed.

The tumour having been opened, the abscess should be carefully examined with a probe, and the deepest part of it ascertained; and, through that a seton should be passed, coming out on the side of the neck below the tumour. 'Two objects will thus be accomplished; no matter will lodge at the base of the abscess, for it will run out as rapidly as it is formed; and the internal surface of the ulcer will be kept in a healthy state, and disposed to fill up.

The part should be daily examined, in order to discover whether there is a deeper sinus, in which a portion of the pus is still lodged, and a seton should be passed in that direction. Setons should be passed in this way through every distinct sinus, taking care to make the lower opening large and free.

This being accomplished, the course is simple, and a specdy and complete cure will sometimes be effected. In most cases it will be sufficient to wash the wound well out, twice in the day, with the tincture recommended (Recipe No.62, p. 158). If this does not appear to be sufficiently active, but the surface presents an unhealthy fungus, the mild canstic wash for wounds (Recipe No. 63, p. 159) may be resorted to, and the quantity of the blue vitriol doubled, or trebled; and should this fail, half an ounce of sulphuric acid may be added to the strong lotion.

The scalding mixtures, to which so many farriers cruelly resort, are sometimes very injurious. They destroy the living surface to which they are applied, and often increase the sloughing and the mischief.

Effectual setons through every sinus, and the frequent application 
of mild stinulating lotions to the interior surface of the abscess, comprise the whole secret of the treatment of poll evil, if attacked before it has deepened and spread too much, or insinuated itself between the murcles of the neck; and even then, all that will be necessary will be to increase the number and depth of the setons, and, very gracually, the strength of the lotion.

Some surgeons have recourse to the knife instead of the setons. They boldly lay open every sinus to its very base. The principle is the same to prevent the lodgment of pus, and to produce a healthy surface. This is a very proper and efficient practice when the sinuses do not run too deeply, or in the neighbourhood of any importint vessels. The system of setoning, however, is the safest, and is generally effectual.

The application of pressure by means of bandages and splints, so as to bring the sides of the sinuses together, has been found very greatly to promote the cure.

\section{FISTULOUS WITHERS.}

These are always to be attributed to carelessness. If the saddle has not been properly chambered, or the padding has shifted, so that the sadlle presses upon the edge of the withers, very unpleasant swellings and sores will be produced which, in bad cases, may run on to ulcers of the same kind as those in the poll. This is even a more serious case than poll evil, for the sinuses may penetrate between the shoulder, and the ribs underneath it; and wherever they go they must be followed, and a seton passed through the very deepest of them. This being effected, the same mode of treatment that has been recommended in poll evil may be adopted, and with equal success, in fistulous withers, and without the scalding mixture or the reckless use of the knife, in which some indulge. Fisiulous withers are more likely to return than poll evil is, from the pressure which may be too soon brought to bear on a tender and irritable part.

\section{WOUNDS FENE'TRATING THE CHEST OR BELLY.}

The horse is not so subject to these as cattle are, but he is now and then staked, and occasionally gored. If the wound is on the side, it will be immediately understood whether it has penetrated the cavity of the chest by a peculiar hissing or rushing sound at each act of breathing, and by a bloody spume or froth being about the mouth of the wound. These wounds must be closed as quickly, and as accurately as possible; a pledget of soft tow, dipped in the incture of aloes, should be placed on the wound, and over this a broad tight bandage, which by straps extending between the fore legs and over the shoulder, or between the hind legs and over the back, is securely fixed in its place. 
The bandage should not, if possible, be removed during the first week. The wound, in a great many cases, will then be nearly or quite closed. If necessary a fresh pledget, dipped in the same tincture, must be put on, and the bandage replaced. The chance of healing the wound, and avoiding unpleasant or fatal pleuritic affection, is to keep the opening into the chest perfectly closed.

Wounds in the abdomen must be treated in a similar way; but it will here be necessary to cast the horse, in order to favour the return of any protruded intestine. The part that has escaped must be carefully cleaned and returned, and great care taken that no portion of it is wounded by, or included in the suture. There need not be so much care about the peritoneum, and some have advised to include a small portion of it in the stitches, in order to form secure and more rapid adhesion. It must be remembered, however, that there is considerable danger of inflammation; that it is a mere choice of evils, and should not be carelessly attempted.

The same pledgets, moistened in a similar way, and confined also by a bandage carefully secured, will be necessary.

In both cases some means should be resorted to, in order to avoid inflammation. The horse should be bled; a mild dose of physic should be given; and he should be put upon mash diet.

\section{CHAPTER XXIX.}

\section{INJURIES AND LAMENFSSES OF THE FORE EXTREMITIES.}

\section{SHOULDER LAMENESS.}

Turs, in a few instances occurs, but not so frequently as the farrier imagines. 'The proof' of the lameness being in the shoulder, and not lower down, is the peculiar gait of the animal. The horse suffers pain at every motion of the shnulder, and therefore limits the action of the shoulfer as much as he can, and scarcely, or not at all, lifts the foot, but drags it along the ground. This is the principal and most general symptom. When the lameness is in the foot or leg, the font is readily lifted; in an affection of the shoulder the foot is scarcely lifted at all.

Another, and even more certain mode of distinguishing between lameriess of the foot and the shoulder, is to lift the font, and then gradually extend the limb forward. If the injury is in the foot the horse will suffer no kind of pain from the extension of the leg; but if the shoulder is injured he will exhibit very great pain the moment the leg is attempted to be brought forward.

The shoulder should be well fomented, a calkin put on the heel 
of the shoe, blood taken from the plate vein, and a dose of physic administered. If the lameness continue after this, a liquid blister should be rubbed on the shoulder daily, until it causes considerable swelling, when it should be discontinued, but afterwards repeated if necessary.

Dislocation of the shoulder very rarely occurs, for the strong mass of muscle accumulated here renders it almost impossible; and should it occur, there is no method by which a sufficient power can be applied to replace the bone.

The point of the shoulder, however, is exposed to injury from its very situation. Fomentations will form the best application in any serious case of bruise of this part, and there cannot be a better one than that composed of equal parts of boiling water and cold vinegar. Local bleeding will be useful if the contusion is severe. A dose of physic should always be given if the laıneness is sufficiently great to render it probable that the horse cannot be worked for a few days. If any portion of the bone of the shoulder-blade above, or of the fore-arm below, should appear to be fractured, the whole joint should be covered with a charge, and the horse turned out.

\section{SPRAIN OF THE FORE-ARM.}

The muscles of the fore-arm are occasionally sprained; the injury may be readily ascertained by the heat and tenderness of the part. The same kind of fomentations will be useful here.

INJURIES OF THE ELBOW-JOINT.

The most frequent injury of the elbow.joint is a tumour (capped elbow), usually at first soft, and growing on the point of the olecranon. The capped elbow arises from various causes; the most frequent are violent blows received on the part in the act of kicking, and the pressure of the calkin of the shoe on the elbow by means of an awkward doubling up of the legs when the horse is lying down. The heels should be examined, and the calkins lowered.

When it is confined to this situation, and its contents are clearly fluid, the best method of getting rid of it is the application of cold discutients, as Recipe No. 65 (p. 160), or a bandage wetted with the same embrocation, and so contrived as to press evenly and firmly on the part. If this does not succeed the humour should be opened.

As the tumour enlarges its weight often causes it to become pendulous. It likewise changes it character; it becomes hard and schirrous. A seton may be passed through it, or an incision through the skin, and the tumour dissected out. 'The first is the preferable way, and will succeed in a great majority of cases. T'he seton (consisting of coarse tape) should be passed through the very body of the swelling, and should be moved morning and night. 
The elbow-joint is occasionally opened by kicking, or being cut by the broken shafts in falling; or oftener still by the carelessness or brutality of the groom or carter. The existence of this may be suspected from the rapid and very great swelling of the joint, and the extreme heat, tenderness, and lameness; and it is clearly ascertained by the glairy nature of the discharge. The treatment of this will be spoken of when "opened joints" come under consideration.

In a few cases fracture of the bone of the elbow has occurred. This is a very serious business, for when the immense stress on the point of this bone in every act of progression is considered, it can rarely be expected that union sufficiently perfect to render the horse capable of hard work will take place. If, however, the animal is valuable, a cure should be attempted. A small but strong leathern case must be contrived, accurately fitting and enclosing the joint. The surgeon will place the bones in their natural position, and then pour melted pitch (not too hot) into the case, so as to fill it up, and surround the whole of the joint with the adhesive mass. 'This will form a secure support, and the rest must be left to quictness and time. A sling will rarely be needed.

\section{BROKEN IKNEES.}

Many a valuable horse is destroyed by this accident. The ligaments of the joint being cut through, two bad consequences ensue. The air has access to a cavity unused to its stimulus, and inflammation ensues: the joint-oil also, which was interposed between the bones above and below, in order to prevent friction, having escaped, the edges of the bone press upon one another, and a still more violent inflammation is established, under which the powers of nature soon fail. Therefore the object to be accomplished is to close the joint, and that as speedily as possible, in order that the air may be excluded, and the joint-oil again collected.

The wound must first be thoroughly cleaned, in order that it may be fairly examined, and all obstacles to its healing, in the form of gravel or dirt, removed. The nature and extent of the wound must then be carefully ascertained, and if the joint is not found to be opened, it should be treated as a common wound. The probe will generally determine very speedily whether the ligaments of the joint have been cut through. The peculiar jar and feeling of the bone underneath, when the metal is brought into contact with it, can scarcely be mistaken.

This being ascertained, the question comes whether the opening can be closed; and this depends partly on the extent, and more on the situation of the wound. If the orifice is large, and extends, as it were, across the knee, and is mucis lacerated and torn, it will probably be a serious affair: it certainly will be so if the wound is epposite to the division or interval between the two rows of the 
knee, for a great deal of action will necessarily be going forward there. If the wound is opposite to the upper row of bones the case is likewise serious, but not quite so much to be dreaded, because there is somewhat less action in this part of the joint; and if it be opposite to the lower row the case is more favourable, for there is the least action.

The old way of closing the wound is often the best that can be adopted, and the practitioner will go to work at once, before the bones have begun to rub upon each other, or the membrane of the joint has taken on much inflammation. Any parts of the wound that are much torn and lacerated must be removed, but as little as possible should be taken away. The common firing-iron should then be taken, and brought almost to a white heat, and run rapidly over the wound, and with a medium pressure; the lines being of a lozenge form and near to each other, and particularly at the centre of the wound.

The object of this is to produce considerable inflammation, and consequent swelling, and so mechanically close up the wound. A pledget of soft tow dipped in Friar's balsam must now be placed over the part, and bound down by a calico bandage four inches wide, and about four yards in length, and applied as equally as possible, with considerable tightness, and which must not be removed for six or seven days. If the firing was necessarily severe, the horse should be bled, and a dose of physic should be given.

There must be very great swelling, and the horse must be suffering dreadfully in order to justify the loosening of the bandage before its time; but two or three little snips in it, above and below, may give some ease.

It will seldom be found that when the bandage is first removed the orifice will have been perfectly closed, and the iron should be in readiness, and applied again, but not so extensively, or so severely. The buddingr-iron may also be resorted to, in order more effectually and deeply to sear the edges of the central opening. Once more the wonnd should not be opened for a week, and even then a third application of the iron may be necessary. In some cases the best application to an open joint will be a strong solution of corrosive sublimate in spirits of wine, applied frequently to the wound until the joint-oil ceases to flow.

No poultice or ointment should be applied to an open joint if they can possibly be avoided; the simple object to be pursued is to close the opening, which they will uniformly retard: but if the surgenn cannot satisfactorily determine at the first examination whether the joint has been penetrated, a poultice may be allowed, and even a second, if the appearance of the first should not be decisive. The intention of the poultice is to soften and relax the part, and to suffer some of the joint-oil to flow out, if the joint should really be opened. 'This fluid may immediately be distinguished from a purulent and an ichorous discharge by its glairy nature, resembling the white of 
an egg. If this appears, the poultice must be discontinued, and the orifice closed by means of the iron.

The surgeon will be enabled to determine at every removal of the bandage whether he is making progress towards a cure; and he should recollect that although a fair chance of success will justify him in resorting to measures even so severe as those that have been recommended, nothing will excuse his prolonging torture when hope is fled.

Some degree of blemish will necessarily remain after such a process of cure, and that will be best diminished by a mild blister, and the more perfect growth of the hair will be promoted by the following ointment :-

RECIPE (No. 67).

\section{Ointment to promote the Growth of Hair.}

TAKE-Calamine powder finely rubbed down, two drachms; Levigated charcoal, one drachm;

Liquid turpentine, one drachm;

Lard, four drachms ;

Rub them well together, and then add, again rubbing the whole together very carefully,

Blister ointment (Recipe 27, p. 80), one drachm.

Let a little of this be rubbed well, but not too hardly, into the part, morning and night.

\section{SPEEDY CUT.}

Another serious evil presents itself immediately below the knee, in the form of a bony swelling on the inside of a leg. This is mostly found in horses with high action, and in fast trotting, the hoof, or edge of the shoe being struck against the inside of the opposite leg. The blow is sometimes so violent, and the pain so great, that many horses suddenly drop, to the imminent danger of the rider. Great tenderness and some bony enlargement remain, and occasionally interfere materially with the action of the joint. The speedy cut materially diminishes the value of the horse, for it is a habit which is not always to be got rid of, and such a horse can never be considered as safe.

The tenderness may be abated or removed by means of cooling applications, and the swelling reduced by the application of blisters; and if the evil is ever to be prevented, it is by filing away any projecting edge of the shoe, or convexity of horn, and especially by the use of a shoe the inner side of which is unfettered.

\section{SPLENT.}

Splents, strictly defined, are ossifications of a peculiar cartilaginous ligamentous substance, interposed between the larger and 
smaller bones of the leg; but horsemen agree in calling any little bony tumour along the side of the leg a splent. Their causes are various; early and hard work, over-weighting of the horse, and external violence.

A splent is the consequence of inflammation of the shank bone, caused by concussion or sometimes external injuries. It is the same kind of swelling which accompanies inflarnmation of almost every part. The growth of the splent is attended by heat, tenderness and pain, and frequently some degree of lameness; these symiptoms being generally owing to the painful stretching of the periosteum or membrane covering the bony substance: but when the inflammation has passed off, and the periosteum accommodated itself to the bony substance beneath, the splent becomes like other bone, in a manner destitute of feeling; and they are injurious or not, according to the situation and the state in which they are found. If they do not interfere with the action of any joint, or the play of any ligament or tendon, and are not in an active or growing state, they may be unsightly, but they are little or no kind of detriment to the horse. Some knowledge of the anatomy of the leg, or considerable observation as to the effect of splents on different parts, is necessary in order to decide on the necessity of their removal.

If they are productive of lameness, or in situations where they are likely to produce lameness, the hair should be cut very closely around them, and a little mercurial ointment well rubbed in for three or four days; or, what is still better, a compound of iodine with mercurial ointment. The mercury will dispose the absorbents to be more easily acted upon by the blister ointment, which should be actively rubbed in on the fourth or fifth morning, the former application having been cleanly washed off. If one blister makes no change in the size of the splent, another should be applied; but beyond this it is not worth while to go; for it will often happen that the effect of the blister is not immediate, but begins to become apparent a week or a fortnight after the practitioner had been led to think that he had been labouring in vain.

A better and more scientific mode of treatment consists in making a small incision through the skin below, and also above the splent, then passing up a convex-edged bistoury, and cutting down on the splent so as to divide its covering, the periosteum; then inserting a small seton from the upper to the lower incision, keeping it in about ten days or a fortnight. This operation will almost invariably succeed in removing the lameness, and preventing its return, and in general materially diminishes the enlargement.

Splents are oftenest seen in young horses, and generally are taken up in old horses by a process of absorption which we have little power to hasten or retard. A far more serious injury of the leg is 


\section{SPRAIN OF THE BACK SINEWS.}

This is often occasioned by the horse being over-weighted, and then ridden far and fast, especially if his pasterns are long; but it may occur from a false step, or from the heels of the shoes being too much lowered. The thin-heeled shoes that were once in fashion did irreparable mischief in this respect.

The nature of the injury consists either in the laceration of some of the small fibres which connect the back sinews or tendons with their sheath, or a bruise, or friction of the tendon against the delicate and sensible membrane which lines the sheath. Inflammation is thus produced, and the natural moisture which lines the sheath, and which was intended to prevent injurious friction, is no longer secreted, but one of a thicker and different character is thrown out, which coagulates, and forms adhesions between the tendon and the sheath, and renders the action of the limb both difficult and painful.

Sprain of the back sinews is detected by swelling and heat at the back of the lower part of the leg; puffiness along the course of the sinews; extreme tenderness, so far as the swelling and heat extend; and very great lameness.

The first object is to abate the inflammation; and this should be attempted by bleeding from the plate vein; by means of which blood is drained from the inflamed part.

Next, local applications should be made to the back of the leg in the form of fomentations of water sufficiently hot, and frequently repeated. At the same time as much strain as possible should be taken from the sinew by putting a high calkin on the heel of that shoe.

The horse should have a dose of physic, and be put on mash diet. When, in the course of a few days, the leg will bear a little pressure, a different course should be pursued. The inflammation having been abated, the practitioner should think of taking up the deposit between the tendon and the sheath, and which, if it did not perpetuate lameness, would at least interfere with the motion, and limit the action of the limb.

It is too frequently the absurd practice of the farrier to attempt this by means of hot oils or blisters, immediately after the accident, and before the inflammation is subdued. By doing this he increases the inflammation, and aggravates the evil, and often renders a thorough cure impossible.

The first application, with a view to promote the absorption of the matter thrown out, should be in the form of pressure, cautiously applied at the beginning, and only as the animal can bear it, but gradually tightened every day- the bandage wetted with the discutient lotion (Recipe No. 65, p. 160), in order that the leg may be kept cool, and thus not only the inflammation lessened, but the tone and strength of the parts in some degree restored. 
In slight cases, when the tenderness, heat, and swelling, and lameness have all subsided, the horse may go to work, if he does not go too far or too fast: but if the sprain has been severe, considerable enlargement will remain after the absolute lameness is gone off. This is the remainder of the coagulated fluid thrown out under inflammation, and it will materially interfere with the free and safe action of the limb; therefure, and especially where quick work is required, it will be expedient to blister the leg, and turn the horse out for a couple of months.

In very bad cases it may be necessary to fire the leg. If this should seem to be required it should be done effectually, that is, until the fired lines present a deep brown colour, showing that the iron has been carried through the cuticle and into the cutis, thus alone will all the purposes of firing be obtained, not merely by abating deep-seated inflammation, but by its acting as a permanent bandage, and thus giving strength to the part; and also, by its constant presure, rousing the absorbents to take up the deposited matter. After firing, the horse should be turned out for two or three months; indeed, it would be worse than useless to attempt this severe operation without the certainty of two or three months being allowed for the gradual abatement of the external inflammation, and the absorption of the internal deposit.

\section{WINDGALLS.}

The sheath of the flexor tendon at the fetlock is confined above by ligamentous substance, which sometimes becomes stretched, and even partially ruptured, by the pressure of an increased quantity of synovial fluid. This constitutes windgalls, which rarely occasion lameness unless they are very large and appear suddenly, being then evidently produced by violent action, and attended with inflammation. They are, however, always blemishes. A distension of the capsular ligament of the fetlock joint itself will also produce windgalls, situated more forward than the others.

The mode of treatment is the same as in sprain of the back sinews. When there is much heat about the part, fomentations will be useful; but the windgall will sooner bear pressure than the sprained sinew will, and a flannel roller should be applied, wetted with the same cooling astringent lotion (Recipe No. 65, p. 160).

If the windgall will not yield to this, the common liquid blister (Recipe No. 31, p. 83) should be lowered with four times its quantity of spermaceti oil, and some of it daily well rubbed in over the enlarged bags. This, which is called sweating down the windgal keeps a constant stimulus upon the part, not sufficient to blister or to cause lameness, but enough to rouse the absorbents to more powerful action: the embrocation must be omitted for three or four days.

If the horse can be spared, a regular blister (Recipe No. 27, p. 
80) will be far more certain and effectual in its operation; and, should even that fail, firing may be resorted to, still in longitudinal lines, sufficiently deep to rouse the absorbents to action, but never cutting into and through the windgall.

\section{SPRAIN OF THE FETLOCK JOINT.}

This is of almost as frequent occurrence as sprain of the back sinews, and it is more serious, for there is more pain during the action of the joint: the inflammation is longer kept up, and the heads of the bones of the joints are apt to become enlarged, constantly interfering with the use of the joint, and the inflammation liable to be renewed from the slightest cause. It may be distinguished from sprain of the back sinews by the heat and tenderness and enlargement being clearly around the joint, and in a manner confined to it.

The mode of treatment is still the same. Fomentations will be as effectual as in strains higher up, and they must in their turn give way to pressure and cold astringent lotions. Firing will sometimes be necessary, but the horse can seldom be safely returned to his work without an active blister.

\section{RUPTURE AND SPRAIN OF THE SUSPENSORY LIGAMENTS.}

At the back of the fetlock, and forming its roundness or projection behind, are two little irregularly shaped, but somewhat circular bones, attached to the joint, yet forming no part of it; they are called the sesamoid bones. A ligament, descending from the upper part of the back of the leg, and pursuing its course by the side of, and more furward than, the back sinews, is attached to the upper and back part uf these bones, and is also continued on, and inserted into, the pastern bone below. It is called the suspensory ligament, because the weight of the body is, when the foot is first put to the ground, in a great measure suspended by it, and much concussion between the bones of the joints is prevented.

It must have been observed how the pasterns and the fetlock yield, and are brought almost to the ground in the rapid action of the horse, and particularly if he has long pasterns. This ligament, very highly elastic, is yielding to the weight of the horse, and extending itself, and the sesamoid bones are turning round in their places to permit this elongation. The foot being again lifted, and the weight removed, the ligament contracts to Its natural length, and the sesamoids turn back and occupy their former places; and it is in this gradual lengthening and contracting of the elastic suspensory ligament, and the rotation of the sesamoid bones, that the easy and pleasant action of the horse with oblique pasterns consists. In the horse with short and upright pasterns the weight and concussion are thrown more on the bones of the joint; the action is jolting, and hence sprain and enlargement of the fetlock joint. 
These ligaments, as it may be easily imagined, are subject to occasional and serious injury. They are sometimes ruptured, and the horse is said to break down.* The fetlock, no longer supported by the suspensory ligament, almost touches the ground, and the lameness is dreadful. This lowering of the fetlock will at all times distinguish rupture of the ligament from sprain of the back sinew. The part injured, in this accident, is generally that below the fetlock joint: not always the suspensory ligament, but sometimes the other ligaments which brace the sesamoid bones to the pasterns.

This is a serious, and, generally speaking, an irreparable injury, though fortunately it is a rare one, for it will be almost impossible to keep the divided edges of the ligament sufficiently long in contact for reunion to take place. A shoe with a very high calkin must be put on; the leg must be well bandaged, and perfect quiet must be enjoined. Inflammation may be kept under by the application of cold to the part, but no stimulating appiication must be used until all inflammation is removed, when the leg should be fired.

A much more frequent injury than that just described, though fortunately one much less severe, is a strain and enlargement of the suspensory ligament, sometimes on one, but generally on both sides. The treatment should be similar to that before advised; that is, first to remove the inflammation, and then to blister or fire the enlargement.

\section{CUTTING.}

The inside of the fetlock is often bruised and cut by the opposite foot. This is particularly the case in young horses, before the joints attain their natural strength, and their straight and level action; for the same reason horses when they are tired frequently cut, for the leg can no longer preserve its perpendicular position and motion.

There are few things more difficult to cure than cutting: the inner heel has been raised or lowered, and the outer one raised or lowered also, and in both cases occasionally with good effect; but, oftener, the horse continues to cut on whichever side the unequal bearing is thrown. That which has oftenest succeeded, and which is most consistent with common sense, is the level paring of the foot, and the level surface and bearing of the shoe; at the same time an additional nail being put on the outer side, and only two nails on the inner side of the shoe, and these near to the toe. This unfettered way of shoeing, while it retains perfect security to the shoe, permits the foot to expand and contract naturally when the horse is in action, and the straightforward and safe motion of the foot is then most likely to be preserved. At the same time any projecting edge of the shoe beyond the crust should be carefully

* This term is also applied by racing men to a severe sprain of the back sinews. 
filed down; and the inside quarters, and particularly if there is any appearance of bulging, should be rasped, for the horse as often bruises the fetlock with the side of the opposite hoof, as he cuts it with the edge of the shoe.

\section{SPRAIN OF THE PASTERN JOINT.}

This joint suffers almost as frequently as the fetlock. The seat of the injury may be detected, as in the other case, by the heat, swelling and tenderness: the same course of treatment must be pursued.

\section{SPRAIN OF THE COFFIN JOINT.}

This may be recognised by heat and tenderness along the coronet, and particularly in the front of the foot. The treatment is the same; but the cooling discutient applications are not always effectual, because this joint is a little way within the foot, and in a manner out of their reach. Fomentations will be of comparatively little use; but the foot may with advantage be surrounded with a poultice, or a strip of cloth may be tied round the coronet, and kept constantly wet with cold water, or the lotion (Recipe No. 66, p. 160). It will seldom be safe to permit the horse to return to his work until he has been actively blistered round the coronet, or, in very bad cases, fired; for thus alone can the inflammation be removed from so deeply-seated a part.

\section{RING-BONE.}

From the great action of the pastern joints, and the injuries to which the ligaments which are attached to those bones are exposed, inflammation there is oftener accompanied by the deposition of bony matter than in any other part. Ring-bone, so called because it sometimes extends round the upper part of the foot like a ring, is the frequent consequence of sprain in the pastern and coffin joints. Sometimes it begins as high up as the middle of the larger pastern bone; oftener about the pastern joint, and sometimes from the lower and smaller pastern bone. It is the consequence of inflammation of the ligaments; bone being deposited upon or about them, and sometimes parts of them being changed to bone. The lateral or side ligaments are those that are oftenest or soonest affected, and ring-bone is then discovered in its early state by a rounded hard projection on each side immediately above the coronet.

Ring-bone is always accompanied by lameness at the commencement; but the continuance and extent of the after lameness depend on the degree in which the bony tumour interferes with the action of either of the joints. In some cases it goes off altogether, particularly in the hind feet, where the concussion is not so great, and the inflammation has not been so intense; but in the fore feel, sup- 
porting more of the weight of the body and liable to severer injury, the bony deposit is usually greater, and involves one or both of the pastern joints, and the cartilages of the feet. Lameness, and often of an incurable nature, is then the result; and it not unfrequently happens that the pastern or coffin joint, being surrounded by unyielding bone, is lost.

It is of little use to meddle with ring-bone unless we begin at its commencement, and then it should be attacked in good earnest. Local bleeding, poultices, and fomentations should first be employed, and, the inflammation being removed, the part should be blistered, and in the majority of cases the cautery is to be preferred to the blister. Both, however, will often fail ; for the incessant action and labour of the parts, and the pressure on them, render it very difficult to arrest the progress of the inflammation. In a confirmed cuse of ring-bone, and especially where the joint is anchylosed, it would be the height of cruelty to subject the poor animal to the useless torture of the iron.

\section{GROGGINESS* - KNUCKLING, FTC.}

This is a frequent tremulous motion of the whole leg, with a bowing of the knee, and some degree of knuckling of the fetlock; while on the slightest tap behind the knee, the joint yields and bends. There is an evident loss of power and energy in the limb; and though in some measure a natural defect and the effect of high breeding, it is often a proof also that the horse has been hardly worked, and injured by that work, and probably can endure comparatively little more extra-exertion.

There is a relaxation of the extensor ligaments and sinews of the joints, or disease within the joints, preventing the animal from giving them that fixed position which he otherwise would do. There is little remedy for it but blistering, and the comparative rest which the horse enjoys when turned out, and the salutary and bracing, and not sufficiently appreciated influence of cool air on weakness of the legs and feet.

\section{FRACTURES.}

A horse is often condemned without cause, on account of fracture of the bones of the fore-legs. Either the practitioner dislikes the trouble of the case, or the proprietor is loth to make the proper remuneration. The only circumstances that will justify the abandonment of a horse with fractured leg are when it is a compound fracture, the integument and muscular parts being lacerated as well as the bone broken, or otherwise the bones so displaced as

* The term grogginess is usually applied by horsemen to chronic foot Jameness. 
to render it impossible to replace them in their proper position; then, indeed, the case is hopeless.

The cure of fracture of the pastern, or the shank bone, may be undertaken with fair prospect of success. All that is to be done is to cut the hair closely from the part; to bring-and as gently as may be-the divided edges of the bones in apposition; to retain them there by a pitch plaster; and then to bind on splints, which shall reach a considerable way above and below the injured part.

This should be done in the box in which it is intended that the horse should remain. He should then be bled, and a dose of physic given, and left as much as possible to himself. He will take care of his broken leg; he will not press upon it for many a day; and not at all, until he can do so without much pain; and in many more cases than some have imagined, the fractured bone will unite, and the horse will do well.

A sling should rarely be used. The sad excoriations and other inconveniences occasioned by the long use of the sling have, more than any thing else, brought the treatment of fractures into disrepute.

Fractures of the hind extremities are more serious affairs, and should be undertaken with still greater caution.

\section{CHAPTER XXX.}

\section{INJURIES AND LAMENESSES OF THE HIND EXTREMITIES,-LOWER}

\section{FRACTURE OF THE HAUNCH.}

THE point of the hip, or haunch, is exposed to considerable danger from accident or brutal force. Either in consequence of falling, or being run violently against, or receiving a heavy blow, the tuberosities of the haunch may be broken off. There is an immense mass of powerful muscle here; so that it would be utterly impossible by any mechanical force to bring the disunited pieces of bone accurately together again; yet nature will do much towards it: for if, after the inflammation has a little abated, a thick charge is put over the loins, the tuberosity will some months afterwards be found connected with the part where it was torn, either by interposed callus, or even bony formation. There will always, however, be some difference in the appearance of the two hips, and occasionally some lameness; but the horse will perform slow work with tolerable ease. 


\section{SPRAIN OF THE ROUND BONE.}

One would think that it was impossible that the ligaments of the joint connecting the thigh bone with the haunch could be subject to sprain; the enormous mass of muscle by which it is surrounded seems to bid defiance to any power of extension or injury. Dislocation, or even strain of this joint, does not occur one-tenth part so often as the groom imagines. Lameness from sprain of the round bone is sometimes characterized by the horse dragging his toe behind him, and at other times by a very peculiar rotatory, indecisive motion of the limb. The best proof, however, of the lameness being seated here is the pain evinced by the animal when this joint is firmly pressed upon. There is seldom much enlargement, and the injured part is too deep for the heat to be always felt.

If fomentations are applied at all in the treatment of this lameness they should be as hot as the hand of the operator will bear, and frequently repeated; but it will generaily be the best practice to have immediate recourse to a blister. Some apply the cautery to the joint. Rest is absolutely necessary, and should the lameness long continue, a charge should be placed on the part, and the horse turned out to grass.

\section{STIFLE LAMENESS.}

There is much oftener lameness in the stifle, and there are few places where the actual cause of lameness is so deceptive, or so little understood. There is seldom sprain of the joint; but frequently dislocation of the patella or knee-cap. The horse is found standing with his hind leg thrust backwards as far as possible, resting upon the fetlock, the pastern perfectly bent, and the whole limb fixed; the animal is evidently in great pain, perspiring profusely, and heaving sadly at the flanks.

The case, however, is easily treated. Some persons proceed in a very summary way: they give the horse a good lash or two with a whip, and by his violent effort to get away from the punishment, the limb is flexed, and the knee-pan returns to its place. This, probably, would succeed in many cases; but there is some danger attending so rude an operation, for the ligaments of the patella may be sprained, or even ruptured, in the sudden and violent action of the limb.

The dislocation can be reduced without much trouble, or any danger. It generally takes place inwardly. An assistant should lift the lame leg, and carry it forward and upward, while the surgeon presses upon the edge of the patella, either outwardly or inwardly, according to the nature of the dislocation, and the bone will be returned to its natural situation with a facility that would scarcely be expected. If some hours have passed, however, be- 
tween the dislocation and its attempled removal, the ligaments will have been so much extended and weakened, that the bone sometimes slips out again, as soon as the limb is quitted: it will always, therefore, be prudent to bathe the joint with cold water; or to blister, if the horse has previously been subject to this dislocation. Should not the ligaments even then have regained sufficient strength, the cautery will probably be needed. Much inflammation, and enlargement of the joint, and even fracture of the patella, arise from contusions received in hunting, or when a horse is running away: rest, fomentation, and, if unavoidable, blistering, are the proper remedies.

The muscles of the thigh, generally, and particularly of the inside of it, and near the stifle, have sometimes been severely sprained in hunting, when the country is deep and the fences high. Rest and fomentation, with mild physic, are the remedies here.

\section{THOROUGH·PIN.}

Approaching the hock, we sometimes find a soft tumour, nccupying the space between the bone and the tendon that passes over the point of the hock. It projects on both sides, and is therefore called a thorough-pin. Sometimes this tumour is situated above the point of the hock, and sometimes below. In the latter situation it is connected with the hock joint itself. It is not necessarily a cause of lameness; it comparatively seldom is so, unless, by its bulk, or by its being nearer the tendon than the bone, it interferes with the action of the joint.

If the tumour is small, and there is no lameness, it is better to let it alone; but if it is evidently increasing, or there is the slightest lameness, an attempt may be made to sweat it down, as recommended in page 170, or the blister ointment (Recipe No. 27, p. 80) may be at once applied. A still better treatment is the frequent application of the following ointment:-

\section{RECIPE (No. 68).}

TAKE-Biniodide of mercury, one part ;

Lard, or palm-oil, seven parts :

Rub together in a mortar.

A bout the size of a hazel-nut to be rubbed on the part at a time, and repeated daily until a considerable scurf is produced.

\section{CAPPED HOCK.}

At the point of the hock a tumour occasionally appears, at first soft, and containing some fluid. It is usually the consequence of violence; and it is most frequently produced by the injury which the animal inflicts on the hock in the act of kicking. It is rarely 
accompanied by lameness, and when there has been impeded action of the joint, it has oftener proceeded from injury inflicted on the hock generally, than from the simple tumour on the point of it. It should, however, be removed; for it is apt to increase with a slight repetition of the first exciting cause, and, if it is sufiered to become hard and callous, it is sometimes exceedingly obstinate.

The inflammation should be reduced by cold applications, and the ointment advised in the last article applied. If this should fail, a seton should be passed through the tumour.

\section{BOG-SPAVIN}

Consists of a distension of the capsular ligament of the upper joint of the hock with synovia: it therefore resembles thorough-pin and windgalls, and should be treated in a similar manner. When it appears suddenly, and is considerable, it is attended with lameness from inflammation of the joint, but otherwise it is generally free from both lameness and inflammation.

The old-fashioned method of passing a ligature round the vein, above and below the varicose enlargement, and cutting out the interposed portion, is now deservedly abandoned by every judicious practitioner.

\section{BONE-SPAVIN.}

From a consideration of the anatomy of the hock, it will be evident that the weight of the horse is not equally borne by the two small bones at the back of the larger and principal orse of the hind Jeg. The inner bone supports considerably more than its share of the burden. It has been shown that this was the case in the fore leg, and that in consequence of it the horse was subject in splent: the substance which united the two bones became inflamed, and was changed into bony matter, and this process of ossification spread beyond the original seat of inflammation, and displayed itself in the form of bony tumours, called splents. In the same manner the substance between the great bone of the hind leg, and the smaller one on the inner side, becomes inflamed from the disproportionate weight that is thrown upon it, and the concussion to which it is exposed, and it becomes ossified, and the process of ossification spreads, and there results the bony tumour on the inside of the hock, which is denominated spavin.

This is always a source of pain and lameness at its first formation; but the continuance of the lameness depends on the progress of this bony growth, and its interfering with the action of the joint. If it is found principally below, and does not spread over the small bones of the joint and limit their motion, the bony tumour may acquire a very large size, and not produce much lameness. The continuance of this exemption from lameness, however, will be very uncertain; 
for no one can tell, when this habit of throwing out bony matter in a part is once established, what direction it will take, or what mischief it will effect.

The treatment of spavin must be energetic. An active blister should at once be applied, and repeated again and again, and in obstinate cases of lameness, the cautery must be resorted to, or a seton inserted so as to extend over the surface of the spavin.

A singular, and yet sometimes an effectual way of relieving, and sometimes removing, the lameness of spavin, is putting the horse to the plough. The slow action of the limb in ploughing can be borre without very great pain, and at length the ossification ceasing to extend, the parts are used without pain.

The farrier once used to have recourse to the chisel and mallet in order to remove this and some other bony productions; the spavin was sometimes punctured with the awl, or perforated with the gimlet; but this, in the majority of cases, only added to the inflammation, and increased the evil ; for it aggravated the inflammation in the part which was previously threatening the loss of the limb.

In some cases the severest treatment will not remove the lameness of spavin, and in others there will be lameness clearly referrible, by the action of the horse, to the hock, but unaccompanied by any external bony enlargement. 'The cause of this was long unsuspectell: at length it was recollected that the joint consisted of several bones, having some slight motion upon one another, and each invested by its own synovial membrane, so as to form a separate perfect joint; and it began to be suspected that the concussion and violent action, which excited inflammation and ossification between the larger and smaller netatarsal bones, might produce injurious effect on some of these little, but complicated joints. 'The examination of some horses after death, that had long laboured under obscure lameness in the hind leg, set the matter in its proper light; for there was found deep, in the internal part of the hock, inflam. mation of the membranes of these little joints, going on to caries of the bones, without one external appearance to indicate such an affection. In other cases equally obscure, the same diseased appearance has been found in the upper joint of the hock, in which the principal motion takes place.

This internal mischief was sometimes unconnected with external hony enlargement; but much oftener accompanied it. The mischief in the first case commenced within; in the latter it was consequent on the spread of the inflammation, and the tendency to the production of bone, which had evinced itself without. 'This satisfactorily accounts for the difficulty of removing spavin-lamenes: in some cases, and affords a new and satisfactory explanation of many a lameness behind, that had been hitherto inexplicable.

This also accounts for the spavined horse occasionally becoming in process of time sound, although the enlargement at the spavin piace remains. 'The inflamed and paiful membrane becomes ossi- 
fied, the bones are united together, and although the joint betrays a greater or less degree of stiffness, the agony occasioned by the rubbing of the bones upon each other has ceased, and the lameness has ceased with this.

Experienced horsemen are now accustomed to refer to the hock nearly every lameness of the hind leg for which they cannot find sufficient explanation elsewhere.

\section{ENLARGED HOCK.}

Either from this inflammation among the small bones of the hock, or from external violence, the whole of the joint begins sometimes to enlarge, accompanied by much heat and lameness: by the application, however, of proper means, the heat and lameness are removed; but the enlargement of the hock is permanent. Such a horse should be regarded with considerable suspicion. He may be capable of common work; but he will often fail if much extra-exertion is required from him, or often repeated. Firing promises to be efficacious here, for a portion, at least, of the mischief is deeply seated.

CURB.

This is inflammation of the ligaments or sinews at the back of the hock, and particularly of the ring-like ligament which binds down the tendon of the leg. It is most frequent in young horses, whose joints have not attained their full strength. A young horse may go out of the yard perfectly sound; he treads awry, or he treads on some inequality of ground, or he makes some sudden exertion, and he immediately becomes decidedly lame in one of the hind legs; and, on being closely examined, there is found to be an enlargement on the hinder part of the hock, three or four inches below the point of it.

The first object to be effected is to remove the inflammation, and as the injured part is so nearly superficial, there will not be much difficulty in that. The hock should be bathed with the lotion (Recipe No. 65, p. 160), or a roller should be passed round the part, and kept constantly wetted with the lotion; at the same time, if the lameness is considerable, a dose of physic should be given, and absolute quietness enjoined; and a high heel or patten shoe should be placed on the foot so as to throw the weight off the affected part.

In three or four days the heat will probably have subsided, and the lameness almost disappeared; but there will remain a slight enlargement of the part. Stimulating applications should now be resorted to, not only to cause the absorbents to take away this deposit, but also to strengthen the ligament thus weakened by distension and inflammation. The liquid sweating blister (Recipe No. $30, \mathrm{p} .82)$, and lowered, as recommended in the same page, will 
generally effect both purposes; but should the slightest lameness be observed, a direct blister (Recipe No. 27, p. 8(1) should be rubbed in. In some cases, neither the enlargement nor the lameness will perfectly subside without the use of the cautery. It should also be remembered, that although the enlargement of curb will occasionally remain for several months, in despite of the blister, it in a great measure disappears in process of time. Curb is apt to return if the horse is sent to work too soon; and it is now a well-established fact, that the predisposition to throw them out is hereditary.

\section{SWELLED LEGS.}

This is a very frequent and most troublesome complaint. The cause is often exceedingly difficult to be detected, and when discovered, is often so complicated, and the disease becomes so inveterate, that the practitioner has little prospect of completely eradicating it.

The fore-legs occasionally take on a disposition to enlarge; but it is oftener, and running to a greater extent, found in the hinder ones. A horse is sometimes left in perfect health at night, and is found, on the next morning, with one or both hind legs enormously enlarged. The skin is tense and glistening; it is hot and exceed. ingly tender; the horse cannot bear to have it touched; he catches up his leg suddenly; the limb moves as if the lower part of it had no joint; and, in the convulsive effort to get it out of reach, the animal not unfrequently loses his balance, and falls, or threatens to fall, on the examiner.

This complaint, which is known by the name of weed in many parts of the country, is evidently sudden and very intense inflammation of the absorbents of the leg. A considerable degree of general fever often speedily follows; the pulse quickens; the mouth is hot; and the horse is entirely off his feed. Young horses are peculiarly subject to this, especially if, after being talsen from grass, they are too highly fed, and suffered to stand idle in the stable. Sometimes in older horses, as well as in the younger ones, it is the sudden shifting of inflammation from some other part, as the lungs or the intestines.

This apparently formidable species of swelled leg readily yields to proper inedical treatment. The leg should be frequently fomented with warm water; from four to six quarts of blood should be taken away, and a good dose of physic administered, which should be followed by diuretic medicine. The swelling, however, having subsided, and the tenderness having gone off, the legs should be well rubbed, and then lightly bandaged; gentle exercise should be used and alterative medicine administered; for the over-distended vessels must necessarily be weakened, and the disease is apt to return.

If an old horse, or a young one that has been over-worked, is suffered to stand a day or two in the stable, his legs often fill, but 
without pain or heat. The legs of some horses regularly swell every night. This is connected with debility, either general or of the part. The case must be considered very attentively before any measures are adopted. The horse may be too highly kepl, but his legs are suffering from occasional over-work: then mild physic, mild diuretics, regular exercise, hand-rubbing, and bandages around the leg, will be the proper means to be adopted; decreasing a little the quantity of food, and giving mashes and green meat, if the season will allow it. The habitual use of the bandage is an excellent thing in these cases, and has often gradually strengthened the vessels of the part, and rendered the lecr as fine as ever.

Frequently an enlargement of the leg is connected with general debility. The horse has been cruelly over-worked,-or he is recovering from serious illness, - or he has been half-starved, and he is generally weak, and these weaker and injured parts yield. A very mild dose of physic will sometimes be indicated even here, and especially if there is any foulness about the horse. A daily mash should be given; a fair allowance of corn; green meat if it can be procured; gentle and regular exercise should be used; and small doses of cantharides, varying from three to five or six grains, and a few tonic diuretic balls (Recipe No. 42, p. 110). Every thing should be done to increase the strength of the system generally, and the vessels of the extremities will soon regain their proper tone.

This course of treatment will be particularly proper if the legs swell at the spring and fall of the year. The horse is then shedding his coat, a process which is always attended by some debility. The tonic diuretic balls will here be exceedingly useful.

In every case, however, of swelled legs, a great deal more depends upon management than on medicine; and there is nothing so likely to be injurious as the frequent use of diuretics, of which many grooms are so fond. They are fruitful sources of debility (the worst cause of swelled legs): they first weaken the urinary organs, and loss of tone in the system generally too soon succeeds.

Connected occasionally with swelled legr, and producing that debility of the parts which takes from the vessels the power of contracting on their contents, is

\section{GREASE.}

This is essentially inflammation of the skin of the lieel. It may be traced to various causes. One of the most frequent is the washing of the heels when the horse comes in from work. He is hot all over, and hot in the heels as much is any where else; but the harness is scarcely taken off, before cold water is sluiced plentifully over them, under the notion of clearing away all the dust that hangs about them. That I could excuse, if they were rubbed thoroughly dry afterwards; but the groom has too much to do, or is ton idle for this: he, perhaps, sponges off a portion of the wet, but he leaves a 
great deal more, and the cold process of evaporation is immediately established. There is nothing so debilitating as this, or so destructive of the very life of a part; and it is the prevailing cause of grease: when the tone of any portion of the trame, or any set of vessels is impaired, they are peculiarly subject to inflammation. It is the character of inflammation to attack the weakest part.

This washing of the heels should be strictly forbilden in every well-regulated stable. After the horse has stood a quarter of an hour, during which time the groom may be employed about the harness, or some of the arrangements of the stable, a great leal of the dirt will be dried upon the leg, and may be easily brushed off. Ten minutes after that, the rest may be brushed away, and a little hand-rubbing will restore the part to its natural glow.

Then, the vessels of the heel being weakened and disposed to inflammation by this absurd system of washing, let it be supposed that the part is exposed to some of the common exciting causes of inflammation; the horse stands in a very hot stable, with a draught of cold air continually blowing upon his heels; he remains day after day in the stable unexercised, until he has swelled legs: there is no system of cleanliness going forward in the stable, but the heels, already irritated, are exposed to the acrimonious influence of the dung, and urine, and filth, of various kinds; and, all this while, the horse has been too grossly fed and has a superabundance of humours about him, ready to settle in the weakest part. Addled to all this, and even under careful management, the heel is, and must be, a weak part: it is farthest from the centre of circulation; the fluids have up-hill work, centrary to the force of gravity, in order to return from the heels. If all these things are talien into consideration, the prevalence of grease needs not to be wondered at. It is, however, a plain and palpable proof of some mismanagement, let it occur when or where it will. It assumes different forms in its different stages; but at first it is pure inflammation of the skin of the heel. The heel is red, tender, dry, scurfy. The natural suppling secretion, from a part that has so much action, is suspended.

If warning is taken in time, the complaint is easily arrested. No effort must be made forcibly to separate the scurf from the skin beneath. There must be no excoriation, or soreness, if it can possibly be avoided. A good thick lather of soft soap and water should be rubbed gently into the heel, and a considerable part of the scurf will be readily removed.

The following ointment should then be rubbed on the heel morn. ing and night.

RECIPE (No. 69).

\section{Ointment for Scurfy Heels.}

TAKE-Extract of goulard, half a drachm;

Lard, an ounce:

Rub these well together until they are thoroughly incorporated. 
This will supple and detach the remaining part of the scurf, and at the same time southe the inflammation of the skin. A mash should be given every night; a diuretic ball twice in the week; green meat should be allowed, and every exciting cause of grease removed.

Possibly the inflammation may have proceeded somewhat farther, or the scurf may have been suffered to remain too long: it becomes hard and brittle, and cracks soon extend through it across the heel. This is the second stage of grease- "cracked heels."

Here no certain plan can be laid down, but the practitioner must be guided by the depth of the cracks, and the general inflammation of the heel. The first thing, however, to be done, is to get rid of the scurf by means of the soap and water, or the ointment for scurfy heels (Recipe No. 69, in the preceding page). If the cracks are superficial, an attempt should be made to dry them up, and a lotion will be most conveniently employed for this purpose. That which will oftenest succeed is a very weak solution of alum. The alum lotion (Recipe No. 20, p. 68) may be lowered with four times its quantity of water.

If the crack is not evidently closing in the course of a very few days, the mild caustic wash for wounds (Recipe No. 63, p. 159), likewise lowered with four times the quantity of water, should be tried; and should the case still be obstinate, the following lotion must be substituted.

RECIPE (No. 70).

\section{Sirong Wash for Grease.}

TAKE-Blue vitriol, a quarter of an ounce;

Alum, three drachms; and dissolve them in a pint of water.

It will occasionally happen, that either there was at first so much inflammation, or it is produced by the slightest stimulating application, that it will be necessary to allay the inflammation before the cracks will heal. Nothing is comparable to the common linseed poultice for this purpose, unless it be one made of carrots, boiled until they are very soft and then mashed. There is something in the juice of the carrot which is peculiarly beneficial in all greasy affections.

If the cracks discharge a thin sanious fluid having an unpleasant and fetid smell, a little of the solution of the chloride of lime (Recipe No. 18, p. 68) should be added to the poultice.

The inflammation having been somewhat subdued, and the cracks beginning to look healthy, the practitioner should return to the lotions, beginning again with the alum wash, which should be applied morning and night; or if this should appear to be a little too stimulating, he may use the following ointment, which, on 
account of its excellent quality, when an ointment is admissible in the horse, I may properly designate-

\section{RECIPE (No. 71).}

\section{A Healing Ointment.}

TAEE-Of lard or palm.oil, four pounds;

Resin, one pound; melt them together, and when they begin to cool and to thicken, add

Calamine powder, well rubbed down, one pound.

A mild dose of physic will be useful in this stage of the complaint, or a diuretic ball every alternate night.

If much swelling should remain around the pastern and fetlock, or extend up the leg, a bandage, not too tightly applied, will be serviceable. The alum or the blue vitriol lotion, changing them as either may seem to lose its effect, should also be daily rubbed into the swelled part, and particularly if there is any scurfiness, or cracks are beginning again to appear. This, of all the stages of grease, is that in which a run at spring grass would be beneficial.

There must be neglect on the part of the veterinary surgeon or the proprietor of the horse, or both of them, if grease proceeds farther than this; and yet there are too many cases in which the heels assume a dreadful appearance. The cracks disappear, or rather, while they seem to fill up, the disease extends, and one continuous oozing and soreness spreads over the pasterns and fetlock. Fungous granulations spring from different points: they increase, they unite, and there is an irregular protruding surface, sore, and bleeding at the slightest touch. Some parts hardening, they are covered with scabs, or sometimes with a spurious kind of horn. The irregular surface by degrees assumes the form of knobs, running in lines, and which often bear no indistinct resemblance to a bunch of grapes; hence they are technically called grapes. A strangely mingled purulent, mucous, sanious discharge runs from the greater part of the surface.

Severe measures alone will be of avail here, and it is, generally, the best practice to proceed to the cautery at once. The scabs and the spurious horn should be removed with a knife, and then a flat heated iron run rapidly over the whole surface. A rowel should be inserted on the inner side of the thigh, and a dose of physic given, after which a course of the tonic diuretic balls (Recipe No. 42, p. 110) should be commenced.

The eschars produced by the cautery beginning to come off, the part should be daily washed with the following lotion:- 
RECIPE (No. 72).

\section{Lotion for confirmed Grease.}

TAKE-Corrosive sublimate, one drachm;

Rectified spirit, half an ounce; rub them well together, until the mercury is dissolved, and then gradually add

Lime water, two ounces.

Few lotions have a better effect than this; but should it seem, after a while, to lose its effect, let the following liniment be tried :-

RECIPE (No. 73).

\section{Liniment for Grease.}

TAKE-Powdered verdigris, and sugar of lead, a quarter of an ounce of each ;

Honey, one ounce:

Rub them together, and form a liniment.

A horse, however, that has once had an attack of grease like this will be very subject to a relapse; great care should, therefore, be taken not to expose him to any of the predisposing causes of grease. No water should be suffered to go near his heels; he should be well but not over fed; a mash should be occasionally given; also green meat, and particularly carrots, mild physic, and tonic diuretics; and if it is practicable, a few weeks' run in a salt marsh should be allowed.

\section{CHAPTER XXXI.}

\section{THE STRUCTURE AND DISEASES OF THE FOOT.}

TuE diseases of the foot are those of most common occurrence, and the treatment of them is often most tedious and difficult. They cannot be explained without a slight sketch of the structure of the foot.

The foot of the horse is composed of a horny covering, or box, and its contents. The horny covering is called the hoof; the portion of it which is visible, when the foot is on the ground, is the crust; and beneath are the sole, the bars, and the frog.

The crust has its lower edge resting on the ground, and as it ascends over the coffin bone it takes a direction obliquely backward. The degree of obliquity is very different in different horses, and much 
of the usefulness of the horse depends on its taking a proper direction. A comparison of different feet has taught the horseman that the degree of obliquity most consistent with soundness and usefulness is about 45 degrees. If it is greater than this, and the crust forms an acute angle with the sole, or the ground, it is an indication of weaknoss or disease in the foot. In the lutter case there has been inflammation of the substance by which the coffin bone is united to the hoof, or extension of it, and partial separation of the bones of the foot from the crust. The bones have receded, and the crust has fallen in; therefore a too oblique direction of the hoof is accompanied by flatness of the soles, and possibly by pumice, or a rounded projection or actual sinking of the sole from the pressure of the coffin bone upon it.

On the other hand, if the crust is not so oblique as it ought to be, but is becoming to a greater or less degree upright, disease of another kind is indicated. There is contraction, the heels are growing narrow, and the contents of the font are forced upward and forward.

On the inside of the crust are numerous little projecting horny lamellæ, or plates, running parallel with each other from the coronet to the sole, over the whole of the interior surface. Corresponding with these are similar ligamentous or membranous projections, or plates, springing from a substance that covers the coffin bone:

The crust diminishes in height and thickness as it proceeds backward, and when it approaches the heel, is distinguished by the name of the quarters. Great attention should be paid to them, in all examinations of the foot. If the crust decreases too much and too rapidly in height, a weal fwot is indicated-an inability to bear much rattling on the hard stones, and a greater liability of being pricked in shoeing, or otherwise injured. Such a horse is said to have low heels. If the decrease in height is little and slow, the horse is said to have high heels, and generally has contraction and thrush.

The crust being still continued backward, forms the heel of the foot, at the very centre of which it turns round and takes a direction again forward, along the outside of the frog, under the name of the bars. This continuation and projection of the crust, known by the name of the bars, is a very important part of the foot. It is one of Nature's protections against contraction; it is one of her guards against injury at that part of the sole: but the farrier knows not this, and in order to give a delusive appearance of openness to the foot, frequently cuts the bars away altogether.

The hecls thus turning inward, there would be a considerable chasm at the back of the foot, were it not for a wedge-shaped horny substance, called the frog. Its office is to fill this chasm,-to afford protection to an elastic substance above, on which the navicular bone and the flexor tendons rest,- and also by its shape, and its 
point projecting forward, to give a degree of security to the tread of the foot.

The sole covers the remaining part of the base of the foot.

Within the foot, and the form of the hoof exactly moulded to it, is the coffin-bone, or principal bone of the foot. It is fitted into the fore-part of the hoof, and occupies about half of it. A small portion of the lower pastern-bone is also found within the horny box, which uniting with the bone of the foot constitutes the coffin-joint. Interposed between the coffin bone and the crust is a dense ligamentous elastic substance, already referred to, adhering firmly to the whole surface of the coffin bone on one side and terminating in numerous little plates, which are received and firmly held between the horny plates of the crust, on the other side. These plates are so many points of support; the whole weight of the horse is thrown upon them, and the elastic yielding nature of the interposed substance prevents that concussion which would speedily injure and destroy the whole mechanism of the foot. The union of the horny and membranous plates affords the requisite strength, while the alternate yielding and contraction of the interposed substance give the elasticity of the foot, and the easiness of motion.

The construction of the back of the foot is more complicated. The pasterns take an oblique direction forward. This obliquity is designed also to obviate concussion, and, by means of an elastic ligament, varies with the different motions of the horse. In the blood-horse, the tuft of hair at the fetlock will often be in contact with the ground: it is a beautiful contrivance, giving easiness of motion to the whole machine. The play of this spring is admirably adapted to the form and destiny of the horse. The long and slanting pasterns of the race-horse suit the springiness of his action and the length of his stride-the medium obliquity and length of the pasterns of the hunter is adapted to the occasional speed and the untired endurance which are required from him in the field, $\rightarrow$ and the comparatively upright position of the pasterns in the road-horse fits him for his daily task. There is sufficient obliquity to insure some pleasantness of action, but nut enough to endanger continuance of strength.

The flexor tendons,- - the tendons by which the foot is bent,-run along the back of the pastern bones. One of them is continued low down into the foot, and is inserted into the heel of the coffin-bone. There must be a great deal of motion and play in this tendon, and a considerable exposure to injury; and the back of the foot presents much contrivance to prevent the mischief that would otherwise ensue. First, there is the navicular bone, placed at the point of union between the lower pastern and the coffin-bones, forming a joint with both of them, yet moving independently of either. It is united to both of them by ligaments, and it presents behind a free broad polished surface over which the tendon plays. The navicular 
bone partially revolves with every motion of the tendon, and thus prevents a great deal of that concussion and friction which must otherwise have taken place had the tendon sharply turned over a fixed bone, in order to be inserted into the coffin-bone.

The navicular bone, while it iurns, descends, and the tendon descends with it, and there is much weight pressing upon both. Then there is interposed between these parts and the bottom of the foot another highly elastic substance, which is destined to receive this pressure, and, yielding as it receives it, obviates unpleasant and dangerous concussion: I mean the internal or sensible frog,- the cushion on which the tendon and the navicular bone rest.

This is an important function of the internal frog; but there is another quite as valuable. The horny covering which is adapted to the foot of the horse is one of the best that could be contrived; but from its very nature it may occasionally subject the foot to considerable pain and inconvenience. It contracts when exposed to dryness or heat. The feet of our stabled horses are too liable to injury from this source, and there is the fetter of the shoe, which still more disposes to contraction, and fixes the contraction when it has once taken place.

The elastic frog yields to the pressure of the descending part of the foot; but how does it yield,-can it be squeezed into a smaller compass? No. It partially shifts its situation. It presses upon the sole, and the sole descends; and being naturally concave, it flattens as it descends, and thus expands the lower part of the foot: and when the weight is taken off in the lifting of the foot, the sole ascends with a kind of rebound, and the frog ascends too, with the same kind of springy action, and forces itself against the upper part of the foot, and expands that: thus the lower part of the heels are cxpanded by the descent of the sole, and the upper part by the compression and elevation of the frog.

To assist in this, there is another elastic mechanism, placed on the upper part of the side of the foot, the lateral cartilages. These receive the pressure of the frog; they receive it without concussion or shock, and they increase the expansive effect. A horse soon becomes lame when, from the tro long continued and violent pressure of the frog upon the cartilages, as in the straining of heavy draught, these cartilages become inflamed, and turned into bone.

A cursory view of the structure of the foot having been thus taken, its diseases and the treatment of them will be more easily understood.*

The diseases of the hoof will first come under consideration.

* For a more extended account the reader is referred to a treatise on the "Structure, Functions, and Diseases of the Foot and Leg of the Horse," by W. C. Spooner, M. R. V. C. 


\section{BRITTLE HOOF.}

This is a very serious inconvenience with some horses, especially in hot and dry weather. The hoofs chip away at every shoeing, until at last there is scarcely nail-hold, and the farrier is compelled to take a great deal more care than smiths in general will take, to a void pricking the horse.

This brittleness of the hoof is a natural defect in some horses; but in others it is brought on by deep and dry litter, and the utter neglect of stopping the feet. The very means adopted by some to remedy it tend only to increase the evil. All applications of tar should be carefully avoided; for a crust is formed over the foot as the fiuid part of the tar evaporates, which stops the pores of the hoof, and o!ten produces, and always aggravates, this brittleness of the foot.

Cow-dung stopping, with a small portion of clay in it, to give it consistence, but not to produce a drying quality, will be found useful; but nothing is comparable with the following preparation :-

RECIPE (No. 74).

\section{Suppling Liniment for the Fect.}

TAKE-Oil or spirit of tar, a pint;

Common fish oil, a quart:

Mix them together.

After the feet are cleansed out when the horse comes from his work, and while considerable moisture continues to hang about ihem, talie a brush, dip one end of it in this liniment, and well rub it over the whole of the crust and sole. This will tend much to restore the natural pliancy of the horn, and at the same time will very considerably increase its growth.

\section{SAND-CRACK.}

Connected with this, and usually produced by it, is a fissure or longitudinal crack in the hoof. It may be produced in a momentone false step may cause it; but the predisposing cause is unnatural brittleness of the hoof. Sand-crack usually takes place at the weakest part of the foot, or where there is most stress and pressure; therefore it is oftenest in the inner quarter of the fore foot, because there the greater part of the weight of the horse is thrown, and the hoof is naturally weaker than at the outer quarter: in the hind foot the sand-crack is most frequently at the toe, for there is the principal stress in the act of drawing. Occasionally it begins at once from the coronet, but more generally it is first perceived about the middle of the hoof. 
The slightest appearance of sand-crack should be attended to. It uniformly begins from without, and penetrates inwardly: it may therefore be arrested in its progress when it is merely superficial. The hoof should be rasped; and if this be done in time the sandcrack may often be fairly rasped out. If, however, it proves to be deep, yet there is no lameness, the foot should not be weakened by cutting to the very bottom of the fissure, but a line should be deeply drawn with a sharp firing-iron, above and below it, in order to prevent the crack from spreading either way.

If lameness accompanies sand-crack, the fissure has penetrated through the horn to the sensible parts; and either gravel has insinuated itself, and is giving pain by its pressure, or a portion of the sensible part beneath has protruded itself into the crack, and is there pressed and confined. The crack must now be searched to the bottom. The sides must be pared off a little, and then, with a very small drawing-knife, the scissure must be opened and examined. When the dirt or gravel is removed, or the imprisoned laminæ liberated, a small piece of tow, dipped in Friar's balsam, must be introduced into the crack, and the font immersed in a linseed poultice for several days, and a stimulating liniment may be rubbed on the coronet to encourage the growth of horn. Should the crack have reached and divided the coronet, it is a more serious business.

Unless the crack is very slight, the horse should be rested for several weeks, and as soon us there is sufficient new horn grown down above the crack, but not before, one or two transverse lines should be drawn above the crack with the firing-iron, so as to cut off it communication with the sound horn: similar lines should be drawn below the crack and on it; a little melted tar and pitch may then be applied to it, and covered with tow and a strap buckled tightly round the hoofs. A bar-shoe should be put on, with the bearing taken off the quarter altogether, and then if the horse is much wanted he may go to work, hut additional rest will best insure the sound growth of the new hoof.

In bad cracks, there may, in the early stage of the treatment, be a protrusion of fungous substance. This will be best destroyed by running the firing-iron down the centre of the crack. The fungus will be burnt down, and a crust will be formed which will defend the part, prevent by its pressure the growth of more fungus, and gradually change into good horn.

The sand-crack being removed, care should be taken to prevent a return of it. A foot naturally brittle will continue brittle still; and hence the necessity of careful stopping at night, and the occasional use of the suppling liniment for the feet. Pieces of thick felt, cut to the shape of the bottom of the horse's foot, introduced within the shoe, and soaked well in water every evening, will form an excellent stopping. They may be bought firm any saddler.

In the hind feet a sand-crack always takes place at the toe, and from the greater strain at this part in heavy draught-horses, to 
which description it is almost always confined, the case is more serious than in the fore feet. The treatment, however, must be the same. The bearing must be altogether taken off the toe; but a bar-shoe will not be required.

\section{TREAD, OR OVERREACH.}

This is a wound on the coronet, caused, in the fore foot, by the hind one overreaching and wounding it, and in the hind foot by the heel or caulking of the fore shoe. Warm fomentations should be applied, or linseed-meal poultices. The contusion will often be so serious, that some degree of sloughing will ensue: the poultices should therefore be continued until the core comes out, when the Friar's balsam will speedily heal the wound.

If the coronet is cut through, it is often a very serious affair, and may lead to quittor, or false quarter. The first thing to be done is here also to poultice, in order to subdue the inflammation, and to be enabled to ascertain the real nature and extent of the wound; and this being accomplished, it must be healed as soon as possible by means of the Friar's balsam. Should any sinuses form between the crust and the coffin-bone, they should be daily injected with the mild caustic wash for wounds (Recipe No.63, p. 159), and when the wound begins to heal up from the bottom, the state of the coronet must be particularly attended to.

\section{FALSE QUARTER.}

Either from neglect of the use of the firing-iron in sand-crack, or too severe use of it, or working the horse too soon, or from contusion, as in tread or overreach, or from the employment of caustics instead of emollients in these cases, there is a want of continuity in the coronet, and the horn grows down, separated on each side from the very beginning; and, after reaching a little way down the foot, one portion of it begins to overlap the other. This is termed false quarter. It is a very serious defect in the foot of the horse, and rarely to be remedied. The strength of that quarter is materially lessened, and dirt and gravel will often insinuate themselves between the two plates of horn, and work their way into the foot.

The course to be pursued in treating this defect in the foot is not very different from that recommended in sand-crack. The overlapping portion of horn must be pared away, and the hot iron run down the line of division between the horn of the quarter and that of the fore part of the hoof. It must also be lightly applied to the coronet; and the application repeated every third or fourth day, until the edges of the coronary fissure begin to adhere. Should not this have commenced, after the lapse of a fortnight or three weeks, it will be advisable to blister the coronet severely; and as soon as the fissure is obliterated there, the pitch envelope may be put on, 
and the horse returned to gentle work; or, what would be the safer plan, turned out to grass.

If the case has been of long standing, the veterinary surgeon must never expect a thorough cure. It will be a great while before he will effect union between the divided portions of the coronet, and then an imperfect and white horn will be secreted; strong enough for ordinary purposes, but always betraying the disease that once existed, and threatening again to give way, if unusual exertion is required: or if it does not quite give way, there will be a degree of weakness in that part of the foot, which will occasiona!ly show itself by decided lameness.

\section{CONTRACTION.}

The font of the young horse, in its perfect state, approaches to a circular form; but he has scarcely entered our service before it generally begins to assume a more lengthened shape, narrower every where, but especially at the heels. This may, or may not, be productive of lameness. If the contraction has been slow in its progress, the internal part of the foot will gradually adapt itself to the change in the external covering. Gentle and long-continued pressure will effect very great changes without being productive of pain or impairment of function. On this account it is that we sce many feet elongated, and narrow, yet not particularly high in the quarters, nor concave in the sole, and in which there has not been the slightest degree of lameness. At other times there will be sudden and dead lameness, with very little contraction.

The causes of contraction are numerous. There is not a more frequent one than neglect of paring out the foot. It has been just observed that one of nature's preventives against contraction is the descent of the sole. In a state of nature, the common action of the hor:e prevents the sole from becoming so morbidly thick that it cannot descend; but under our mismanagement, and especially that of an idle smith, who suffers the sole to thicken month after month, because it is too much trouble to him, and too great expenditure of time, to pare it well out at each shoeing, it by degrees becomes so thickened that it cannot descend; then the hrof, exposed to the heat produced by exercise, the heat of the stable, and many a cause of infarmmation, very speedily contracts or wires in. I would here quote from a work which contains, in a condensed form, the "Useful Knowledge" of "The Horse." "There is no rule which admits of so little exception, that once in abont every three weeks the growth of horn, which the natural wear of the foot cannot get rid of, should be pared off; the toe should be shortened, the sole should be thinned, and the heels lowered."

The heat of the stable, the loss of the bars, and the fettering of the shue, will likewise give a disposition to contraction; but the 
main cause of it is disease of the internal part of the foot, however proluced.

The lameness of contraction is different from that of sprain or corn: it is, at first, more a short, fumbling mode of going, than direct lameness. The foot is scarcely lifted from the ground, because concussion and pain will be lessened in proportion as the horse goes closely to the ground.

Contraction is therefore both a cause and an effect of disease of other parts; the latter, perhaps, more frequently than the former. It is easy to conceive that when the foot is rested in the stable, and the horse favours it by going lame, that this want of pressure on the back part of the foot must speedily occasion contraction. Although, therefore, it is a predisposing cause of disease, it is a matter of doubt whether alone it ever produces lameness. The disease with which it is mostly connected is the navicular-joint disease, which remains to be considered.

The treatment will consist in removing the causes of contraction. The sole must be pared all round, until the blood starts as from many little pin-holes. The strength of horn must be weakened where the pressure is greatest and inost painful. Carefully avoiding to wound the coronary ring, the quarters must be rasped until the blond starts. The overloaded vessels of the foot should be re. lieved, and three or four quarts of blood taken from each toe: after this, the feet should be enveloped in poultices, changed every day, until the unnatural heat of the foot has disappeared.

When evident, but too often temporary relief is thus afforded, tips should be tacked on, and the horse turned ont to grass, and if possible, in a marsh: at all events, it should be in a moist pasture; and there he should remain until the quarters are grown down, being taken up once in three weeks, or a month, to have his sole pared out, and his quarters rasped.

If the case is not sufficiently severe to require or to warrant the loss of the services of the horse during the long period of turning out, swabs should be worn during the day, while the animal is standing in the stable, and the feet should be well stopped with cow-dung at night. The suppling liniment for the feet (Recipe No. 74, p. 190) should also be daily used, and an unfettered shoe (a shoe nailed on the outside, and with only one nail beyond the toe on the inside) should be applied. This shoe will be sufficiently secure under any work that can be required from such a horse, and it leaves the quarters at liberty to expand.

The shoe with a joint at the toe is worse than useless; for the stress on every nail-hole soon breaks away the lower part of the crust from a foot rendered by the disease a great deal too brittle. The shoe with a clip at each heel, to prevent its wiring in, is also pernicious; for the process of contraction will gro on, and the clip will eat into the foot, and be a fruitful source of corns. More injurious still were those screws by which it was attempted me- 
chanically to force the heels asunder. Nature rebelled against this violence; inflammation tenfold greater was excited, and the work of contraction was hastened: or, if the heel yielded for a while to the force that was used, it was necessarily at the expense of some lesion within, which, as soon as the screw was removed, exhibited itself in lameness of a worse character than before.

\section{INFLAMMATION OF THE LAMINE.}

Proceeding to the diseases of the parts immediately within the hoof, "Inflammation of the Laminæ," or "Fever in the feet," first presents itself, whether its frequency, obstinacy, or sad consequences, are considered.

When it is recollected what the laminæ or the substance that covers the coffin-bone have to bear, even during the quiet standing of the horse (for they support all his weight), and the violent concussion and straining to which they are exposed when in rapid action the foot comes forcibly in contact with the ground, it will not appear surprising that they are often injured, and that intense inflammation ensues. Besides this, there is no part of the horse so exposed to other causes of inflammation as the foot. After the animal has been ridden far and fast, and is hot all over, some have most absurdly recommended a general washing for him. While he is reeking hot, he is plunged up to his belly in the nearest pond or river. There are few, however, who act so brutally as this; but almost every groom immediately washes the feet of his horse, while very few of them will afterwards take the pains carefully to dry the feet. What is so likely to follow as inflammation? A horse may have been travelling many a mile up to his coronets in snow, and when he arrives at his journey's end, instead of having the warmth gradually restored to his feet by half an hour's good hand-rubbing, he is put up to his knees in straw; is it not natural to expect that violent fever in the feet will follow this sudden and unnatural change? In other cases, there may be a metastasis or change of the place of inflammation: the animal is recovering from inflammation of the lungs, yet still with a strong tendency to fever, and suddenly the next'weakest part, the feet, are attacked, and that without any fault of the surgeon or groom.

Inflammation of the laminæ can scarcely be mistaken. The horse is continually shifting his posture, yet without the violent action or sudden plunges of colic and inflammation of the bowels. The feet are constantly moving, but they are moved as gently as possible. When the hand is passed down to them, the heat, sometimes the almost burning heat, of the feet is evident enough. Soon, however, the horse, tired of shifting his place and yet retaining the pain, lies down, and can with difficulty be induced to risc again. There is not one character in common with inflammation of any of the viscera, except the acceleration of the pulse, and sometimes the 
breathing, and the heat of the mouth; and if there were, the horse would soon undeceive us, for he often points out his feet as the seat of pain, by looking at them, and resting his muzzle upon them.

The treatment of inflammation of the feet must be prompt. The sole must be pared, and the crust rasped, and blood taken from the toe, and at least four quarts from each foot (the two fore feet are generally those which are attacked). The feet must then be enveloped in cloths, and kept constantly wet with the solution of nitre (Recipe No. 66, p. 160); and a strong dose of physic administered, and mashes, or gruel alone, allowed.

Other inflammations may possibly, to a certain degree, brook delay, but here not a moment is to be lost. The inflammation must be made to terminate in resolution; for if the next process, and in some inflammations a salutary one, commences-if pus is thrown out, within the foot, the hoof will inevitably come off. Slight injuries of the foot may sometimes be mistaken for inflammation of the laminæ, and may yield to mild treatment; but true inflammation of this part being once recognised, there is no case which more certainly distinguishes the skilful from the unskilful practitioner.

The bleeding must be repeated in five or six hours, either from the feet, the coronet, or the arm, if evident relief is not obtained; and a third bleeding should not be delayed if the inflammation is obstinate. On the second day recourse should be had to a severe blister round the coronet. Some recommend a blister at the very beginning, but a blister has generally the most decisive good effect when inflammation has been previously a little lowered by other means.

The practitioner will carefully look out for the worst symptoms, as well as those of amendment; and when separation begins to take place at the coronet, hetween the hoof and the foot, it indicates that the process of suppuration is established; and that process once established in the foot, will go on in defiance of all that can be done. It will be useless further to punish the horse, but some relief may be obtained by surrounding the feet with poultices. Another hoof will in process of time be produced; but it will be smaller and weaker than the first, and liable to inflammation and contraction.

It is seldom that intense inflammation of any kind terminates without effecting some change of structure in the part. Disunion to a very considerable extent between the horny and fleshy laminæ is a frequent consequence of inflammation of the feet, and the result of that is, that the coffin-bone is no longer retained in its place, but sinks backwards and downwards, and this produces

\section{PUMICED FEET *}

The sole is naturally concave: too often, under our improper management, it becomes flat, but here, the coffin-bone descending,

* A remedy for founder, which, we are well assured, is infallible' giving relief in eighteen or twenty-four hours, so that the animal may 
presses upon the sole, and that pressure produces absorption of a portion of the sole, and consequent weakening of it. It is not long able to support this pressure of the coffin-bone, and the weight of the horse, but. it yields and bulges ont, and presents a convex surface to the ground. This is an incurable state of the foot. The attempt at forcing up again the coffin-bone betrays ignorance of anatomy and of the progress of disease. When the coffin-bone begins to recede from the crust, the hoof follows it to a certain degree; but its structure limits this, and another process commences in order to fill up the vacuum: an unnatural quantity of horny matter is secreted by the sensitive laminæ, and the crust thickens, and projects inwardly as the coffin-bone retires: it has sometimes been observed more than two inches in thickness. Nature is, as it were, attempting still to maintain the union between the parts.

What power applied to the sole can force back the coffin-bone, pressed upon and kept down by-this thickness of horn; or what power can be applied to the external sole without bruising the internal and sensible one, and causing inflammation and worse lameness?

By a shoe with a narrow, but deep web, the sole may be raised so high that it can scarcely come into contact with the ground; or a very strong shoe can be applied with a convex surface towards the ground, and a concave one towards the foot, and adapted to the degree of projection of the sole, and almost covering it, and rendering impossible either pressure on the part, or accidental bruise fiom any irregularity of the ground. By means of the last shoe a pumicefooted horse may go to slow work for some years, care being taken that little or none of the sole is pared away,-that the nail-holes are so changed and contrived that the necessary irregular stress upon them does not break off the lower part of the crust, and that the shoe is strong enough to bear the weight of the horse.

Pumiced feet are, however, not always the effect of inflamed laminæ, nor is the hoof and the tne of the coffin-bone always separated. For, in some cases of large heavy horses having originally thin, flat feet, the weight of the animal causes the crust to become more oblique, and the sole to bulge. Pumiced feet from this cause are by no means so unserviceable as those proceeding from inflamed laminæ; careful shoeing, indeed, renders the animal useful for steady work.

\section{WOUNDS IN THE FEET.}

The most frequent of these are from pricking in shoeing, or the picking up of sharp substances upon the road. If discovered in

proceed on his journey, is to dissolve two heaping table-spounsfull of alum in water, and give it as a drink. Instead, as might be supposed, of constipating the bowels, it has an opposite effect, rarely requiring any aperient to follow. 
time they are very easily managed; but if the process of suppuration; and underrunning has commenced, the cure will be tedious, and not always certain.

When a horse is pricked or stubbed, the farrier pares away the horn to the very bottom, and then sometimes places a bit of tow wetted with spirit of turpentine on the part, and sets it on fire; and if there is no underrunning, and he has fairly laid open the wound, it is no very censurable practice, for he forms a kind of crust upon the part which at no great distance of time changes into good horn.

It is indispensable that the wound should be freely opened, and to the very bottom; and then, if a bit of tow, dipped in Friar's bal$\mathrm{sam}$, is put on the wound, and a little more tow on that, and the whole is confined with a firm pressure, new horn will very speedily be formed.

When the wound is opened on the following day it should be carefully examined all round with the finger-nail, in order to discover whether there is any separation between the horny and sensible sole, which either had escaped the first examination, or has since taken place. If it exists in the slightest degree, the separated part must be carefully and thoroughly removed. If there is one caution of greater importance than any other in the treatment of wounds of the feet, it is to remove every portion of horn that has ceased to adhere to the fleshy part beneath. Union can never be re-effected; but the horn thus detached will remain as a foreign irritating body.

If it has been necessary to open round the original wound, the exposed surface should be very lightly touched with the chloride (butyr) of antimony, applied to it by means of a feather. A pledget of soft dry tow, shaped to the wound, should then be put on it, a larger piece over that, and the whole confined as before with a firm and uniform pressure. There are few wounds over which fresh horn will not readily grow by means of this treatment.

If, however, as is sometimes the case after the horse has been pricked in shoeing, the wound cannot be fuirly got at, it must at least be opened so far as it safely can be, and then a poultice applied for two or three days. The Friar's balsam, or the chloride of antimony, applied according to circumstances, will after that usually complete the cure.

[In every stable and in every traveller's pocket there should be a Picker.]

"A horse-picker is a small iron instrument, so truly convenient upon many emergencies, that a prudent traveller, or experienced sportsman, is hardly ever seen withont one annexed to the handle of a knite which he carries in his pocket: its use is to extract stones, pebbles, or flints, from the bottom of the foot, when they are picked up in hunting, or upon the road. 'They are sometimes so firmly fixed between the inner elge of the shoe and the frog. that nothing but very violent force with a hammer can remove them; in such 
cases, horses are sometimes led a considerable distance to some dwelling house, before the stone can be extracted; and the foot is probably bruised, or sustains a serious injury, for what might be obtained at a trifling expense, and carried with little inconvenience."

\section{QUITTOR:}

In some cases, and particularly when the wound is beneath the crust, pipes or sinuses are formed. Pus has been thrown out, and has burrowed between the crust and the sensible parts beneath. Irreparable mischief is sometimes done by this process. The most favourable state of the case is when matter breaks out at the coronet, soon after the lameness is perceived; but, occasionally, either the farrier has been very careless in his examination of the foot, or no notice has been taken of the lameness until the matter has burrowed in every direction, and has insinuated itself under the cartilages and ligaments, and into the interior part of the foot. None but very general rules, therefore, can be laid down for the treatment of quittor, and no one but a skilful practitioner should be employed in such a case.

The first rule is to ascertain the direction and extent of the sinuses, so as to be enabled to form thence some opinion as to the probability of a cure. If the matter has penetrated deep among the cartilages a cure is very difficult; if it has found its way into the coffin-joint, a perfect cure is impossible. The probe, therefire, must be carefully used in order to discover what important parts may be involved.

The matter generally finds its way out at one of the quarters, and sometimes rather backward in the quarter. If the sinuses run backward, the practitioner has a fair chance of success, and may undertake the case; but if they run forward, he must conduct his examination carefully and cautiously, and hesitate before he delivers a decisive opinion. Here a knowledge of the anatomy of the foot will be indispensable.

The case being undertaken, a second rule comes into action; endeavour to discover some dependent orifice. A sinus may, perhaps, be traced down to the sole, or in the direction of the sole; or pressure with the pincers will detect some spot in the sole, or low down on the crust, where the horse feels particular pain. The practitioner should pare down upon that, for it is probable that he will find a sinus there. If he is disappointed in this, he must examine the fistula afresh, and ascertain where it runs deepest; and where, with least danger, he may pass a seton and make an opening. There can be little danger in doing this in the posterior part of the foot.

Every part of the sole that is detached must immediately be removed. Some recommend the removal of the quarters also, so far as the sinuses extend; but the practitioner will hesitate about this, 
because some months must pass before the horn will grow down again so far as to render it practicable to work the horse; and because, although the horn, once separated, will never again unite with the parts beneath, yet, if you have a fair and dependent orifice, the internal wound may heal, the old horn may cover and defend it; and, by degrees, the new horn will grow down, carrying with it a sound substance underneath.

An attempt must next be made to excite a healthy action in the parts beneath; which will be most quickly and effectually done by injecting a saturated solution of the sulphate of zinc (white vitriol) in water. Let this be repeated during four days. Then change the injection for one of Friar's balsam, examining the wound every two or three days with the probe, in order to ascertain the progress of the cure, and also judging of this (and perhaps more accurately) by the nature of the matter discharged from the orifice below.

In some, but comparatively few cases it may be necessary to have recourse to a more potent caustic. A saturated solution of corrosive sublimate may be substituted for the sulphate of zinc; or powdered corrosive sublimate may be rolled in paper and forced into the sinuses. The veterinary surgeon will, however, pause before he resorts to this last inethod; for the sloughing may be too deep, and the destruction of the surrounding parts too extensive. More horses have been destroyed in consequence of the unnecessary severity and wide sloughing of the caustics used, than from the natural progress of the disease.

\section{BRUISE OF THE SOLE.}

This is a circumstance of frequent occurrence; and of very little consequence, if timely and properly treated. A horse in rapid action may tread on a sharp projecting stone; or a stone may have fixed itself within the span of the shoe; or a smaller one may have insinuated itself between the web of the shoe and the foot; or the sole may not have been pared properly out, and a flat shoe may have been worn; all of these things will cause pressure upon, and bruise of the sole. The injured part may always be detected by the pain which the horse evinces when it is pressed upon, and often by the discoloration of the horn.

The sole, over and around the tender or discoloured spot, should be pared, not only until it yields to the pressure of the thumb, but until the blood begins to start. The appearance of the blood will be a satisfactory proof that the bruise has not run on to suppuration. Bleeding at the toe, and one or two poultices, will remove the effects of bruises of this kind.

CORNS.

These are bruises of a more serious nature. They are situated in the angle between the bar and the quarter, and generally on the 
inner side of the fore-foot. They generally indicate neglect or false economy in the owner, or unskilfulness in the farrier.

The owner is in fault when he suffers the shoe to remain on too long. It should be removed, and the foot well pared out, once in every three weeks, otherwise the shoe will, in the farrier's language, "grow into the foot," $i$. $e$. the shoe preventing the natural growing down of the horn at the heel, the crust will be prolonged on the outside of the shoe, and the bearing will be thrown upon, and bruise a portion of the sole. If the shoe becomes loosened at the heel, gravel will frequently insinuate itself between the crust and the shoe, within the bar, and accumulate there, and bruise the sole; or if the shoe is made narrow at the heel, which it too often is for the purpose of giving a false appearance of width to the heels, the portion within the bar and the quarter is injuriously exposed; or if, for the same ridiculous purpose, the bars are pared away, a slanting direction is given to the shoe, perfectly inconsistent with level bearing, and a necessary cause of partial pressure. The habitual use of shoes raised at the heels is a cause of corn, from the disproportionate pressure and concussion thrown on that part of the foot. On the other hand, a foot naturally, or from neglect or disease, contracted, often has corns, because the portion of the foot between the quarter and the bar is squeezed into smaller compass, and bruised.

Severe bruises are generally accompanied by extravasation of blood in the cellular membrane beneath the skin; so, in consequence of a bruise between the quarter and the bar, a little blood is thrown out, which insinuates itself into the young horn, and the existence of corn is indicated by the red appearance of the horn, when the angle of the bars is cleared out.

Corns are too much trifled with in common practice. A horse with a corn cannot be considered as sound, unless the diseased appearance is so very slight as not by any possibility to occasion lameness, for in general he is liable to become lame without a moment's notice, and it is seldom that the corn can be completely cured. The habit of secreting unhealthy and soft horn (and that must be unhealthy which is mixed up with blood) cannot always be broken off; the tenderness occasioned by bad corn will not soon subside; and the least neglect in shoeing will almost inevitably produce a return of the evil.

The cure is to be attempted by paring out the angle at the quarter and the bar almost to the quick. The extent of the mischief will thus be rendered evident, while the horse will be relieved by the pressure being taken from the part. If it is a simple bruise, without suppuration, which will be immediately known by the pressure of the thumb, and by the starting of the blood from a pin-hole or two, a little of the butyr of antimony should be lightly applied, by means of a small quantity of tow, wrapped round a bit of stick, and then the shoe should be so contrived that all pressure shall be 
taken from the part. The butyr of antimony will stimulate the almost denuded sole to throw out more healthy horn, and the re. moval of the pressure of the shoe will be the most likely method to prevent a return of the complaint. If lameness, however, attends the corn, it will be most prudent to poultice the foot for a few days before the shoe is applied, as this will remove the inflammation and dispose the parts to secrete healthy horn. The daily use of the "suppling liniment for the feet" (Recipe No. 74, p. 190) will go far to restore the natural elasticity and uniform growth and bearing of the horn. A bar shoe, however, will most effectually relieve the pressure on the seat of corn, and may be worn for a month or two, but it must not be adopted for constant wear; for although it takes a way the pressure which the quarter will not now bear, it too often throws it on a part-the heel-which was never designed to receive permanent pressure, and which often becomes considerably injured by this means. After the bar shoe has been left off, the unfettered shoe, and always seated, will be resorted to with much advantage, either for temporary or permanent use.

Corn is in some cases a more complicated affair. The inflammation will run on to suppuration. Matter is thrown out between the horny and sensible sole, and produces separation between them, and lays the foundation for quittor, or canker. Every separated portion of horn must be removed; the separation must be followed to its full extent; and the means adopted which are recommended under quittor and canker.

The farrier and the owner should make themselves perfectly masters of the kind of foot which the horse with corns may possess, for different horses require essentially different treatment. A horse with high heels, and hard hoof, can scarcely have his foot too thoroughly pared out at each shoeing; while the horse with low weak heels has not a particle of horn to lose, and the inner heel, the seat of corn, should more especially be spared.

\section{CANKER.}

Canker is not merely the separation of the horn from the sensible part of the foot, but the growth of a fungous substance instead of healthy horn.

In bad cases of long standing, in which the sole, bars, and crust are all involved, it will rarely be prudent to attempt a cure; but in milder cases every portion of separated horn must be removed, otherwise the confinement of the fungus beneath it will not only exceedingly torture the horse, but, by the irritation which it produces, prolong the disposition to throw out this substance. This is a rule which admits of no exception; and the farrier must never be terrified at the extent to which he lays the foot bare: not the slightest good can be done while there is any portion of fungus confined. 
Having laid the unhealthy part perfectly open, the practitioner will consider what kind of surface it presents. If there is much fungus, he will probably resort to the knife or the cautery, or both. The fungus must be destroyed, and it cannot be done too soon, or with too unsparing a hand. A level surface being thus produced, the butyr of antimony should be lightly applied over the whole of it. Farriers have a long list of torturing substances for the cure of cankers, and which not only destroy the surface to which they are applied, but deeply and injuriously eat into the foot. The butyr of antimony acts where we want it, on the surface alone; and as it becomes combined with the fungous substance to which it is applied, and the moisture which exudes, it becomes weaker, and is speedily neutralized. Except it is used in outrageous quantities, it cannot deeply corrode the foot.

This being done, dry soft tow must be spread over the whole of the exposed surface, and made firmly and equally to press upon it; and the horse must be put into a thoroughly dry box, from which the urine will immediately run off, and where no kind of moisture can reach the diseased part. Every case of canker should be daily dressed; for the fungus sprouts very rapidly, and the habit of forming it, instead of healthy horn, is too soon established. Every time that the foot is opened, it should be carefully examined, in order to see that there is no other portion of horn separated; for if there is, it must be immediately removed. The appearance of the exposed surface must also be inspected with great attention. Fresh fungus will require a fresh and severe application of the butyr, or possibly of the knife. Every little pellicle of skinny matter or soft and porous horn must also be pared away; the healthy horn which has been secreted must be lightly run over with the knife; and then the butyr of antimony once more applied to the whole of the surface, the quantity used on the different portions of it varying with the progress towards a cure. After this the foot must be bound up as before.

A few days having passed, if the sprouting of the fungus has been quite checked, but yet the horn does not grow so healthily as could be wished, the butyr may be omitted, and a pledget of tow, dipped in genuine Friar's balsain (compound tincture of benzoin), spread over that portion of the foot, and more dry tow placed upon this, and bound down as before, and as firmly and equably as possible. A sudden change of the soft spongy horn into that which is healthy and without pores will, by this application, often be effected; but should not this take place to the desired extent, the use of the butyr must be for a while resumed.

'The whole secret of the treatment of canker consists in the use of superficial caustics or stimulants,-pressure as firmly and as cquably as it can be made, and the careful avoidance of all greasy applications, and all moisture, either applied immediately to the foot, or suffered to penetrate to it through the dressing. 'The Friar's 
balsam is only a seeming, not a real exception to this; for the spirit quickly evaporates, and leaves a firm glutinous surface in contact with the cankered part.

If wet can certainly be avoided, a horse with a cankered foot will, immediately after the first apparent growth of good horn, do much better at work than standing idle in the stable.

As this is a mere local complaint, medicines are not often needed, except it should be a mild dose of physic, or a few diuretic balls, in order to get rid of any humour, or tendency to grease; for canker and grease are not unfrequently connected, and the one will too often terminate in the other.

\section{THRUSH.}

Thrush, oftener found in the hind feet than in the fore ones, and more inveterate there, is recognised by a discharge of offensive matter from the cleft of the frog. It is inflammation of the lower surface of the heel of the sensible frog; and the matter oozes through the horn, or a cleft formed in it. It is not always accompanied by lameness, but there is a treachery about it, against which all due precaution should be taken. There is often more mischief done within than is at first indicated, and it may run on to inveterate canker, and incurable lameness.

Many horsemen suppose that thrushes are things of very little consequence; nay, that they are sometines useful, by carrying away humours that might break out injuriously elsewhere. Nothing can be more erroneous than this. Recent thrush cannot be too quickly got rid of; and one established for many years should be stopped, but somewhat more cautiously and slowly. Little credit is to be given to the stories of cutaneous eruption, staggers, or blindness being produced by the too speedy stoppage of thrush.

The frog should be carefully examined, and every ragged and separated portion pared away; and then a little of the following paste should be spread on a pledget of tow, and introduced as neatly and as deeply as may be into the cleft of the frog, the ends of the tow being carefully tucked in.

\section{RECIPE (No. 75).}

\section{Thrush Paste.}

\section{TAKE-Alum;}

Bltie vitriol; and

White ditto, of each an ounce:

Rub them to fine powder. Melt logether two pounds of tar and one of lard, and when they are getting cool stir in the powder.

If the disease has spread, so as to render a portion of the frog Lare, some of the paste should be spread on a piece of tow of a cor- 
responding size, and placed over the sore, and the whole covered with dry tow, or tow dipped in the ointment (Recipe 71, p. 185). It occasionally may be necessary to touch the sore part with the butyr of antimony. In cases of bad thrush a bar shoe should be worn, in order to protect the frog from pressure and injury, and the foot should be kept from moisture almost as carefully as in canker.

\section{NAVICULAR-JOINT DISEASE.}

This is a very frequent cause of great and almost incurable lameness; but its nature and treatment have not, until lately, been understood.

The manner of the insertion of the flexor tendon into the base of the coffin-bone, and the interposition of the navicular-bone in order to prevent that concussion and friction which must otherwise have taken place whenever the foot was put forcibly on the ground, have been already explained at p. 188.

A moment's reflection will, however, satisfy any one, that, notwithstanding the admirable mechanism of the part, there must occasionally, in sudden and violent motion, be bruise and injury of the membrane of the tendon, or the cartilage of the bone. This will especially happen if, after the horse has stood idle for several days, and the parts are somewhat indisposed for motion, he is suddenly taken from the stable, and ridden far and fast. The bone will not then descend with sufficient freedom, nor the tendon play with perfect ease, and the parts will of necessity be bruised; and the membrane of a joint being as sensible as the membrane of the eye, the animal will suffer acute pain, and the inflammation will be rapid and intense. This is the unsuspected cause of many a sad and incurable lameness.

The foot may become so altered in structure that the navicularbone cannot descend, and thence will necessarily result concussion, and bruise, and lameness. This is the explanation of the fact already adverted to, that contraction is not always accompanied by lameness. The wiring in of the heels may have been so gradual that the internal part of the foot may have adapted itself to the slow change; the navicular-bone may have become shortened as the heels contracted, and may still have had room to descend in the action of the foot. This will usually be the case when the contraction of the heel is not accompanied by much hollowness of the sole, or elevation of the frog. But when the heels become high, $i$. $e_{\text {, }}$, the frog is elevated from the ground, and the sole becomes concave, it will be evident that the descent of the navicular-bone will be limited, or perhaps allogether prevented; and then there must be concussion and bruise, and injury of the tendon, or of the cartilage of the bone, or of both.

Of the cure of this disease little that is satisfactory can be said. The course, however, that is to be pursued is plain enough. The 
inflammation must be abated by bleeding at the toe, by poultices long continued, and by physic. The contraction must be attacked in the manner already described. The coronet should be blistered in an early stage of the disease, with the hope of transferring a portion of the inflammation from the interior to the exterior of the foot; and a seton should be passed through the frog, which, by exciting constant irritation and discharge so near to the original disease, may also be productive of benefit in a similar way.

Should all other means fail, neurotomy may be resorted to: it is, however, subject to the objection that, in a case that has been long established, it is impossible to tell what mischief may have been done either to the tendon or the navicular-bone. The tendon may have been partly worn through; the bone may have become carious; and then, all pain being removed by the operation, and the weight of the horse thrown suddenly and flush upon the part, the tendon may be ruptured, or the bone fractured, and thus lameness a thousand times worse, and perfectly incurable, may be established.

In recent cases neurotomy must not be resorted to until inflammation is, as much as possible, subdued in the part. Many a horse has been lost from want of attention to this. The effect of neurotomy is confined to the relief of pain. Inflammation and disorganization will go on as before; they will even proceed with increased rapidity when the part is called into violent action, or subjected to injuries and bruises from which the sense of pain would have preserved it.

\section{CHAPTER XXXII.}

ON SHOEING.

THE principle of shoeing is to afford a secure defence for the foot without interfering more than is necessary with its functions. In ancient times horses went unshod. The roads, where there were any, were probably as rough as they now are, but the horse derived from its parents a hoof little susceptible of injury. Our horses have for many centuries been shod; and shoeing is become a necessary evil among us, for the foot of the horse is now hereditarily soft and liable to injury. We obtain by means of the shoe a defence for the horse's foot against the hard and flinty roads over which a great portion of his work must be performed; but the crust being fettered by the iron and the nails, we lose much of the natural elasticity of the fuot; and by carelessness or ignorance in the manner of affixing the shoe, we often occasion an unequal 
bearing on the different parts of the foot, necessarily productive of great mischief.

The first object of shoeing is defence; that is accomplished by almost any kind of shoe nailed round the bottom of the foot, the web of which is sufficiently wide and thick. We prevent mischief to a certain extent, by contriving to have the bearing as nearly as possible where nature designed that it should be. The whole weight of the horse is supported by the crust when the foot first comes in contact with the ground, and the sole afterwards descends for the purpose of preserving the elasticity of the foot. Then nature and reason demand that the shoe shall be constructed so that the bearing shall still be thrown on the crust, and that the sole shall have room and power to descend.

\section{THE CONCAVE-SEATED SHOE.}

The concave-seated shoe answers these purposes well. It has a flat surface on the foot-side, running round it, and corresponding with the thickness of the crust; and the lower part of the crust being pared evenly round, the whole weight of the horse is placed on a flat level bearing. A shoe, however, simply of the width of the crust would not afford sufficient defence to the sole, therefore the web is prolonged on the inner part of the circle for about double the width of the seaied part all round. But this must not press upen the sole, for, whatever might have been the case before the art of shoeing was invented, the sole will not now bear the slightest pressure wihhout injury. Then the foot-side of the shoe is bevelled or hollowed out, and presents a concave surface to the sole, so that even when the sole descends immediately after the foot is brought into contact with the ground, there is room left for that descent, without the possibility of touching any part of the shoe.

The concave-seated shoe presents to the ground an accurately flat surface, and to the foot a surface flat towards the outside, where it is to receive the crust, and hollow over the sole. Towards the quarters the shoe narrows, and the seating widens, so as to afford a level bearing, sufficiently broad to receive and protect the union of the bar and the quarter, and the angle which is formed between them.

The common country-shoe is a very different one, and highly objectionable. It also is flat towards the ground, but it presents to the foot either a flat surface, or an uniformly-bevelled concave one. It is much more easily made than the other, and that is a very considerable object with too many smiths. If the foot surface of the shoe is slanting, the crust must be cut in a slanting direction, in order to correspond with the shoe; and there will be much difficulty in doing this so as to obtain a perfectly level bearing for the crust. The slanting direction of the shoe will also give a slanting direction to the nails, and throw an unequal stress upon them, so 
that the crust will be likely to chip and break. If the foot surface of the shoe is flat, there will be no room left for the descent of the sole, which will, consequently, be continually bruised and injured, and little pieces of gravel, introduced between the shoe and the sole, will get embedded there, and do considerable mischief: whereas, from the larger space in the concave-seated shoe they are much more easily shaken out again, and can scarcely be retained at all.

This shoe will suit almost every kind of foot, even that which is a little disposed to pumice; whereas, the common shoe, although it may be worn without inconvenience on the concave foot, must be dangerous on the flat one, and almost necessarily productive of evil where the sole is in the least degree convex.

Usually also in the seated shoe,-and a point of very great importance it is,- the web is of the same thickness from the toe to the heel. 'This best suits the majority of feet, for it gives the most level bearing.

After all, however, more depends on the preparation of the foot than on the kind of shoe. The sole should be well pared out all round, until it will yield a little to the pressure of the hardened thumb of the operator. In a state of nature the sole would be prevented from morbidly thickening by the natural wear and tear of the foot; but we prevent this by the defence which we give to the sole, and the horn is continually accumulating; we must therefore periodically remove it with the knife, or we shall lose altogether that little portion of the elasticity of the foot which shoeing has left to us. A great deal depends here on the skill of the smith and the nature of the foot. From some feet very little can be taken with safety, because, although we must have an elastic, we must not have a thin and tender sole. From other feet too much can scarcely be pared away, and mischief will inevitably be produced if the horn is suffered to accumulate.

The sole being pared out, an even surface must be given to the crust; but must not be brought precisely iaon a level with the sole, lest that part should be unnecessarily exposed to bruise, either from the shoe or from other causes.

The bars must always be left prominent, for they are nature's chief impediments to contraction. The angle between them and the quarter should be very carefully pared out, on account of its being the seat of corn.

The frog should be left in a somewhat prominent state, and this should be the measure of its prominence:-it should, when practicable, be on a level, or rather more projecting than the heels of the foot, so that it may not touch the ground when the foot is first set down; and yet so slightly removed from a level with the lower surface of the shoe, that it shall certainly touch it when the ground is anyways soft or uneven. All the ragged and diseased parts of the frog must be rernoved at every shoeing.

The heels will form the last, and one of the most important points of consideration; for, from unequal or undue pressure on them 
much mischief often arises. The inner heel is always the weaker of the two; the principal wear will be on it; and there, in a great majority of instances, corn and sand-crack, and quittor will be found. The growth of the inner heel must be encouraged as much as possible; a little only must generally be pared from it, and, more particularly, care must be taken that it is not left higher than the other.

Then comes the selection of the shoe to suit the different feet. It should, with few exceptions, be the concave-seated shoe, and with a web equally thick from the toe to the heel; but the bearing of the shoe will strangely vary with the kind of foot. It is scarcely possible that a shoe, thinner at the heel than at the toe, can ever be serviceable; on the contrary, it will generally do much harm, by throwing undue stress on the flexor tendon. It will be a fruitful source of sprain of the back sinews and pasterns, and also of the navicular disease. On the other hand, a shoe a little elevated at the heel, may favour a leg weak in the back sinews; but, if it is used constantly, it will also be injurious by unnecessarily pressing upon, and bruising the heels. In the hinder foot, and particularly in draught horses, custom has sanctioned the use of a shoe raised at the heel by calkins. This certainly gives the horse a better purchase, and enables him to draw a heavier load. A draught-horse always digs his toe into the ground when he has a heavy weight to move, and he can do this more effectually when the heel is raised. But this practice is carried to an absurd and ruinous length. In many horses of heavy draught, the only bearing points, - the only parts of the shoe which touch the ground,-are the tip of the toe, and the end of the calkin. There must be sad inequality of pressure here; and the ossification of the cartilages, and enlargement of the pasterns, and grease, and other diseases with which the draught-horse is too often afllicted, are too well accounted for.

Of the varieties of shoes in common use, it is necessary to notice only the following:-

\section{THE BAR SHOE.}

This is often indispensable. It is the only means by which the pressure can be thrown from the seat of sand-crack or corn; but then it is thrown on a part,- the frog, - which nature never designed to receive much pressure, and therefore the bar shoe should be left off as soon as the case will permit. On the other hand, it is sometimes used to protect a tender frog from injury, the hinder part of the shoe being thickened, and hollowed over the frog; but, unless it is made exceedingly heavy, it will soon be flattened down and in the meantime it will most injuriously press upon the heels.

For pumiced feet, a bar shoe is usually necessary; the dressing cannot be confined on a cankered foot without one; but the bar shoe is only a make-shift one, and the horse that wears it can never be 
said to be safe, especially in frosty weather. If it is at times necessary, it is nevertheless an evil, and should be got rid of as soon as possible.

\section{THE ONE-SIDED NAILED SHOE.}

This shoe has one more than its complement of nails on the outer side, a nail at the centre of the toe, and one or two tolerably close to it on the inner side. It was applied by the old farriers and often with good effect, in the prevention of cutting; but it is now discovered to have more important uses. The inner quarter, where contraction usually first commences, and where it exists in the greatest degree, is in a manner free; it can expand when the foot comes on the ground, and it can contract again when it is lifted in the air. This shoe afturds all the defence to the foot for which we have recourse to shoeing; while it leaves much of that natural action of the foot, the loss of which is the greatest evil inflicted by shoeing.

When adopted early, it preserves to a very material degree the natural shape of the foot; and when resorted to after contraction has commenced, it restores always to some beneficial degree, and sometimes in a very surprising manuer, the former width of the heels. It prevents corn, and it removes that concussion and pain which the animal feels when the shoe is firmly fixed to the quarter, and presses on the heel.

It has an appearance of insecurity ahout it, but that insecurity is only in appearance. The shoe will remain, and last its usual time on the foot of a hackiey, not too hardly worked; and many stagecoach horses now run with it and do not cast their shoes oftener than they used to do. It would not, however, suit heavy draught horses, and it might be wrenched from the foot of the hunter when he went over a stiff' country.

THE EXPANSION SHOE.

This is a shoe with a joint in the centre of the toe, moving, or supposed to move, on a pivot, and thus expanding the heel. It must, however, be evident that when once nailed to the foot, the expansion can be very little, and such as it is, it must necessarily be different in different parts of the foot. In the heel it is considerable; towards the toe it can scarcely be said to exist: yet the nails are all equally fixed, and any action of the joint would only throw destructive stress on that part of the shoe which should expand most, but which is tied down like the rest, and thus tear and destrny the crust, and break out almost every nail-hole. This shoe is therefore now little used.

There is a clip on the inside of each heel, which passes over and 
presses upon the inside of the bar, and is thought by some to oppose a mechanical obstruction to the progress of contraction. But this is all delusion; no contrivance of this kind can stop the wiring in of the heels, when it has once commenced. They will continue to narrow, and the bars will press upon the clips, and the clips will embed themselves in the bars, or sadly bruise them, and corn, and perhaps quittor, will be added to the original evil.

\section{THE SCREW SHOE.}

This shoe, likewise, had its day. It was jointed at the tie, and it had a screw at the heel, passing from one side to the other, and by means of which the heels of the shoe were forced asunder, and, with them, the quarters to which they were attached. The feet were macerated day after day by means of poultices and warm water, and a deceptive degree of pliability was given to the horn. The screw-shoe was then put on, and the screw was turned a little every day, and the heels were slowly, but evidently widened, and the foot began to assume a new appearance, and it was believed that wonders were performing. There were two things, however, not taken into calculation:- the difference between moist and dry horn, and the impossibility of introducing any thing into the interior of the foot, to fill the chasm which the forcible separation of the horn from the sensible parts beneath was making. Therefore it happened that, ere many weeks had passed, and in some cases, ere many days had gone by, the heels had narrowed again, and the contraction was aggravated, and the lameness materially increased by the absurd violence that had been used.

TIPS.

These are half shoes, extending only around the toe, and put on in order to preserve the crust from being battered and torn when the horse is turned out. The quarters are left perfectly unfettered, and therefore it is that a horse with contracted feet often derives so much good from a run at grass. The advantage of the tips may be carried still farther: every horse that is soiled during the summer should wear tips. If a horse is turned into a loose box, only for a week or tivo, he should have tips. No harm can ever be produced by them; but, on the contrary, much benefit must ensue from this unfettered state of the foot. 



\section{N D E X.}

A.

Amputation of the penis, when necessary, 145; mode of, 146

Arch, zygomatic, description and uses of, 16

Arsenic, as a medicine, 122 ; poisoning from, 122

Ascarides in horses, 125 ; injection for, 125

B.

Back, length of, in the horse, 25 ; proper form of, 26

Back sinews, sprains of the, causes and treatment of, 169

Bar shoe, description and uses of, 209

Bladder, inflammation of the, 138 ; of the neck of, 139 ; gravel and stonc in the, 140 ; inversion of the, 147

Blain in the horse, symptoms and treatment of, 67

Bleeding, when to be performed, 34 ; method of, 34 ; from the jugular vein, 35 ; local, in inflammation, 35 ; in carditis, 111

Blistering, a remedy for grogginess, 174

Bog spavin, treatment of, 178

Bone, round, sprain of the, 176

Bones of the fore-legs, fractures of the, treatment of, 174

Bone spavin, causes of, 178 ; remedy for, 179

Bots, symptoms and treatment of, 123

Bowels, inflammation of the, 126 ; of the muscular and mucous coats of, 126,127 ; calculi in the, 133

Brain, inflammation of the, 54 ; treatment of, 55

Breaking of the horse, directions for, 28

Brittle hoof, remedy for, 190

Broken knees, treatment of, 165

Bronchitis, symptoms and treatment of, 85-87

Bruise of the sole, treatment of, 200 
C.

Calculi in the bowels, 133

Canker, treatment of, 203

Carditis, causes and symptoms of, 111 ; treatment of, 112

Castration, directions for, 142

Catarrh, epidemic, 87; malignant epidemic, 90

Chest, description of, 23

Clip shoe, description and uses of, 210

Coffin joint, sprain of the, 173

Colic, spasmodic, symptoms and treatment of, 129,130 ; flatulent, 131

Concave-seated shoe, description and uses of, 207.

Condition, want of, 151

Consumption, treatment of, 102

Contagion, a source of mange, 153

Contraction of the hoof, remedy for, 193-195

Corns, causes of, 201 ; treatment of, 202

Corrosive sublimate, poisoning from, 123

Coryza, treatment of, 70

Cough, chronic, remedy for, 100

Curb, definition of, 180 ; symptoms and treatment of, 180

Cutting, in horses, treatment of, 172

D.

Diabetes, inconvenience from, 134 ; treatment of, 134,135

Diaphragm, spasm of, remedy for, 113

Diseases of the skin, treatment of, 151

Docking, method of performing, 148

Dropwort-water, poisoning from, 122

E.

Ears, characteristics of, 17

Elbow joint, injuries of the, 164

Enlarged hock, remedy for, 180

Enlargement of the heart, 113

Enteritis, symptoms and treatment of, 126

Epidemic catarrh, 87; malignant, 90

Epilepsy, causes and symptoms of, 119 ; incurable, 119

Excoriations, treatment of, 157

Expansion shoe, description of, 210

Extremities, fore, injuries of, 163-175; hind, injuries of, 175-186

Eye, a guide to the quality of a horse, 16 ; inflammation of, 61

F.

False quarter, treatment of, 192

Farcy, symptoms and treatment of, 75-78 
Fetlock joint, sprain of the, 171

Feet, pumiced, treatment of, 196 ; wounds in the, management of, 197

Fistulous withers, causes and treatment of, 162

Flatulent colic, remedy for, 131

Foot, structure and diseases of the, 186-206

Fore-arm, sprain of the, 164

Fure extremities, injuries and lameness of, 163-175

Fractures, of bones of the fore-legs, treatment of, 174; of the haunch, 175

G.

Gigs, in horses, treatment of, 84

Glanders, symptoms and treatment of, 70-75

Glands, inflammation of, 82-84

Gravel in the bladder, operation for, 140

Grease, remedies for, 183

Grogginess, directions for the cure of, 174

Gutta serena, or glassy eye, 66

H.

Haunch, fracture of the, treatment of, 175

Head of the horse, description of, 13 ; setting on of, 14

Heart, inflammation of the, 111; enlargement of, 113

Hide-bound, symptoms and treatment of, 151

Hind extremities, injuries and lamenesses of, 175-186

Hock, enlarged, remedy for, 180

Hoof, brittle, remedy for, 190; laminæ of the, inflammation of, 195

Hydrothorax, symptoms and treatment of, 108

I.

Indigestion, symptoms of, 58 ; treatment of, 59

Inflammation, general remarks on, 33 ; of the brain, 54 ; of the eye, 61 ; of the tongue, 67 ; of the palate, 68 ; of the membrane of the nose, 70; specific, or glanders, 70 ; of the absorbents, 75-78; of the cellular substance under the jaw, 79-81; of the glands, 82; of the bronchial tubes, 85 ; of the lungs, 93 ; of the heart and its investing inembrane, 111; of the stomach, 120; of the bowels, 126 ; of the kidneys, 135 ; of the bladder, 138 ; of the skin of the heel, 182 ; of the laminæ of the hoof, 195

Influenza, treatment of, 92

Injuries of the fore extremities, 163-175; of the elbow joint, 164 ; of the hind extremities, $175-186$

Intestines of the horse, description of, 28 ; strangulation and introsusception of, 132

Inversion of the womb, 146 
J。

Jaw, lower, importance of, 22

Joint, fetlock, sprain of the, 171 ; pastern, sprain of, 173 ; navicular, disease of, 205

K.

Kidneys, inflammation of the, 135

Knees, broken, treatment of, 165

Knuckling, remedy for, 174

L.

Lameness, and injuries of the fore extremities, 163-175; shoulder, 163; of the hind extremities, $175-186$

Laminæ of the hoof, inflammation of, 195

Lampas, symptoms and treatment of, 68,69

Legs, swelled, cure of, 181

Lips, description of, 14; criterion of the quality of a horse, 14

Liver, functions of, 28

Locked jaw, causes and symptoms of, 115, 116; remedies for, 117

Loins, breadth of, 27.

Lumbricus teres, in horses, 124

M.

Madness, symptoms and treatment of, 60

Malignant catarrh, symptoms and treatment of, 90

Mange, causes and symptoms of, 153; similarity of, to surfeit, 154; remedies for, 154-156

Moulting, a natural process, 156 ; treatment during, 157

Muscular and mucous coats of the bowels, inflammation of, 126

N.

Navicular joint, disense of the, 205; bleeding for, 206

Neck, characteristics of, 22

Neck of the bladder, inflammation of the, symptoms and treatment of, 139

Nicking, objections to, 149; mode of performing, 149

Nostrils, characteristics of, 14 ; false, 15 ; cartilaginous division of, 15

O.

Overreach, in horses, treatment of, 192 
P.

Palate, soft, of the horse, 17

Palsy, causes and treatment of, 119,122

Paps, treatment of, 84

Parsley water, palsy produced by, 122

Pastern joint, sprain of the, reduction of, 173

Penis, swelling of the sheath of the, 145 ; amputation of, 146 ; warts on the, 146

Pericarditis, symptoms and treatment of, 112

Phrenitis, symptoms of, 54 ; treatment of, 55

Pleurisy, definition and causes of, 105 ; symptoms of, 106; remedies for, 106-108

Pneumonia, symptoms of, 93, 94; treatment of, 95-98

Poisoning, symptoms of, 121; from yew, 121; from water dropwort, 122 ; from arsenic, 122 ; from corrosive sublimate, 123

Poll evil, the result of carelessness or brutality, 160 ; treatment of, 160

Polypus in the vagina, 147

Pumiced feet, treaiment of, 84

Purging, abuses of, 36 ; when proper, 37 ; recipes for, $38,39,42,43$; by the hand, 40 ; by injection, 40 ; Mr. Denny's remarks on, 42-54; inflammation from, 128

Q.

Quarter, false, treatment of, 192

Quittor, definition of, 199 ; treatment of, 200

R.

Rabies, symptoms and treatment of, 60

Ringbone, treatment of, 173

Roaring, causes of, 101 ; remedy for, 102

Round bone, sprain of the, 176

Rupture of the suspensory ligaments, 171

S.

Saddle-galls, treatment of, 157

Sand-crack, causes of, and remedy for, 190-192

Screw shoe, description of, 211

Shoe, various kinds of, 206 ; uses and object of, 206 ; concave.seated. 207 ; bar, 209 ; one-sided nailed, 210 ; expansion, 210 ; $\operatorname{clip}_{2} 210$; screw, 211 ; tip, 211.

Shoeing of horses, object of, 206

Shoulder lameness, treatment of, 164

Sinews, back, sprain of the, causes and treatment of, 169

Sit-fasts, treatment of, 158

Skin, diseases of the, 151 
Sleepy staggers, symptoms and treatment of, 55

Sole, bruise of the, management of, 200

Spasmodic colic, symptoms and treatment of, 129, 130

Spavin, bog, treatment of, 178 ; bone, causes of, 178

Speedy.cut, management of, 167

Spine, anatomy of, 25

Splent, definition of, 167 ; eauses of, 168; treatment for the cure of, 168

Sprain, of the fore-arm, 164; of the back sinews, 169; of the fetlock joint, 171; of the suspensory ligaments, 171 ; of the pastern joint, 173 ; of the coffin joint, 173 ; of the round bone, 176

Staggers, impropriety of using the word, 54 ; symptoms of, 55 ; sleepy, 55 ; stomach, 58

Staling, profuse, 134 ; difficulty of, 135

Stifle lameness, description of, 176 ; treatment of, 177

Stomach, proper qualifications of, 27 ; staggers, symptoms and treatment of, 58

Stone in the bladder, operation for, 141

Strangles, symptoms and treatment of, 79-81

Strangulation of the intestine, 132

Strongylus in horses, 125

Sublimate, corrosive, poisoning from, 123

Superficial wounds, treatment of, 158

Surfeit, symptoms of, 152 ; origin of, 152 ; remedies for, 153

Suspensory ligaments, rupture and sprain of the, 171

Swelled legs, cure of, 181

\section{T.}

'Tail of the horse, operations on, 148

Teeth, description of, 18; wolves', in horses, 19; how to judge of age by the, 19

Tetanus, canses and symptoms of, 115,116 ; treatment of, 117

Thick wind, remedy for, 98

Thorough-pin, treatment of, 177

Thrush, danger of, 204 ; remedy for, 204

Tips, description of, 211 ; advantages of, 211

Tongue of the horse, peculiarities of, 17

Tread, in horses, definition of, 192 ; treatment of, 192

\section{V.}

Vagina, polypus in the, 147

Vertigo, symptoms of, 56 ; treatment of, 57

Vives, in horses, remedies for, 83

W.

Warbles, treatment of, 158

Warts on the penis, 146 
Water dropwort, poisoning from, 122

Water, parsley, palsy produced by, 122

Windgalls, definition of, 170 ; treatment of, 170

Wind, thick, 98 ; broken, 99

Withers, importance of, to strength, 24; fistulous, causes and treatment of, 162

Womb, inversion of the, 146

Worms, in horses, 123

Wounds, superficial, treatment of, 158; incised and lacerated, 159; penetrating the chest or belly, 162; in the feet, 197

\section{Y.}

Yew, poisoning from, 121

Z.

Zygomatic arch, description and uses of, 16 



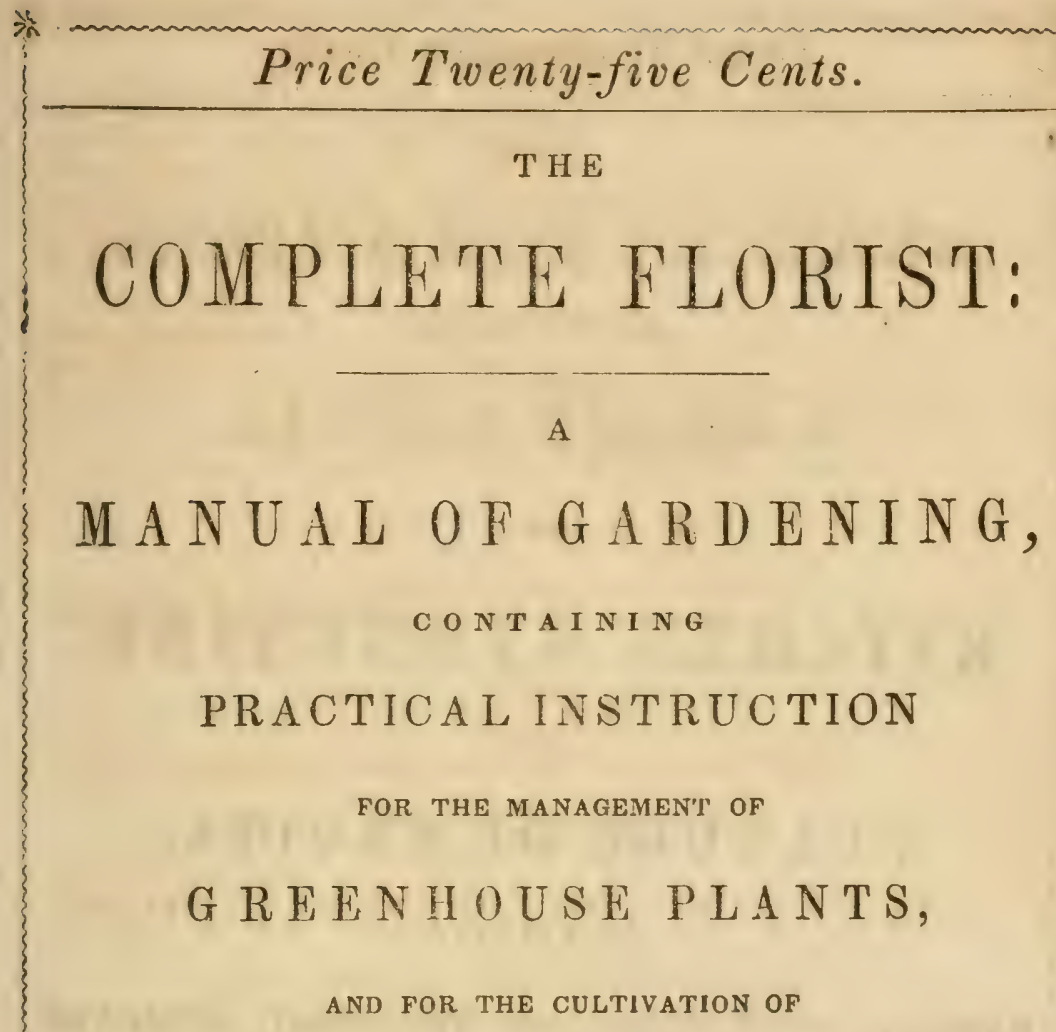

THE SHRUBBERY, THE FLOWER GARDEN, A N D THE LAWN.

WITH DESCRIPTIONS OF THOSE

PLANTS AND TREES MOST WORTHY OF CULTURE, IN EACH DEPARTMENT.

WITH ADDITIONS AND AMENDMENTS, ADAPTED TO THE CLIMATE OF THE UNITED STATES.

PHILADELPHIA:

LEA A N D B L A N C H A R . AND SOLD BY ALL BOOKSELLERS AND NEWS AGEN'S. 1.44. 
Price Twenty-five Cents.

\title{
IHE
}

KITCHEN AND FRUIT GARDENER.

\author{
A SELECT MANUAL
}

OF

KITCHEN GARDENING, A N D

\section{CULTURE OF FRUITS,}

\section{CONTAINING}

FAMILIAR DIRECTIONS FOR THE MOST APPROVED PRACTICE IN EACH DEPARTMENT,

DESCRIPTIONS OF MANY VALUABLE FRUITS, A N D

A CAIENDAR OF WORK TO BE PERFORMED EACH MONTH IN THE YEAR.

THE WHOLE ADAPTED TO

THE CLIMATE OF THE UNITED STATES.

PHILA DELPHIA:

L EA A N D B L A N C H A R D, AND SOLD BY ALL BOOKSELLERS AND NEWS AGENTS. 





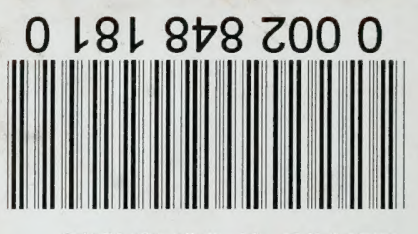

